\title{
Release-to-Birth Ratios for AGR-2 Operating Cycles 147A through 154B
}

\section{Dawn Scates}

March 2014

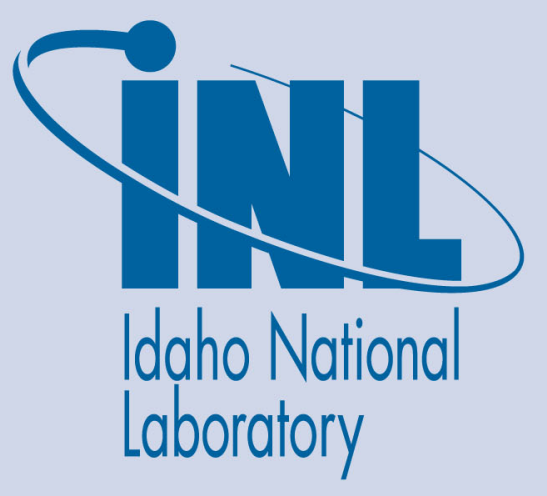

The INL is a U.S. Department of Energy National Laboratory operated by Battelle Energy Alliance 


\title{
Release-to-Birth Ratios for AGR-2 Operating Cycles 147A through 154B
}

\author{
Dawn Scates \\ March 2014 \\ Idaho National Laboratory \\ Idaho Falls, Idaho 83415 \\ http://www.inl.gov \\ Prepared for the \\ U.S. Department of Energy \\ Under DOE Idaho Operations Office \\ Contract DE-AC07-05ID14517
}




\section{Engineering Calculations and Analysis}

ECAR Title: Release-to-Birth Ratios for AGR-2 Operating Cycles 147A through 154B

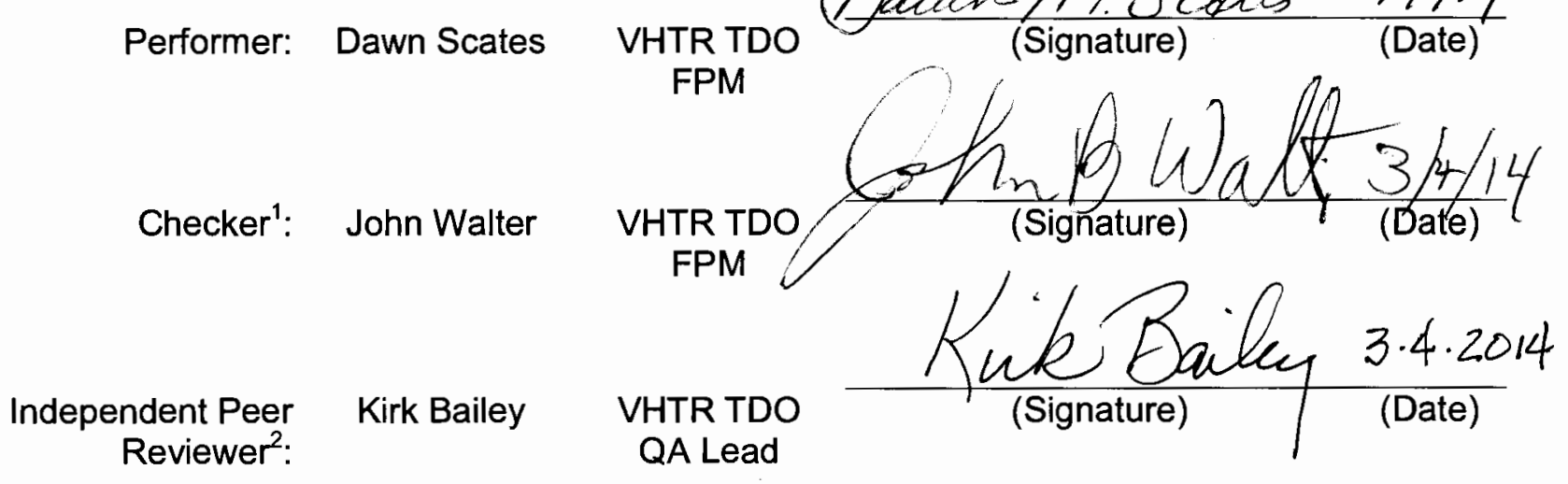
CUI Reviewer: Yes _or N/A $\overline{N o}^{5} \underline{x}$
Manager" $\quad$ Michael Davenport
VHTR TDO Irradiations Technical Lead

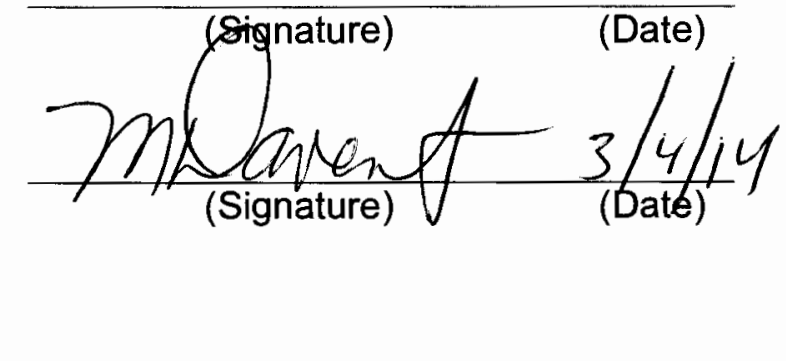

Requestor ${ }^{4}$ : John Maki VHTR TDO $\frac{\text { folen I. Thali } 3-4-14}{\text { (Signature) }}$

1. Confirmation of completeness, mathematical accuracy, and correctness of data and appropriateness of assumptions.

2. Concurrence of method or approach. See definition, LWP-10106, "Engineering Verification."

3. Concurrence of procedure compliance. Concurrence with method/approach and conclusion.

4. Concurrence with the document's assumptions and input information. See definition of acceptance, LWP-10200, "Engineering Calculations and Analysis Report."

5. Does the document contain CUI material? Please check either yes or no. 
TEM-10200-1

$03 / 01 / 2012$

ENGINEERING CALCULATIONS AND ANALYSIS

Page 1 of 73

Rev. 06

Title: $\quad$ Release-to-Birth Ratios for AGR-2 Operating Cycles 147A through 154B

ECAR No.: 2420

Rev. No.: 0

Project No.: $\quad 23843,23841$ Date: $03 / 04 / 2014$

REVISION LOG

\begin{tabular}{|c|c|c|c|}
\hline Rev. & Date & Affected Pages & Revision Description \\
\hline 0 & 03/04/2014 & All & Initial issue. \\
\hline & & & \\
\hline & & & \\
\hline & & & \\
\hline & & & \\
\hline & & & \\
\hline & & & \\
\hline & & & \\
\hline & & & \\
\hline & & & \\
\hline & & & \\
\hline & & & \\
\hline & & & \\
\hline & & & \\
\hline
\end{tabular}


TEM-10200-1

$03 / 01 / 2012$

ENGINEERING CALCULATIONS AND ANALYSIS

Page 2 of 73

Rev. 06

Title: $\quad$ Release-to-Birth Ratios for AGR-2 Operating Cycles 147A through 154B

$\begin{array}{lllll}\text { ECAR No.: } 2420 & \text { Rev. No.: } 0 & \text { Project No.: } & 23843,23841 \text { Date: } & 03 / 04 / 2014\end{array}$

\begin{tabular}{|c|c|c|}
\hline 1. Quality Level (QL) No. & 2 & \multirow{6}{*}{$\begin{array}{l}\text { Professional Engineer's Stamp } \\
\text { N/A }\end{array}$} \\
\hline 2. QL Determination No. & RTC-000668 & \\
\hline 3. Engineering Job (EJ) No. & N/A & \\
\hline 4. SSC ID & N/A & \\
\hline 5. Building & N/A & \\
\hline 6. Site Area & N/A & \\
\hline
\end{tabular}

7. Objective/Purpose:

This Engineering Calculations and Analysis Report (ECAR) documents the release-to-birth (R/B) ratios of the Advanced Gas Reactor (AGR) experiment, AGR-2, irradiated in the Advanced Test Reactor (ATR) B-12 position during Cycle 147A (AGR-2 irradiation interval \#1) through Cycle 154B (AGR-2 irradiation interval \#11).

8. If revision, please state the reason and list sections and/or pages being affected:

9. Conclusions/Recommendations:

The R/B ratios for AGR-2 operating Cycles 147A, 148A, 148B, 149A, 149B, 150B, 151A, 151B, $152 \mathrm{~B}, 154 \mathrm{~A}$, and $154 \mathrm{~B}$ are presented in this ECAR. AGR-2 was moved to the ATR canal during Cycle 150A; to position I-24 during Cycle 153B; Cycle 152A consisted of low-power testing; therefore, no burn-up was accumulated and no R/B values were calculated for these cycles. For the 11 cycles evaluated in this ECAR, there are no indications that the fission product monitors (FPM) failed to capture data reliably. Helium/neon gas flows recorded during Cycle 149A and forward may not adequately represent the gas flow mixture through the associated capsule due to relief valve failure, gas line crosstalk, and capsule leakage (i.e., the collected data are correct, but do not support application to the defined intended use); therefore, the reported values from the FPMs will serve as trending information and not as quantifiable capsule isotopic data. 
TEM-10200-1

$03 / 01 / 2012$

ENGINEERING CALCULATIONS AND ANALYSIS

Page 3 of 73

Rev. 06

Title: $\quad$ Release-to-Birth Ratios for AGR-2 Operating Cycles 147A through 154B

$\begin{array}{llll}\text { ECAR No.: } 2420 \quad \text { Rev. No.: } 0 & \text { Project No.: } 23843,23841 \text { Date: } 03 / 04 / 2014\end{array}$

\section{CONTENTS}

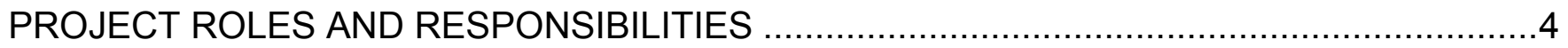

ACRONYMS

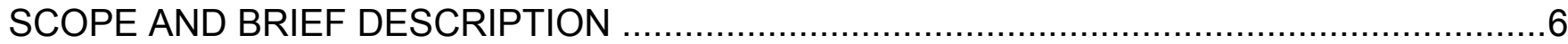

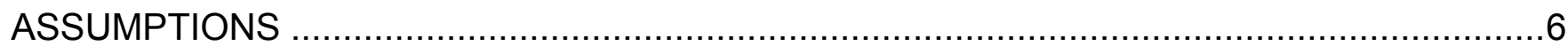

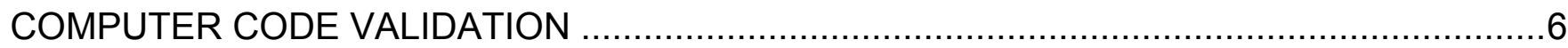

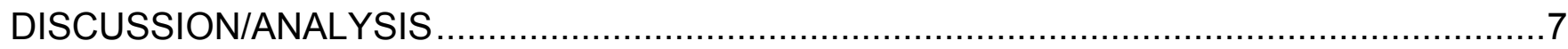

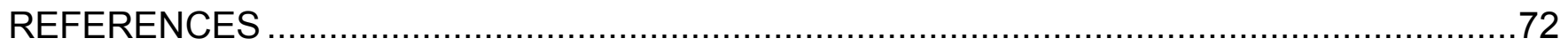

\section{APPENDIXES}

Appendix A - FP_PostProc Constants Text File

Appendix B - Sample Flow Data

Appendix C - Sample Input Birthrate Files

Appendix D - Sample FP_PostProc Output Files

Appendix E - Supplemental Information to Support ECAR-2420; AGR-2 Cycles 147A through 154B, Capsule 1

Appendix F - Supplemental Information to Support ECAR-2420; AGR-2 Cycles 147A through 154B, Capsule 4 
TEM-10200-1

$03 / 01 / 2012$

ENGINEERING CALCULATIONS AND ANALYSIS

Page 4 of 73

Rev. 06

Title: $\quad$ Release-to-Birth Ratios for AGR-2 Operating Cycles 147A through 154B

ECAR No.: 2420

Rev. No.: 0

Project No:

23843, 23841 Date: 03/04/2014

\section{PROJECT ROLES AND RESPONSIBILITIES}

\begin{tabular}{|c|c|c|c|}
\hline Project Role & Name (Typed) & Organization & $\begin{array}{c}\text { Pages covered } \\
\text { (if applicable) }\end{array}$ \\
\hline Performer & Dawn M. Scates & $\begin{array}{l}\text { Very High Temperature } \\
\text { Reactor Technology } \\
\text { Development Office Fission } \\
\text { Product Monitor Lead }\end{array}$ & \\
\hline Checker $^{a}$ & John Walter & $\begin{array}{l}\text { Very High Temperature } \\
\text { Reactor Technology } \\
\text { Development Office Fission } \\
\text { Product Monitor }\end{array}$ & All \\
\hline Independent Reviewer ${ }^{b}$ & Kirk Bailey & $\begin{array}{l}\text { Very High Temperature } \\
\text { Reactor Technology } \\
\text { Development Office QA Lead }\end{array}$ & \\
\hline CUI Reviewer ${ }^{c}$ & & & \\
\hline Manager $^{d}$ & Michael Davenport & $\begin{array}{l}\text { Very High Temperature } \\
\text { Reactor Technology } \\
\text { Development Office } \\
\text { Irradiations Technical Lead }\end{array}$ & \\
\hline Requestor $^{\mathrm{e}}$ & John Maki & $\begin{array}{l}\text { Very High Temperature } \\
\text { Reactor Technology } \\
\text { Development Office }\end{array}$ & \\
\hline Nuclear Safety ${ }^{\mathrm{e}}$ & & & \\
\hline Document Owner ${ }^{\mathrm{e}}$ & & & \\
\hline
\end{tabular}

\section{Responsibilities:}

a. Confirmation of completeness, mathematical accuracy, and correctness of data and appropriateness of assumptions.

b. Concurrence of method or approach. See definition, LWP-10106.

c. Concurrence with the document's markings in accordance with LWP-11202, "Controlled Unclassified Information Program."

d. Concurrence of procedure compliance. Concurrence with method/approach and conclusion.

e. Concurrence with the document's assumptions and input information. See definition of acceptance, LWP-10200.

NOTE: Delete or mark "NA" for project roles not engaged. Include ALL personnel and their roles listed above in the eCR system. The list of the roles above is not all inclusive. If needed, the list can be extended or reduced. 
TEM-10200-1

$03 / 01 / 2012$

ENGINEERING CALCULATIONS AND ANALYSIS

Page 5 of 73

Rev. 06

Title: $\quad$ Release-to-Birth Ratios for AGR-2 Operating Cycles 147A through 154B

$\begin{array}{lllll}\text { ECAR No.: } 2420 & \text { Rev. No.: } 0 & \text { Project No.: } & 23843,23841 \text { Date: } & 03 / 04 / 2014\end{array}$

\section{ACRONYMS}

AGR Advanced Gas Reactor

ATR Advanced Test Reactor

ECAR engineering calculations and analysis report

FPM fission production monitoring

FPMS fission production monitoring system

INL Idaho National Laboratory

JMOCUP Jim's MCNP ORIGEN Coupled Utility Program

LOC Loop Operation Control

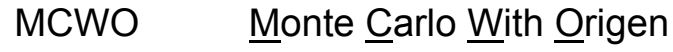

NDMAS Nuclear Data Management and Analysis System

PALM powered axial locator mechanism

PCGAP Personal Computer Gamma Analysis Package

$\mathrm{R} / \mathrm{B} \quad$ release rate to birthrate ratio 
TEM-10200-1

$03 / 01 / 2012$

ENGINEERING CALCULATIONS AND ANALYSIS

Page 6 of 73

Rev. 06

Title: $\quad$ Release-to-Birth Ratios for AGR-2 Operating Cycles 147A through 154B

$\begin{array}{lllll}\text { ECAR No.: } 2420 & \text { Rev. No.: } 0 & \text { Project No.: } & \text { 23843, } 23841 \text { Date: } 03 / 04 / 2014\end{array}$

\section{SCOPE AND BRIEF DESCRIPTION}

The AGR-2 experiment was a fueled, multiple-capsule irradiation experiment that was irradiated from June 2010 until October 2013 in ATR in support of the Very High Temperature Reactor Technology Development Office's Fuel Development and Qualification Program. An important measure of the fuel performance of these tests is the quantification of the fission product releases over the duration of the experiment. To provide these data for the inert fission gasses, a fission product monitoring system (FPMS) was developed and implemented to monitor the individual capsule effluents for the radioactive species.

The FPMS continuously measures the sweep gas from each of the 6 AGR-2 capsules to provide an indicator of fuel irradiation performance. Spectrometer detector systems measure the concentrations of various krypton and xenon isotopes in the sweep gas from each capsule. Eight-hour counting intervals are used to measure the concentrations of Kr-85m, Kr-87, Kr-88, Kr-89, Kr-90, Xe-131m, Xe-133, Xe135, Xe-135m, Xe-137, Xe-138, and Xe-139. These concentrations, along with gas flow data, are converted to release rates. $R / B$ values provide indicators of initial fuel quality and fuel performance during irradiation.

The release activity must be measured, derived and paired with calculated birthrates to determine the initial fuel quality and fuel performance data.

The FPMS post-processing program FP_PostProc is used to calculate the R/B values, interpolating birthrates between the provided values to obtain estimates at the times corresponding to spectra for which the reactor is at full power. It also averages the provided flows during the spectra, ignoring any incidental zero-flow values. The intent of this ECAR is to present the R/B ratios for AGR-2 operating Cycles 147A through 154B.

\section{ASSUMPTIONS}

1. The FPMS must be operational.

2. Summary files from the FPMS must be available.

3. Summary Comma Delimitated text files need to be generated from FP_Examiner for use in FP_PostProc.

4. Flow data from the ATR AGR experiment for the entire operating cycle must be supplied.

5. As-run birthrate input files must be provided.

\section{COMPUTER CODE VALIDATION}

- Computer type: The FP_PostProc processing software runs on a Dell Optiplex GX270 PC, running Microsoft Windows XP Professional 2002, Service Pack 3 and Microsoft Windows 7 Enterprise, Service Pack1.

- Computer program name and revision: The birth ratio processing code name is FP_PostProc Version 06/19/12-08/23/12. 
TEM-10200-1

$03 / 01 / 2012$

ENGINEERING CALCULATIONS AND ANALYSIS

Page 7 of 73

Rev. 06

Title:

Release-to-Birth Ratios for AGR-2 Operating Cycles 147A through 154B

ECAR No.: 2420

Rev. No.: 0

Project No.:

23843, 23841 Date: 03/04/2014

- Inputs:

- AGR outlet flow data is generated from the Next Generation Nuclear Plant Data Management and Analysis System (NDMAS) database.

- As-run birthrate input files are provided by Next Generation Nuclear Plant physics staff.

- Outputs (may refer to an appendix): Sample FP_PostProc output files are listed in Appendix D. All FPMS input and output data files are sent to the NDMAS server and are part of the program record.

- Evidence of or reference to computer program validation: PLN-3392, "Fission Product Monitoring PCGAP Software Modification and Operability Test Plan," and PLN-3551, "Fission Gas Monitoring System Control and Analysis Software Operability Test Plan."

\section{DISCUSSIONIANALYSIS}

\section{Birthrate Computation}

The AGR-2 experiment capsule assembly consists of six axially stacked capsules. Each capsule contains a graphite holder with three channels to accommodate three stacks of compacts (four compacts per stack). Each holder then accommodates 12 fuel compacts per capsule; therefore, the entire AGR-2 experiment consists of 72 fuel compacts. Uranium oxycarbide fuel was placed in Capsules 6, 5, and 2. Uranium oxide fuel was placed in Capsules 1, 3, and 4.

For the physics calculations of the birthrates, two separate physics calculations were performed with different time resolutions; one calculation used a four-point subdivision of each ATR cycle, the second high-resolution calculation estimated birthrates on a daily basis. ATR cycle lengths during AGR-2 ranged from approximately 50-60 days.

The four-point isotopic birthrates for the isotopes listed in Table 1 were computed from inventory data supplied using MCWO that linked neutronic data computed in MCNP to inventory data computed in ORIGEN2 [1]. Daily isotopic birthrates are computed using the JMOCUP ORIGEN2.2[1] code system which is similar to MCWO but fully automated.

By definition, birthrate is the rate of production for a specific isotope. Birthrate is different than isotopic inventory in that production of an atom is considered to be a birth, even if it is immediately lost to transmutation or decay. To calculate birthrates using ORIGEN2.2, the depletion of isotopes through transmutation and decay needs to be turned off. This was accomplished by creating modified decay and activation libraries for each isotope of interest. In addition, in the isotope-specific decay libraries, the half-life of the isotope was set to zero in order to have ORIGEN2.2 treat the isotope as a stable isotope, which turns off the decay for the isotope. In the isotope-specific activation library, the absorption cross sections were set to zero to turn off transmutation for the isotope. With decay and transmutation turned off for the specific isotope, the change in inventory for the isotope divided by the irradiation time results in the birthrate [2]. 
TEM-10200-1

$03 / 01 / 2012$

ENGINEERING CALCULATIONS AND ANALYSIS

Page 8 of 73

Rev. 06

Title: $\quad$ Release-to-Birth Ratios for AGR-2 Operating Cycles 147A through 154B

$\begin{array}{lllll}\text { ECAR No.: } 2420 & \text { Rev. No.: } & 0 & \text { Project No.: } & \text { 23843, } 23841 \text { Date: } 03 / 04 / 2014\end{array}$

\section{Release Activity Computation}

The performance of a nuclear fuel test is typically evaluated using R/Bs - the ratio of the released activity $(R)$ of an isotope from the fuel to the predicted creation rate of the isotope because of irradiation conditions (birth activity $[B]$ ). The gamma-ray spectrum measurements from the high-purity germanium detectors in each FPMS were used to find the release activities of several different isotopes of krypton and xenon (Table 1). The acquired spectra were automatically analyzed using the INL-developed Personal Computer Gamma Analysis Package (PCGAP) gamma-ray spectral analysis code [3, 4] and were stored electronically. At the end of each irradiation cycle, the FPMS-measured activities were corrected to account for decay that occurred during transport from the capsules to the detectors. Transport times were calculated from outlet gas flow rates recorded by the automated experiment data control system of ATR and the capsule-specific volumes through which samples flow to reach the respective monitoring stations [5].

Table 1. Isotopes of interest for R/B calculations.

\begin{tabular}{lrl}
\hline \multicolumn{3}{c}{ Isotope } \\
\hline Kr-85m & Xe-131m & Xe-135m \\
Kr-87 & Xe-133 & Xe-137 \\
Kr-88 & Xe-135 & Xe-138 \\
Kr-89 & - & Xe-139 \\
Kr-90 & - & - \\
\hline
\end{tabular}

Release activities were measured with the FPMS and fission product birthrates were estimated using MCWO. The activities measured from the spectra collected by the FPMS and corrected for decay during transport were converted to released atoms per second at the capsule. The proper correction for the measured activity is calculated for equilibrium conditions for the different components illustrated in the simplified flow system in Figure 1.

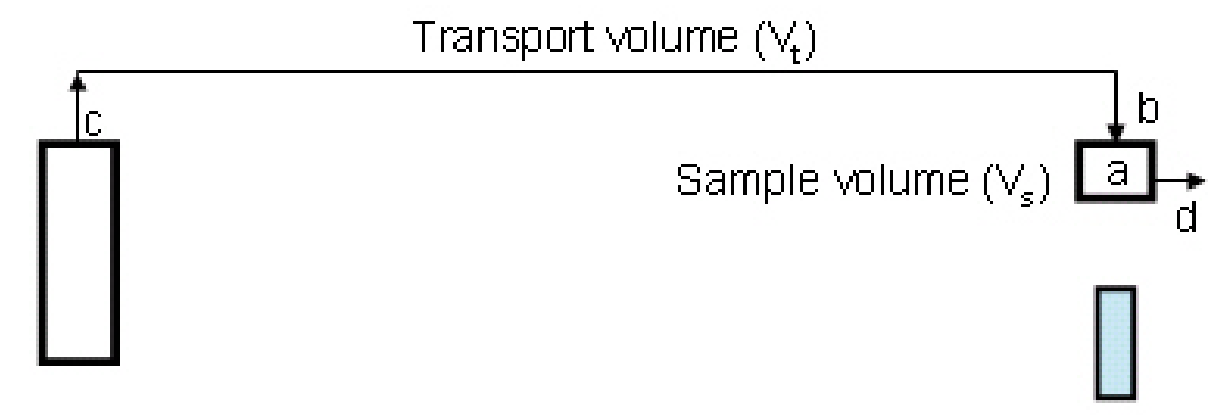

Capsule Detector

Figure 1. A simplified single capsule flow graphic to aid in flow correction calculations. 
TEM-10200-1

$03 / 01 / 2012$

ENGINEERING CALCULATIONS AND ANALYSIS

Page 9 of 73

Rev. 06

Title:

Release-to-Birth Ratios for AGR-2 Operating Cycles 147A through 154B

ECAR No.: 2420

Rev. No.: 0

Project No::

23843, 23841 Date: 03/04/2014

At equilibrium, when the rate of change of the number of atoms of an isotope of interest in the sample volume, 'a,' is zero, one can derive

$$
R_{c}=\frac{A_{a} \cdot e^{\lambda \cdot V_{t} / \dot{f}}}{\left(1-e^{-\lambda \cdot V_{s} / \dot{f}}\right)}
$$

where:

$$
\begin{aligned}
& \mathrm{R}_{\mathrm{c}}=\text { Release rate (atom/sec) of isotope at the capsule exit }(c) \\
& A_{a}=\text { Activity }(\mathrm{Bq}) \text { of isotope in sample volume a } \\
& \lambda=\text { Decay constant of isotope }\left(\mathrm{sec}^{-1}\right) \\
& V_{T}=\text { Transport volume }(\mathrm{mL}) \text { between }(c) \text { and }(b) \\
& V_{s}=\text { Sample volume }(\mathrm{mL})(a) \\
& f=\text { Capsule specific flow }(\mathrm{mL} / \mathrm{sec}) .
\end{aligned}
$$

The flow rate is taken as the average of all values with times during the spectrum acquisition. The activities $(A)$ provided by the INL-developed PCGAP analysis are corrected for random summing and detector efficiency. The first exponential involving the transport volume $\left(V_{t}\right)$ accounts for the probability of decay before reaching the sample volume, while the remaining factor $\left(V_{s}\right)$ accounts for the probability of decay while passing through the sample volume. This equation is valid as long as the specie involved remains entrained in the effluent gas, travels through the gas lines and sample volume at the flow rate, and the flow rate is fairly constant. Any specie trapping prior to exiting the sample volume or large variations in the flow rate during acquisition would compromise the calculation.

The estimated uncertainty in $R_{c}$ can be determined from standard error propagation techniques to be

$\sigma_{R_{c}}^{2}=\left(\frac{R_{c}}{A_{a}}\right)^{2} \cdot\left(\sigma_{A_{a}}^{2}\right)+\left(\frac{R_{c} \cdot \lambda}{\dot{f}}\right)^{2} \cdot\left(\sigma_{V_{t}}^{2}\right)+\left(\frac{R_{c} \cdot e^{-\lambda \cdot V_{s} / \dot{f}} \cdot \lambda}{\dot{f} \cdot\left(1-e^{-\lambda \cdot V_{s} / \dot{f}}\right)}\right)^{2} \cdot\left(\sigma_{V_{S}}^{2}\right)$

or in terms of relative errors

$\left(\frac{\sigma_{R_{c}}}{R_{c}}\right)^{2}=\left(\frac{\sigma_{A_{a}}}{A_{a}}\right)^{2}+\left(\frac{\lambda \cdot V_{t}}{\dot{f}}\right)^{2}\left(\frac{\sigma_{V_{t}}}{V_{t}}\right)^{2}+\left[\frac{V_{s} \cdot e^{-\lambda \cdot V_{s} / \dot{f} \cdot \lambda}}{\dot{f} \cdot\left(1-e^{-\lambda \cdot V_{s} / \dot{f}}\right.}\right]^{2}\left(\frac{\sigma_{V_{s}}}{V_{s}}\right)^{2}$ 
TEM-10200-1

$03 / 01 / 2012$

ENGINEERING CALCULATIONS AND ANALYSIS

Page 10 of 73

Rev. 06

Title:

Release-to-Birth Ratios for AGR-2 Operating Cycles 147A through 154B

ECAR No.: 2420

Rev. No.: 0

Project No.:

23843, 23841 Date: 03/04/2014

To speed up the calculation of these ratios and to ensure accuracy, a semiautomatic processing code called FP_PostProc was developed. This program accesses the summary file of each spectral analysis to extract the required results for activity at the detector at a given time.

\section{The FP_PostProc Program}

The FP_PostProc Program was developed to compute R/B ratios for selected isotopes. As input, the software loads the capsule summary file generated by FP_Examiner, capsule-specific flow information, and birthrate information. The isotope activities and effluent flow rate are used to compute the release rate from the fuel compacts, corrected for decay during transport to the spectrometer sample volume and accounting for effluent residence time in the sample volume. This calculation assumes a steady-state condition that is valid as long as the reactor is stable and none of the fuel particles have recently failed. For this ECAR, reactor average daily and four-point birthrates were provided. The FP_PostProc analysis interpolates between the four-point times, or between the mid-day times, to obtain birthrate values for each of the spectrum times, using these to compute an R/B ratio for each nuclide for all spectra.

The relationship between the capsule release rate and the activity in the detector sample volume was determined during a leadout flow experiment. These transport volumes are listed in Table 2.

Table 2. AGR-2 transport volumes determined during a leadout flow experiment performed at the beginning (June 2010) of the AGR-2 experiment.

AGR-2 Transport Volumes
(sccm)

To couple the birthrate data with the FP_PostProc software, the birthrate values for a capsule represent a volume integral over all of the compacts within the capsule and are presented in units of atoms/sec. The birthrate file lists values for each of the six capsules at a set number of times distributed over the irradiation cycle. The FP_PostProc software interpolates between these points to obtain estimates at the times corresponding to spectra for which the reactor is at full power.

The desired $\mathrm{R} / \mathrm{B}$ ratio for the desired isotope is then calculated as

$$
\left(\frac{R}{B}\right)(t)=\frac{R_{c}(t)}{B(t)}
$$

with a percent uncertainty $(\% \sigma)$ given by

$$
\% \sigma=\sqrt{\left(\frac{\sigma_{R_{c}}}{R_{c}}\right)^{2}+\left(\frac{\sigma_{B}}{B}\right)^{2}} \times 100
$$


TEM-10200-1

$03 / 01 / 2012$

ENGINEERING CALCULATIONS AND ANALYSIS

Page 11 of 73

Rev. 06

Title:

Release-to-Birth Ratios for AGR-2 Operating Cycles 147A through 154B

ECAR No.: 2420

Rev. No.: 0

Project No.:

23843, 23841 Date: 03/04/2014

The activities in the summary file are in units of microcuries in the sample volume, which can be converted to decays-per-second in the sample volume by multiplying by $3.7 \times 10^{4}$. Once the FP_PostProc Program has loaded the activity summary file and the capsule-specific flow information, the release rates are calculated as

$$
R=3.7 \times 10^{4} \frac{A e^{\frac{\lambda V_{T}}{f}}}{\left(1-e^{-\lambda V_{S} / f}\right)}
$$

where:

$A=$ the activity in microcuries in the sample volume $V_{S}$

$\lambda=$ the nuclide decay constant

$f \quad=$ the capsule outlet flow rate

$V_{T}=$ the transport volume from the capsule to the sample volume and where the volumes, decay constants, and flow rates are in consistent units.

As described above, the flow rate is taken to be the average of all values with times during the spectrum acquisition. The activities $(A)$ provided by the standard PCGAP analysis are corrected for random summing and detector efficiency. The first exponential involving the transport volume $\left(V_{T}\right)$ accounts for the probability of decay before reaching the sample volume, while the remaining factor $\left(V_{S}\right)$ accounts for the probability of decay while passing through the sample volume. This equation is valid as long as the specie involved remains entrained in the effluent gas, travels through the gas lines and sample volume at the flow rate, and the flow rate is fairly constant. Any trapping of the specie prior to exiting the sample volume or large variations in the flow rate during acquisition would invalidate this calculation.

The birthrate data file is provided by reactor physics personnel. The analysis methodology MCWO is used to calculate the birthrates of the 12 fission product isotopes listed in Table 1 for each capsule. The values for a capsule represent a volume integral over all of the compacts within the capsule and are presented in atoms/sec. The birthrate file lists values for each of the six capsules at a set number of times distributed over the irradiation cycle. The FP_PostProc software interpolates between these points to obtain estimates at the times corresponding to spectra for which the reactor is at full power. The June 19, 2012 through August 23, 2012, versions are compatible with both the earlier birthrate layout (where the birthrates are specified at specified full power times) and the daily birthrate layout (where an average daily birthrate is provided for each day the reactor is up). An example of a daily birthrate file can be found in Appendix $C$. To identify spectra times for which the reactor is at full power, the list of dates at the start of the file includes the reactor startup times in addition to the full power and scram times. The FP_PostProc Program uses decay constants from the constants.txt text file (Appendix A). It requires the user to specify a transport volume text file because these are different for the various in-pile experiments such as AGR-2. These are used to calculate release rates for the 12 isotopes listed in Table 1. 
TEM-10200-1

$03 / 01 / 2012$

ENGINEERING CALCULATIONS AND ANALYSIS

Page 12 of 73

Rev. 06

Title:

Release-to-Birth Ratios for AGR-2 Operating Cycles 147A through 154B

ECAR No.: 2420

Rev. No.: 0

Project No.:

23843, 23841 Date: 03/04/2014

When the release activity has been computed, the software uses the average birthrate of each isotope within the capsule in atoms/sec to compute and generate an interpolated R/B output file. Example outputs for the release activity and R/B ratio files can be found in the appendix section of GDE-503 [6]. These .txt files are easily imported into Excel and/or other data management systems and can be further processed at the request of AGR project management. Prior to generation of R/B ratio files, all operational buttons in the FP_PostProc software must be functional. If a feature is not operational, a FORTRAN error will display. If just the birthrate file is omitted, this version still computes release rates.

At the end of every irradiation cycle, AGR-2 project staff reports the R/B values for the radioactive fission gases listed in Table 1.

\section{Experiment Performance}

The functionality and accuracy of the data reprocessing process is documented in PLN-3392 [7] and PLN-3551 [8].

The $\mathrm{R} / \mathrm{B}$ results reported in this transmittal are computed as the measured release activity at the associated FPMS detector corrected for decay during transport using the average flow rate over the spectral acquisition period and the previously determined transport volumes, divided by the provided/interpolated birthrate over the same period. FP_PostProc Versions 06/19/12-08/23/12 were used to process these data over the course of the 3-year experiment. AGR-2 reactor physics personnel provided as-run fission product birthrates for $\mathrm{Kr}-85 \mathrm{~m}, \mathrm{Kr}-87, \mathrm{Kr}-88, \mathrm{Kr}-89$, and $\mathrm{Kr}-90$ and $\mathrm{Xe}-131 \mathrm{~m}$, $\mathrm{Xe}-133, \mathrm{Xe}-135, \mathrm{Xe}-135 \mathrm{~m}, \mathrm{Xe}-137, \mathrm{Xe}-138$, and $\mathrm{Xe}-139$. These isotopes are useful because the half-life for each isotope is short enough to enable the inventory to reach equilibrium within the fuel. Helium/neon gas flows recorded during Cycle 149A and forward may not adequately represent the gas flow mixture through the associated capsule due to relief valve failure, gas line crosstalk, and capsule leakage (i.e., the collected data are correct, but do not support application to the defined intended use); therefore, the reported values from the FPMs will serve as trending information and not as quantifiable capsule isotopic data. Figures 2 through 82 capture the R/B and gross gamma values for each specific cycle. Capsule-specific R/B summary plots are contained in Figure 83.

\section{Cycle 147A}

Nuclides of greatest interest from the R/B determinations for ATR Operating Cycle 147A are presented in Figures 2 through 7. ATR reached full power on June 23, 2010, at 04:00 (Day 0.15). During the first part of the experiment, leadout flow testing was performed from June 23, 2010, until July 1, 2010. The reactor experienced a scram on July 23, 2010, at 06:00 (Day 30.25). The outage lasted until July 25, 2010 (Day 30.30), when the reactor was started up again and reached full power at 13:00 [9]. This outage is reflected in Figures 2 through 6.

Figures 2 through 6 capture the leadout flow and transport time testing that began on June 23, 2010, and continued until July 1, 2010. During leadout flow testing, capsule flow was initially set to $30 \mathrm{sccm}$ helium for Capsules 1 through 6 . During testing, neon was introduced individually into each capsule at a flow of $2 \mathrm{sccm}$ for 1 hour and the leadout flow was decreased by $2 \mathrm{sccm}$ each hour until neon was detected in a capsule other than the one that was under injection. Per the Operational Intent Letter, HJS-23-10, Capsule 4 was the only capsule in which leadout flow started at $30 \mathrm{sccm}$ and was taken down hourly by $2 \mathrm{sccm}$ to a value of $0 \mathrm{sccm}$. All other initial leadout flows were set per the document to be $6 \mathrm{sccm}$ above the recorded value, which equates to the following for starting leadout flow rate: Capsule 6-6 sccm, Capsule 3 - $6 \mathrm{sccm}$, Capsule $1-6 \mathrm{sccm}$, Capsule 2 - $8 \mathrm{sccm}$, and Capsule 5 $12 \mathrm{sccm}$. FPM run times were set to 20 -minute periods instead of the standard 8-hour acquisition times. 
TEM-10200-1

$03 / 01 / 2012$

ENGINEERING CALCULATIONS AND ANALYSIS

Page 13 of 73

Rev. 06

Title: $\quad$ Release-to-Birth Ratios for AGR-2 Operating Cycles 147A through 154B

\begin{tabular}{llll} 
ECAR No.: 2420 & Rev. No.: 0 & Project No.: & 23843,23841 Date: \\
\hline
\end{tabular}

Through this testing, it was determined that the leadout flow would be set to $10 \mathrm{sccm}$ to prevent capsule cross talk.

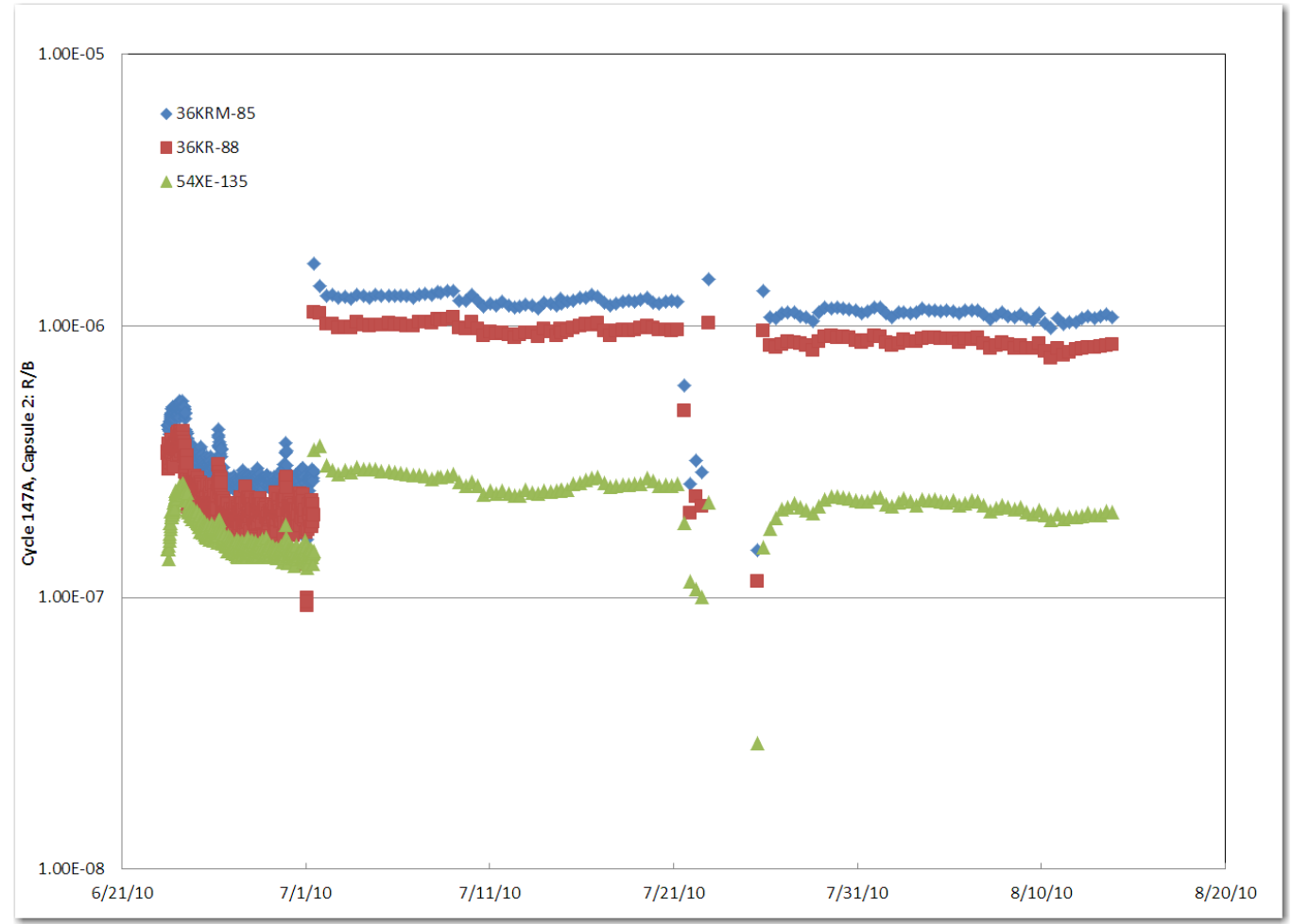

Figure 2. Cycle 147A, Capsule 2 R/B ratios Kr-85m, Kr-88, and $\mathrm{Xe}-135$. 
TEM-10200-1

$03 / 01 / 2012$

ENGINEERING CALCULATIONS AND ANALYSIS

Page 14 of 73

Rev. 06

Title: $\quad$ Release-to-Birth Ratios for AGR-2 Operating Cycles 147A through 154B

$\begin{array}{lllll}\text { ECAR No.: } 2420 & \text { Rev. No.: } 0 & \text { Project No.: } & \text { 23843, } 23841 \text { Date: } 03 / 04 / 2014\end{array}$

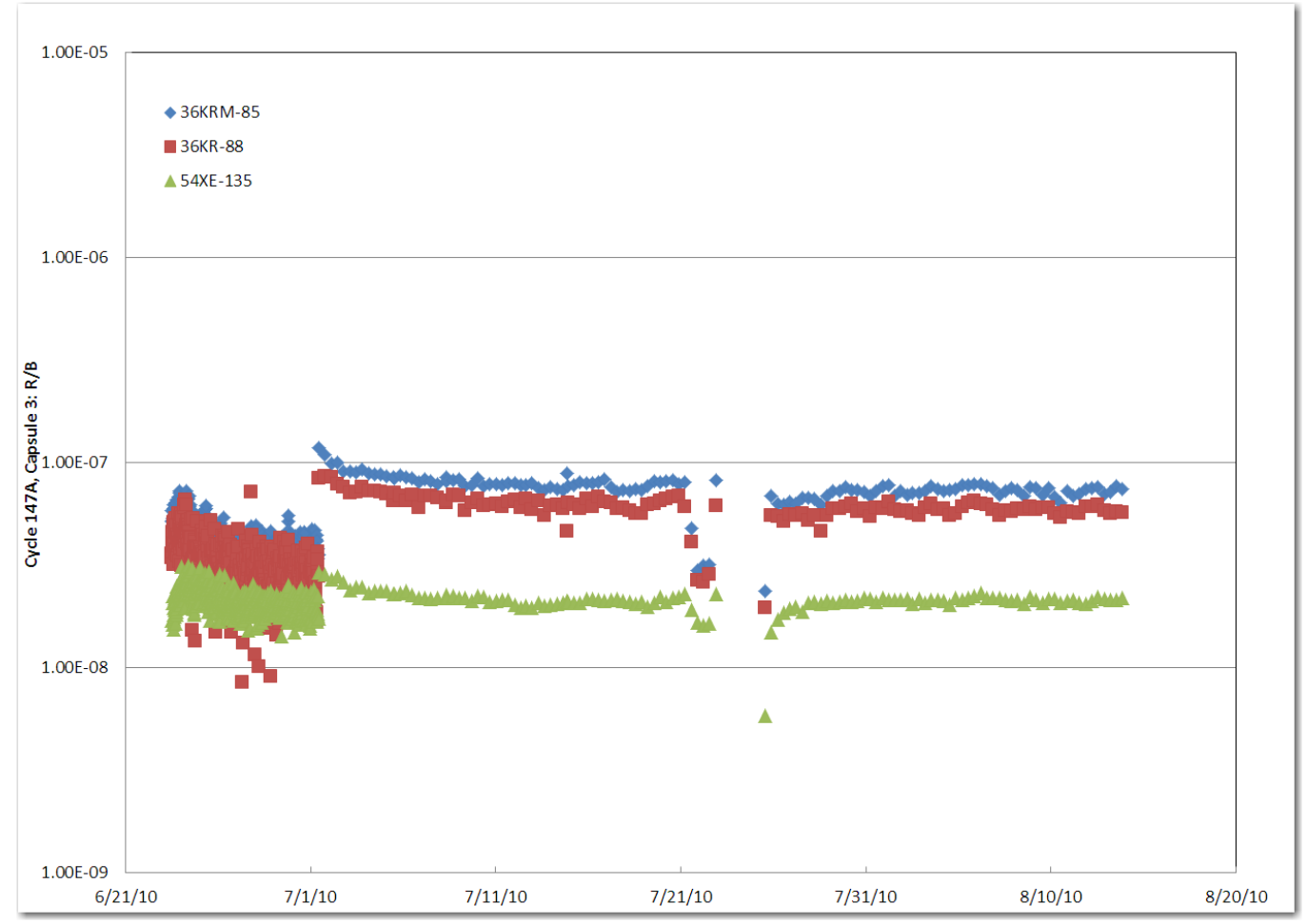

Figure 3. Cycle 147A, Capsule 3 R/B ratios Kr-85m, Kr-88, and Xe-135.

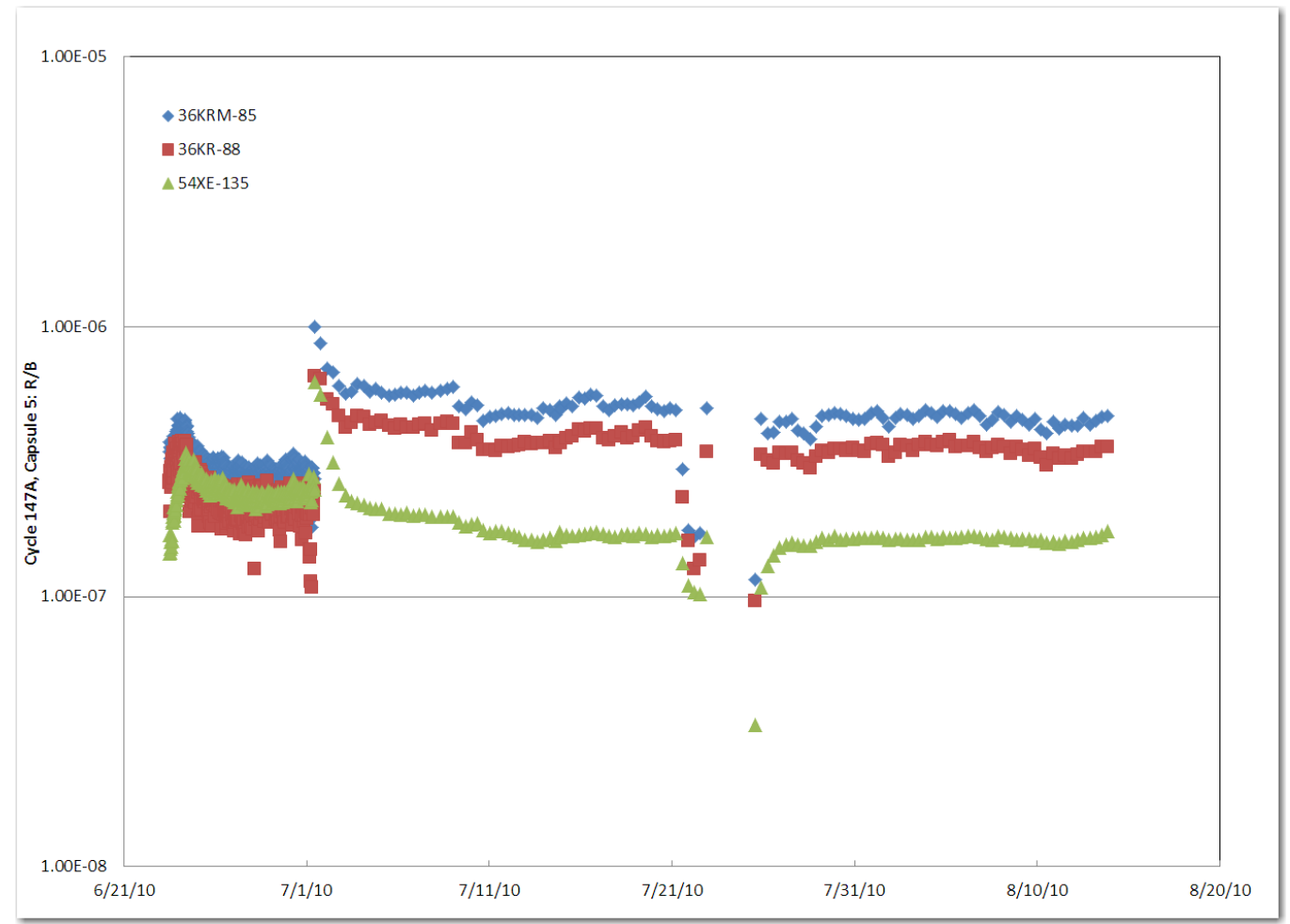

Figure 4. Cycle 147A, Capsule $5 \mathrm{R} / \mathrm{B}$ ratios $\mathrm{Kr}-85 \mathrm{~m}, \mathrm{Kr}-88$, and $\mathrm{Xe}-135$. 
TEM-10200-1

$03 / 01 / 2012$

ENGINEERING CALCULATIONS AND ANALYSIS

Page 15 of 73

Rev. 06

Title: $\quad$ Release-to-Birth Ratios for AGR-2 Operating Cycles 147A through 154B

\begin{tabular}{lllll} 
ECAR No.: 2420 & Rev. No.: & 0 & Project No.: & 23843,23841 Date: \\
\hline
\end{tabular}

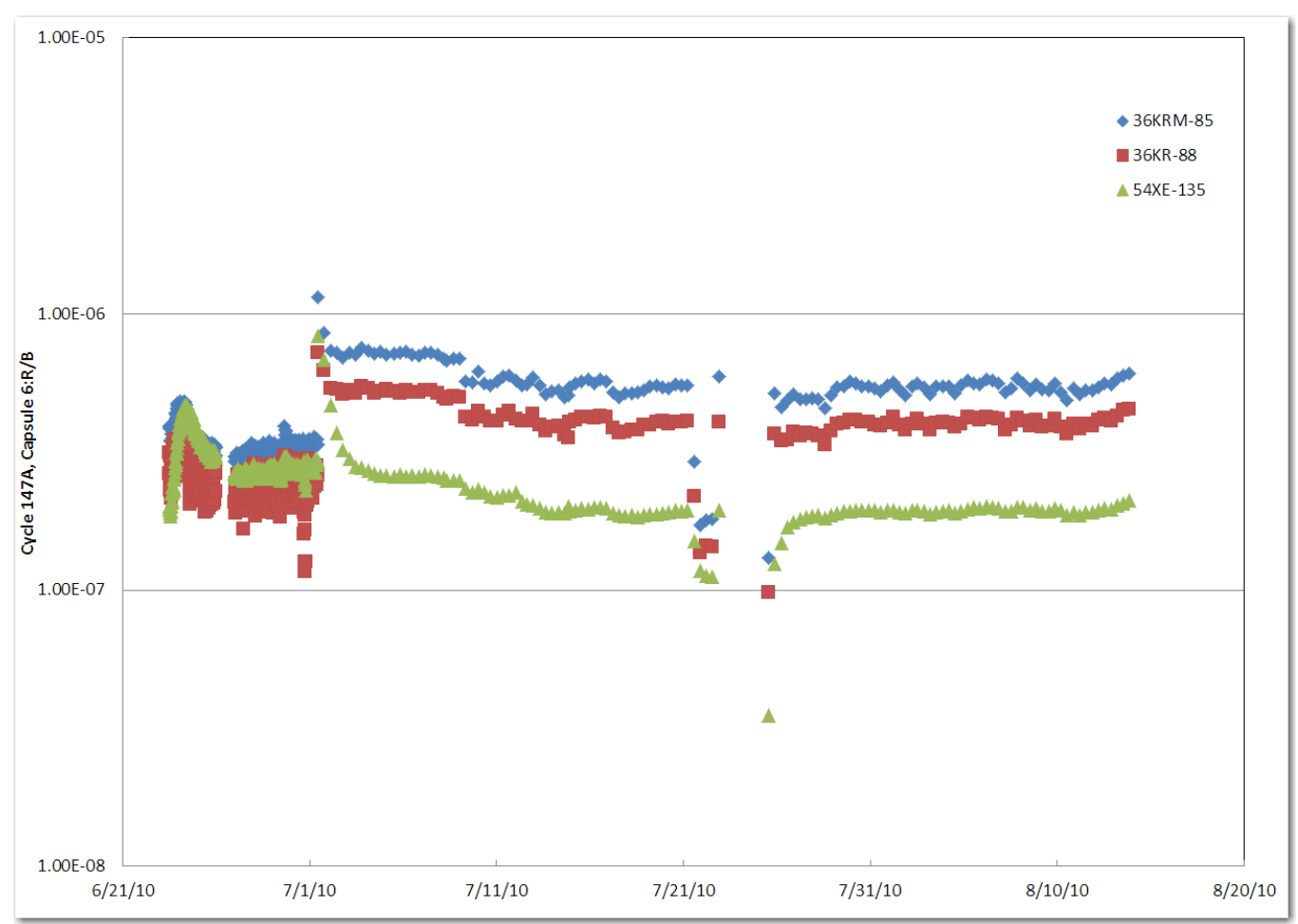

Figure 5. Cycle 147A, Capsule 6 R/B ratios Kr-85m, Kr-88, and Xe-135.

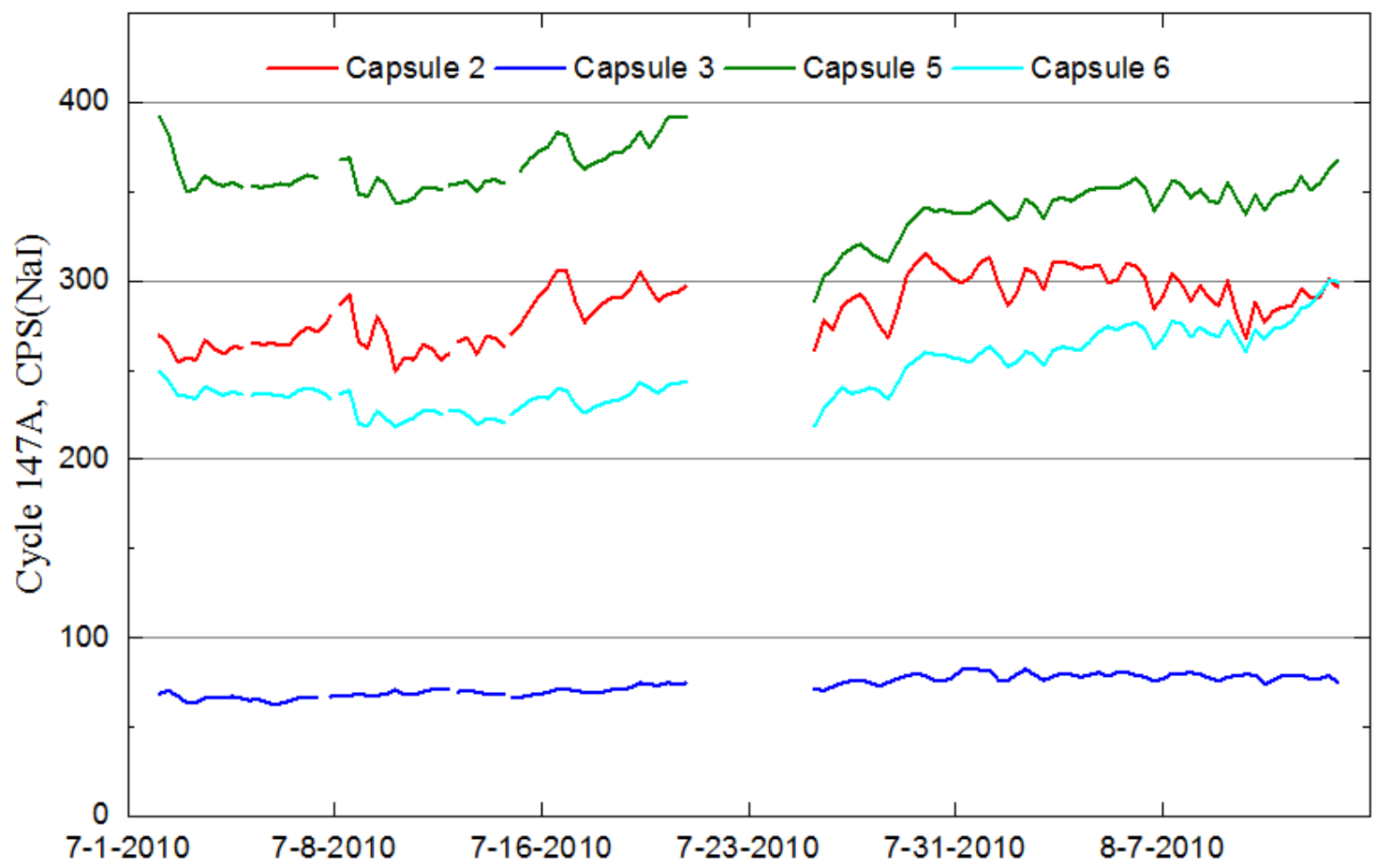

Figure 6. Gross gamma for Cycle 147A, total counts per second for Capsules 2, 3, 5, and 6. 
TEM-10200-1

$03 / 01 / 2012$

ENGINEERING CALCULATIONS AND ANALYSIS

Page 16 of 73

Rev. 06

Title:

Release-to-Birth Ratios for AGR-2 Operating Cycles 147A through 154B

ECAR No.: 2420

Rev. No.: 0

Project No::

23843, 23841 Date: 03/04/2014

On June 26, 2010, a remote processing unit alarm was received by Loop Operation Control (LOC), indicating that there was an Analog Output Buffer (AOB) card status error. The result of this was loss of flow data for Capsule 6. This gap in data is reflected in Figure 5. This type of error has been corrected by project support and is captured in the LOC logbook.

\section{Cycle 148A}

Nuclides of greatest interest from the R/B determinations for ATR Operating Cycle 148A are presented in Figures 7 through 11. ATR reached full power on September 1, 2010, at 04:00 (Day 50.35). The reactor experienced a scram on October 12, 2010, at 21:00 (Day 92.05). The outage lasted until October 17, 2010 (Day 92.15), when the reactor was started up again and reached full power at 22:00 [10]. This outage is reflected in Figures 7 through 11.

Figures 7 through 10 capture the isolation testing that began on September 30, 2010, and continued until October 7, 2010. This testing occurred because of suspect excess gas leaking into the test train. During isolation flow testing, the leadout flow gas mixture was switched to $30 \mathrm{sccm}$ helium and $0 \mathrm{sccm}$ neon to purge the experiment. The test was then isolated and pressure tested to a normal operating pressure of 25 psig to ensure there were no leaks in the gas supply system. No leaks were found.

Figure 11 captures the gross gamma data for AGR-2 Cycle 148A for Capsules 2, 3, 5, and 6. Data collected during the isolation test are not presented in this plot because the count rate was very low; however, they are preserved in the NDMAS database.

Figure 12 shows a portion of the data from one of the gross monitors during the isolation test. With flow to the experiment isolated, no effluent was flowing from the capsule to the detector. The activity at the detector decays when it is not refreshed by the flow, however the activity in the capsule builds because of the continued irradiation of the fuel. When flow is reestablished, as it was in the center of the plot, the higher than normal activity that built up in the capsule produces a spike in the counting rate as it reaches the detector. Soon after, the activity in the capsule and at the detector returns to normal. Subsequently the flow was again isolated, and the counting rate decayed away until flow was again restored. All gross monitors exhibited similar results. 
TEM-10200-1

$03 / 01 / 2012$

ENGINEERING CALCULATIONS AND ANALYSIS

Page 17 of 73

Rev. 06

Title: $\quad$ Release-to-Birth Ratios for AGR-2 Operating Cycles 147A through 154B

$\begin{array}{lllll}\text { ECAR No.: } 2420 & \text { Rev. No.: } & 0 & \text { Project No.: } & 23843,23841 \text { Date: }\end{array}$

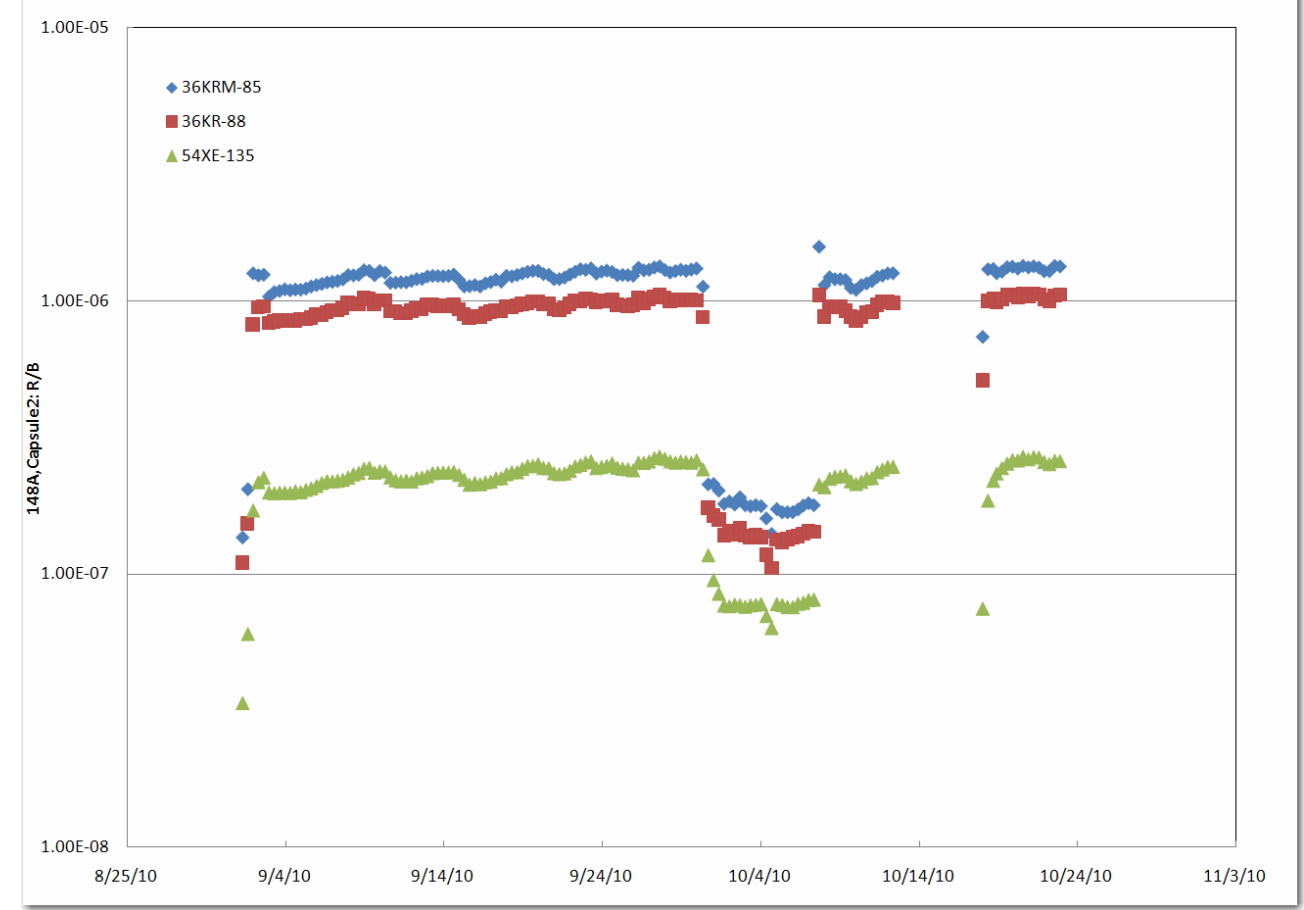

Figure 7. Cycle 148A, Capsule 2 R/B ratios Kr-85m, Kr-88, and Xe-135.

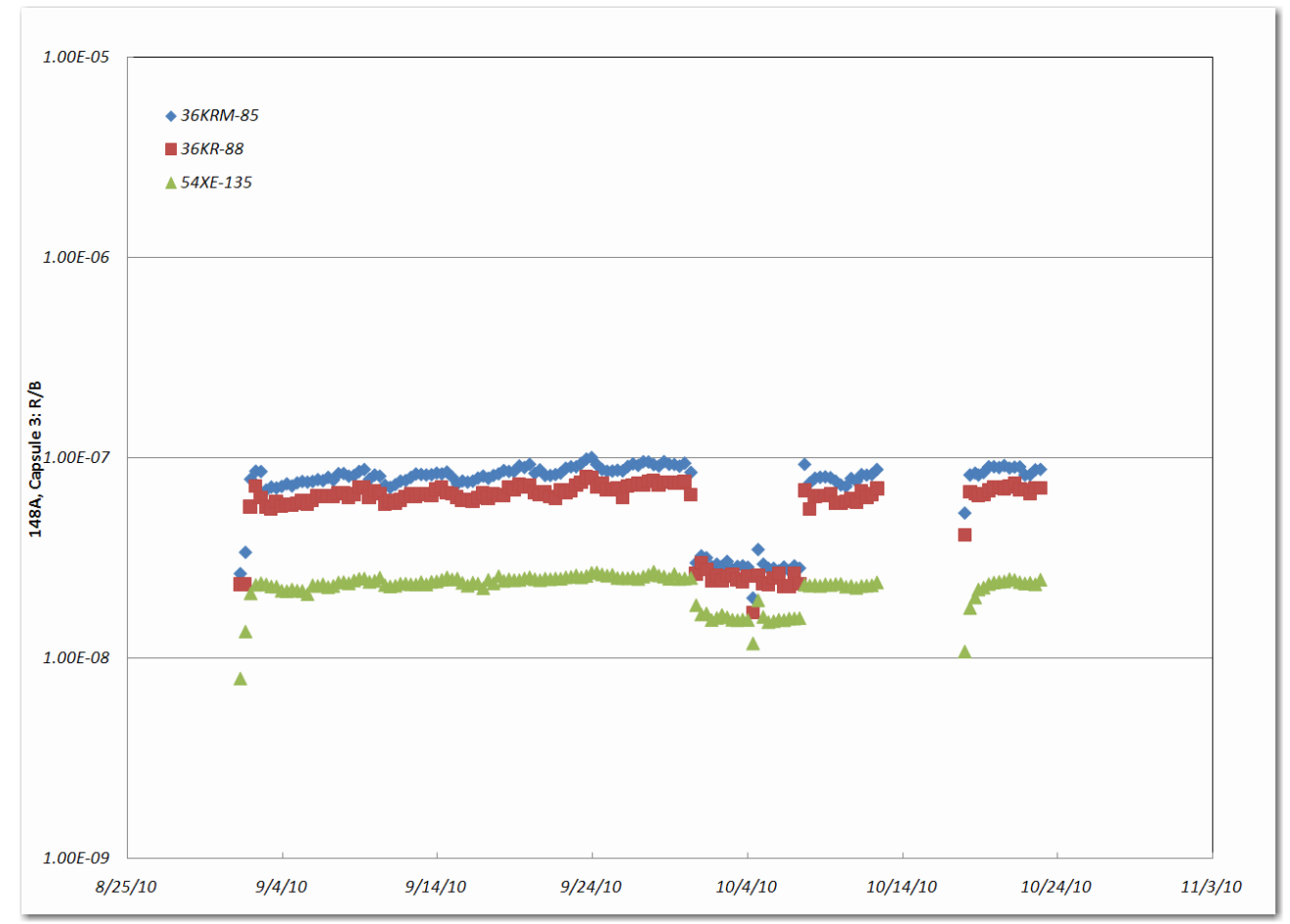

Figure 8. Cycle 148A, Capsule 3 R/B ratios Kr-85m, Kr-88, and Xe-135. 
TEM-10200-1

$03 / 01 / 2012$

ENGINEERING CALCULATIONS AND ANALYSIS

Page 18 of 73

Rev. 06

Title: $\quad$ Release-to-Birth Ratios for AGR-2 Operating Cycles 147A through 154B

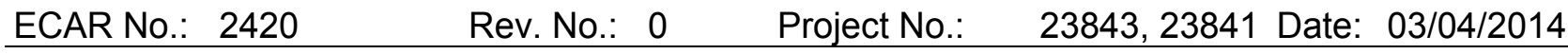

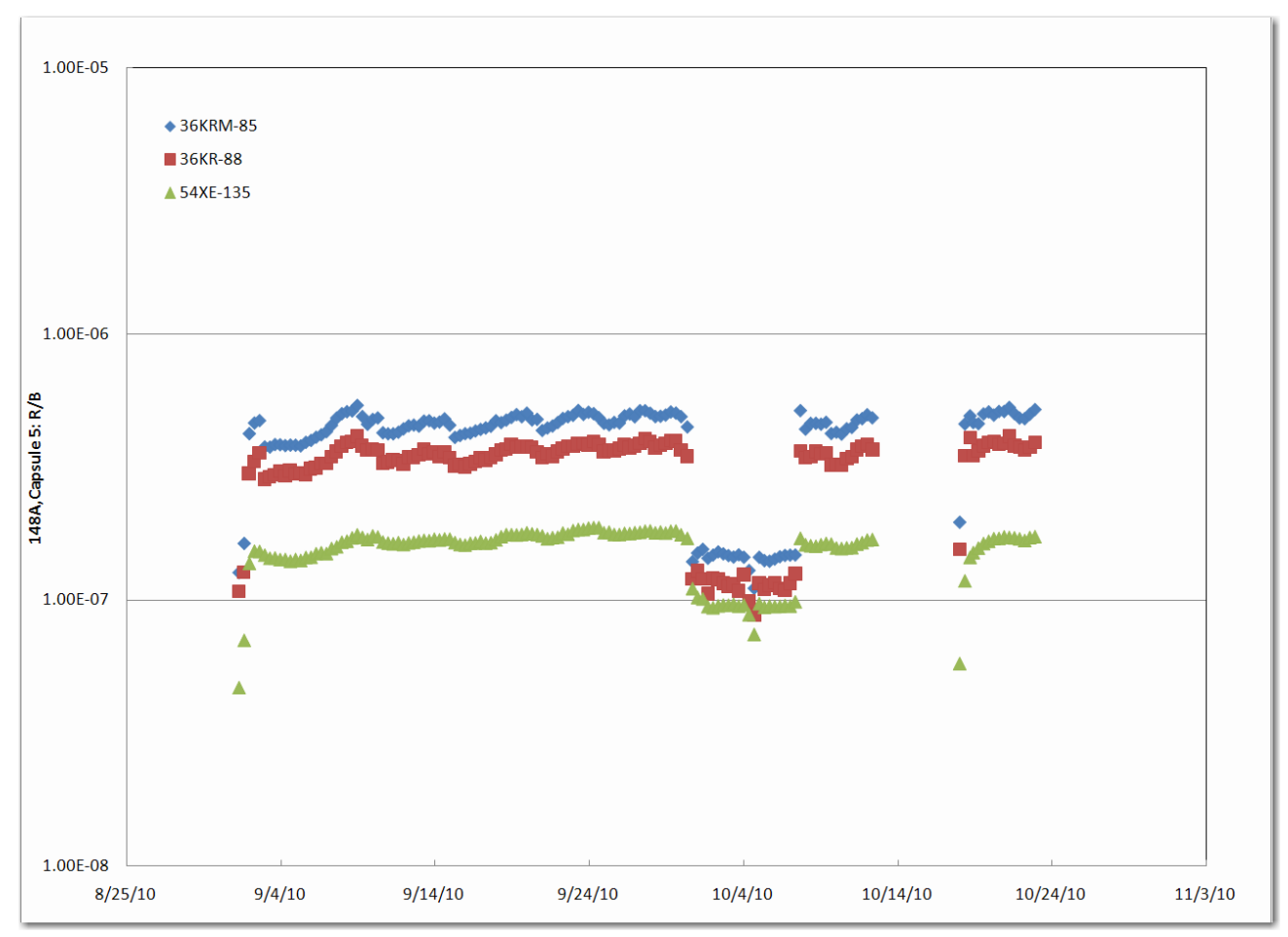

Figure 9. Cycle 148A, Capsule 5 R/B ratios Kr-85m, Kr-88, and $\mathrm{Xe}-135$.

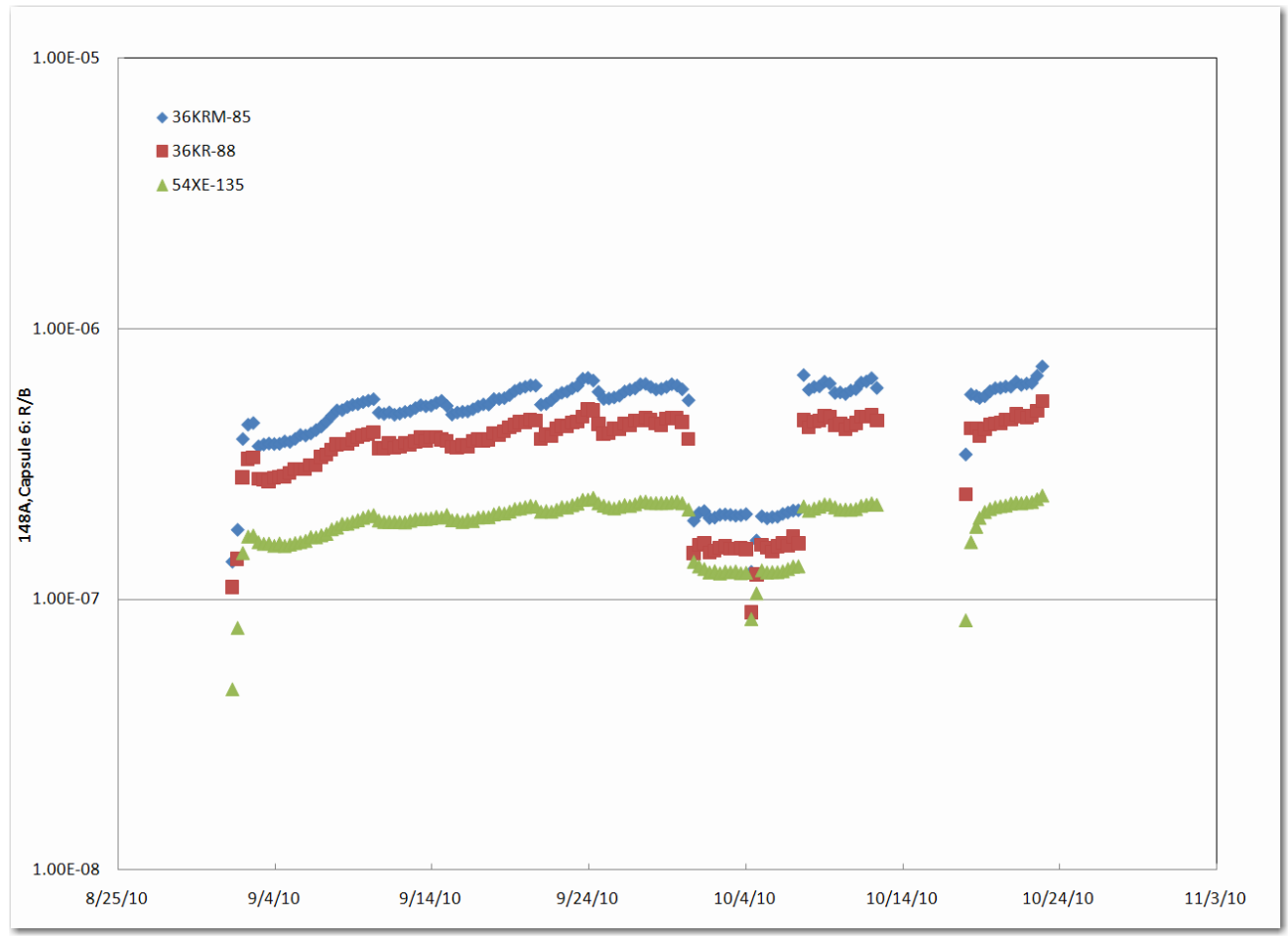

Figure 10. Cycle 148A, Capsule 6 R/B ratios Kr-85m, Kr-88, and Xe-135. 
TEM-10200-1

$03 / 01 / 2012$

Rev. 06

ENGINEERING CALCULATIONS AND ANALYSIS

Page 19 of 73

Title: $\quad$ Release-to-Birth Ratios for AGR-2 Operating Cycles 147A through 154B

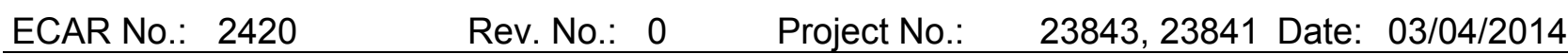

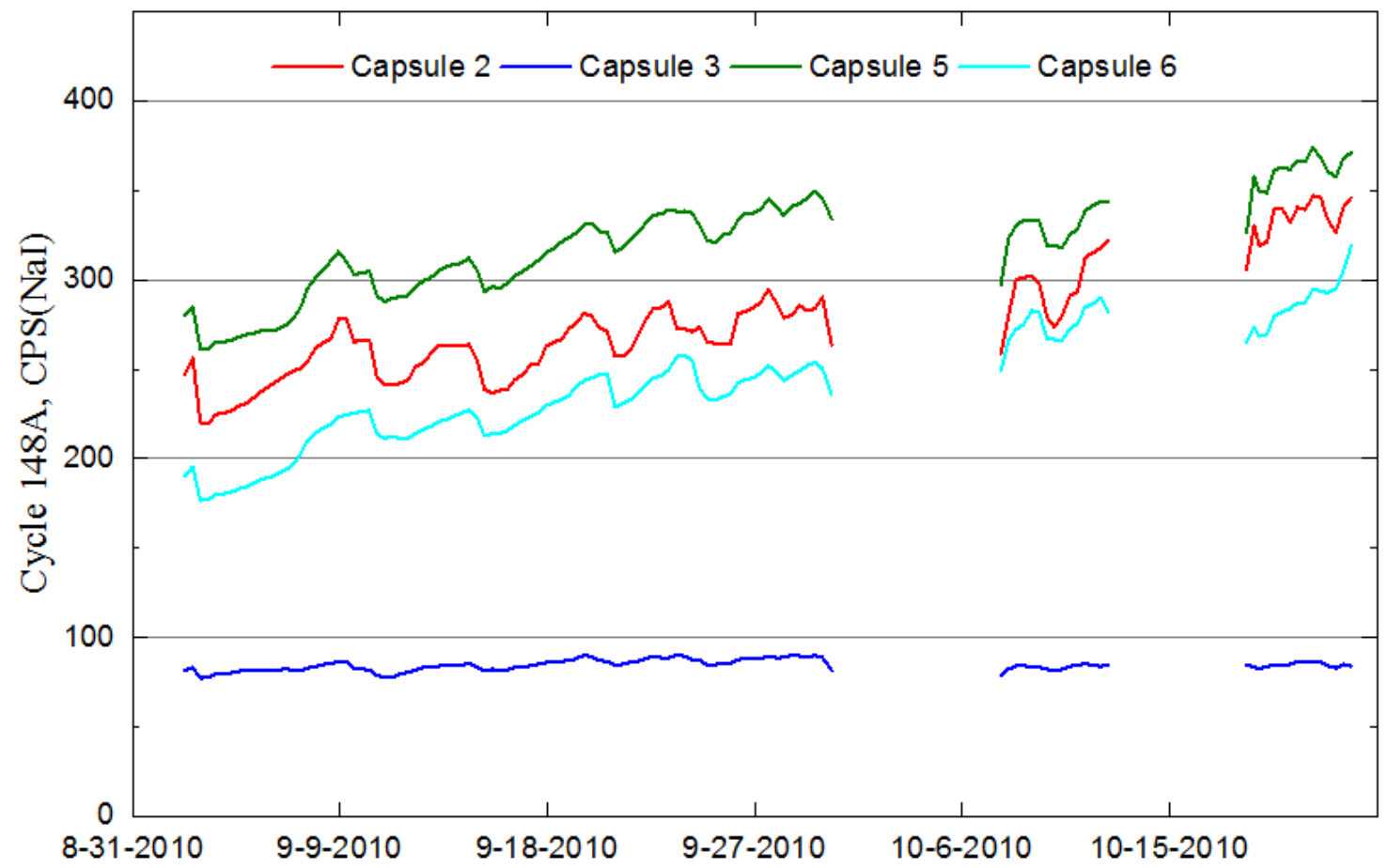

Figure 11. Gross gamma for Cycle 148A, total counts per second for Capsules 2, 3, 5, and 6.

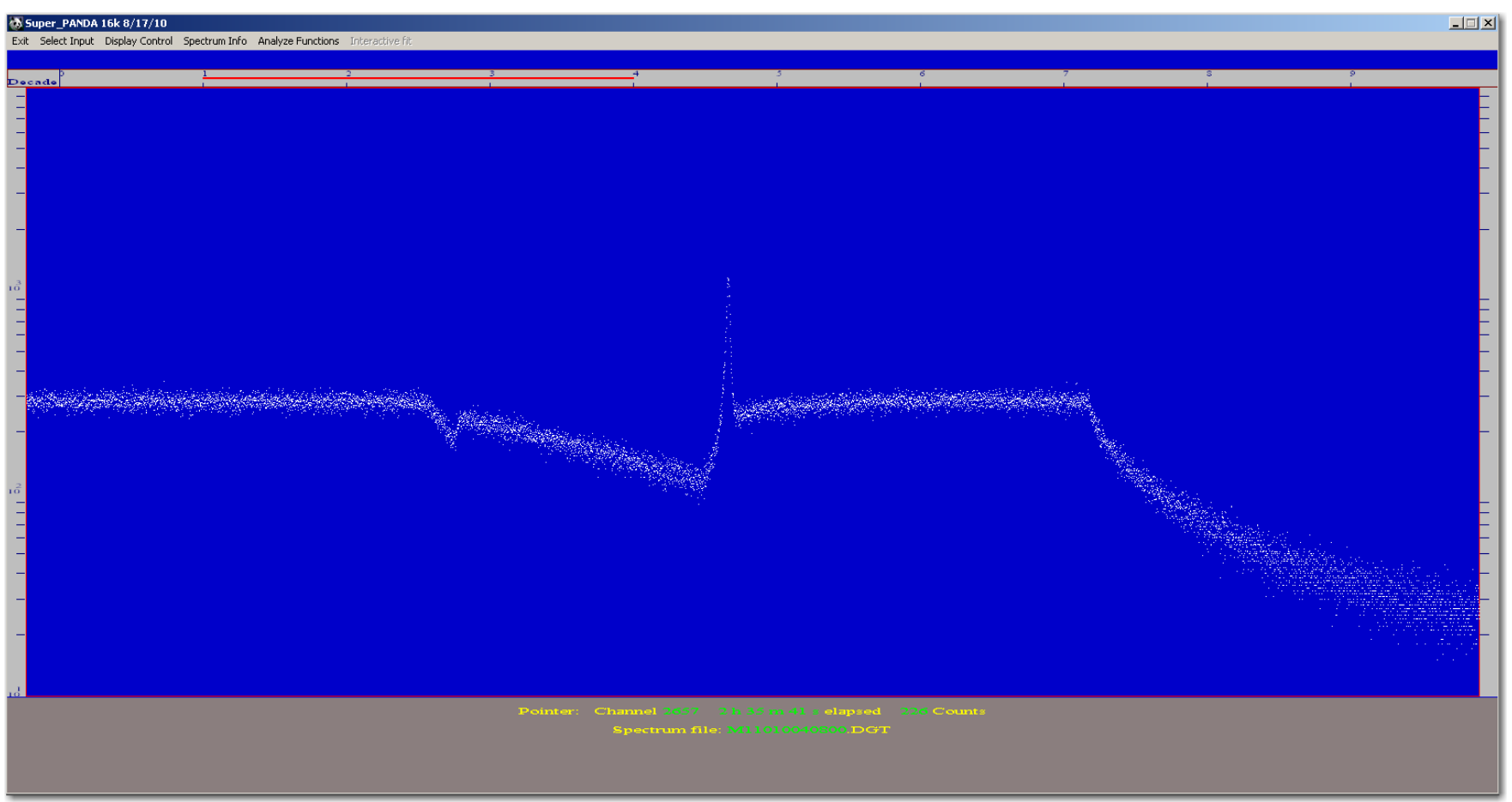

Figure 12. AGR-2 sample gross monitor data collected on October 4, 2010. 
TEM-10200-1

$03 / 01 / 2012$

ENGINEERING CALCULATIONS AND ANALYSIS

Page 20 of 73

Rev. 06

Title:

Release-to-Birth Ratios for AGR-2 Operating Cycles 147A through 154B

ECAR No.: 2420

Rev. No.: 0

Project No:

23843, 23841 Date: 03/04/2014

\section{Cycle 148B}

Nuclides of greatest interest from the R/B determinations for ATR Operating Cycle 148B are presented in Figures 13 through 17. The ATR reached full power on November 18, 2010, at 05:59 (Day 98.08) [11].

Figures 13 through 16 captured AGR-2 neon transport testing, which started on November 18, 2010, and finished on November 19, 2010. During neon transport testing, neon was held constant at $2 \mathrm{sccm}$ for all capsules while the total flow was set to 35,25 , and $15 \mathrm{sccm}$. Measurements for each capsule were acquired. This testing was performed to accurately determine the transport volumes needed to compute the release activity for the AGR-2 experiment.

On November 27, 2010, the flow to Capsule 2 was changed to $15 \mathrm{sccm}$ helium and 0 sccm neon, which is depicted in Figure 13. The capsule flow stayed at this rate until December 2, 2010, when the gas mix was changed to $16 \mathrm{sccm}$ helium and $14 \mathrm{sccm}$ neon. The initial change was triggered due to thermocouple loss in Capsule 2.

Figure 17 captures the gross gamma data for AGR-2 Cycle 148B for Capsules 2, 3, 5, and 6. Gross gamma data for capsule 2 reflects the decrease in count rate because of the lack of neon in the capsule and are not presented in this plot because the count rate was very low; however, they are preserved in the NDMAS database.

Starting on December 11, 2010, the FPMS computer experienced a 37.9-hour gap in data collection. The FPMS data collection computer experienced a Windows XP memory leak, causing the AGR monitor and the FPM to cease function, but did not affect the system process controlling the alarm wired to the LOC operators. A modification to the AGR monitor software was made to alarm the LOC operators via iBoot in the event the AGR monitor script fails for any reason. This modification allows for a faster response to a similar problem in the future. 
TEM-10200-1

$03 / 01 / 2012$

ENGINEERING CALCULATIONS AND ANALYSIS

Page 21 of 73

Rev. 06

Title: $\quad$ Release-to-Birth Ratios for AGR-2 Operating Cycles 147A through 154B

ECAR No.: 2420

Rev. No.: 0

Project No.:

23843, 23841 Date: 03/04/2014

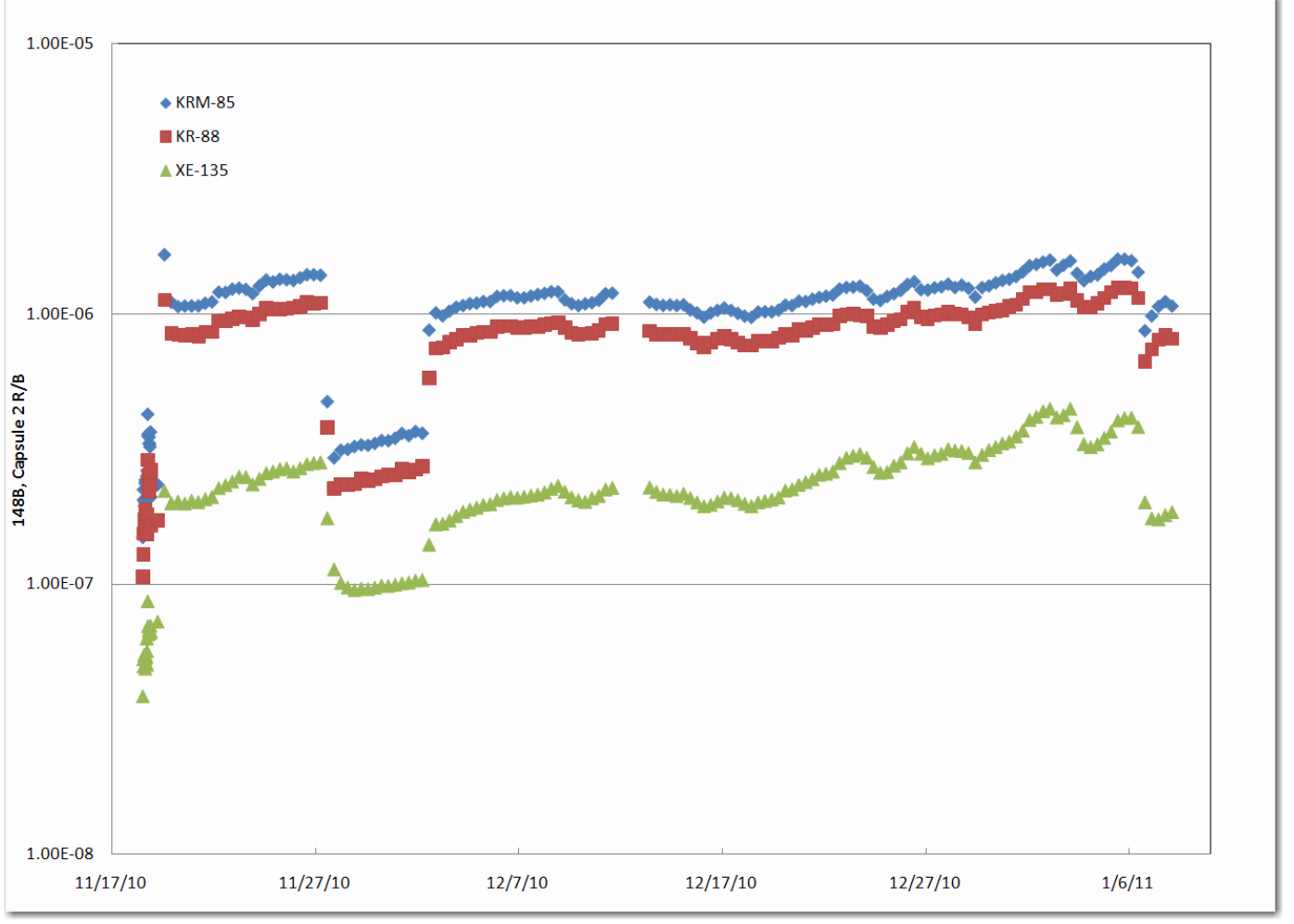

Figure 13. Cycle 148B, Capsule 2 R/Bs Kr-85m, Kr-88, and Xe-135. 
TEM-10200-1

$03 / 01 / 2012$

ENGINEERING CALCULATIONS AND ANALYSIS

Page 22 of 73

Rev. 06

Title: $\quad$ Release-to-Birth Ratios for AGR-2 Operating Cycles 147A through 154B

$\begin{array}{lllll}\text { ECAR No.: } 2420 & \text { Rev. No.: } & 0 & \text { Project No.: } & 23843,23841 \text { Date: }\end{array}$

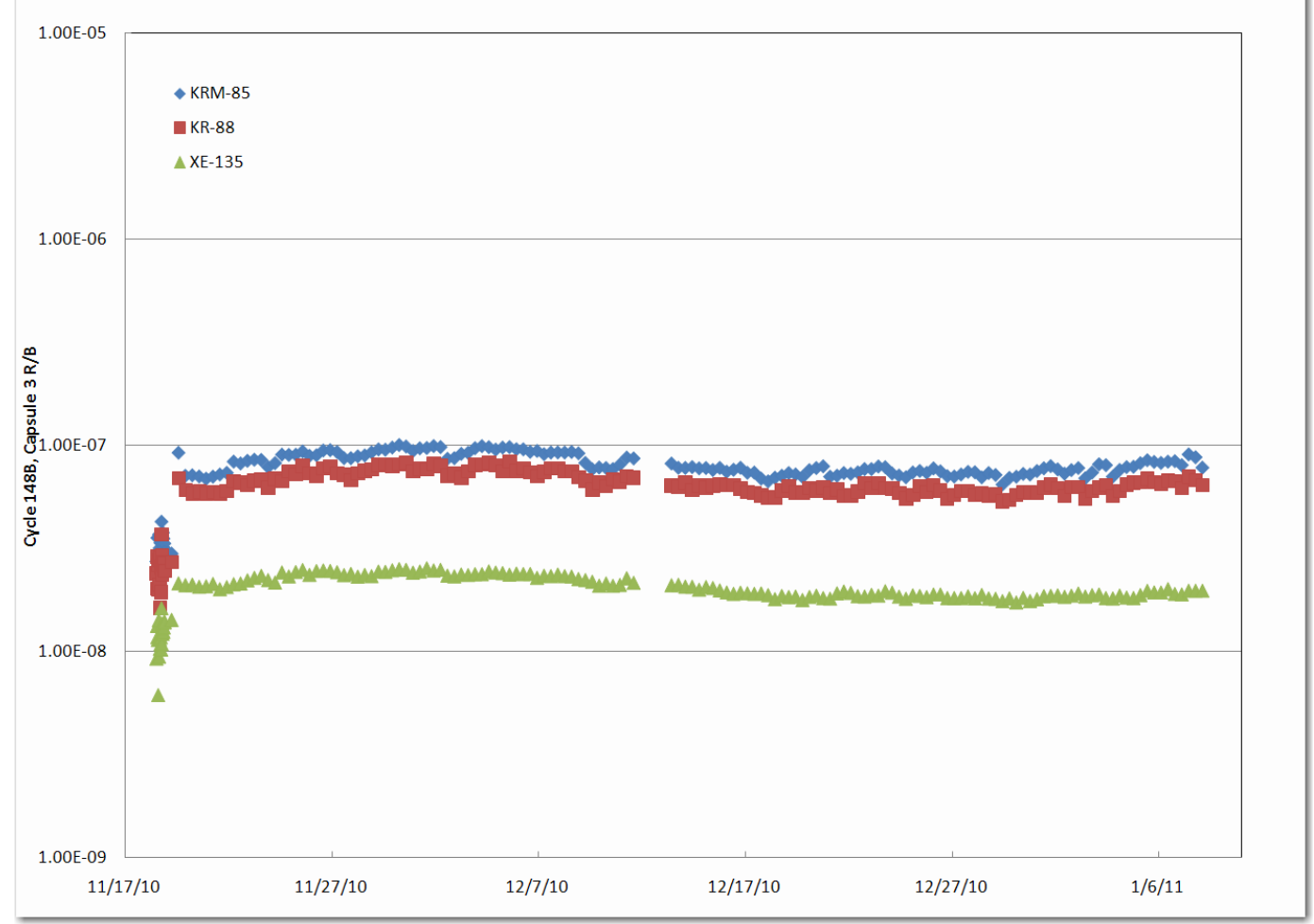

Figure 14. Cycle 148B, Capsule 3 R/Bs Kr-85m, Kr-88, and Xe-135.

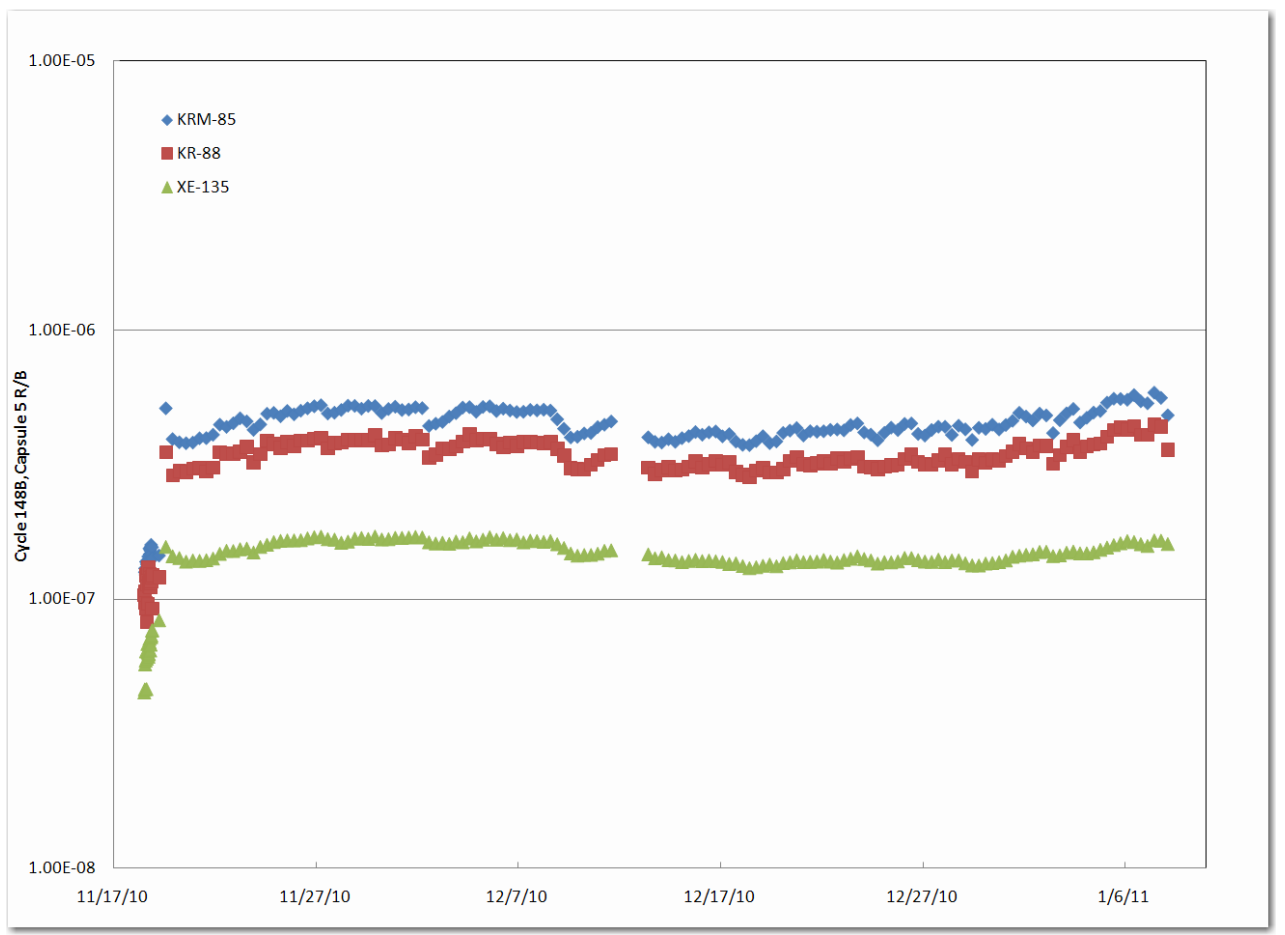

Figure 15. Cycle 148B, Capsule 5 R/Bs Kr-85m, Kr-88, and Xe-135. 
TEM-10200-1

$03 / 01 / 2012$

ENGINEERING CALCULATIONS AND ANALYSIS

Page 23 of 73

Rev. 06

Title: $\quad$ Release-to-Birth Ratios for AGR-2 Operating Cycles 147A through 154B

\begin{tabular}{lllll} 
ECAR No.: 2420 & Rev. No.: & 0 & Project No.: & 23843,23841 Date: \\
\hline
\end{tabular}

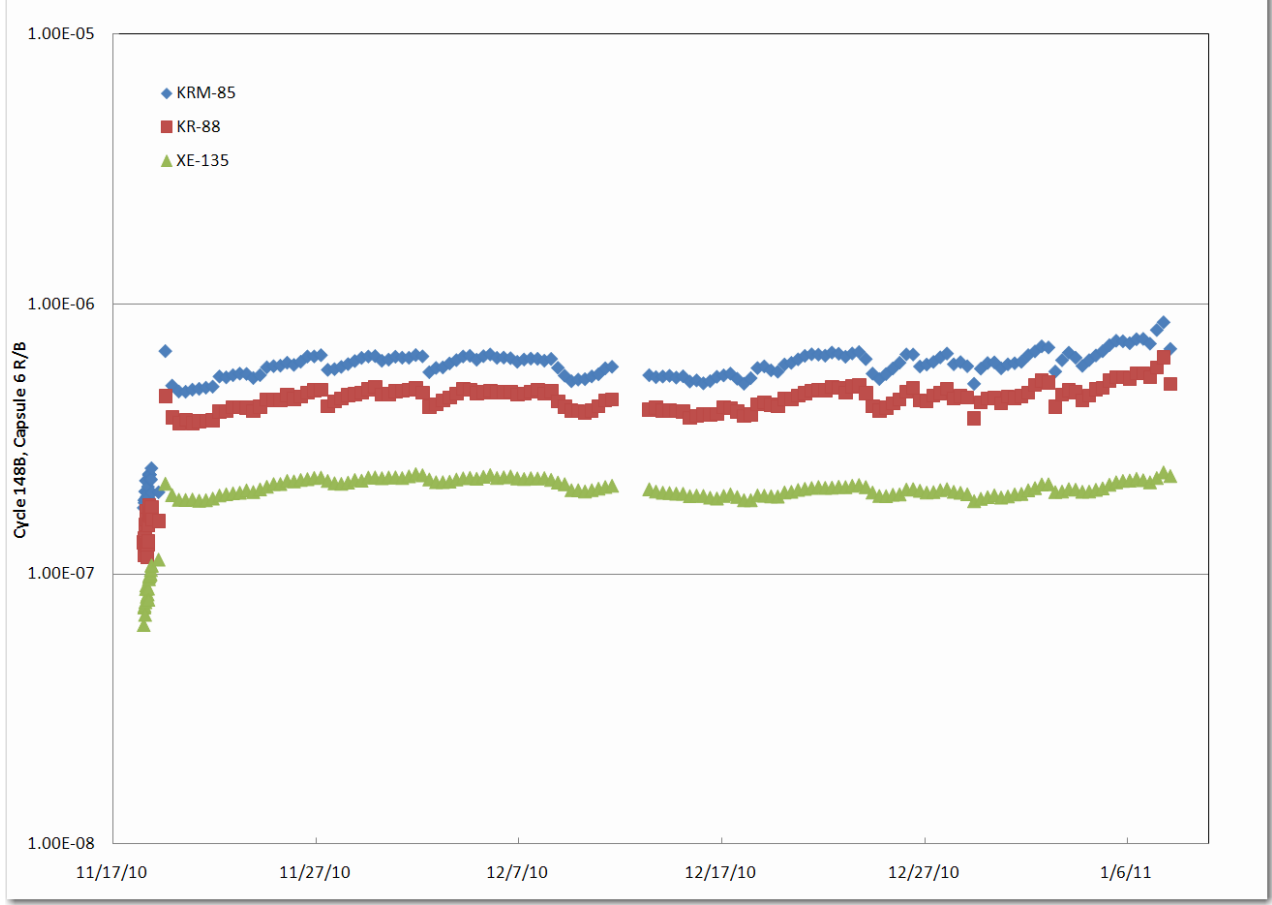

Figure 16. Cycle 148B, Capsule 6 R/Bs Kr-85m, Kr-88, and Xe-135.

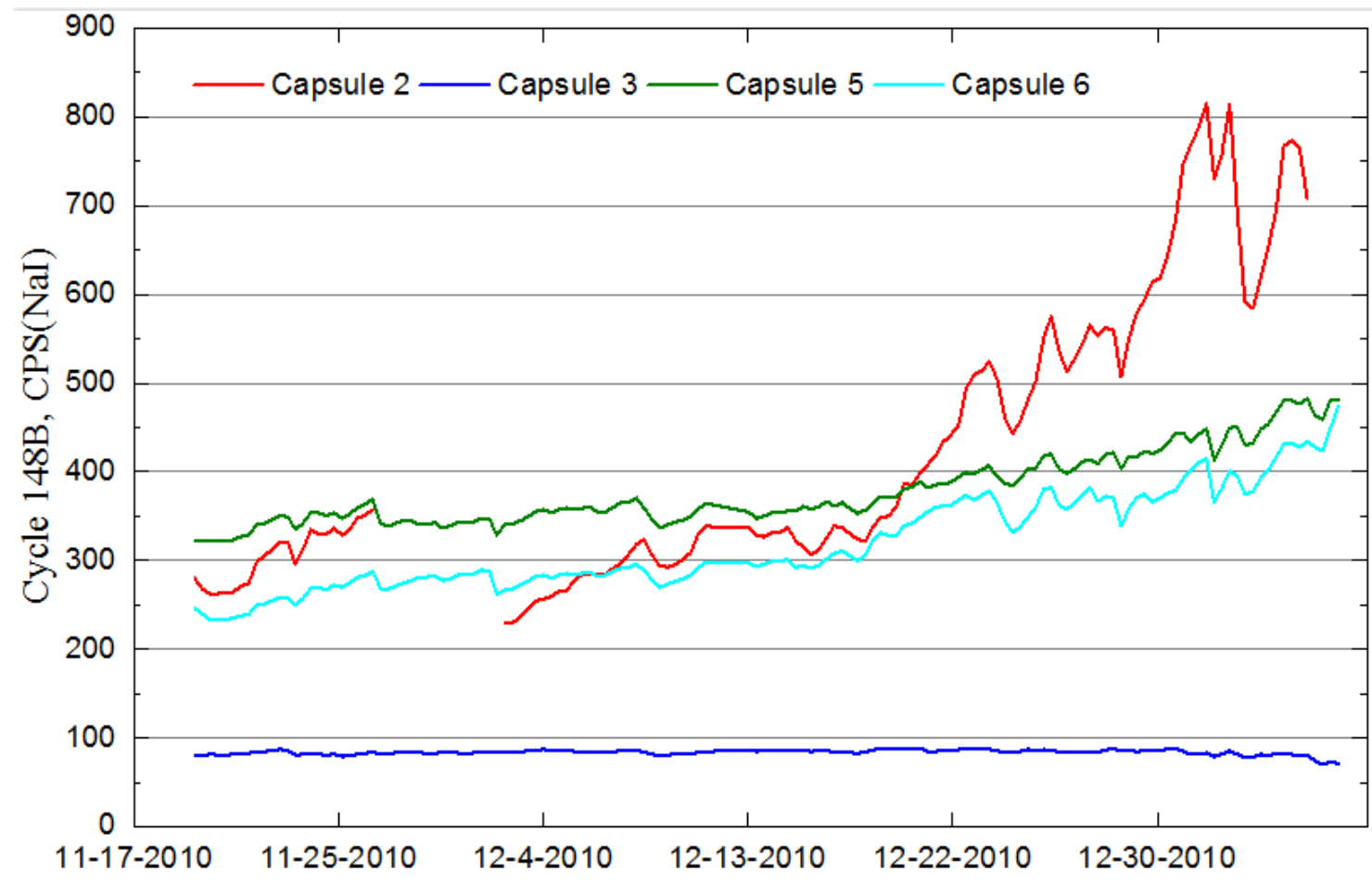

Figure 17. Gross gamma for Cycle 148B, total counts per second for Capsules 2, 3, 5, and 6. 
TEM-10200-1

$03 / 01 / 2012$

ENGINEERING CALCULATIONS AND ANALYSIS

Page 24 of 73

Rev. 06

Title: $\quad$ Release-to-Birth Ratios for AGR-2 Operating Cycles 147A through 154B

ECAR No.: $2420 \quad$ Rev. No.: $0 \quad$ Project No.: 23843,23841 Date: 03/04/2014

At the end of Cycle 148B, Capsule 2 flow was changed from $20 \mathrm{sccm}$ helium/10 sccm neon to $30 \mathrm{sccm}$ helium/0 sccm neon on January 6, 2011, at 17:30. For the duration of the cycle, neon for Capsule 2 remained at $0 \mathrm{sccm}$. This cooling effect is captured in Figure 13.

\section{Cycle 149A}

During the Cycle 149A outage, which started January 8, 2011, poppet check valves on the AGR-2 outlet distribution panel were replaced with actual relief valves. These new relief valves have a set pressure of only 5 psig versus the 10 psig of the original set of pressure check valves. The FPMS inlet isolation ball valves also were replaced with needle valves. These valve changes were anticipated to be transparent to the operation of the experiment; however, they had unexpected consequences for the FPMS measurements. Upon initial reactor startup, review of the gross gamma data revealed that something was not as intended. The expected activity levels were seen for all capsules except 2, which showed only FPM chamber background. Changes to the flow configuration were made to clarify the situation. These changes dominate Figures 18 and 19 of the R/Bs for Capsules 2 and 3. Shifts on April 20, April 26, and May 10, 2011, are associated with the flow configuration changes [12].

Nuclides of greatest interest from the R/B determinations for ATR Operating Cycle 149A are presented in Figures 18 through 22. ATR reached full power on April 14, 2011, at 18:59 (Day 149.40).

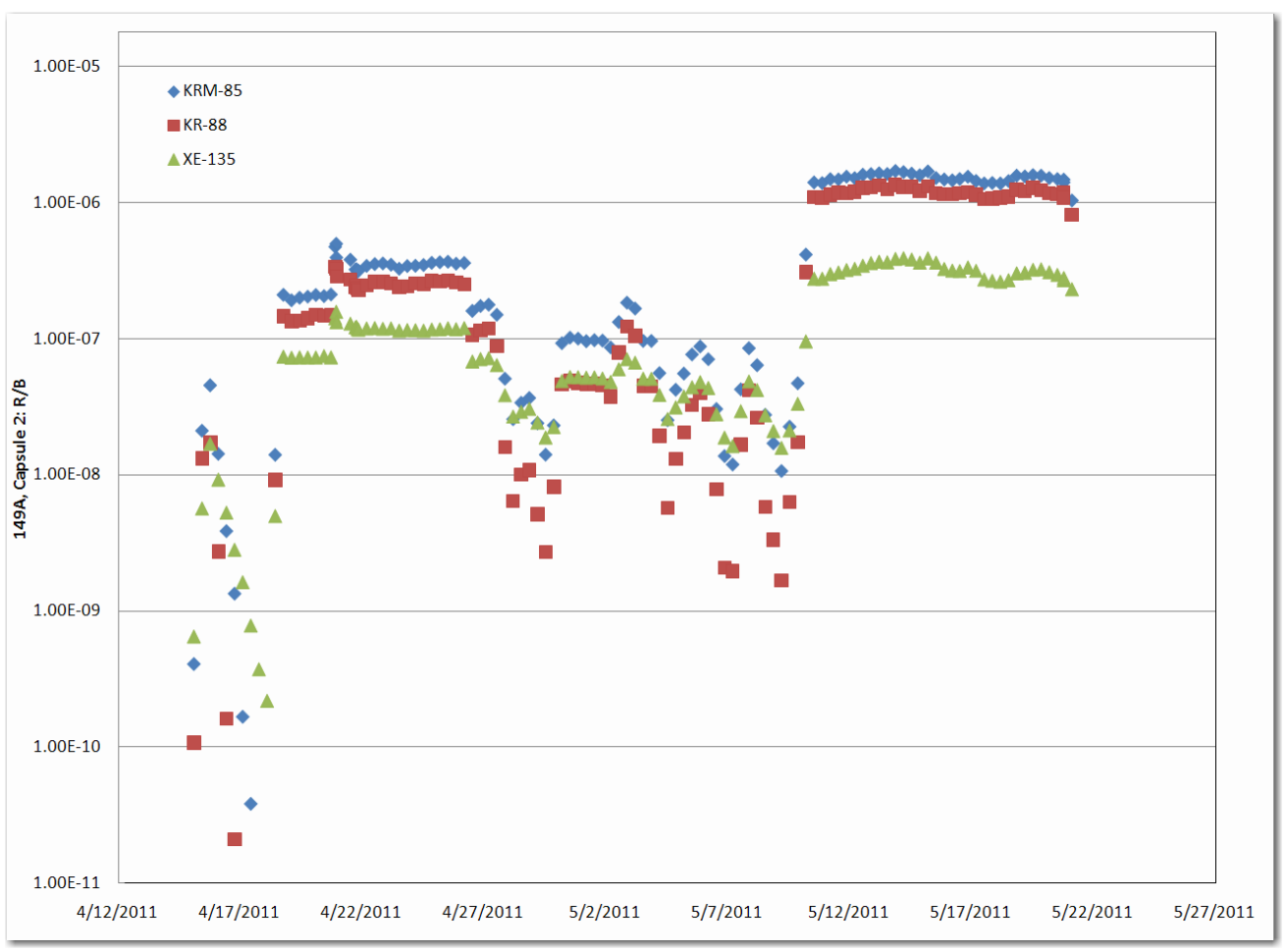

Figure 18. Cycle 149A, Capsule 2 R/B ratios Kr-85m, Kr-88, and Xe-135. R/B ratios for Capsule 2 are not reliable due to experiment flow issues. 
TEM-10200-1

$03 / 01 / 2012$

ENGINEERING CALCULATIONS AND ANALYSIS

Page 25 of 73

Rev. 06

Title: $\quad$ Release-to-Birth Ratios for AGR-2 Operating Cycles 147A through 154B

$\begin{array}{llll}\text { ECAR No.: } 2420 & \text { Rev. No.: } 0 & \text { Project No.: } & \text { 23843, } 23841 \text { Date: } 03 / 04 / 2014\end{array}$

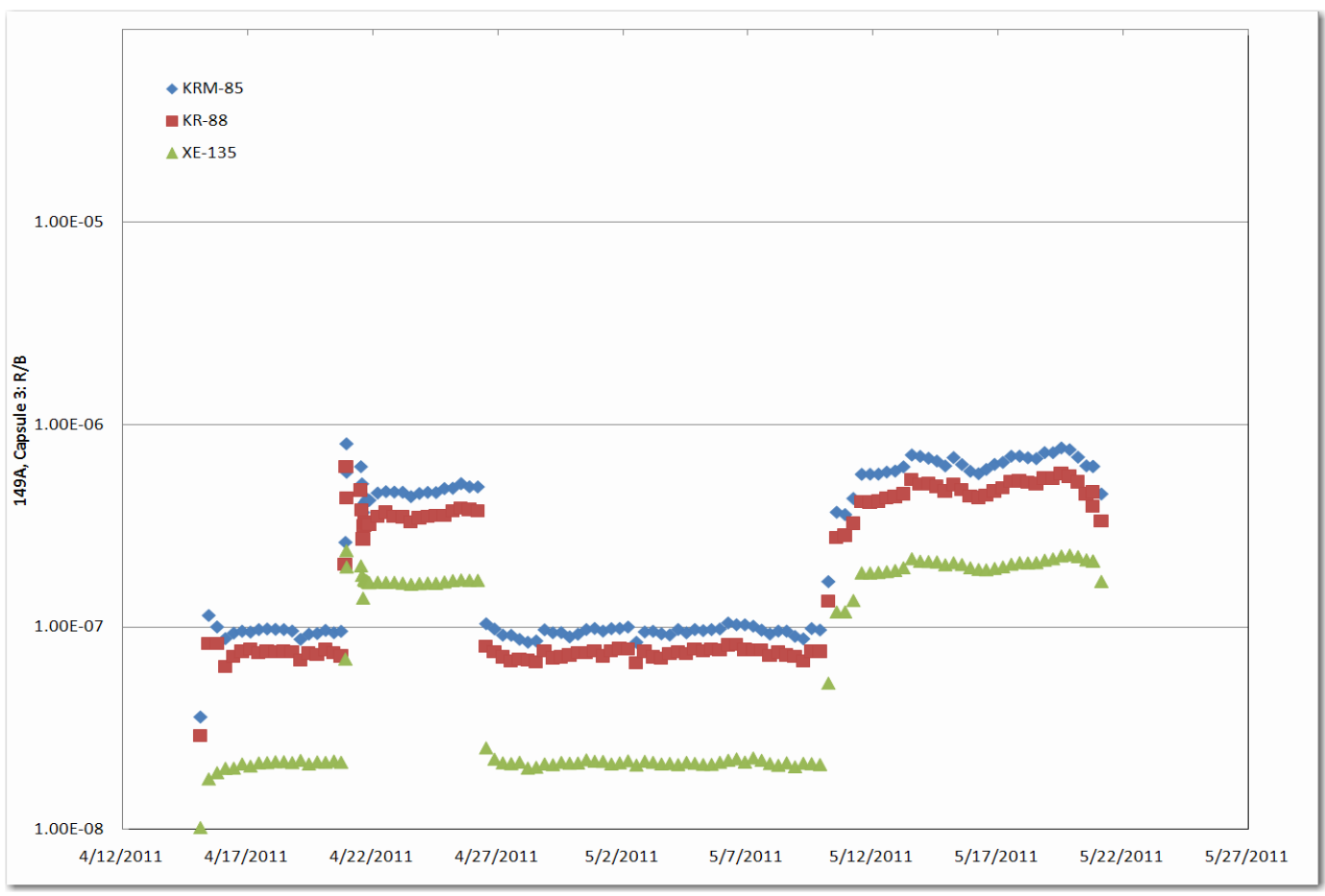

Figure 19. Cycle 149A, Capsule 3 R/Bs Kr-85m, Kr-88, and Xe-135. R/Bs for Capsule 3 are not reliable because of experiment flow issues.

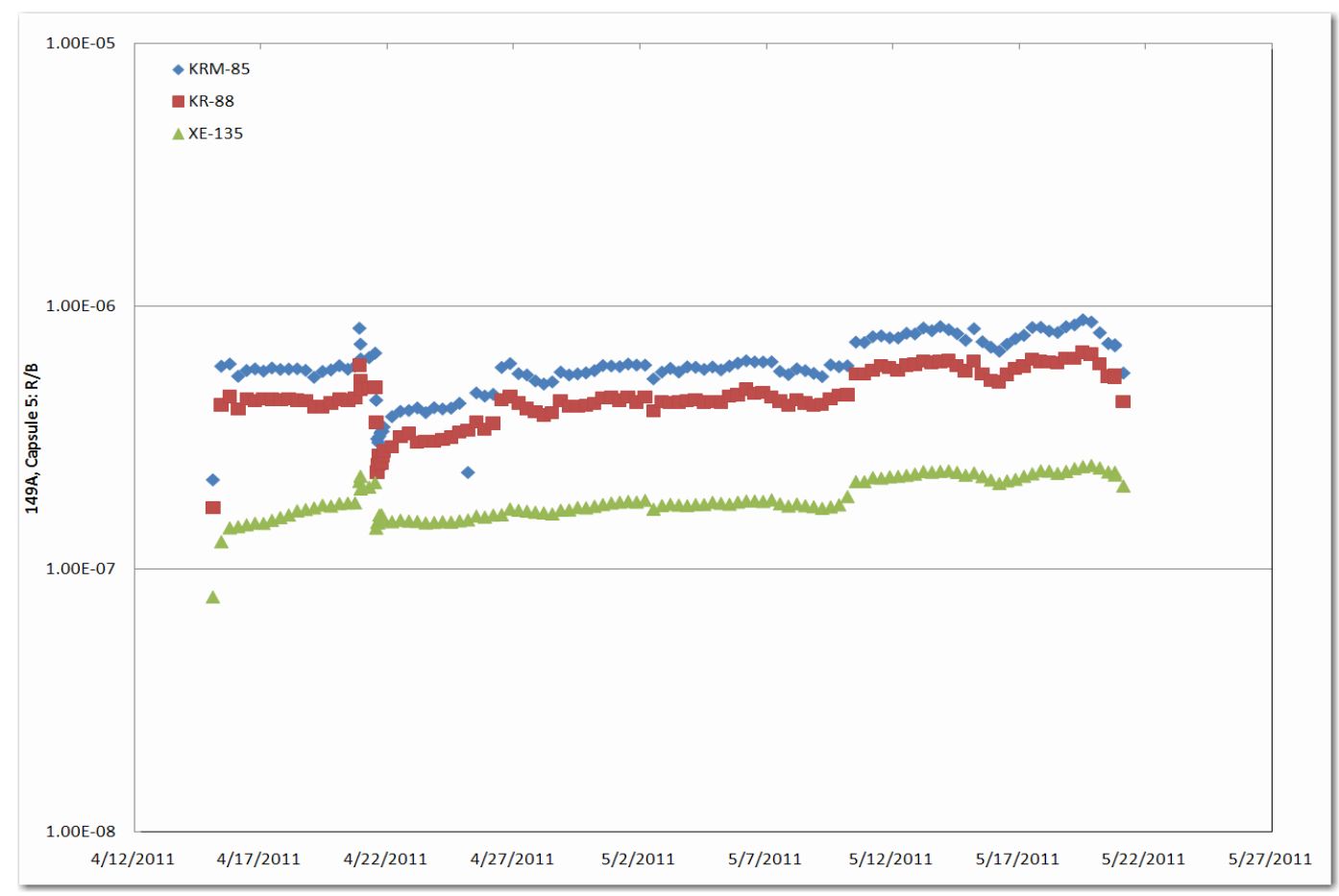

Figure 20. Cycle 149A, Capsule 5 R/Bs Kr-85m, Kr-88, and Xe-135. 
TEM-10200-1

$03 / 01 / 2012$

ENGINEERING CALCULATIONS AND ANALYSIS

Page 26 of 73

Rev. 06

Title: $\quad$ Release-to-Birth Ratios for AGR-2 Operating Cycles 147A through 154B

$\begin{array}{llll}\text { ECAR No.: } 2420 & \text { Rev. No.: } 0 & \text { Project No.: } & \text { 23843, } 23841 \text { Date: } 03 / 04 / 2014\end{array}$

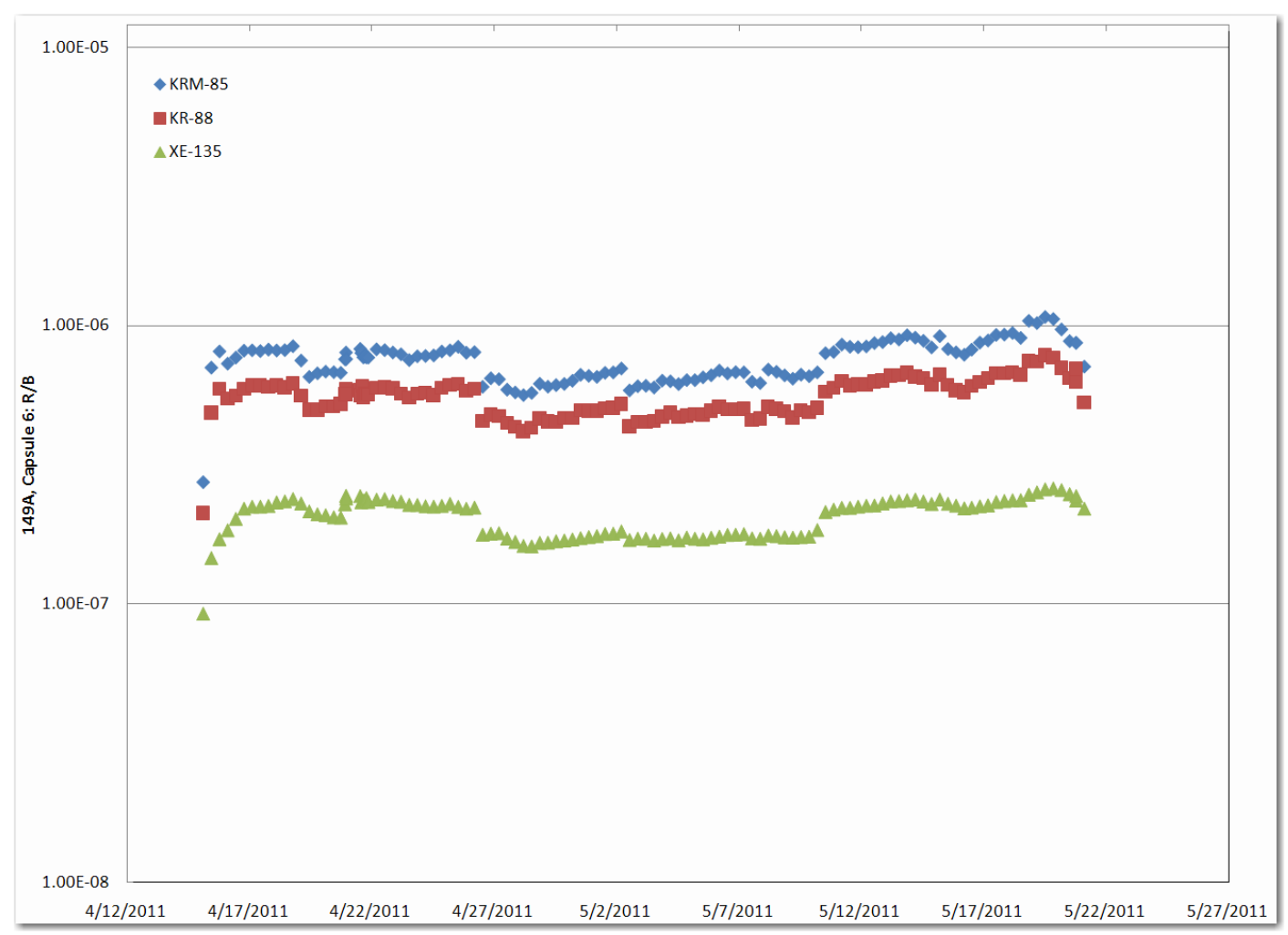

Figure 21. Cycle 149A, Capsule 6 R/Bs Kr-85m, Kr-88, and Xe-135.

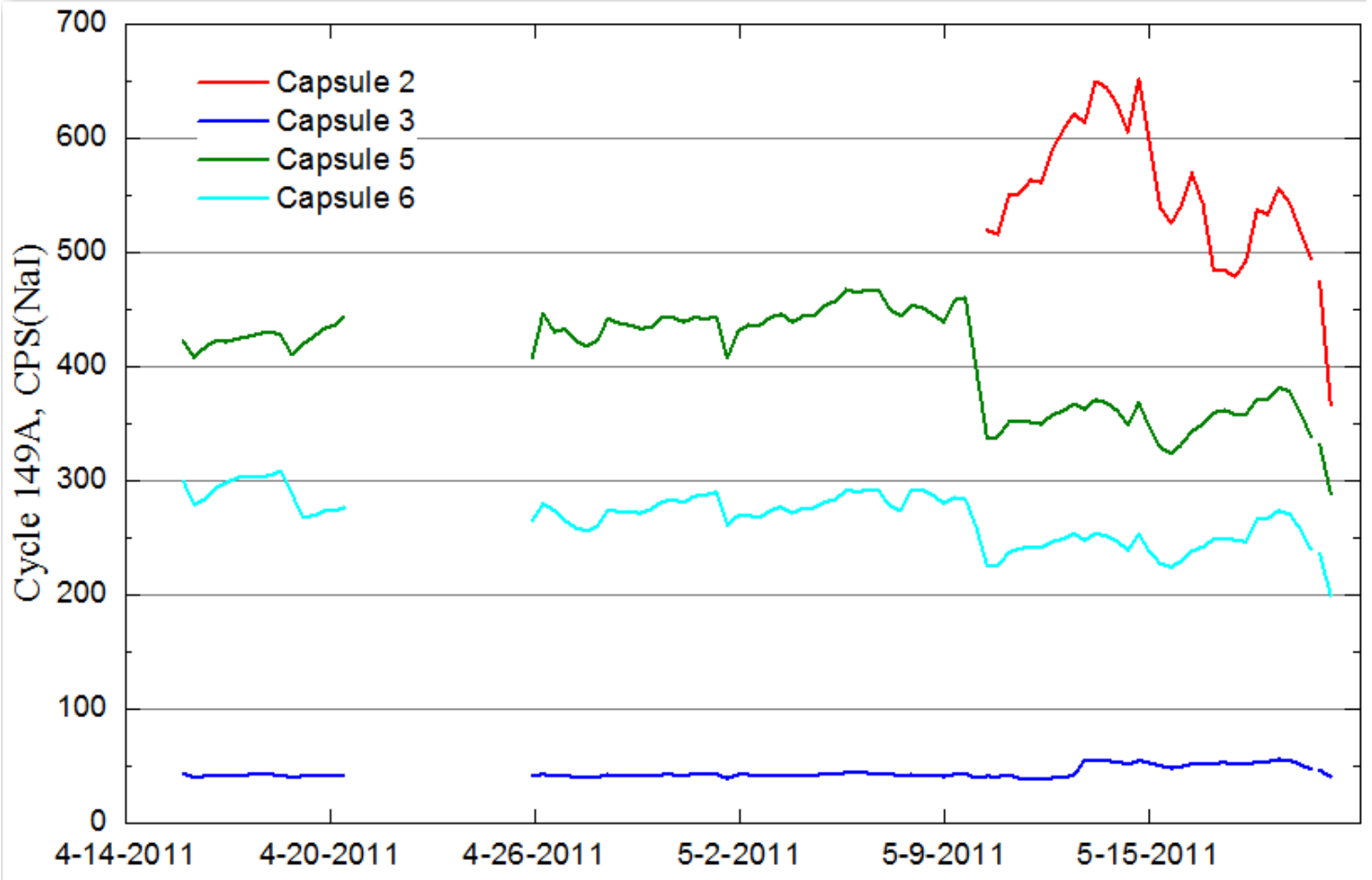

Figure 22. Gross gamma for Cycle 149A, total counts per second for Capsules 2, 3, 5, and 6. 
TEM-10200-1

$03 / 01 / 2012$

ENGINEERING CALCULATIONS AND ANALYSIS

Page 27 of 73

Rev. 06

Title:

Release-to-Birth Ratios for AGR-2 Operating Cycles 147A through 154B

ECAR No.: 2420

Rev. No.: $0 \quad$ Project No.:

23843, 23841 Date: 03/04/2014

The reactor came to full power on April 14, 2011, and the lack of activity was noted in the Capsule 2 effluent. On April 15 at about noon, effluent from Capsule 2 was routed to FPM7 instead with no change in the gross activity measurements. Closer examination of FPM2 spectra later revealed that there had been minimal activity for the longer-lived isotopes, which died away when FPM2 was isolated. No real change was made to the effluent flowing to FPM7, except that the effluent from Capsule 2 bypassed FPM2. On April 18, effluent from Capsule 2 was routed back to FPM2.

Subsequent examination of those spectra showed that minimal activity was restored at FPM2. On April 20 at 21:48, all capsule flow was through the manual sample line, thus isolating the spare FPM7. This resulted in obvious changes to the gross counters for FPM2 and FPM7. Activity in the latter died away as expected; however, activity in FPM2 increased to near normal for a capsule at temperature. Subsequent examination of the high-purity germanium detector spectra also showed substantial change in FPM3, with subtler changes in the other detectors. While the gross count rate for FPM3 was not much changed, the spectra showed short half-life activity vanishing and long life-time activity increasing by factors of 4 and more. On April 21 at 13:40, after the fission products in FPM7 had decayed away to background levels, effluent from Capsule 5 was routed through FPM5 then onto the spare FPM7. Capsule 5's temperature instantly dropped to $718^{\circ} \mathrm{C}$ and a high-flow alarm for Capsule 5 was recorded at 13:47. From 14:08 to 14:38, LOC worked to get the temperature and pressure back within the nominal operating bands. At 14:38, LOC placed Capsule 5 outlet valve SV-315-2 to sample, sending the Capsule 5 temperature soaring to $900^{\circ} \mathrm{C}$. Capsule 5 was manually purged. This event is shown as a rapid increase in activity in Figures 18 and 19 on April 21, 2011. Routing all capsules through the sample (glovebox) caused a pressure increase in all capsules because of the more torturous route. When Capsule 5 (lowest downstream pressure and easiest flow path) was rerouted to a normal flow path, the other capsules may have partially vented into the leadout, which then vented through Capsule 5 (a path of less resistance). Some of the other capsules must have had a higher neon fraction, which increased the temperature in Capsule 5, resulting in the spike observed in Figures 18 through 20. On April 26, the flow configuration was returned to normal, reproducing the activities observed on April 18, 2011.

At 09:50 on May 10, 2011, effluent was routed from Capsule 2 through FPM2 and then through FPM7. The AGR-2 experiment was cooled for roughly 10 minutes prior to the configuration change. Figure 23 shows the initial increase, then a decrease in activity, which is normal when effluent is rerouted. The exception is seen in FPM2 data, where the counts increase to $500 \mathrm{cps}$ (shown in Figures 23 and 24). It appears as though the flow was turned in such a way that effluent from Capsule 2 was able to make its way to FPM2. The AGR-2 experiment was brought back to operating temperature at 11:02 on May 10, 2011, where it was maintained until reactor shut down on May 21, 2011 [12].

After Cycle 149A ended, the data from the FPM spectrometers was analyzed and R/Bs were generated. An interesting situation was noticed on FPM2 (Capsule 2) and FPM3 (Capsule 3). The data in Figures 18 and 19 seem to show a common trend that was unique to the FPM2 and FPM3 flow paths. Upon closer examination, it was noticed that there was an increase in fission activity in FPM3 during the time periods from April 20 through 26 and May 10 through 21, 2011. These increases in activity were caused by the longer-lived isotopes from krypton ( $\mathrm{Kr}-85 \mathrm{~m}, \mathrm{Kr}-88$, etc.) and xenon (Xe135). The shorter lived krypton (Kr-89, Kr-90, etc.) and xenon (Xe-139) did not make it to the FPM3 collection trap. It is believed that this happened, in part, due to an increase in pressure from the capsules when gas flow was rerouted. This pressure increase was great enough to cause the newly installed relief valve to exceed the 5-psig rating, causing the relief valve to open. R/B data for Capsules 2 and 3 are not reliable because of experiment flow issues. R/B data for Capsules 1, 4, 5, and 6 appear to be consistent with Cycle 148B data, thus no observed failures. 
TEM-10200-1

$03 / 01 / 2012$

ENGINEERING CALCULATIONS AND ANALYSIS

Page 28 of 73

Rev. 06

Title: $\quad$ Release-to-Birth Ratios for AGR-2 Operating Cycles 147A through 154B

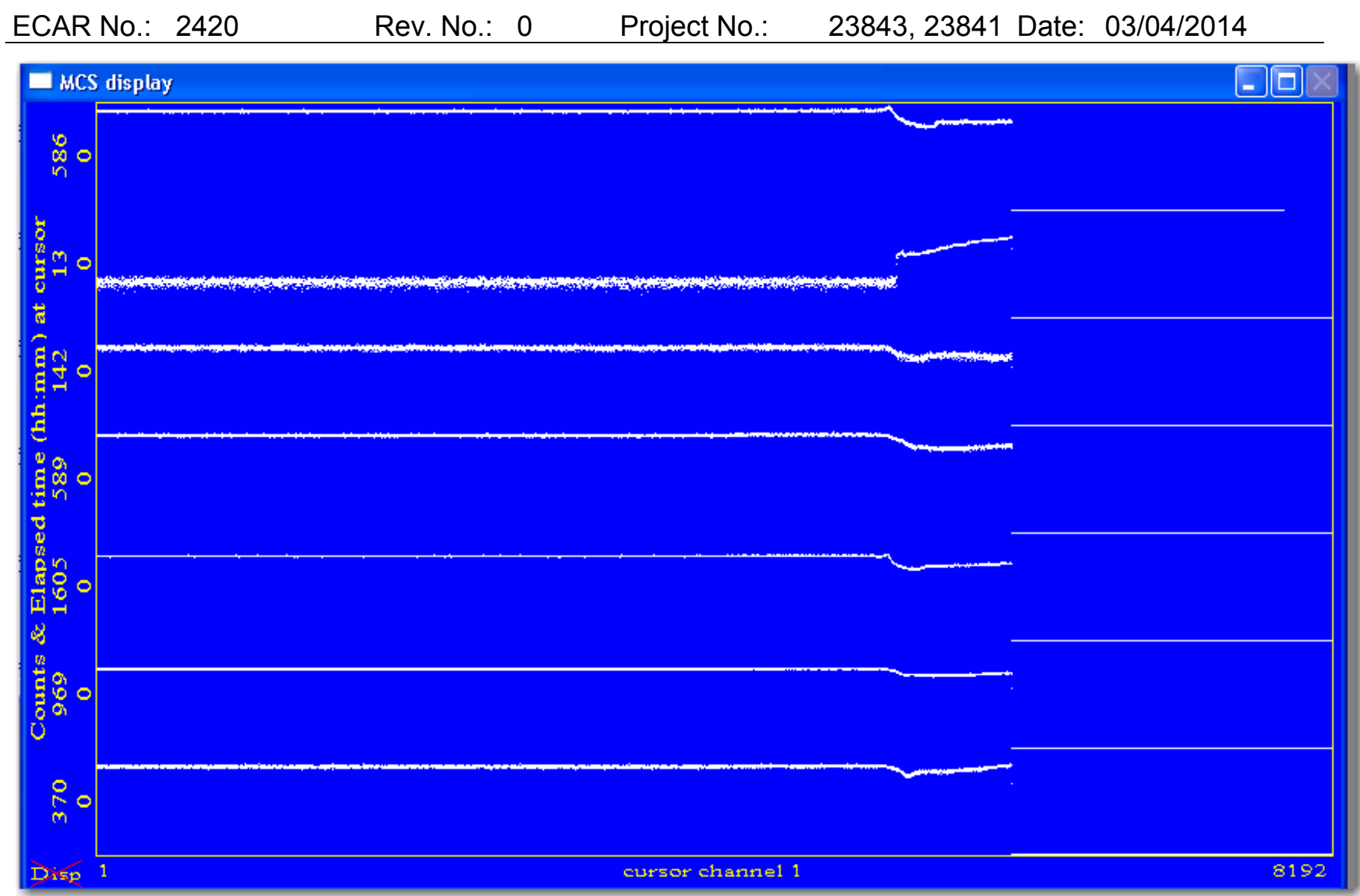

Figure 23. A screen capture of the gross monitors from the FPM software, capturing the effluent change that took place on May 10, 2011. 
TEM-10200-1

$03 / 01 / 2012$

Rev. 06

Title:

Release-to-Birth Ratios for AGR-2 Operating Cycles 147A through 154B

ECAR No.: 2420

Rev. No.: 0

Project No:

23843, 23841 Date: 03/04/2014

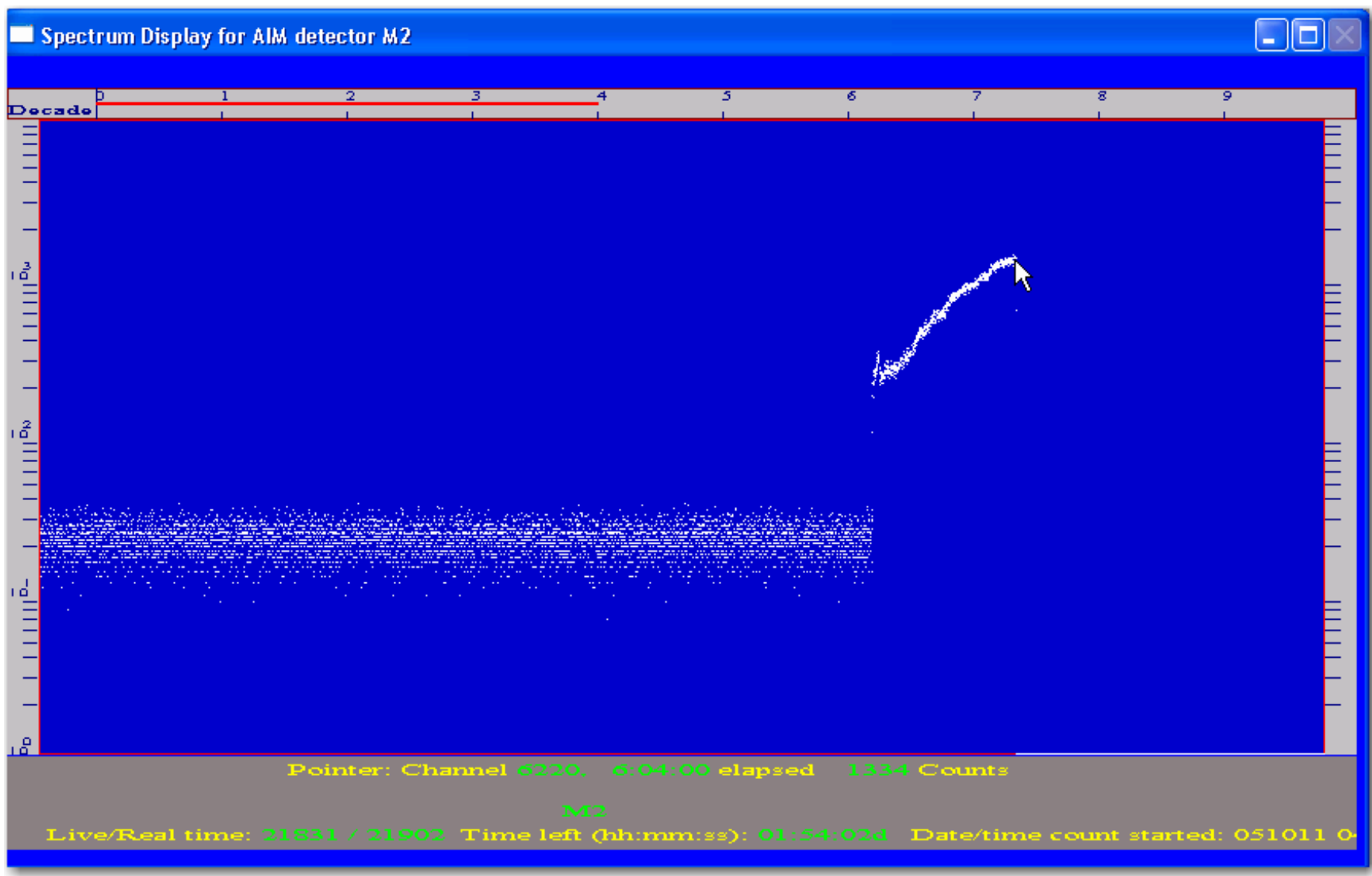

Figure 24. Gross monitor data from FPM2 after effluent was routed from Capsule 2 through FPM2 and then FPM7.

\section{Cycle 149B}

During the Cycle 149A outage, which started January 8, 2011, poppet check valves on the AGR-2 outlet distribution panel were replaced with actual relief valves. These new relief valves have a set pressure of only 5 psig versus the 10 psig of the original set of pressure check valves. The FPMS inlet isolation ball valves also were replaced with needle valves. These valve changes were anticipated to be transparent to the operation of the experiment; however, they had unexpected consequences for the FPMS measurements. Upon initial reactor startup, review of the gross gamma data during Cycle 149A revealed something was not as intended. Expected activity levels were seen for all capsules except 2, which showed only the FPM chamber background. The relief valve situation continued through to Cycle 149B because it was not possible to replace the relief valves during the Cycle 149B outage. Changes to the flow configuration were made to clarify the situation. These changes dominate Figures 25 through 28 of the R/Bs for Capsules 2 and 3. Shifts on June 28 and July 26 are associated with flow configuration changes [13].

Nuclides of greatest interest from the R/B determinations for ATR Operating Cycle 149B are presented in Figures 25 through 32. ATR reached full power on June 6, 2011, at 03:00 (Day 186.30). 
TEM-10200-1

$03 / 01 / 2012$

ENGINEERING CALCULATIONS AND ANALYSIS

Page 30 of 73

Rev. 06

Title: $\quad$ Release-to-Birth Ratios for AGR-2 Operating Cycles 147A through 154B

$\begin{array}{lllll}\text { ECAR No.: } 2420 & \text { Rev. No.: } & 0 & \text { Project No.: } & 23843,23841 \text { Date: }\end{array}$

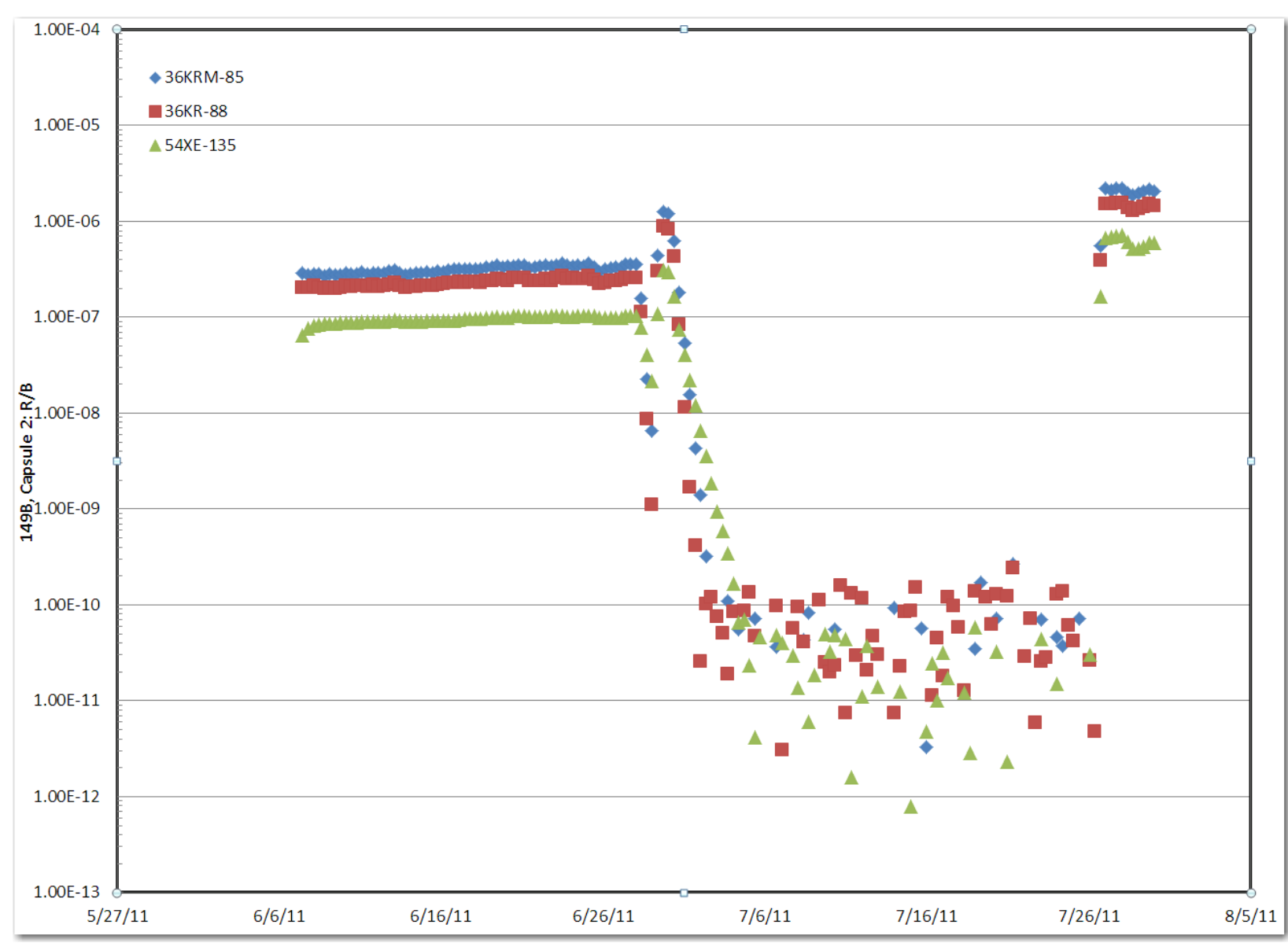

Figure 25. Cycle 149B, Capsule 2 R/B ratios Kr-85m, Kr-88, and Xe-135. R/B ratios for Capsule 2 are not reliable due to experiment flow issues. On June 26, 2011, flow was routed to FPM7. However, the relief valve was upstream of the FPMs therefore R/B data for Cycle 149B is not reliable. The system was returned to normal on July 26, 2011. 
TEM-10200-1

$03 / 01 / 2012$

ENGINEERING CALCULATIONS AND ANALYSIS

Page 31 of 73

Rev. 06

Title: $\quad$ Release-to-Birth Ratios for AGR-2 Operating Cycles 147A through 154B

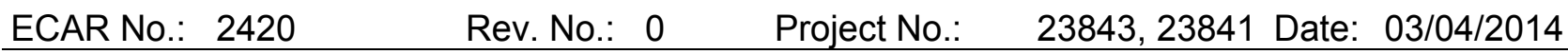

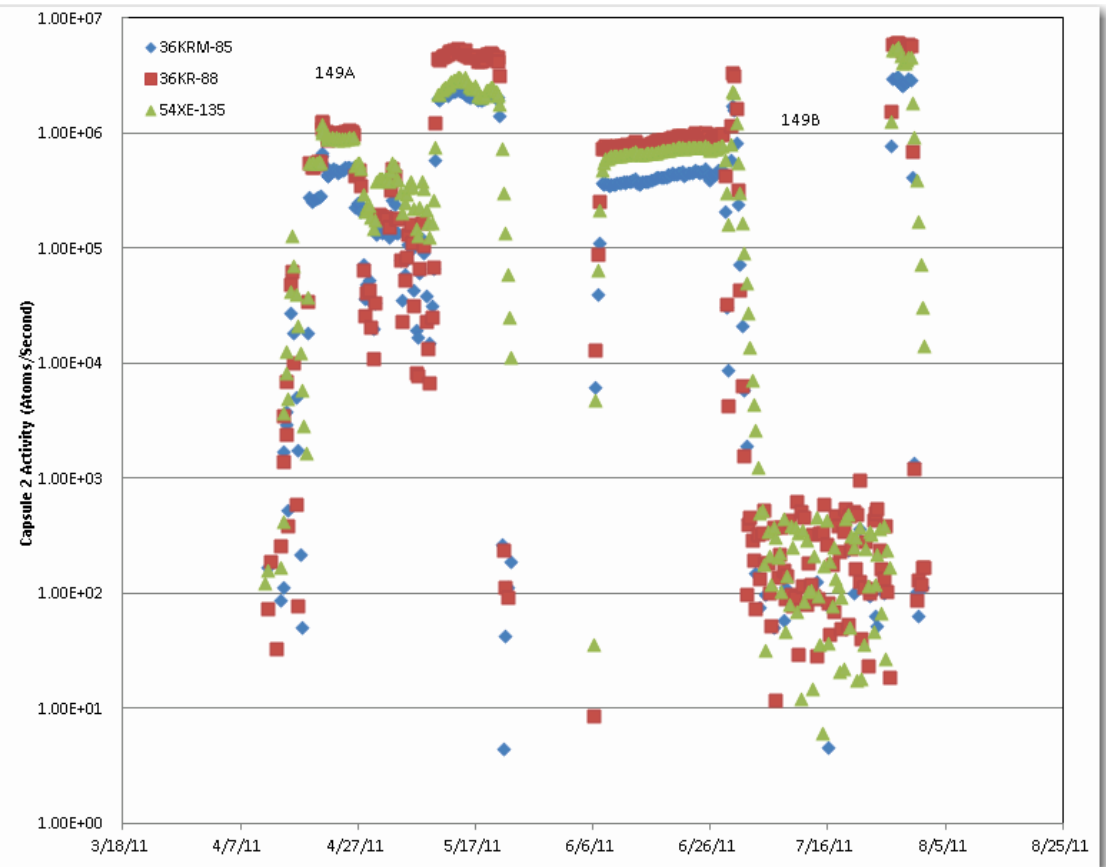

Figure 26. Release activity for Capsule 2, capturing Cycle 149A and 149B.

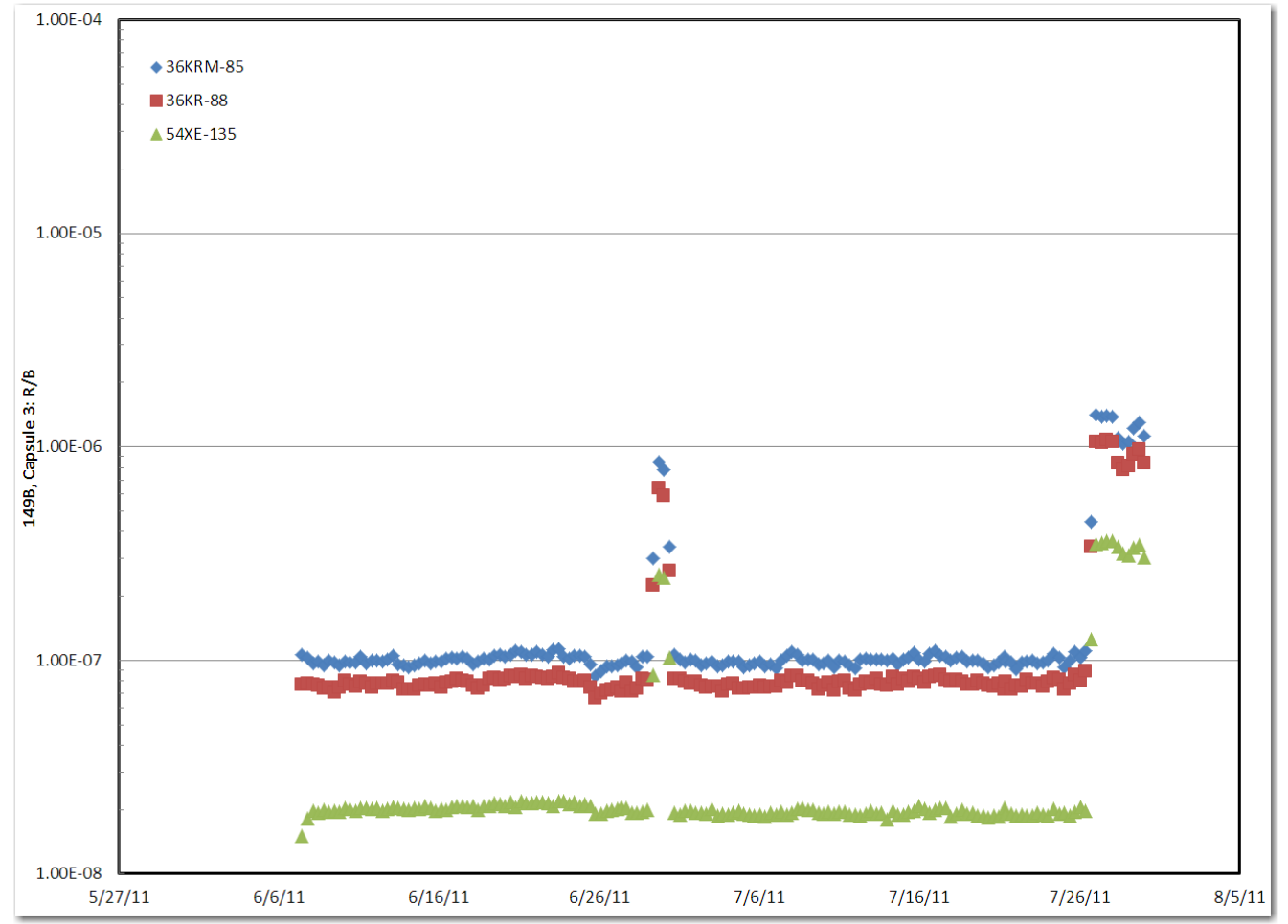

Figure 27. Cycle 149B, Capsule 3 R/Bs Kr-85m, Kr-88, and Xe-135. R/Bs for Capsule 3 are not reliable because of experiment flow issues. 
TEM-10200-1

$03 / 01 / 2012$

ENGINEERING CALCULATIONS AND ANALYSIS

Page 32 of 73

Rev. 06

Title: $\quad$ Release-to-Birth Ratios for AGR-2 Operating Cycles 147A through 154B

$\begin{array}{lllll}\text { ECAR No.: } 2420 & \text { Rev. No.: } 0 & \text { Project No.: } & 23843,23841 \text { Date: } & 03 / 04 / 2014\end{array}$

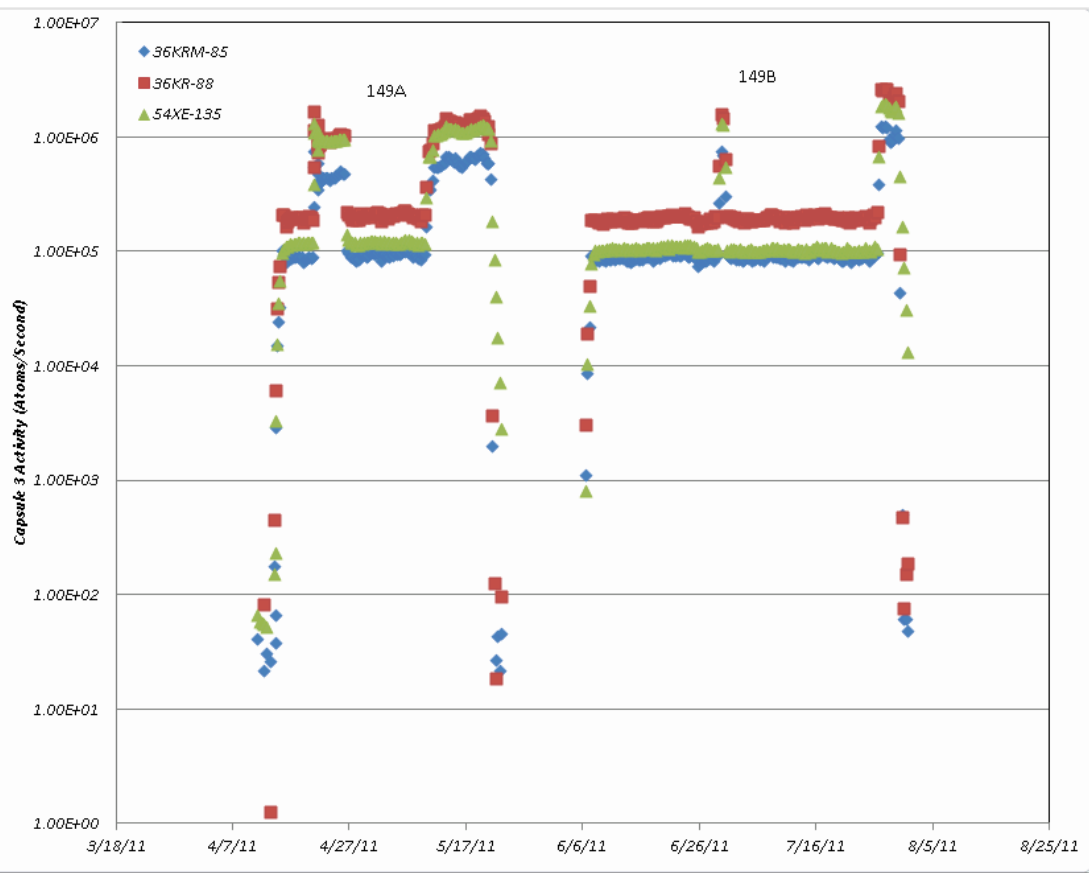

Figure 28. Release activity for Capsule 3, capturing Cycle 149A and 149B.

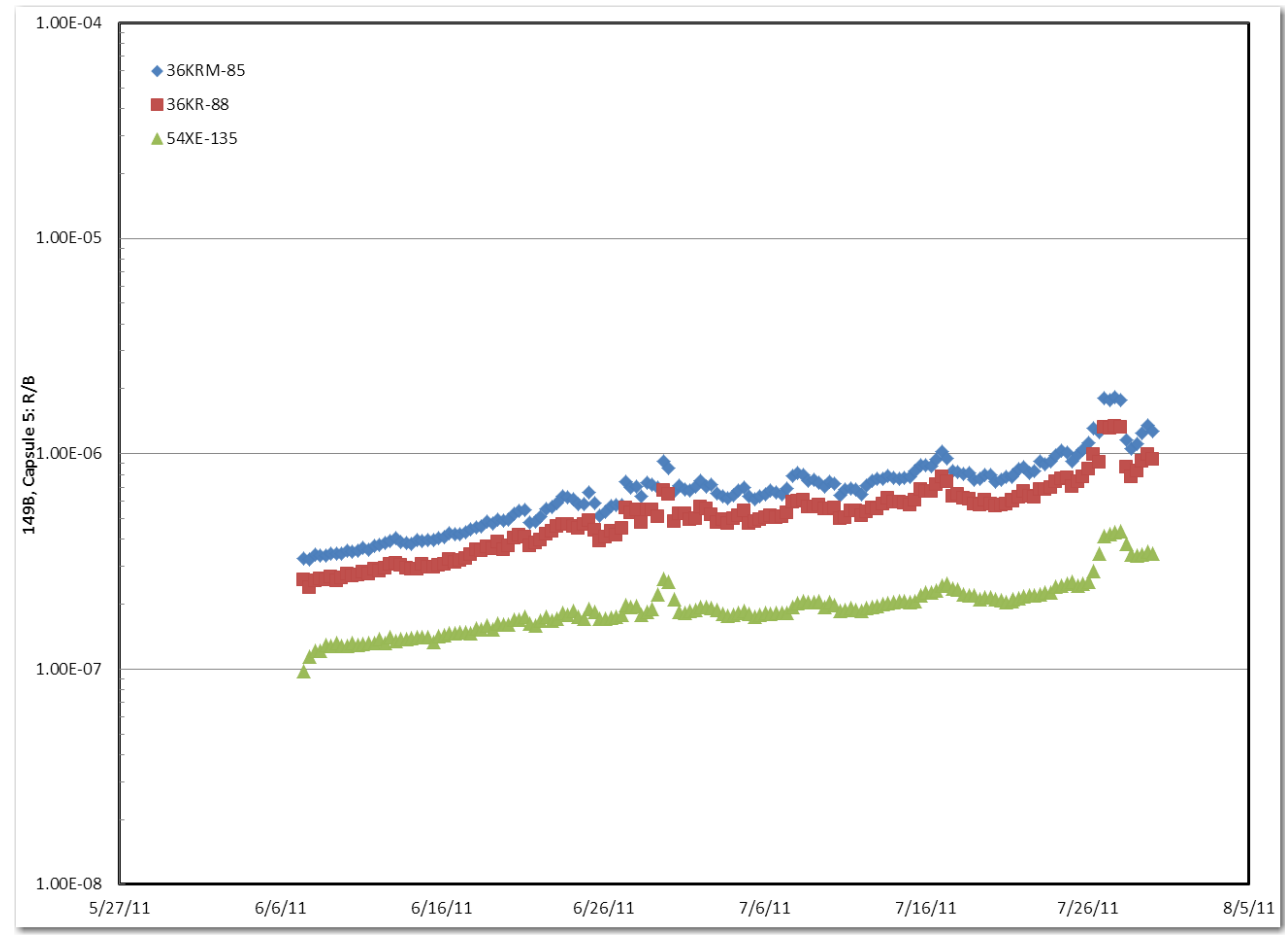

Figure 29. Cycle 149B, Capsule 5 R/Bs Kr-85m, Kr-88, and Xe-135. 
TEM-10200-1

$03 / 01 / 2012$

ENGINEERING CALCULATIONS AND ANALYSIS

Page 33 of 73

Rev. 06

Title: $\quad$ Release-to-Birth Ratios for AGR-2 Operating Cycles 147A through 154B

$\begin{array}{llll}\text { ECAR No.: } 2420 & \text { Rev. No.: } 0 & \text { Project No.: } & \text { 23843, } 23841 \text { Date: }\end{array}$

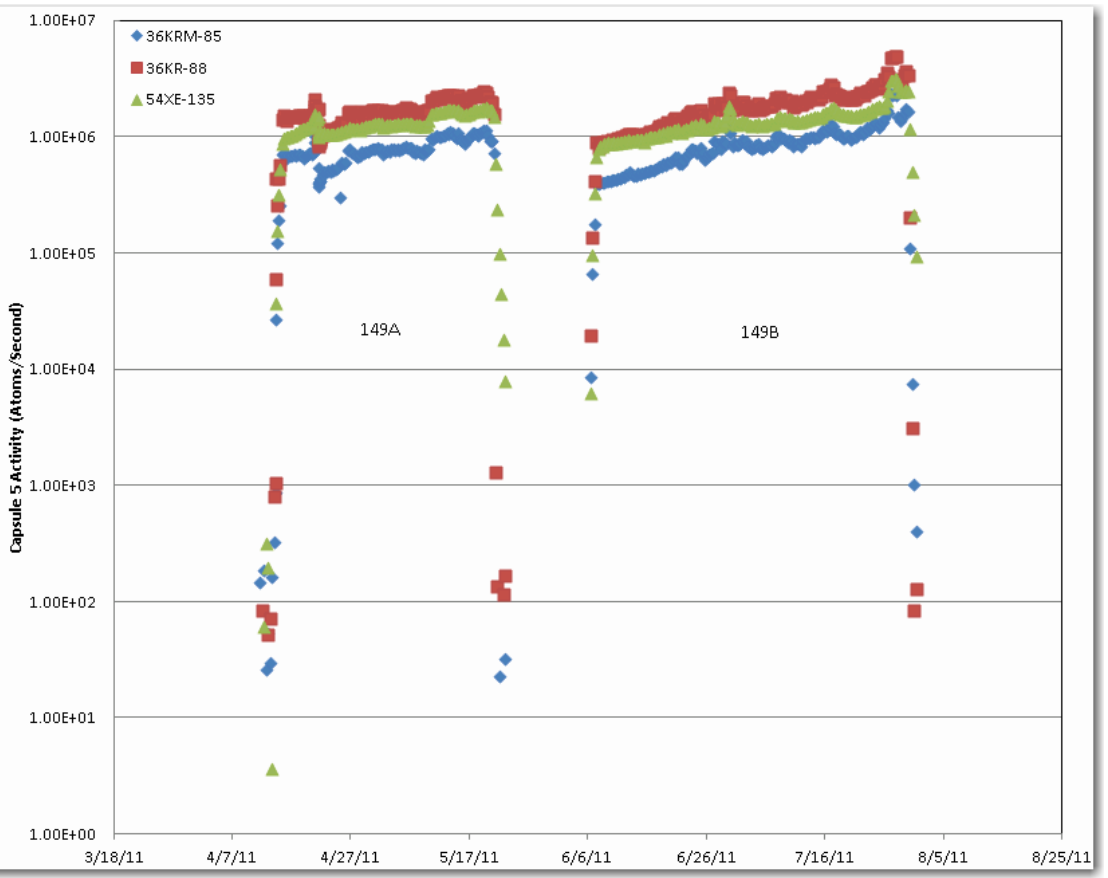

Figure 30. Release activity for Capsule 5, capturing Cycle 149A and 149B.

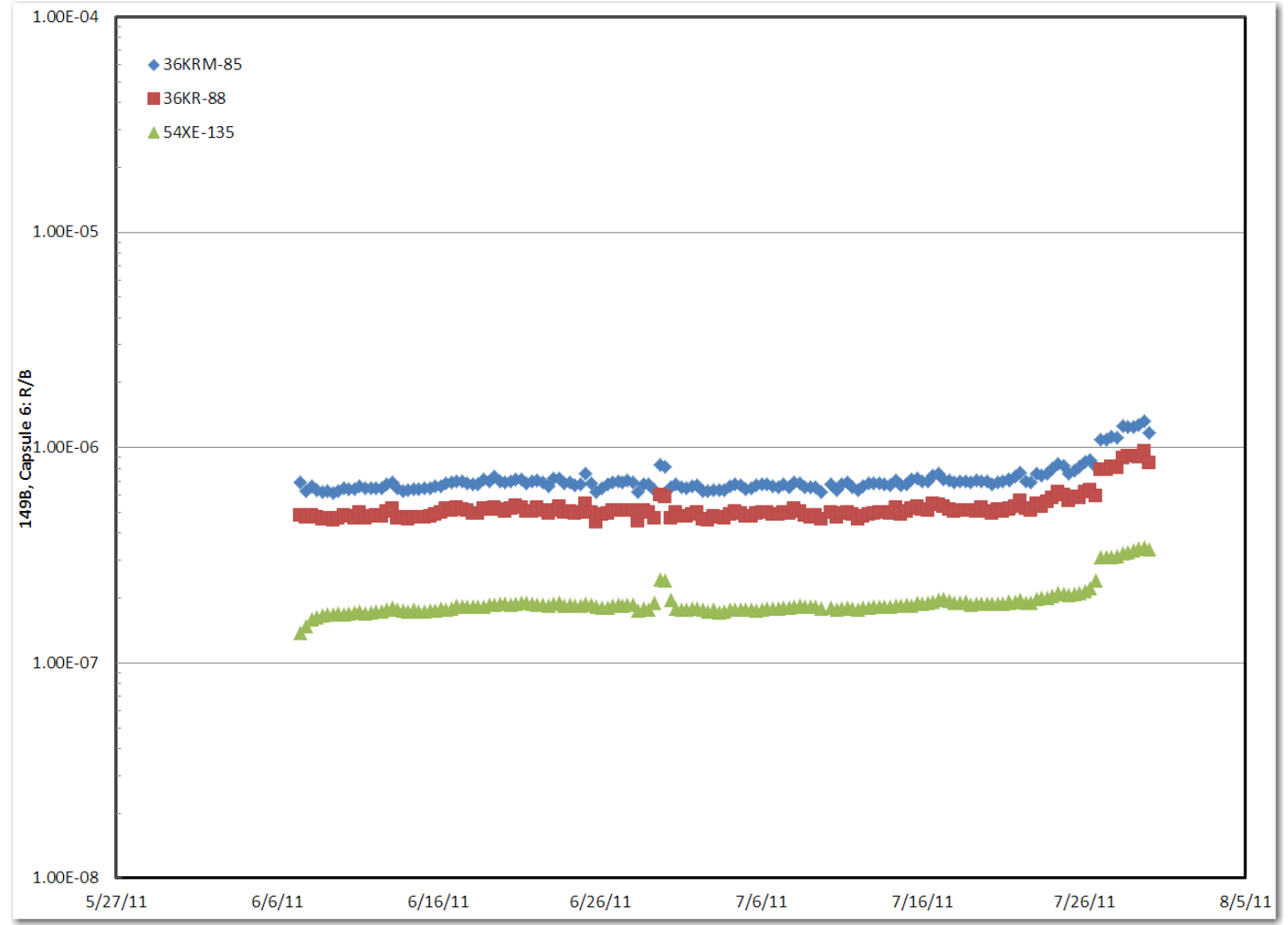

Figure 31. Cycle 149B, Capsule 6 R/Bs Kr-85m, Kr-88, and Xe-135. 
TEM-10200-1

$03 / 01 / 2012$

ENGINEERING CALCULATIONS AND ANALYSIS

Page 34 of 73

Rev. 06

Title: $\quad$ Release-to-Birth Ratios for AGR-2 Operating Cycles 147A through 154B

$\begin{array}{llll}\text { ECAR No.: } 2420 & \text { Rev. No.: } 0 & \text { Project No.: } & \text { 23843, } 23841 \text { Date: } 03 / 04 / 2014\end{array}$

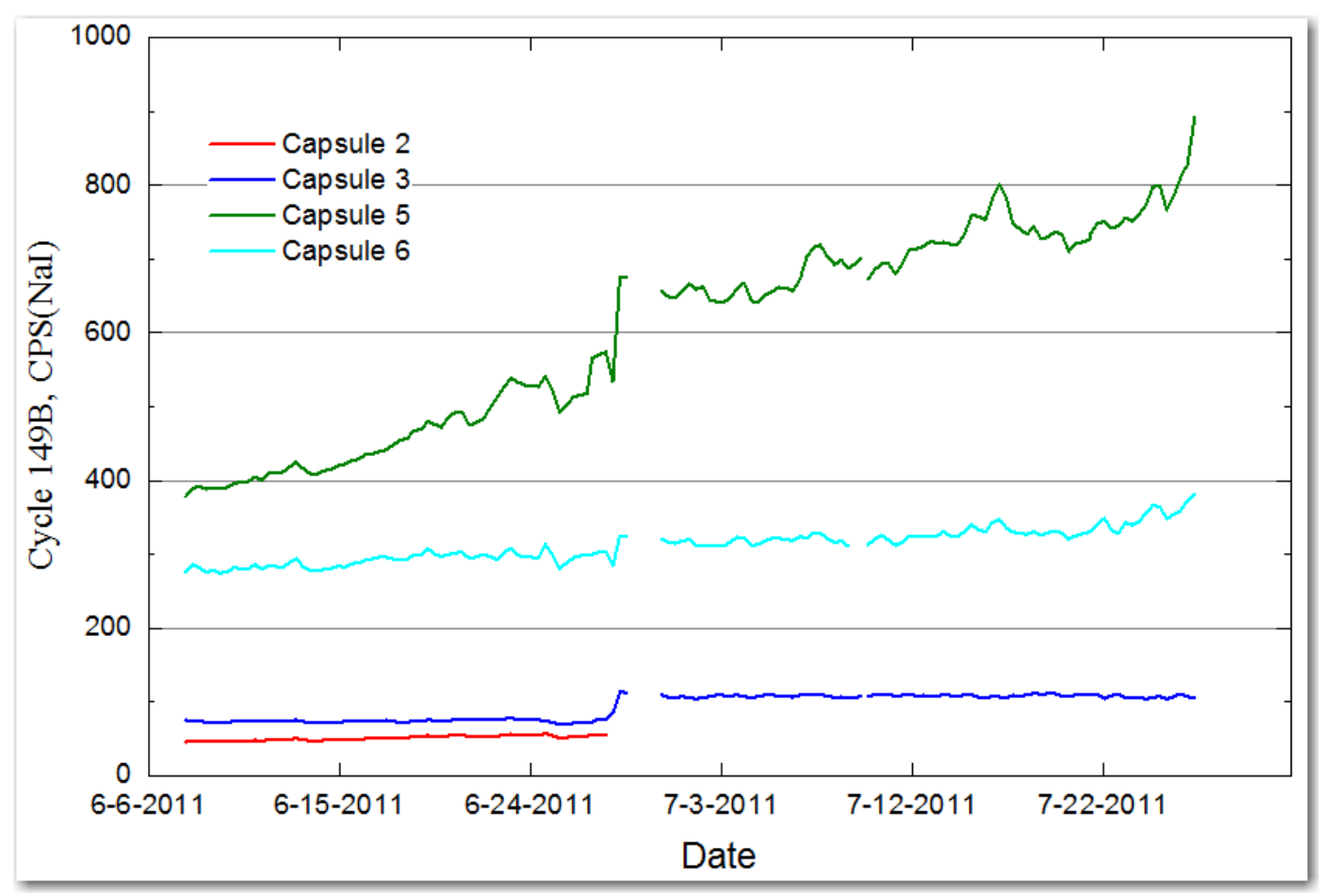

Figure 32. Gross gamma for Cycle 149B, total counts per second for Capsules 2, 3, 5, and 6.

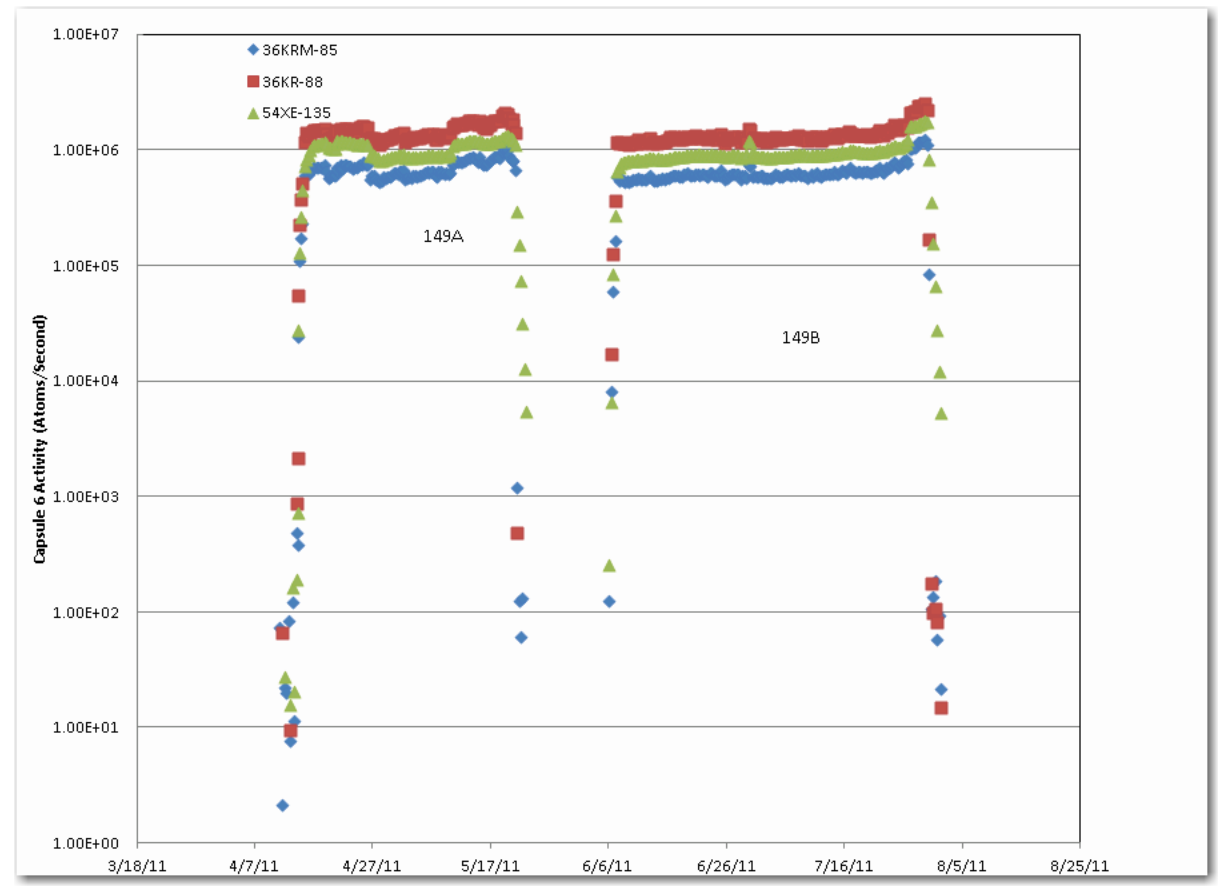

Figure 33. Release activity for Capsule 6, capturing Cycle 149A and 149B. 
TEM-10200-1

$03 / 01 / 2012$

ENGINEERING CALCULATIONS AND ANALYSIS

Page 35 of 73

Rev. 06

Title: $\quad$ Release-to-Birth Ratios for AGR-2 Operating Cycles 147A through 154B

$\begin{array}{llll}\text { ECAR No.: } 2420 & \text { Rev. No.: } 0 & \text { Project No.: } & \text { 23843, } 23841 \text { Date: } 03 / 04 / 2014\end{array}$

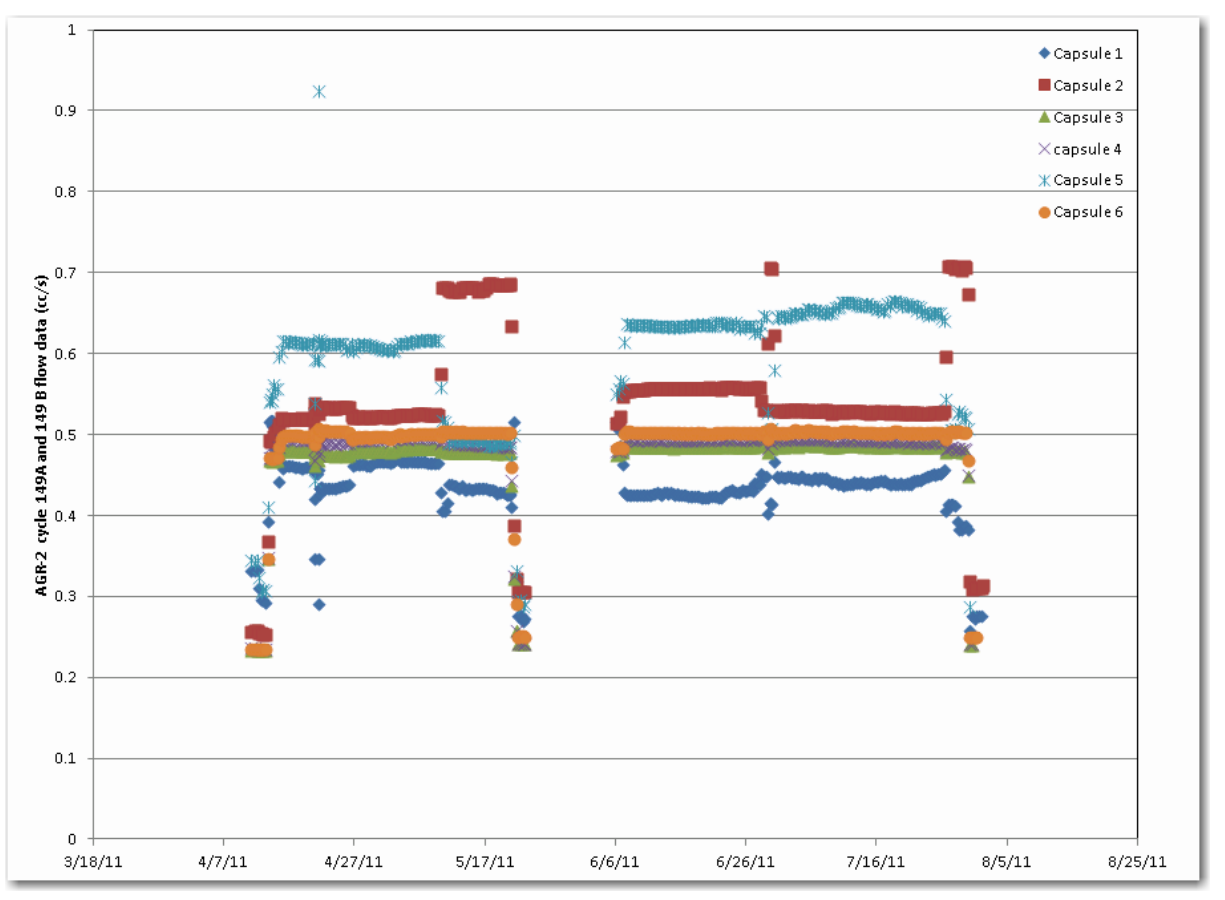

Figure 34. Cycle 149A and 149B AGR-2 flow data.

During the Cycle 149B outage, four anomalies were identified and addressed prior to reactor start up on June 7, 2011. The identified anomalies were as follows:

1. The piping and instrumentation diagram Drawing 628627 was in error. The drawing was redlined and revised prior to startup.

2. The LOCs operator control "mimic" on the distributed control system was in error, because it was based on Drawing 628627. The "mimic" panel on the DCS was corrected to agree with the corrected drawing before reactor startup for Cycle 149B.

3. The circle seal valve on the distribution and filter panel (AGR-SV-312-1), located on the outlet filter and distribution panel in the subpile room, was discolored. This valve was replaced on June 1, 2011.

4. The flow path through the ASCO valves on the discharge panel when the valve is energized was reversed from what the manufacturer says it should be. After valve changeout, operations brought the system up on June 4, 2011, and tested the valves in both positions. With normal valve lineup (each channel flowing through its own FPM and the sum of the flow passing through FPM 7), the flows and back pressures were as follows:

Channel 1

Channel 2

Channel 3

Channel 4

Channel 5

Channel 6
$17.7 \mathrm{sccm}$ at the Output Iso Pnl $16.1 \mathrm{sccm}$ at the Output Iso Pnl $14.4 \mathrm{sccm}$ at the Output Iso Pnl $14.6 \mathrm{sccm}$ at the Output Iso Pnl $13.8 \mathrm{sccm}$ at the Output Iso Pnl $14.6 \mathrm{sccm}$ at the Output Iso Pnl
13.3 psia backpressure 12.9 psia backpressure 13.3 psia backpressure 13.4 psia backpressure 13.7 psia backpressure 13.3 psia backpressure 
TEM-10200-1

$03 / 01 / 2012$

ENGINEERING CALCULATIONS AND ANALYSIS

Page 36 of 73

Rev. 06

Title: $\quad$ Release-to-Birth Ratios for AGR-2 Operating Cycles 147A through 154B

ECAR No.: 2420

Rev. No.: 0

Project No.:

23843, 23841 Date: 03/04/2014

After 2 to 4 hours, they were as follows:

Channel 1

Channel 2

Channel 3

Channel 4

Channel 5

Channel 6
$17.83 \mathrm{sccm}$ at the Output Iso Pnl $16.2 \mathrm{sccm}$ at the Output Iso Pnl $14.35 \mathrm{sccm}$ at the Output Iso PnI $13.55 \mathrm{sccm}$ at the Output Iso Pnl $15.27 \mathrm{sccm}$ at the Output Iso Pnl $14.6 \mathrm{sccm}$ at the Output Iso Pnl (average 15.3)
13.35 psia backpressure 12.9 psia backpressure 13.3 psia backpressure 13.37 psia backpressure 13.68 psia backpressure 13.27 psia backpressure (average 13.31)

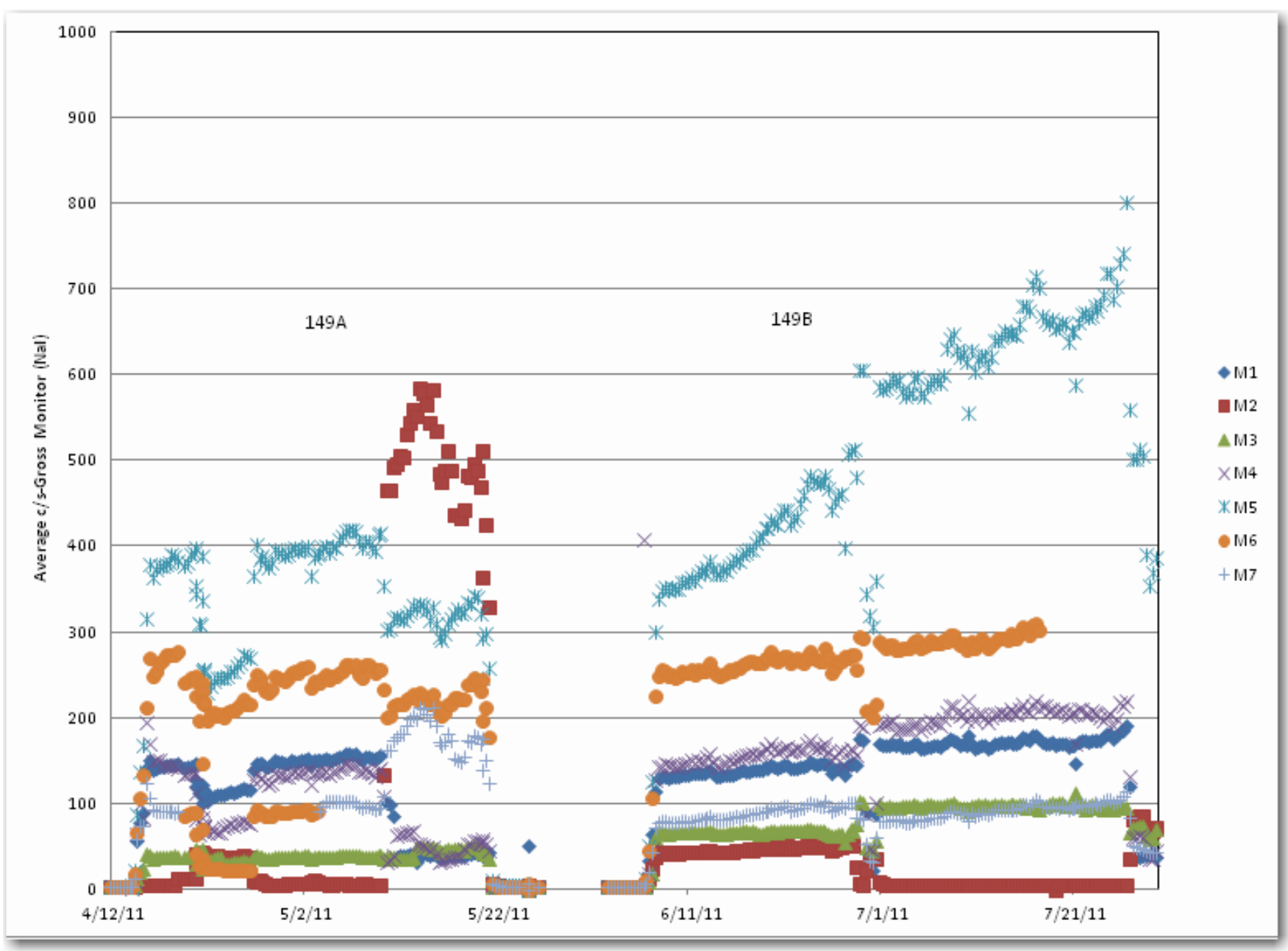

Figure 35. Gross monitor average counts per second for Cycle 149A and 149B. During Cycle 149B, only minimal fission products were observed for FPM 2, while it appears fission products in FPM 5 were elevated possibly due to leakage into Capsule 5 from other capsules.

On June 7,2011 , the reactor came to full power. Upon initial inspection, minimal fission products were getting through to FPM2; however, it was observed that activity was not increasing with the increasing temperature. Therefore, the Capsule 2 effluent was not making it downstream to FPM2 (Figures 25, 26, 
TEM-10200-1

$03 / 01 / 2012$

ENGINEERING CALCULATIONS AND ANALYSIS

Page 37 of 73

Rev. 06

Title:

Release-to-Birth Ratios for AGR-2 Operating Cycles 147A through 154B

ECAR No.: 2420

Rev. No.: 0

Project No.:

23843, 23841 Date: 03/04/2014

and 35). On June 28, 2011, the Capsule 2 effluent was routed from FPM2 to FPM7 (spare) per OMM7.20.3.1.6. FPM support personnel were unable to determine if the fission products from Capsule 2 were traveling to the spare FPM because the gross monitor activity remained constant (Figure 35). Review of the gross monitor data revealed that prior to routing the Capsule 2 effluent to the spare monitor, the FPM2 count rate was approximately $190 \mathrm{cps}$. Once the flow was routed to FPM7, the FPM2 count rate dropped to background levels $(20 \mathrm{cps})$. The normal operating range for this capsule should be approximately $900 \mathrm{cps}$. On July 26, 2011, the decision was made to return the capsule effluent to normal operating condition. As time progressed during this operating cycle, it was determined that the relief valves used in the experiment were leaking. Testing was performed on spare relief valves, and it was discovered that the 5-psi relief valves did not reseat even when mounted vertically. The project came to the conclusion that all relief valves would be replaced during the Cycle $150 \mathrm{~A}$ outage. It is important to note that the R/B data for Capsules 1, 4, 5, and 6 appeared to be consistent when compared to past data as is shown in Figures 29 through 31 and 33 and data included in ECAR-1412. However, the FPM team feels that data obtained from Cycle 149B may be unreliable due to the nature of the leaking relief valves [13].

\section{Cycle 150B}

\section{Leadout Flow and neon injection testing:}

On October 15, 2011, the reactor came to full power. During the first week of irradiation, activity for Capsule 2 was increasing, leading the FPM team to think that the temperature within the test train for Capsule 2 was increasing as well. Figure 36 shows the increase in activity from the start of Cycle 150B through November 7, 2011. Figures 37 through 46 show the increase in activity from the start of Cycle 150B through November 28, 2011.

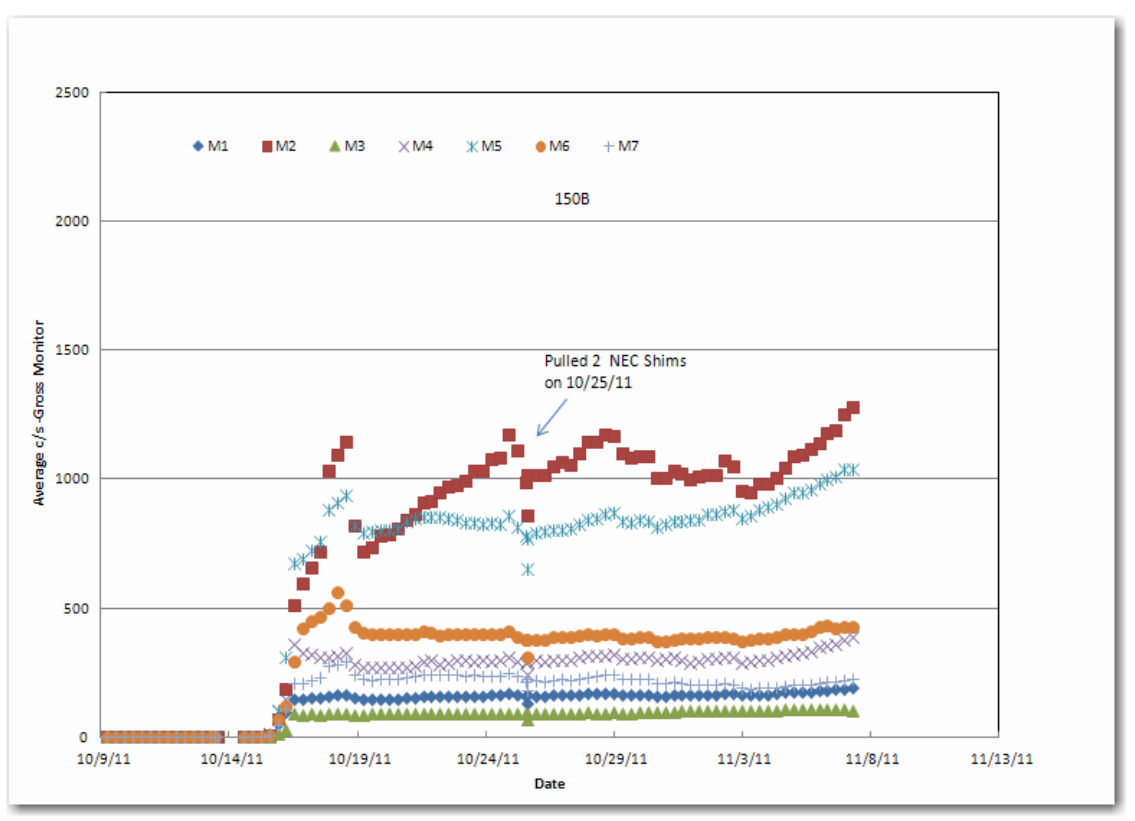

Figure 36. Gross monitor data for Cycle 150B. Activity for Capsules 2 and 5 is higher than in past cycles. 
TEM-10200-1

$03 / 01 / 2012$

ENGINEERING CALCULATIONS AND ANALYSIS

Page 38 of 73

Rev. 06

Title: $\quad$ Release-to-Birth Ratios for AGR-2 Operating Cycles 147A through 154B

$\begin{array}{llll}\text { ECAR No.: } 2420 & \text { Rev. No.: } 0 & \text { Project No.: } & \text { 23843, } 23841 \text { Date: } 03 / 04 / 2014\end{array}$

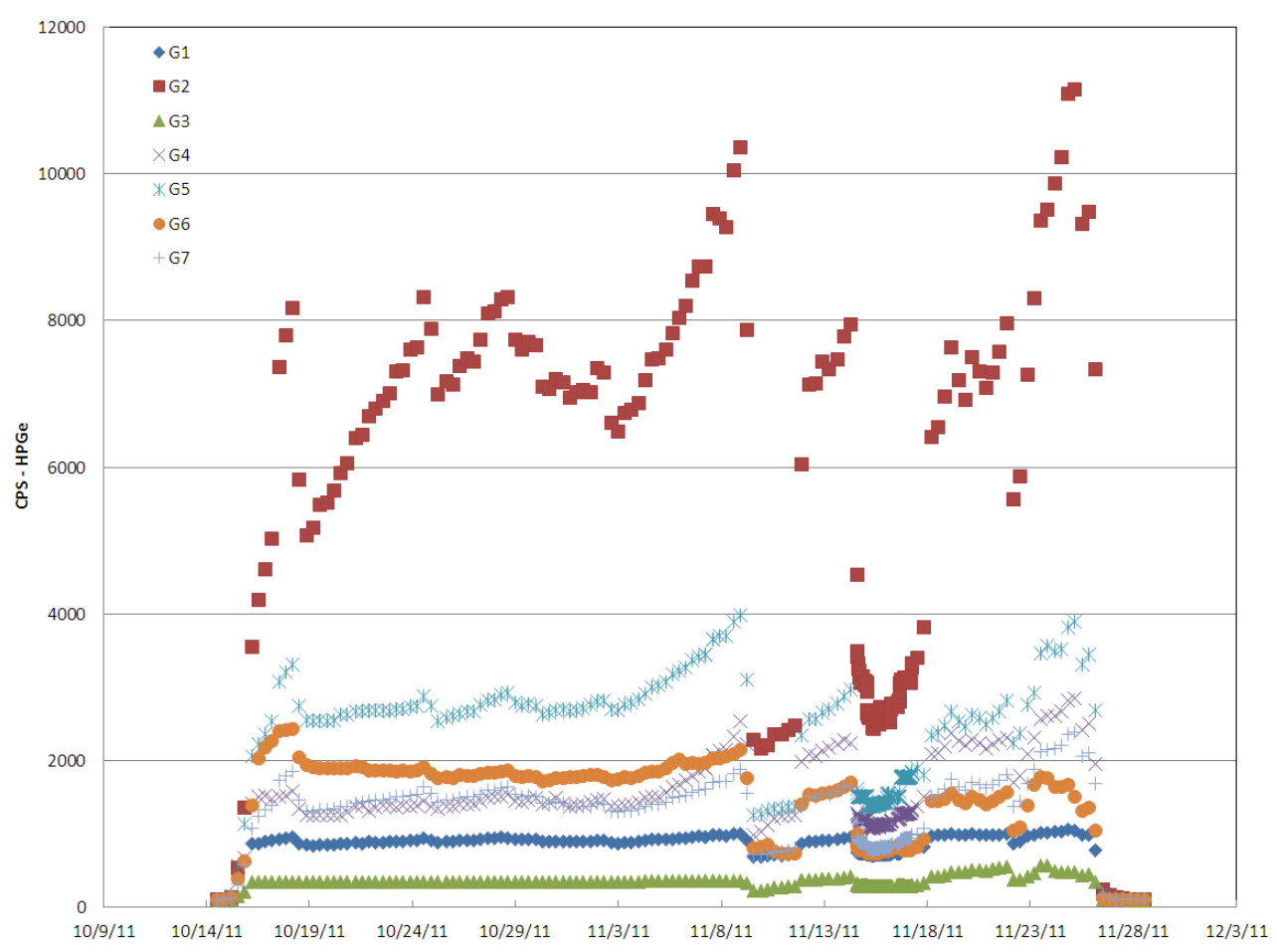

Figure 37. Total spectrum counts from the high-purity germanium detectors showing agreement with the gross monitor data. Data from Capsules 2 and 5 are increasing.

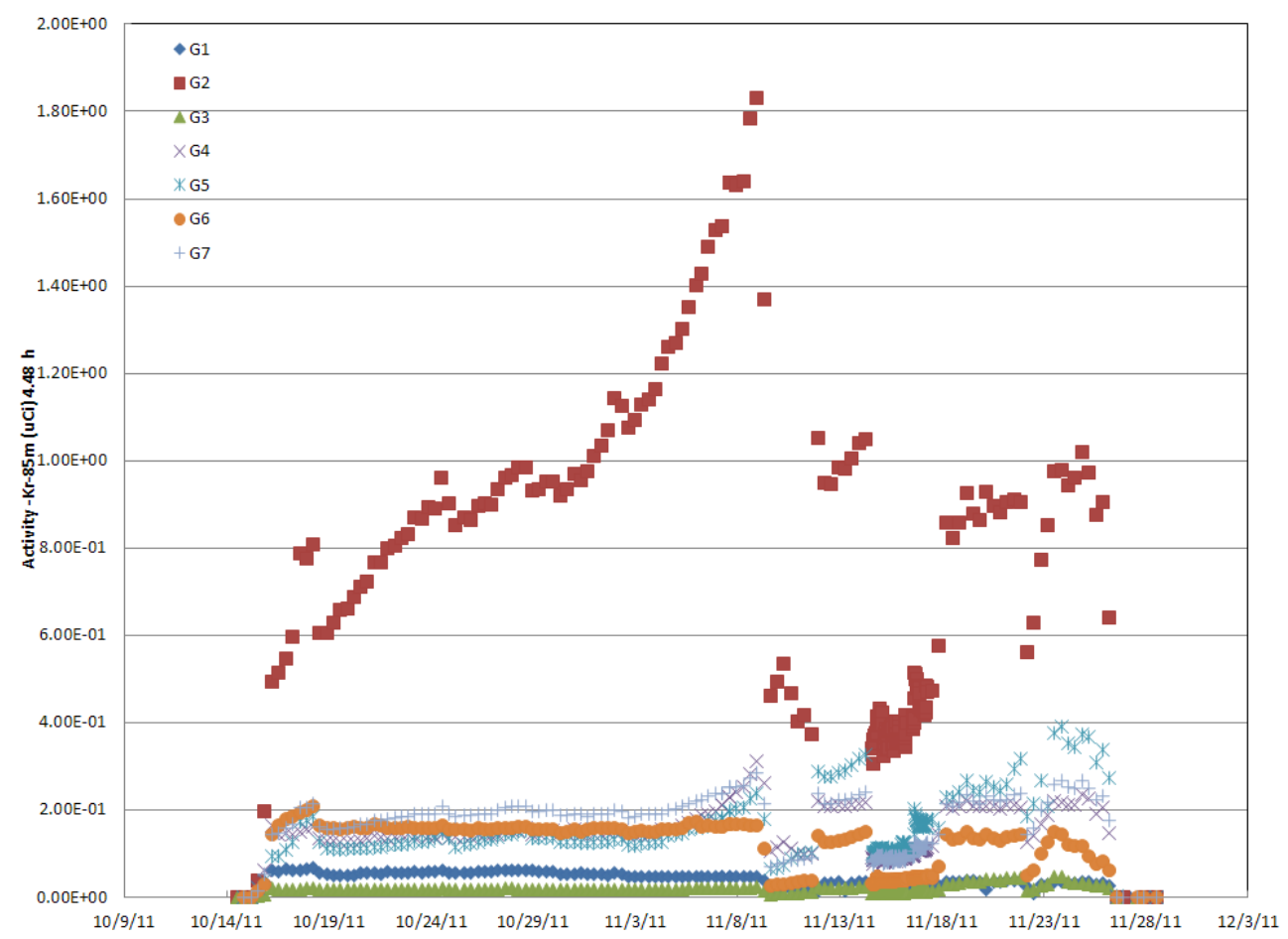

Figure 38. Cycle 150B, Kr-85m activity for Capsule 2 is clearly higher than the other capsules. 
TEM-10200-1

$03 / 01 / 2012$

ENGINEERING CALCULATIONS AND ANALYSIS

Page 39 of 73

Rev. 06

Title: $\quad$ Release-to-Birth Ratios for AGR-2 Operating Cycles 147A through 154B

$\begin{array}{llll}\text { ECAR No.: } 2420 & \text { Rev. No.: } 0 & \text { Project No.: } & \text { 23843, } 23841 \text { Date: } 03 / 04 / 2014\end{array}$

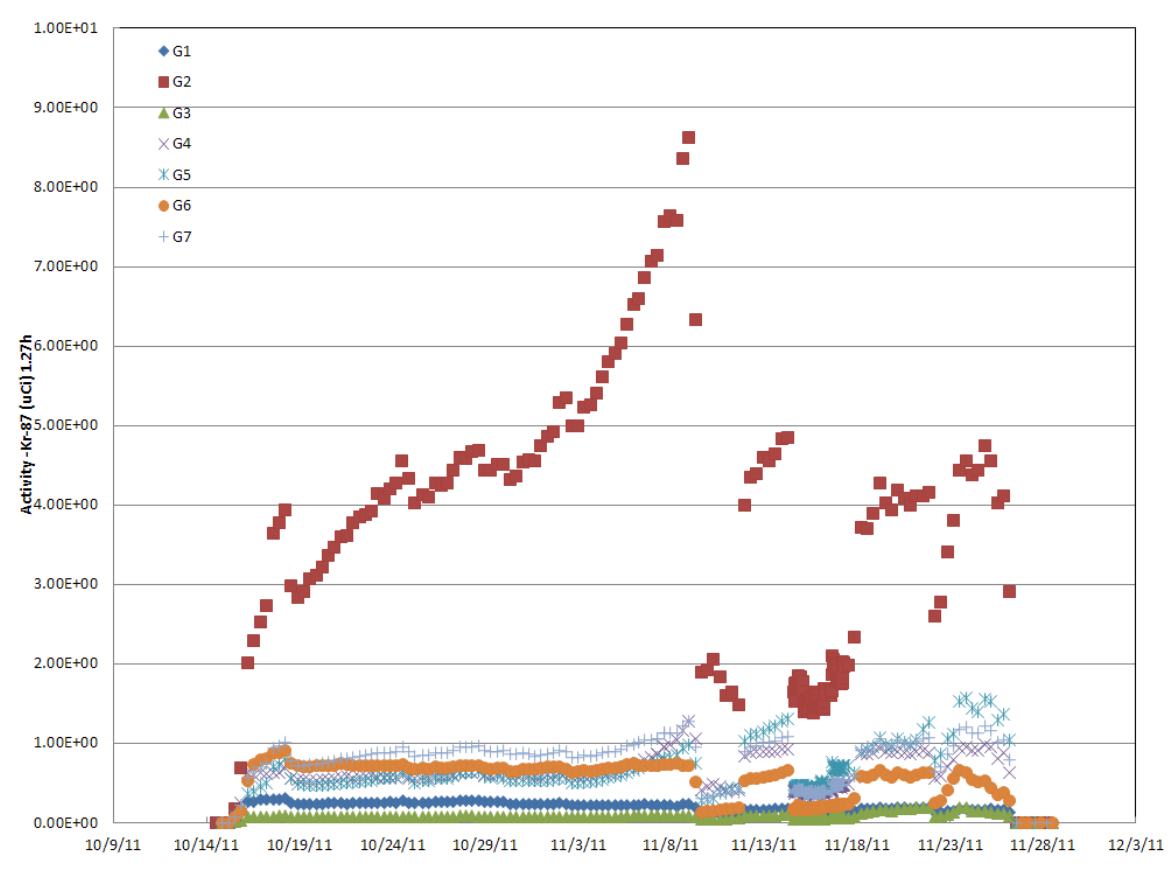

Figure 39. Cycle 150B, Kr-87 activity for Capsule 2 is clearly higher than the other capsules.

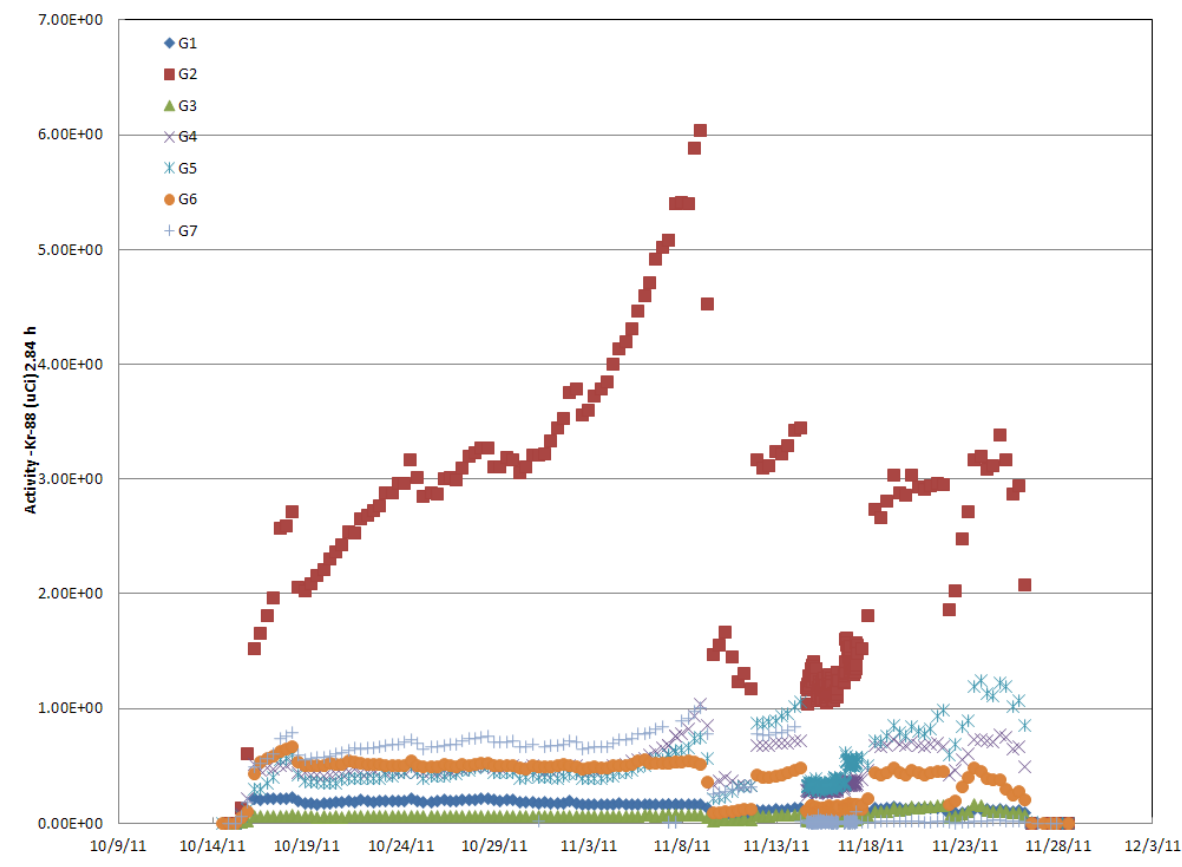

Figure 40. Cycle 150B, Kr-88 activity for Capsule 2 is clearly higher than the other capsules. 
TEM-10200-1

$03 / 01 / 2012$

ENGINEERING CALCULATIONS AND ANALYSIS

Page 40 of 73

Rev. 06

Title: $\quad$ Release-to-Birth Ratios for AGR-2 Operating Cycles 147A through 154B

$\begin{array}{llll}\text { ECAR No.: } 2420 & \text { Rev. No.: } 0 & \text { Project No.: } & \text { 23843, } 23841 \text { Date: } 03 / 04 / 2014\end{array}$

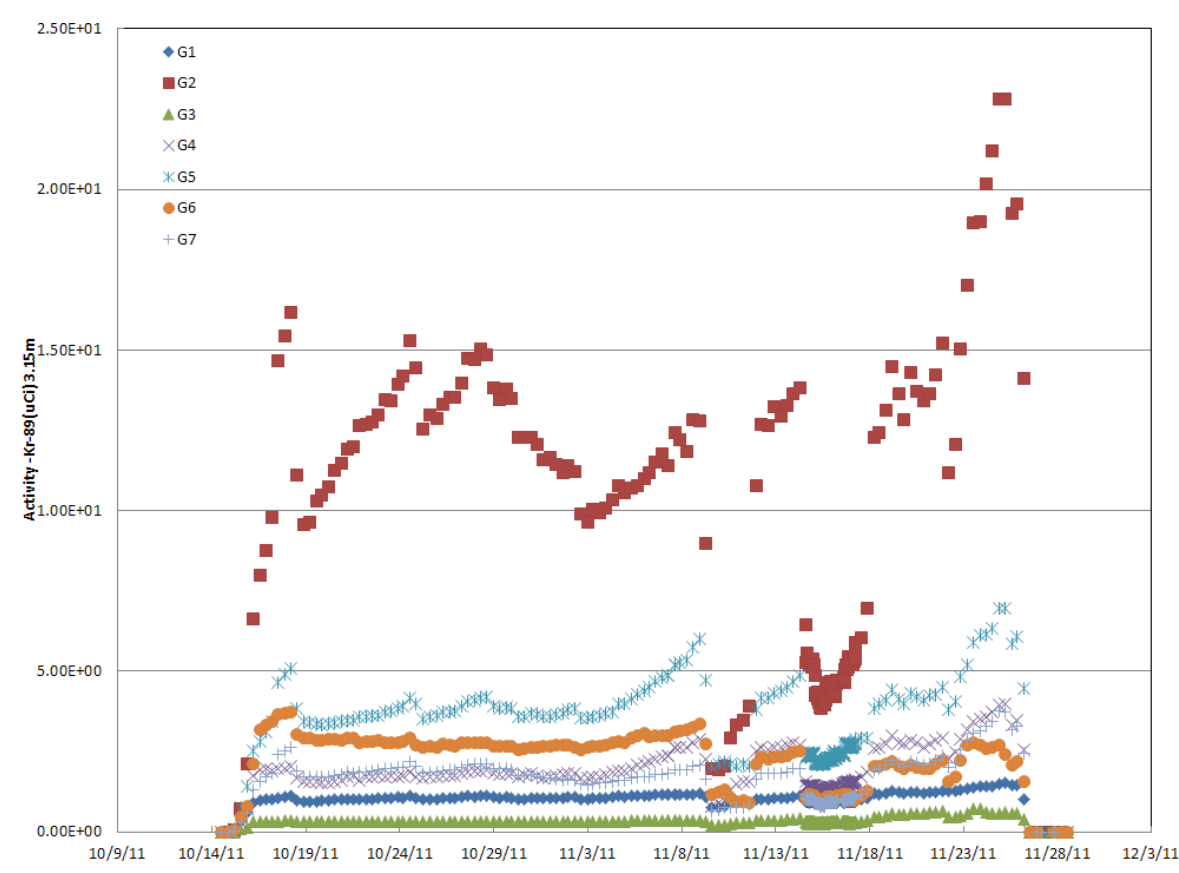

Figure 41. Cycle 150B, Kr-89 activity for Capsule 2 is clearly higher than the other capsules.

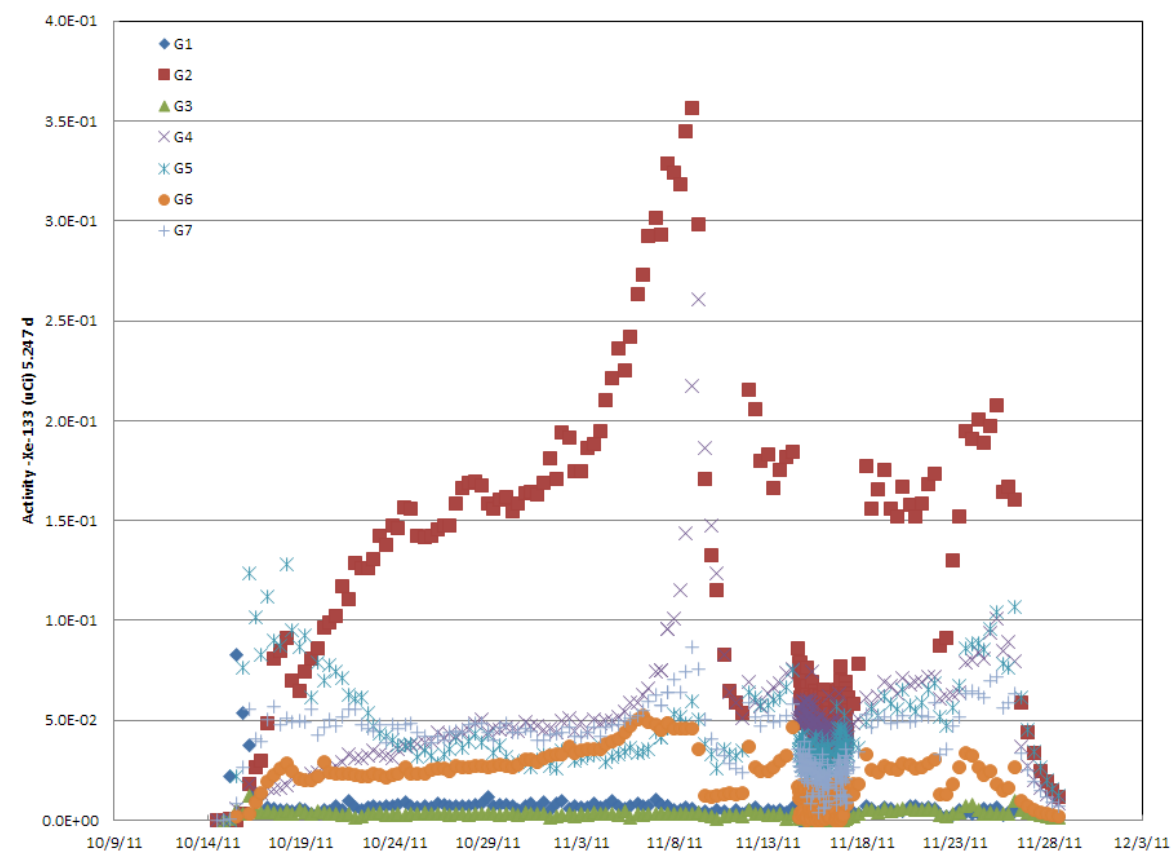

Figure 42. Cycle 150B, Xe-133 activity for Capsule 2 is clearly higher than the other capsules. Xe-133 is the primary contributor to the gross gamma count rate. 
TEM-10200-1

$03 / 01 / 2012$

ENGINEERING CALCULATIONS AND ANALYSIS

Page 41 of 73

Rev. 06

Title: $\quad$ Release-to-Birth Ratios for AGR-2 Operating Cycles 147A through 154B

$\begin{array}{llll}\text { ECAR No.: } 2420 & \text { Rev. No.: } 0 & \text { Project No.: } & \text { 23843, } 23841 \text { Date: } 03 / 04 / 2014\end{array}$

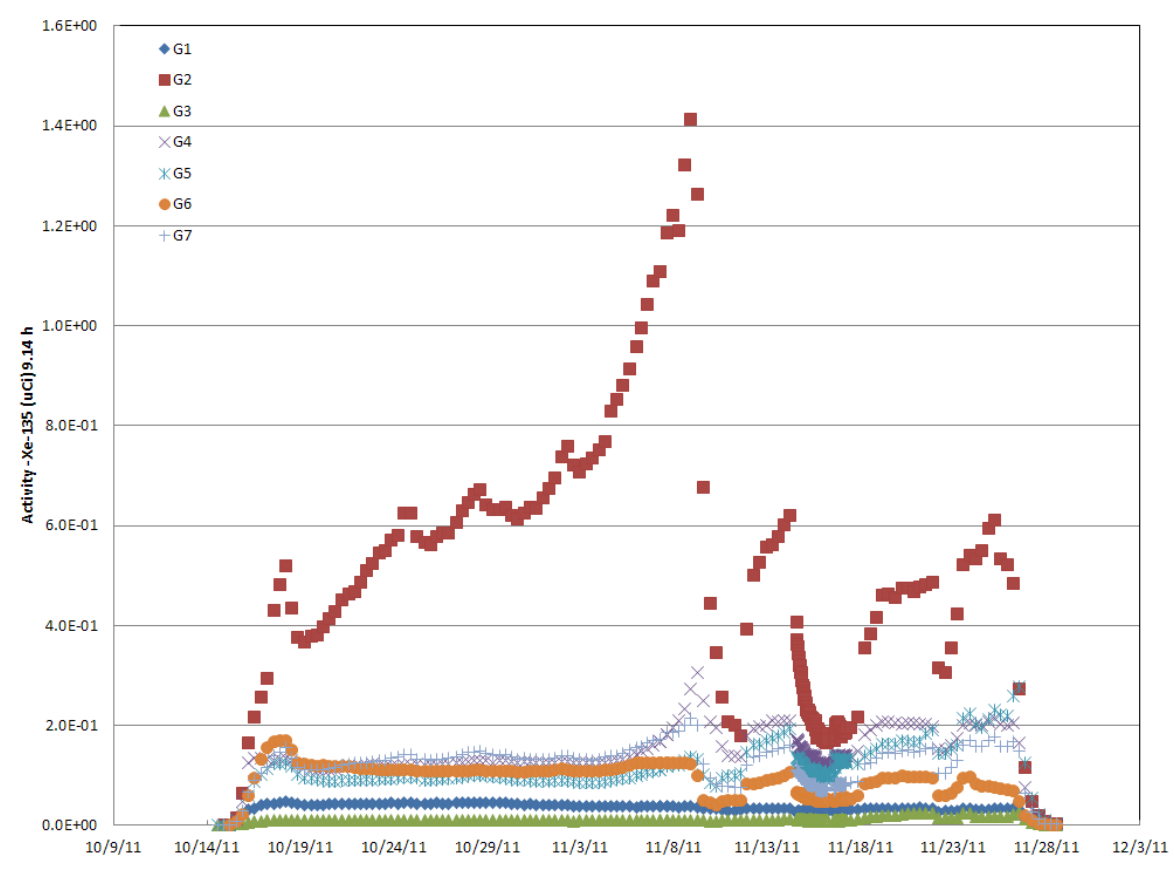

Figure 43. Cycle 150B, Xe-135 activity for Capsule 2 is clearly higher than the other capsules.

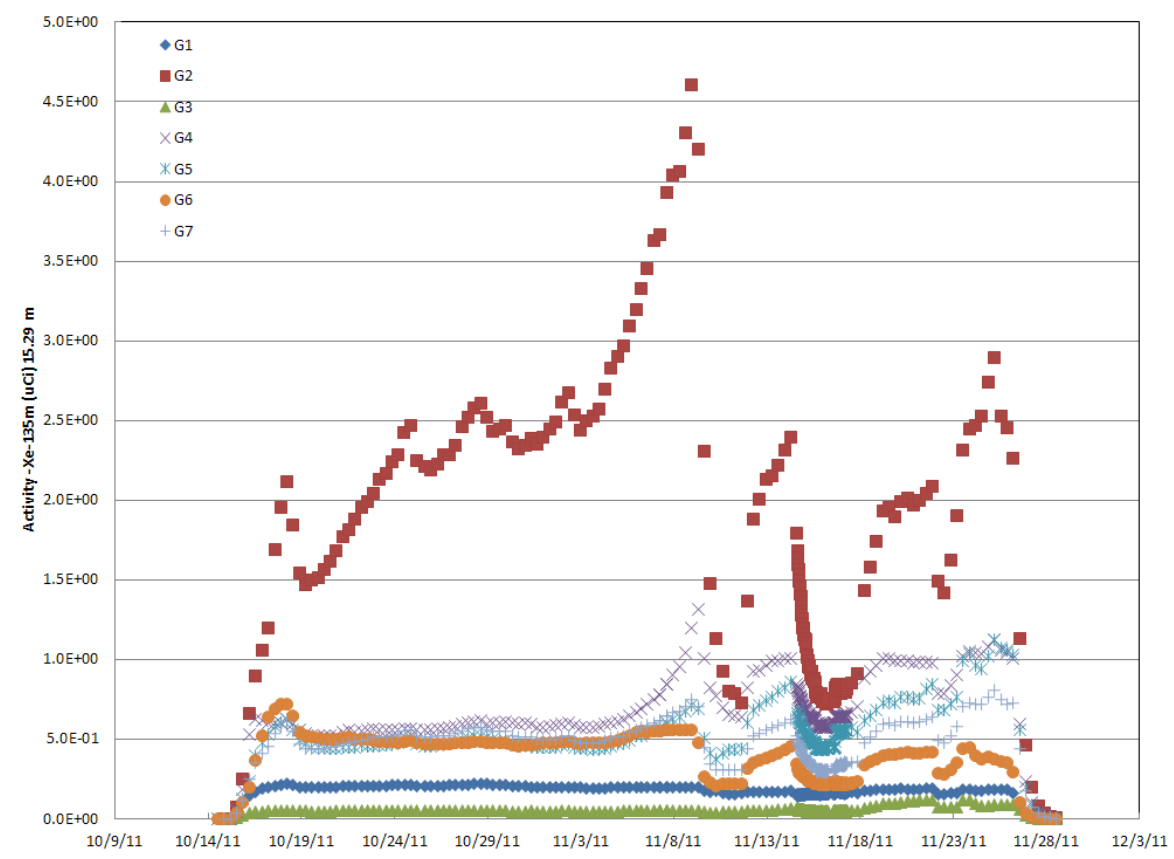

Figure 44. Cycle 150B, Xe-135M activity for Capsule 2 is clearly higher than the other capsules. 
TEM-10200-1

$03 / 01 / 2012$

ENGINEERING CALCULATIONS AND ANALYSIS

Page 42 of 73

Rev. 06

Title: $\quad$ Release-to-Birth Ratios for AGR-2 Operating Cycles 147A through 154B

\begin{tabular}{lllll} 
ECAR No.: 2420 & Rev. No.: & 0 & Project No.: & 23843,23841 Date: \\
\hline
\end{tabular}

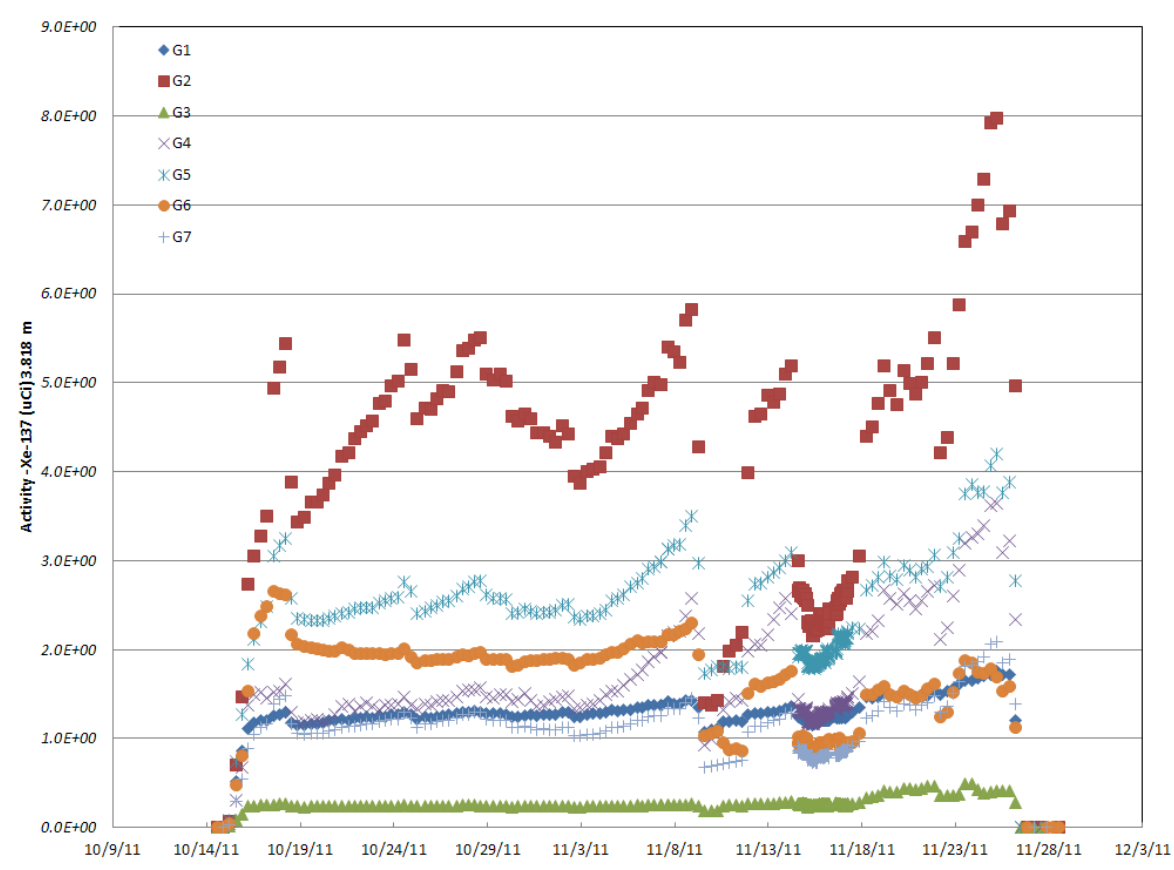

Figure 45. Cycle 150B, Xe-137 activity for Capsule 2 is clearly higher than the other capsules.

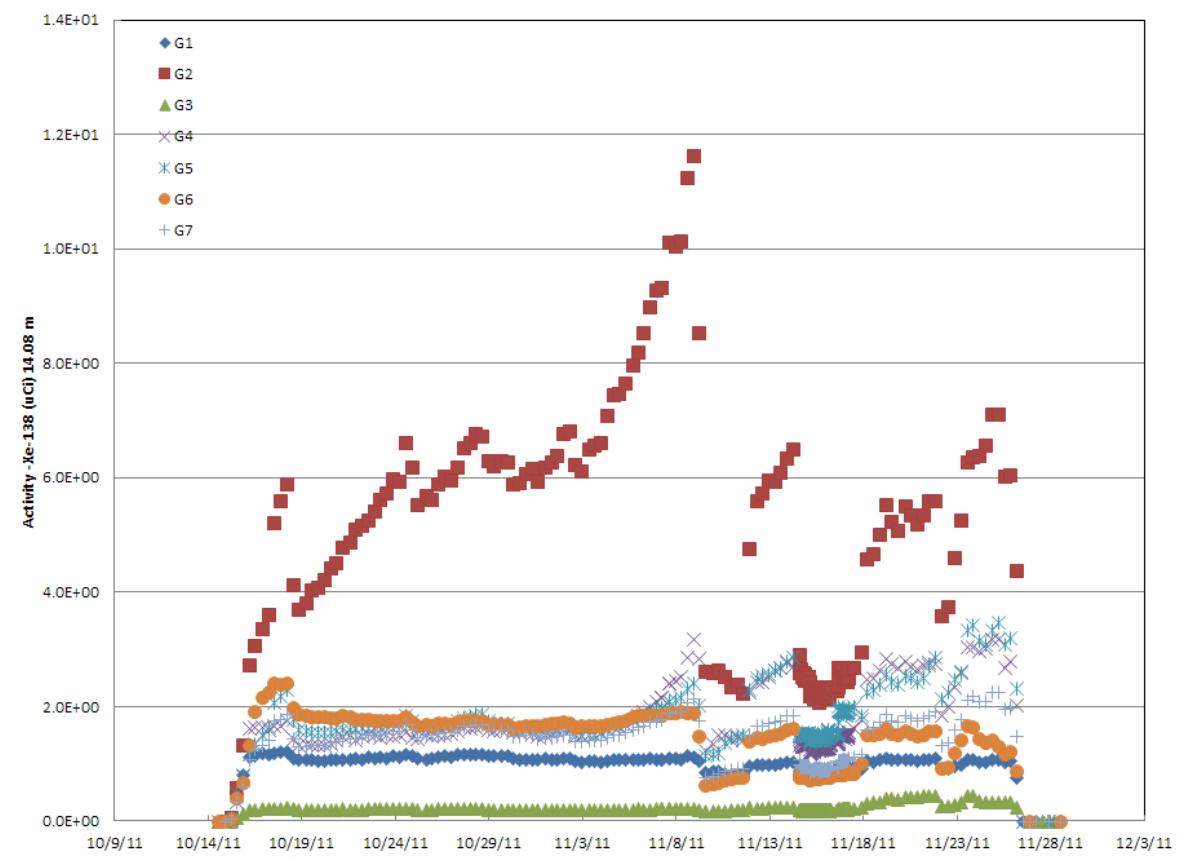

Figure 46. Cycle 150B, Xe-138 activity for Capsule 2 is clearly higher than the other capsules.

On November 9, 2011, flow for AGR-2 was taken to 30-sccm helium until November 11, 2011, at 22:26, when neon was placed back into the test train. This test was performed to see if some valves may be reseated and if the FPM team could determine what fission products were making it to the FPMS traps. During Cycle 150A, the AGR-2 test train was moved to the canal to avoid the powered axial locator 
TEM-10200-1

$03 / 01 / 2012$

ENGINEERING CALCULATIONS AND ANALYSIS

Page 43 of 73

Rev. 06

Title:

Release-to-Birth Ratios for AGR-2 Operating Cycles 147A through 154B

ECAR No.: 2420

Rev. No.: 0

Project No::

23843, 23841 Date: 03/04/2014

mechanism (PALM) cycle. The AGR experiment team was beginning to suspect damage may have occurred during movement of the test train.

On November 11, 2011, the experiment team started a new leadout flow test to try and determine which capsules had cross talk, if any, indicating damage to the AGR-2 test train. Figures 47 through 52 capture the results of the leadout injection test.

To help control capsule temperature, the program decided to inject $8 \mathrm{sccm}$ of neon into the leadout flow and then adjust the throttle valves upstream of the FPMs to balance the capsules as is shown in Figure 53. By adjusting the gas mixtures, the ATR operators were able to maintain the desired temperature range in Capsules 2, 3, 5, and 6.

Figures 54 through 59 are screen captures from FP Examiner that are intending to provide a more detailed representation of the fission product activity. The y-axis is activity in $\mathrm{uCi}$.

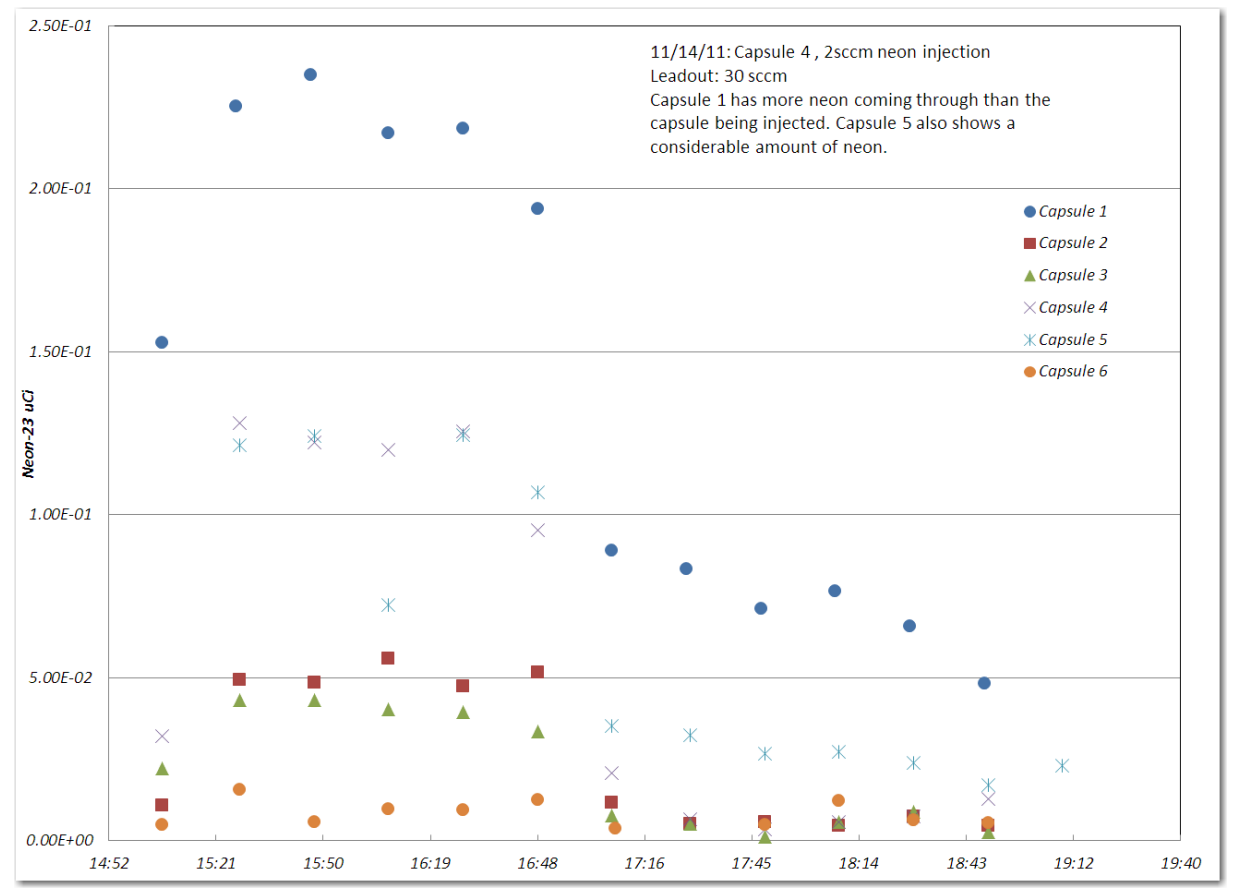

Figure 47. Cycle 150B, leadout flow injection test. Capsule 4 was injected with 2-sccm neon and a small amount of this neon appears in Capsule1 and Capsule 5, indicating capsule cross talk. 
TEM-10200-1

$03 / 01 / 2012$

ENGINEERING CALCULATIONS AND ANALYSIS

Page 44 of 73

Rev. 06

Title: $\quad$ Release-to-Birth Ratios for AGR-2 Operating Cycles 147A through 154B

ECAR No.: 2420

Rev. No.: 0

Project No::

23843, 23841 Date: 03/04/2014

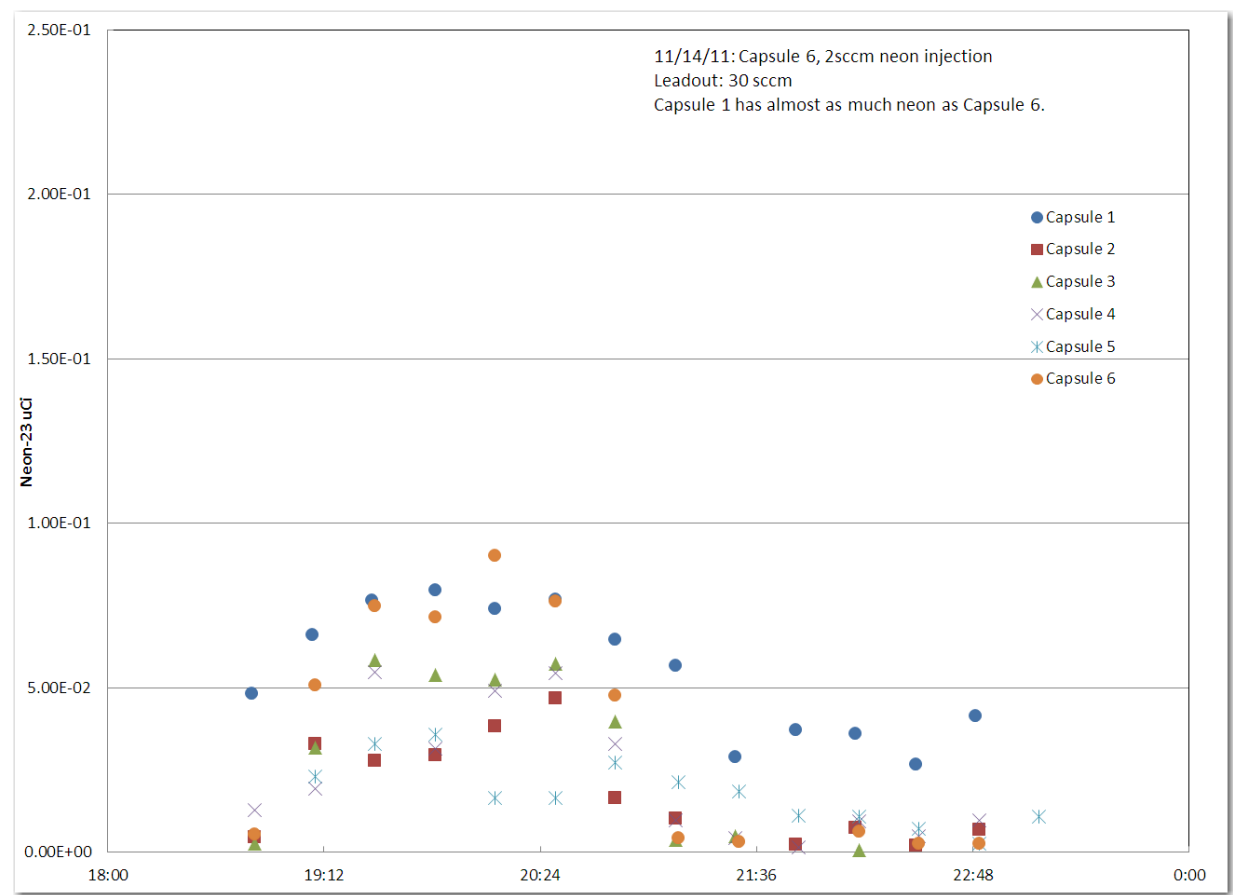

Figure 48. Cycle 150B, leadout flow injection test. Capsule 6 was injected with 2-sccm neon. Almost as much neon appears in Capsule 1 and Capsule 6, indicating capsule cross talk.

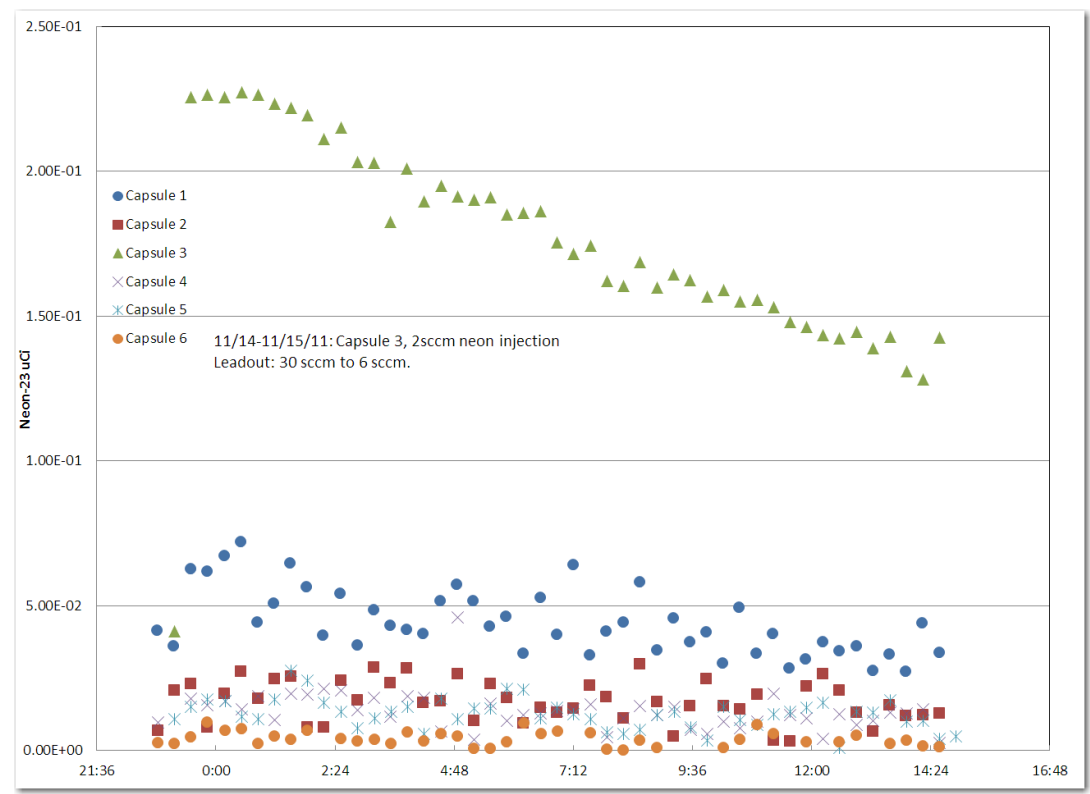

Figure 49. Cycle 150B, leadout flow injection test. Capsule 3 was injected with 2-sccm neon. Neon appears to have entered Capsule 3. 
TEM-10200-1

$03 / 01 / 2012$

ENGINEERING CALCULATIONS AND ANALYSIS

Page 45 of 73

Rev. 06

Title: $\quad$ Release-to-Birth Ratios for AGR-2 Operating Cycles 147A through 154B

ECAR No.: 2420

Rev. No.: 0

Project No.:

23843, 23841 Date: 03/04/2014

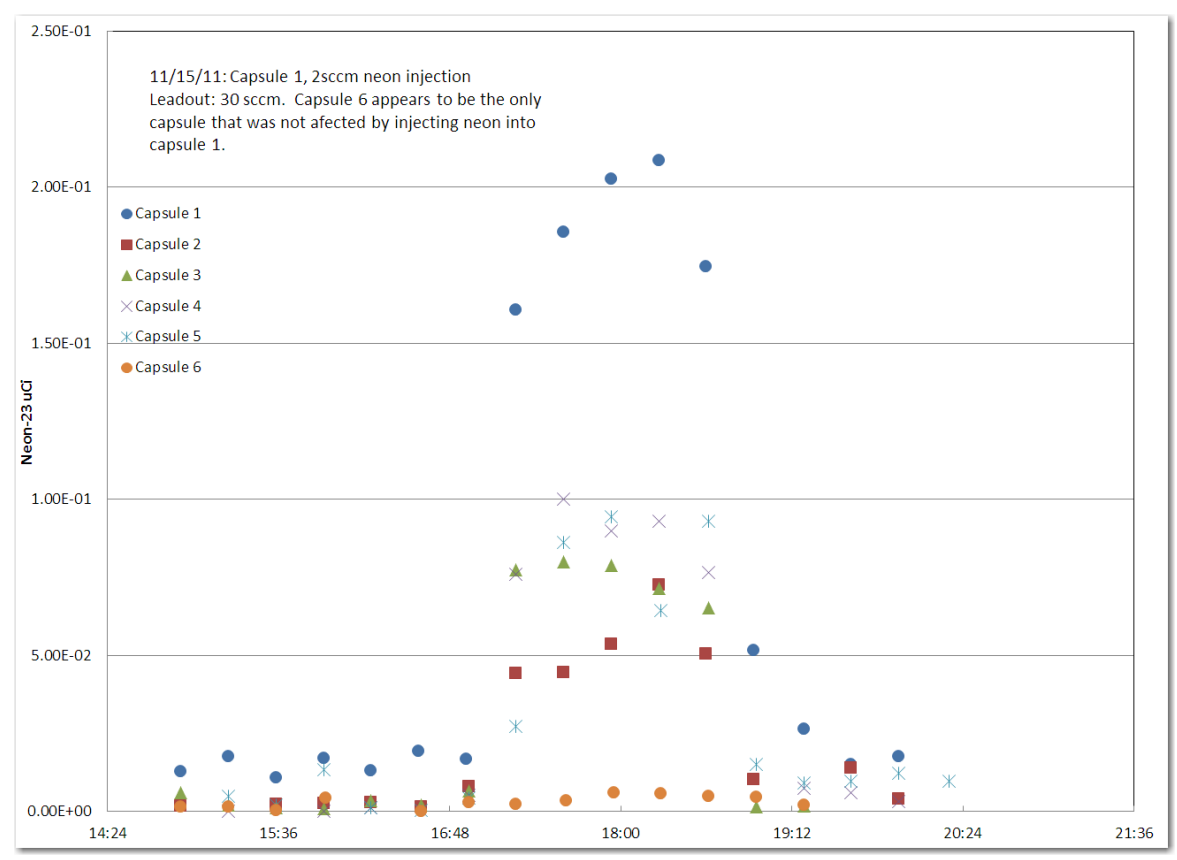

Figure 50. Cycle 150B, leadout flow injection test. Capsule 1 was injected with 2-sccm neon. Capsule 6 is the only capsule not indicating any leakage from the test.

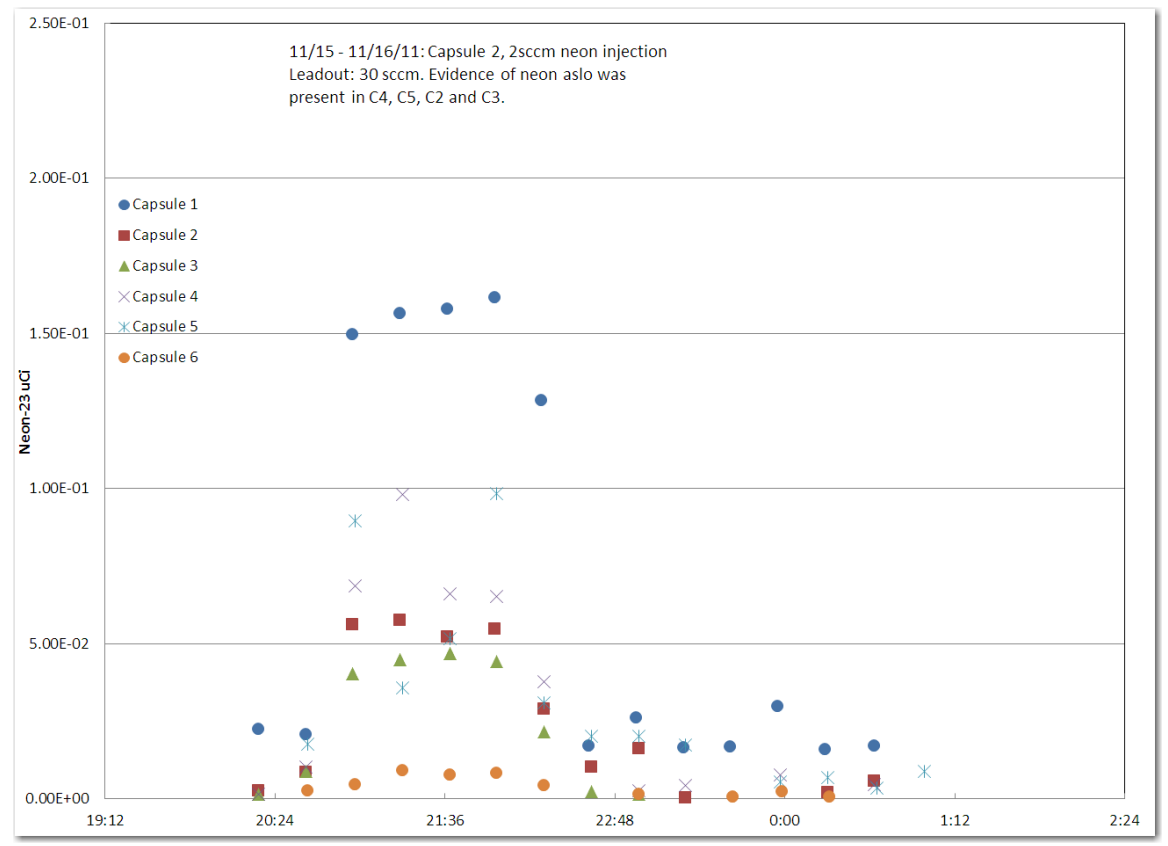

Figure 51. Cycle 150B, leadout flow injection test. Capsule 2 was injected with 2-sccm neon, simultaneously, neon appeared in Capsules 4, 5, 2, and 3, indicating capsule cross talk. 
TEM-10200-1

$03 / 01 / 2012$

ENGINEERING CALCULATIONS AND ANALYSIS

Page 46 of 73

Rev. 06

Title: $\quad$ Release-to-Birth Ratios for AGR-2 Operating Cycles 147A through 154B

ECAR No.: 2420

Rev. No.: 0

Project No.:

23843, 23841 Date: 03/04/2014

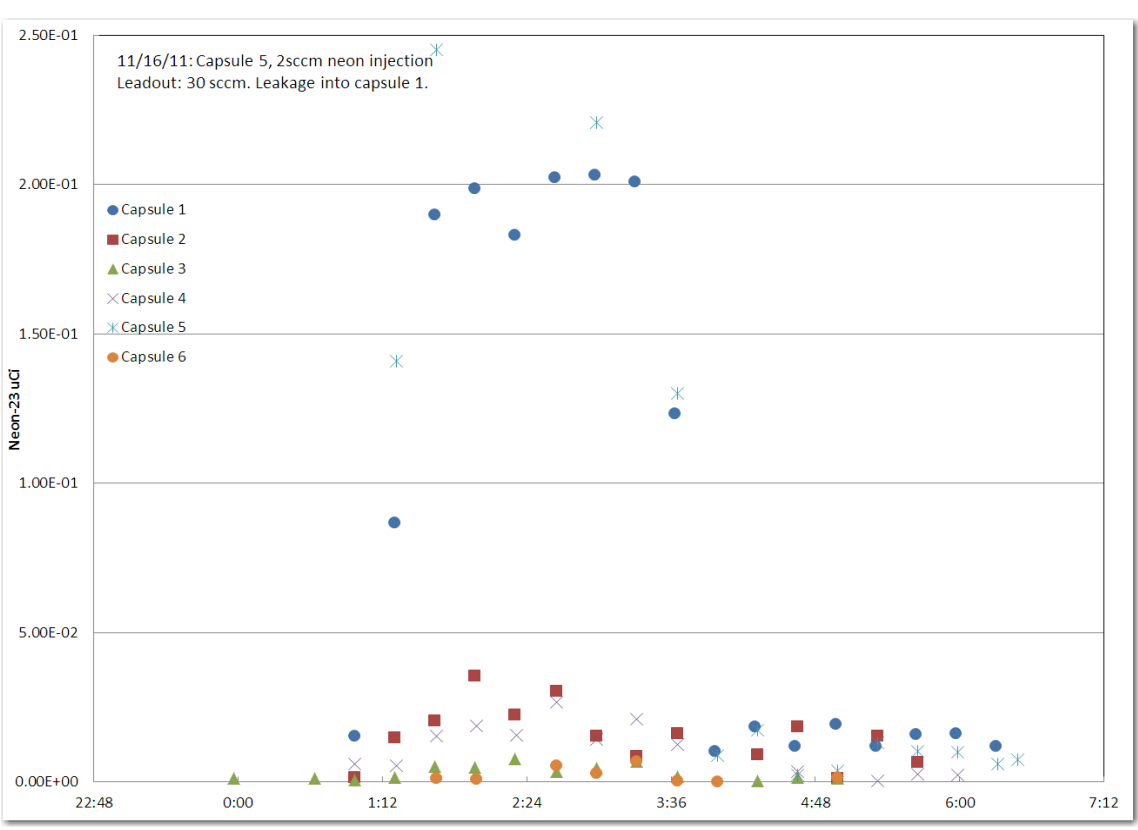

Figure 52. Cycle 150B, leadout flow injection test. Capsule 5 was injected with 2-sccm neon and leakage was observed in Capsule 1.

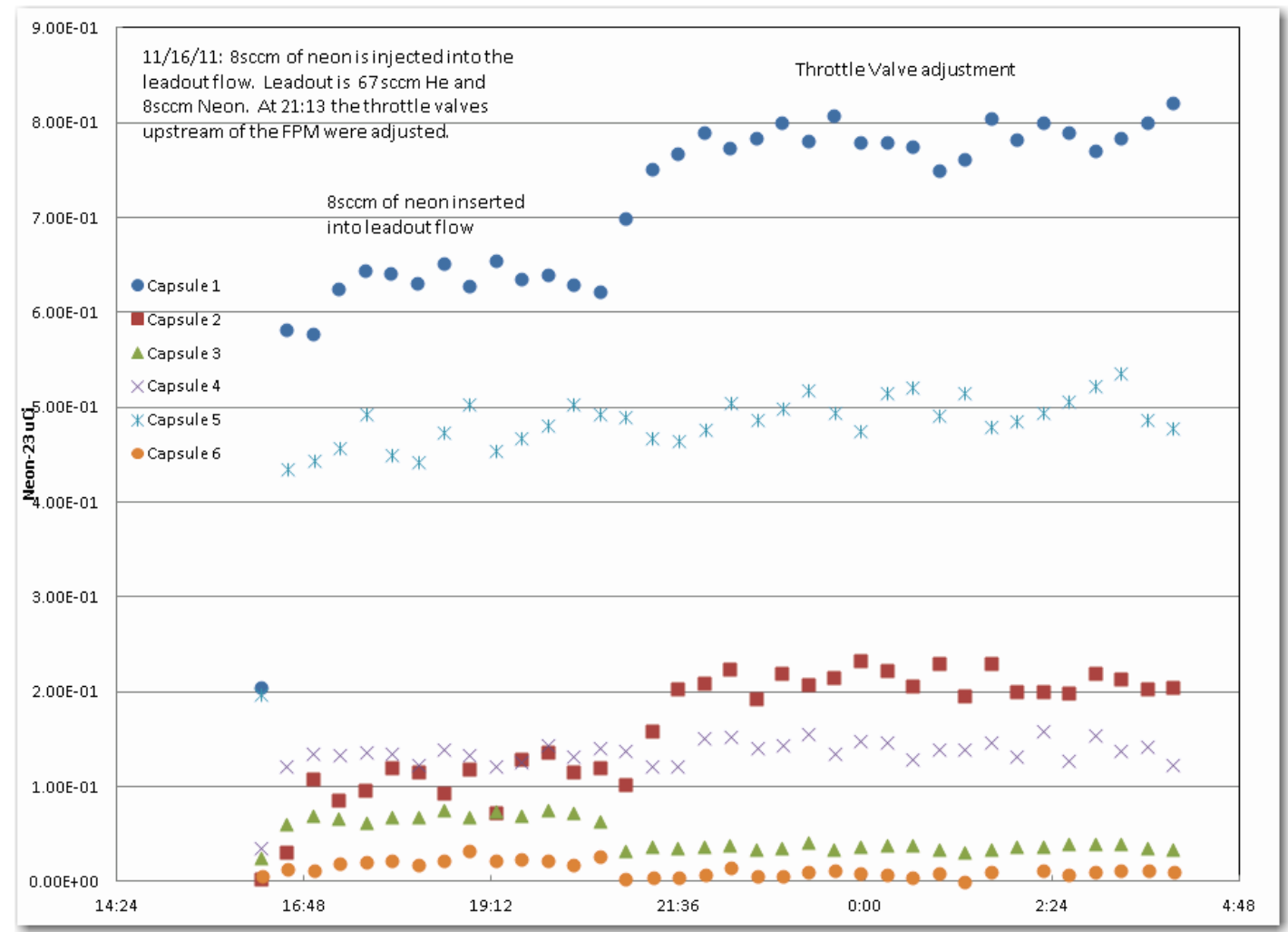

Figure 53. During Cycle 150B, to help control capsule temperature, the program decided to inject $8 \mathrm{sccm}$ of neon into the leadout flow and then adjust the throttle valves upstream of the FPMs to balance the capsules. 
TEM-10200-1

$03 / 01 / 2012$

ENGINEERING CALCULATIONS AND ANALYSIS

Page 47 of 73

Rev. 06

Title: $\quad$ Release-to-Birth Ratios for AGR-2 Operating Cycles 147A through 154B

ECAR No.: 2420

Rev. No.: 0

Project No.:

23843, 23841 Date: 03/04/2014

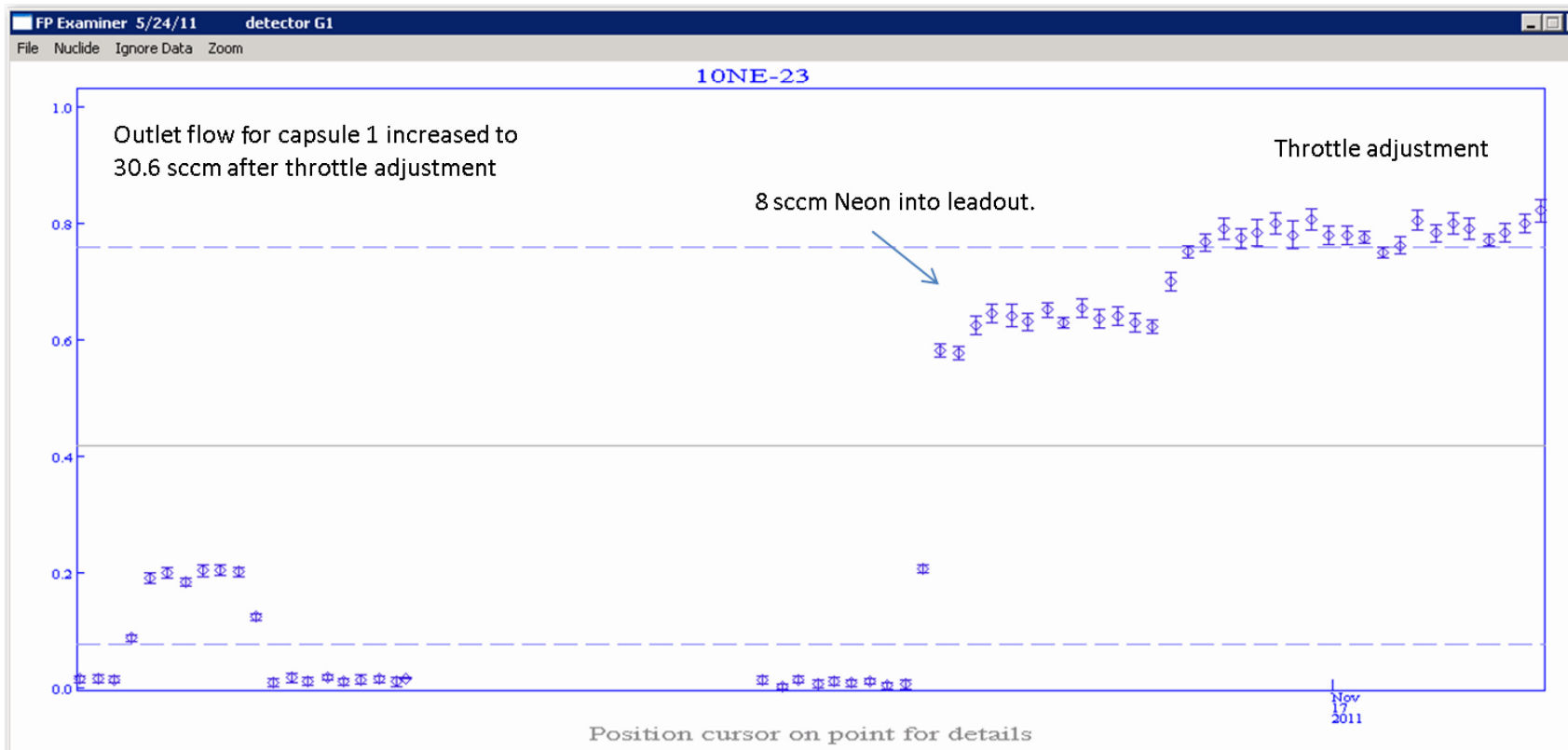

Figure 54. Cycle 150B, activated neon as seen by the FPM for Capsule 1. Outlet flow for Capsule 1 increased from 29.9 to $30.6 \mathrm{sccm}$ after the throttle adjustment.

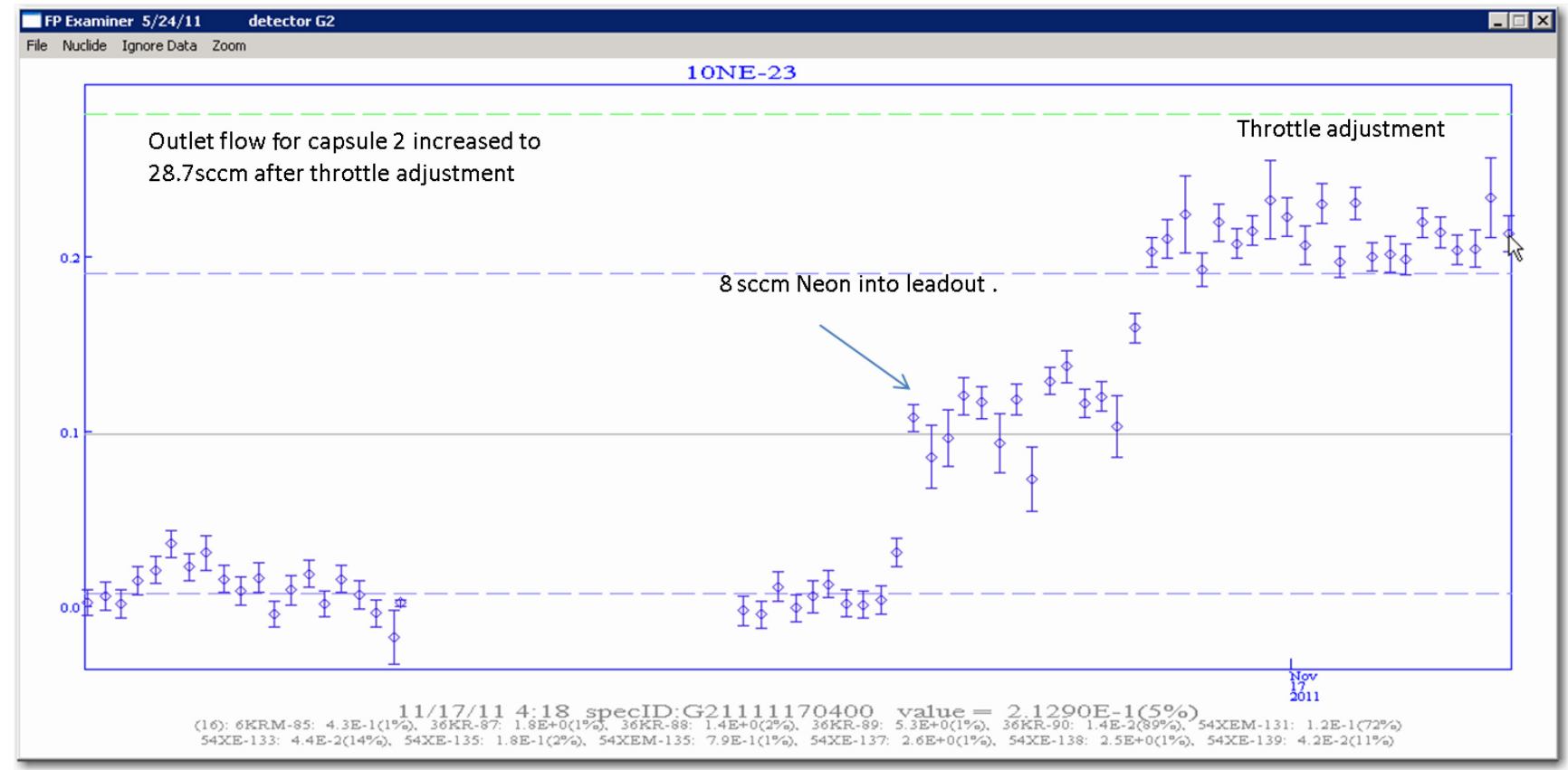

Figure 55. Cycle 150B, activated neon as seen by the FPM for Capsule 2. Outlet flow for Capsule 2 increased from 26.6 to $28.7 \mathrm{sccm}$ after the throttle adjustment. 
TEM-10200-1

$03 / 01 / 2012$

ENGINEERING CALCULATIONS AND ANALYSIS

Page 48 of 73

Rev. 06

Title: $\quad$ Release-to-Birth Ratios for AGR-2 Operating Cycles 147A through 154B

ECAR No.: 2420

Rev. No.: 0

Project No::

23843, 23841 Date: 03/04/2014

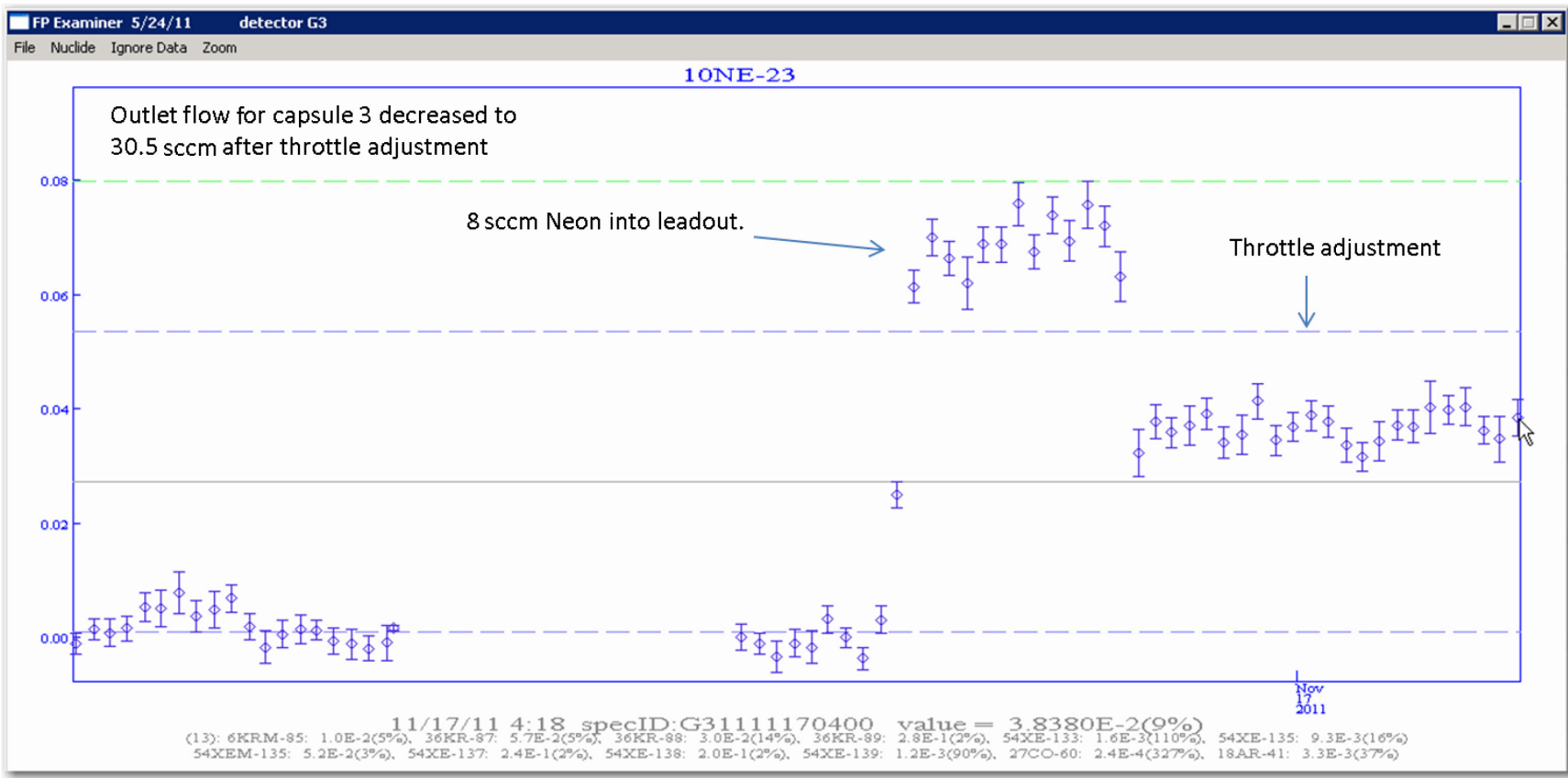

Figure 56. Cycle 150B, activated neon as seen by the FPM for Capsule 3. Outlet flow for Capsule 3 decreased from 33.3 to $30.5 \mathrm{sccm}$ after the throttle adjustment.

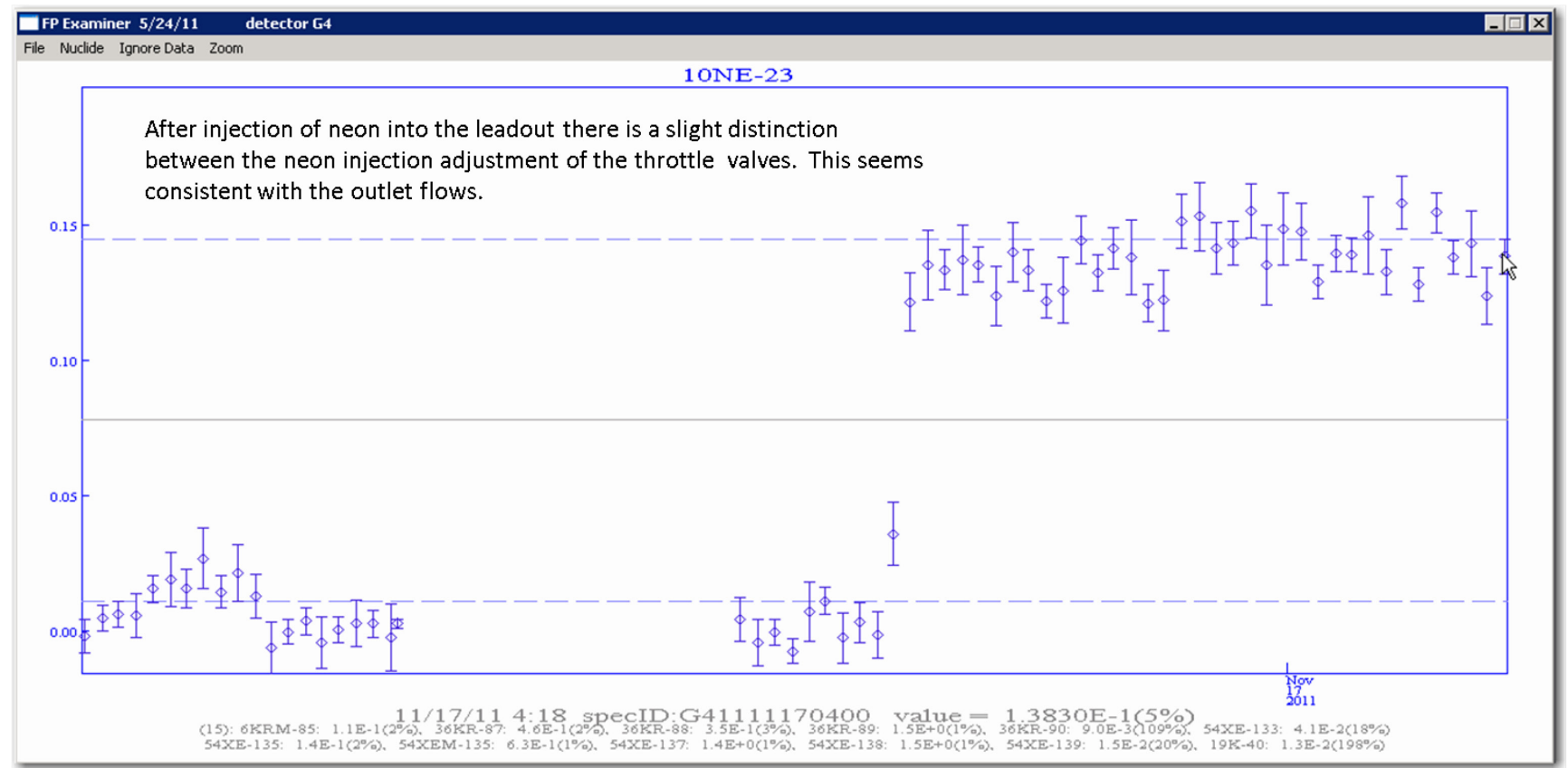

Figure 57. Cycle 150B, activated neon as seen by the FPM for Capsule 4. Outlet flow for Capsule 4 increased slightly from 30.4 to $30.6 \mathrm{sccm}$ after the throttle adjustment. 
TEM-10200-1

$03 / 01 / 2012$

ENGINEERING CALCULATIONS AND ANALYSIS

Page 49 of 73

Rev. 06

Title: $\quad$ Release-to-Birth Ratios for AGR-2 Operating Cycles 147A through 154B

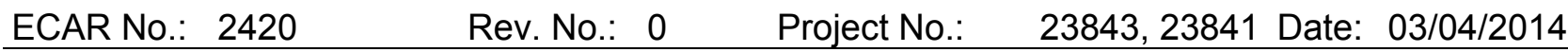

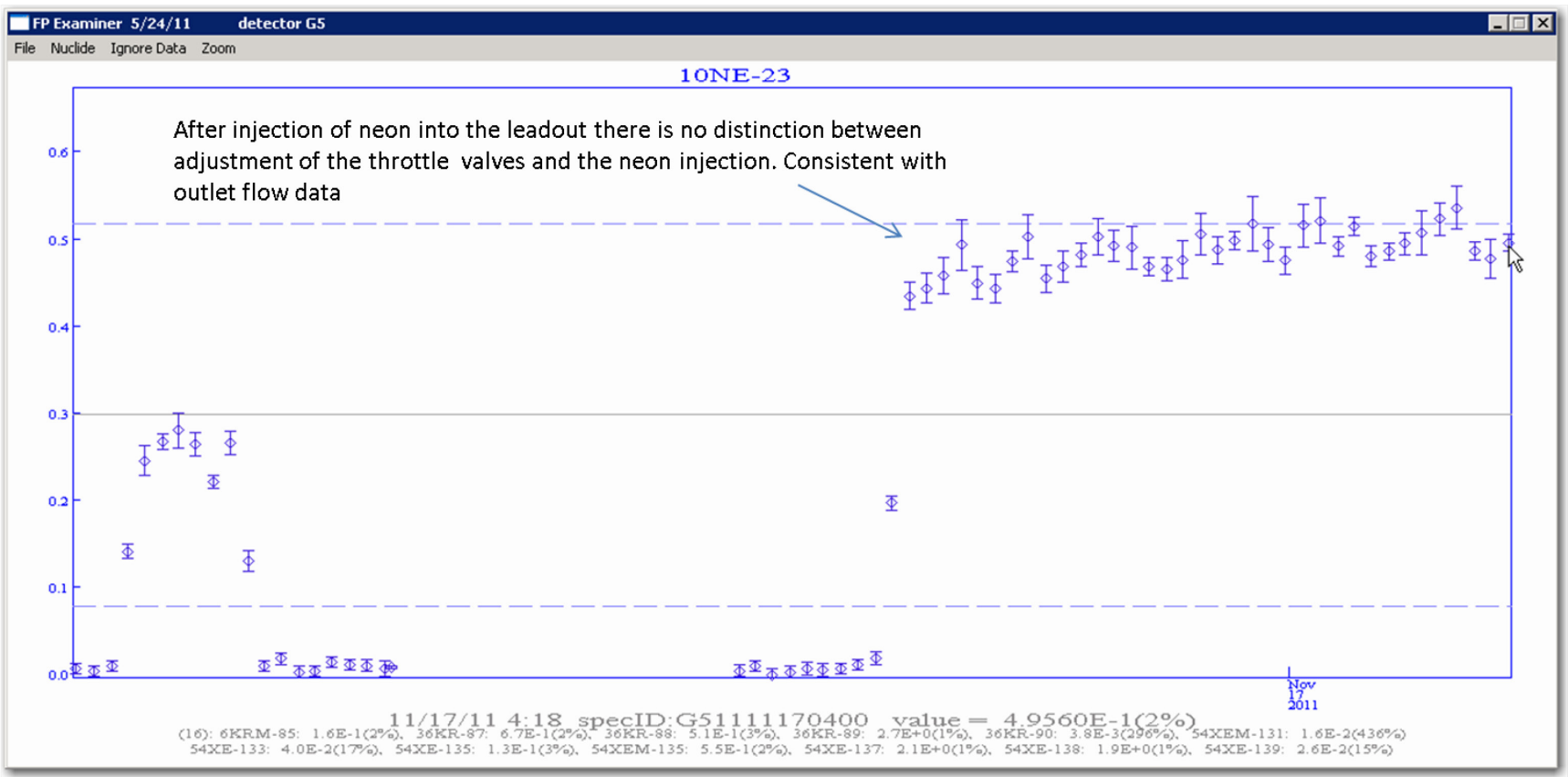

Figure 58. Cycle 150B, activated neon as seen by the FPM for Capsule 5. Outlet flow for Capsule 5 remained consistent at $30.5 \mathrm{sccm}$ after the throttle adjustment.

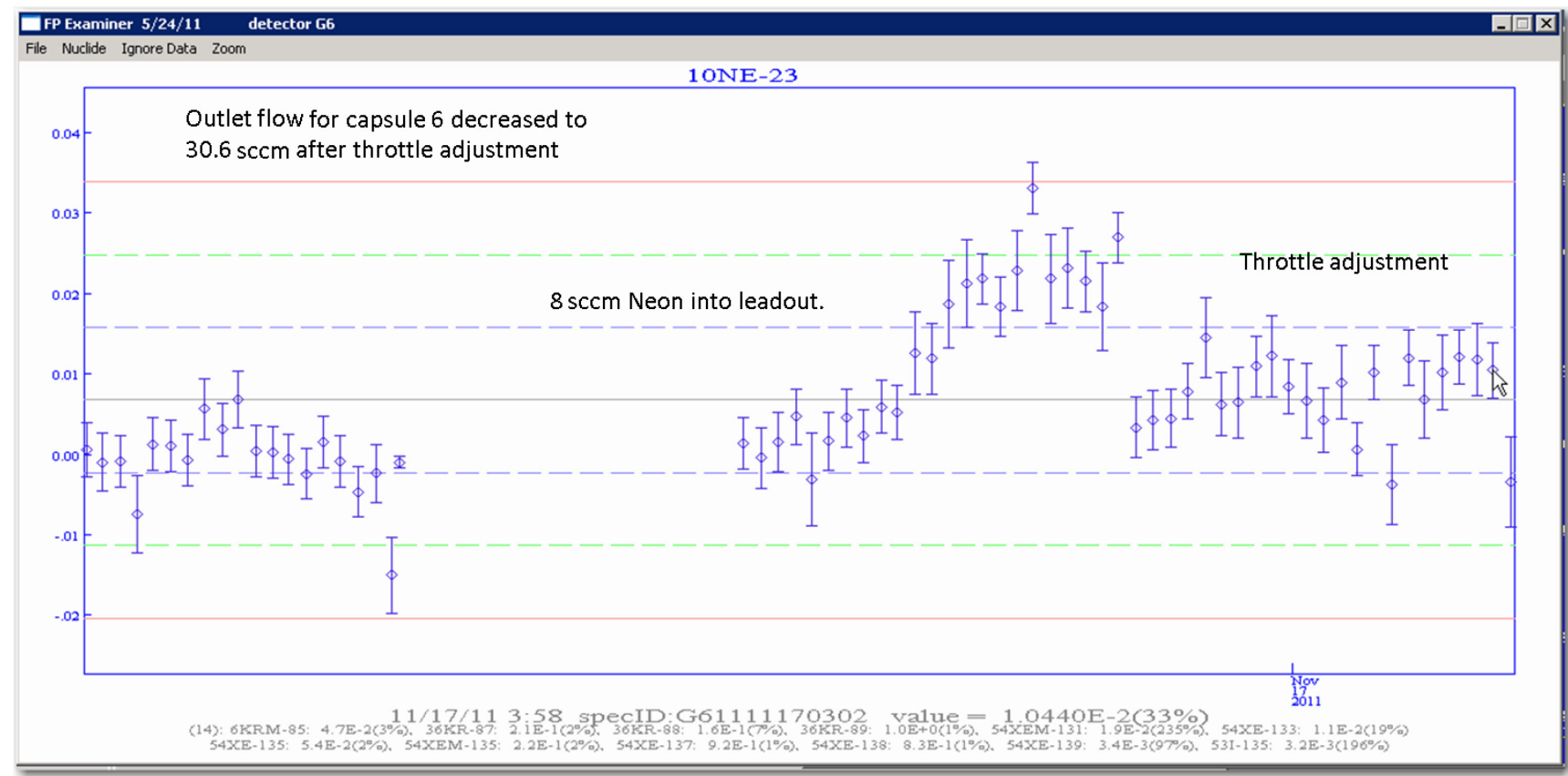

Figure 59. Cycle 150B, activated neon as seen by the FPM for Capsule 6. Outlet flow for Capsule 6 decreased from 33.7 to 30.6 sccm after the throttle adjustment. 
TEM-10200-1

$03 / 01 / 2012$

ENGINEERING CALCULATIONS AND ANALYSIS

Page 50 of 73

Rev. 06

Title:

Release-to-Birth Ratios for AGR-2 Operating Cycles 147A through 154B

ECAR No.: 2420

Rev. No.: 0

Project No:

23843, 23841 Date: 03/04/2014

A lot of communication was required between experiment engineers, LOC and the FPM support staff to try to understand in real time what happening within the test train during the leadout injection test. Adjustments to the test were made based of of results obtained with the FPM system. The results of these numerous tests and adjustment are captured in Figures 47-59 and are summarized below.

Summarized results of the leadout injection test that was performed starting on November 16, 2011:

16:06 Reduced mass flow controller on Capsules 2 and 5 to $0 \mathrm{sccm}$

16:09 Leadout flow was increased from 30 -sccm helium to 75 -sccm helium

16:25 Leadout flow was set to $67-$ sccm helium and 8-sccm neon.

20:40 outlet flows:

C1: $29.9 \mathrm{sccm}$

C2: $26.6 \mathrm{sccm}$

C3: $33.3 \mathrm{sccm}$

C4: $30.4 \mathrm{sccm}$

C5: $30.4 \mathrm{sccm}$

C6: $33.7 \mathrm{sccm}$.

The experiment was placed on full helium flow (i.e., $30 \mathrm{sccm}$ ) until all capsule temperatures had stabilized at low temperatures. The newly installed throttle valves (immediately upstream of the FPMs) were utilized to balance the back pressure and the outlet flow among all capsules.

21:13 outlet flows after throttle valve adjustment:

C1: $30.6 \mathrm{sccm}$

C2: $28.7 \mathrm{sccm}$

C3: $30.5 \mathrm{sccm}$

C4: $30.6 \mathrm{sccm}$

C5: $30.4 \mathrm{sccm}$

C6: $30.6 \mathrm{sccm}$.

An attempt was made to bring the experiment back to operating temperature; however, the temperature in Capsule 4 continued to increase, which indicated there must be leakage between the capsules; therefore, the experiment was taken to full helium flow and cooled down again. 
TEM-10200-1

$03 / 01 / 2012$

ENGINEERING CALCULATIONS AND ANALYSIS

Page 51 of 73

Rev. 06

Title:

Release-to-Birth Ratios for AGR-2 Operating Cycles 147A through 154B

ECAR No.: 2420

Rev. No.: 0

Project No:

23843, 23841 Date: 03/04/2014

Leakage between the capsules appears to have been caused by gas path failures inside the test train, resulting from the handling required to transfer the experiment from the reactor to the ATR canal (storage pool) and back into the reactor [14]. After using the throttle valves to balance the capsule back pressures and outlet flows, the leadout minimum flow test was performed to verify if leakage (or cross talk) between the capsules in the test train was causing the temperature anomalies. Unfortunately, there was significant leakage between the capsules at very high (e.g., $30 \mathrm{sccm}$ versus previous $6 \mathrm{sccm}$ ) leadout flow rates.

The thermal model of the experiment was then used to calculate a uniform gas mixture that could be introduced to all capsules and the leadout to best meet all capsule desired temperatures without exceeding high-temperature limits on any single capsule. Another attempt was made to bring all capsules up to temperature using this uniform gas mixture; however, the neon content had to be reduced in some capsules to avoid excessive temperatures and, eventually, the experiment was taken to full helium for the last few days of the operating cycle.

\section{Release-to-Birth Ratios for Cycle 150B}

Nuclides of greatest interest from the R/B determinations for ATR Operating Cycle 149B are presented in Figures 60 through 64. ATR reached full power on November 15, 2011, at 18:00 (Day 239.8) and continued until November 26, 2011, at 11:00 (Day 281.5). The leadout flow testing and throttle valve adjustments were conducted in low neon, and are reflected in Figures 60 through 64 as depressed R/B values because of the lower capsule temperatures. Significant capsule gas line cross talk and leadout leakage problems started to occur early in Cycle 150B [14] after the AGR-2 test was reinstalled back into the reactor, following the Cycle 150A PALM cycle. These cross talk and leakage problems made it impossible to control the temperature in each capsule through independent gas mixture composition, as designed; therefore, the FPM data are used for trending purposes only. 
TEM-10200-1

$03 / 01 / 2012$

ENGINEERING CALCULATIONS AND ANALYSIS

Page 52 of 73

Rev. 06

Title: $\quad$ Release-to-Birth Ratios for AGR-2 Operating Cycles 147A through 154B

\begin{tabular}{lllll} 
ECAR No.: 2420 & Rev. No.: & 0 & Project No.: & 23843,23841 Date: \\
\hline
\end{tabular}

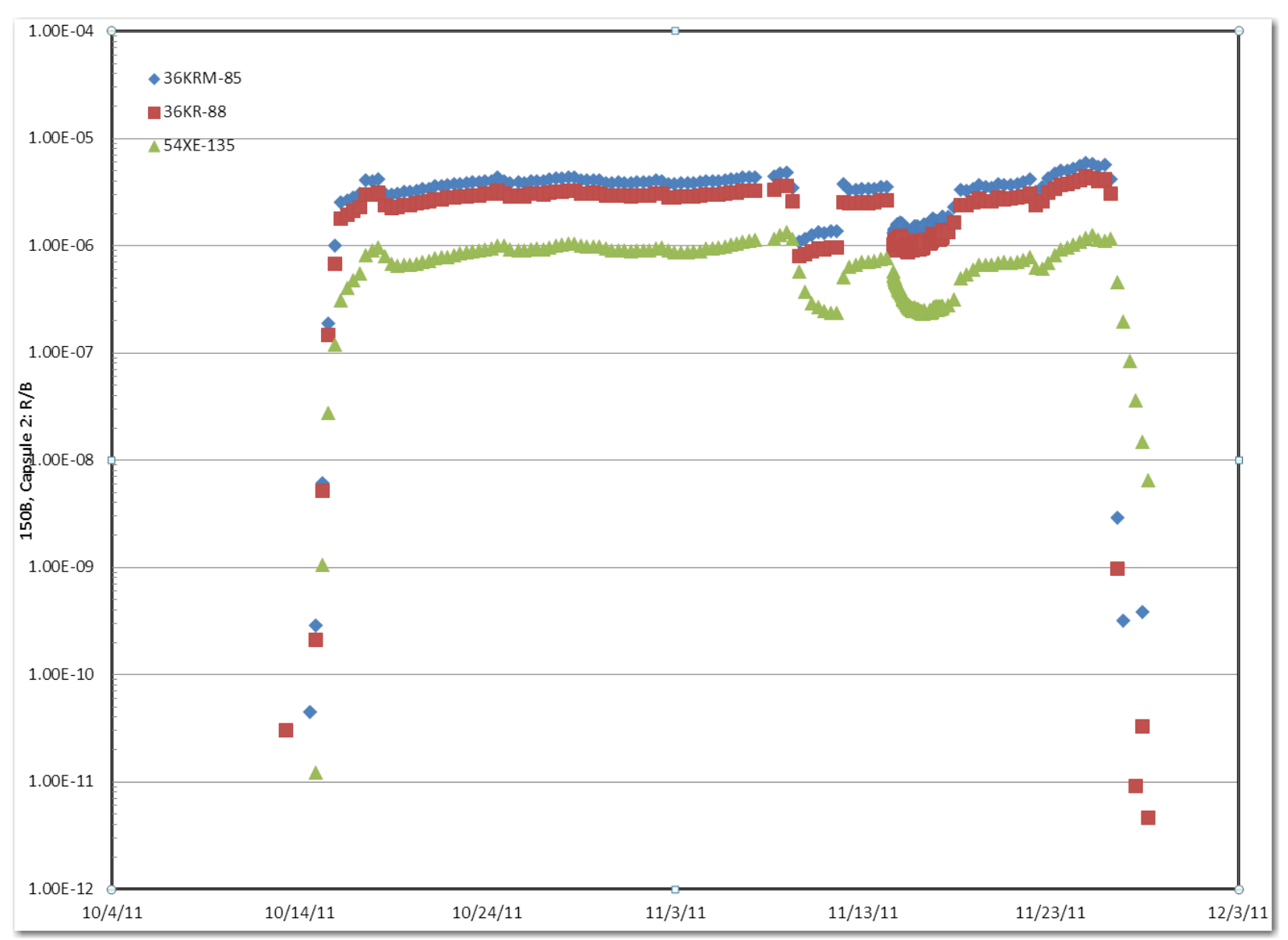

Figure 60. Cycle 150B, Capsule $2 \mathrm{R} / \mathrm{B}$ ratios $\mathrm{Kr}-85 \mathrm{~m}, \mathrm{Kr}-88$, and $\mathrm{Xe}-135$. Leadout flow testing is evident in the above plot. 
TEM-10200-1

$03 / 01 / 2012$

ENGINEERING CALCULATIONS AND ANALYSIS

Page 53 of 73

Rev. 06

Title: $\quad$ Release-to-Birth Ratios for AGR-2 Operating Cycles 147A through 154B

ECAR No.: 2420

Rev. No.: 0

Project No.:

23843, 23841 Date: 03/04/2014

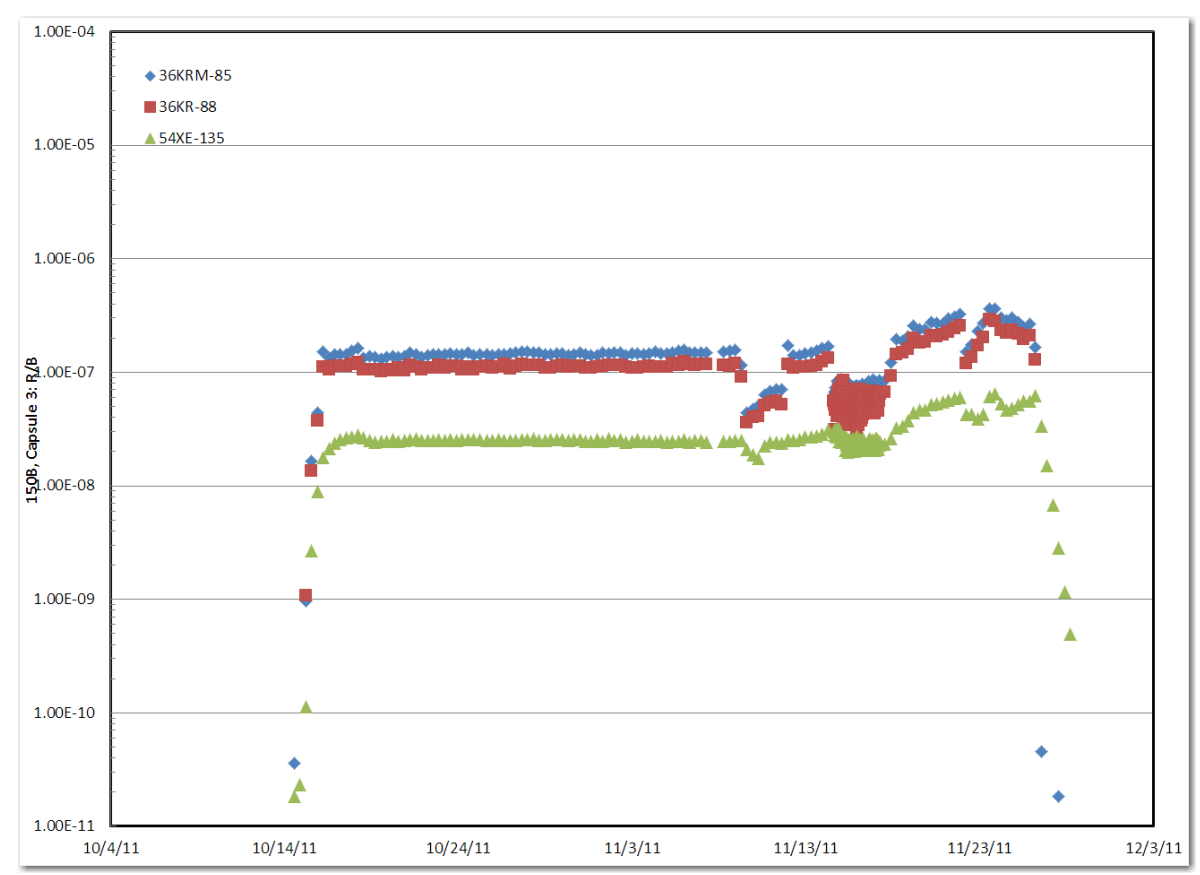

Figure 61. Cycle 150B, Capsule $3 \mathrm{R} / \mathrm{B}$ ratios $\mathrm{Kr}-85 \mathrm{~m}, \mathrm{Kr}-88$, and $\mathrm{Xe}-135$. Leadout flow testing is evident in the above plot.

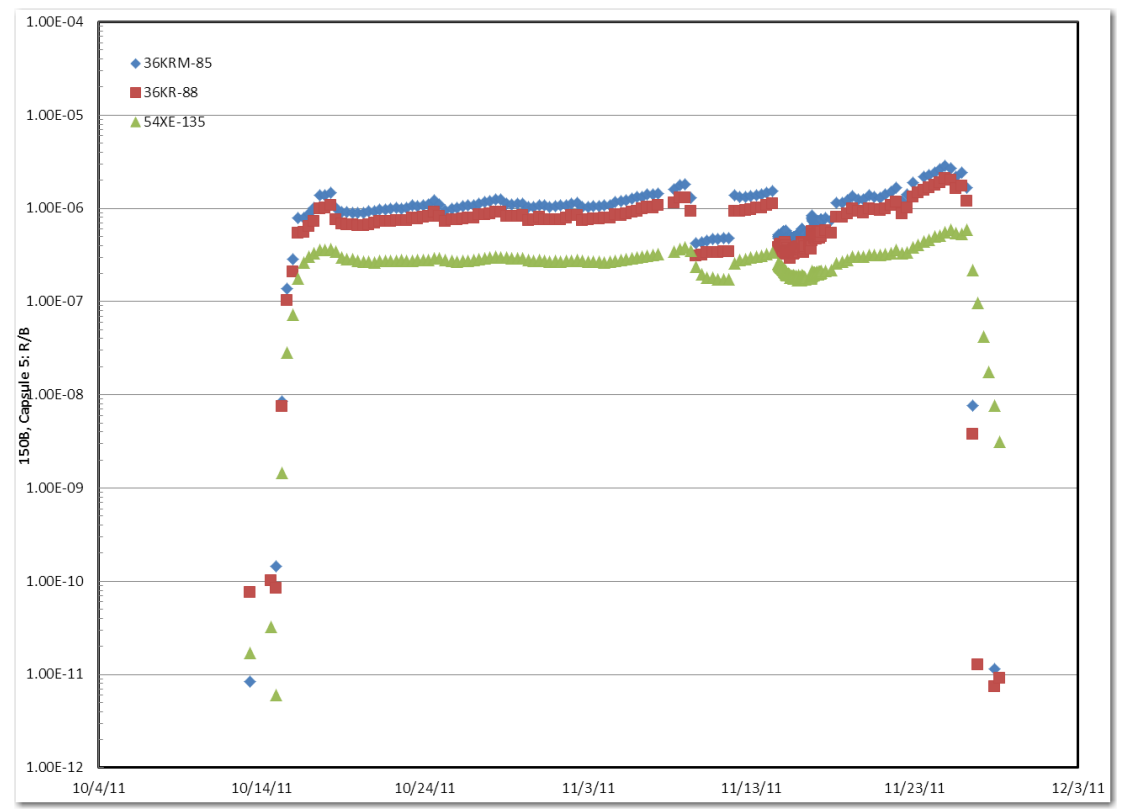

Figure 62. Cycle 150B, Capsule $5 \mathrm{R} / \mathrm{B}$ ratios $\mathrm{Kr}-85 \mathrm{~m}, \mathrm{Kr}-88$, and $\mathrm{Xe}-135$. Leadout flow testing is evident in the above plot. 
TEM-10200-1

$03 / 01 / 2012$

ENGINEERING CALCULATIONS AND ANALYSIS

Page 54 of 73

Rev. 06

Title: $\quad$ Release-to-Birth Ratios for AGR-2 Operating Cycles 147A through 154B

ECAR No.: 2420

Rev. No.: 0

Project No.:

23843, 23841 Date: 03/04/2014

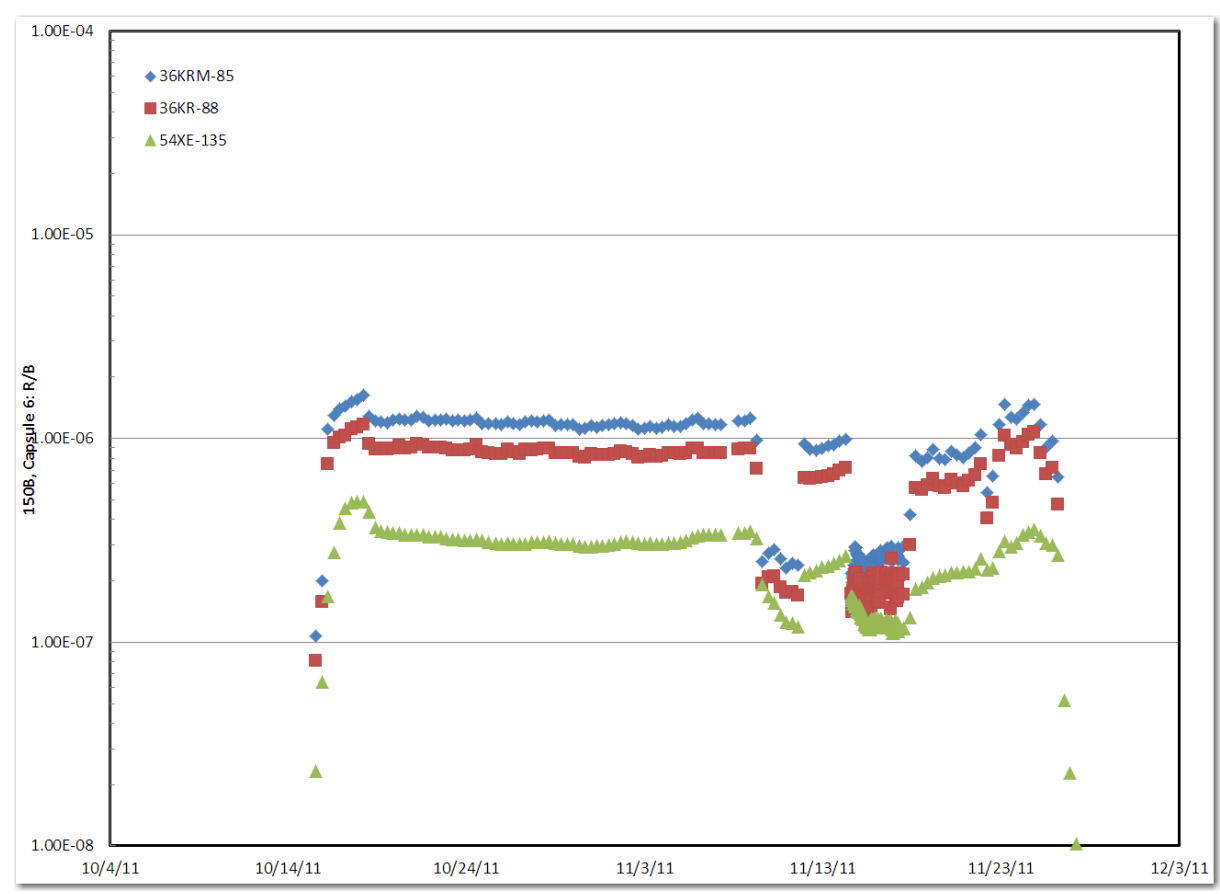

Figure 63. Cycle 150B, Capsule $6 \mathrm{R} / \mathrm{B}$ ratios $\mathrm{Kr}-85 \mathrm{~m}, \mathrm{Kr}-88$, and $\mathrm{Xe}-135$. Leadout flow testing is evident in the above plot.

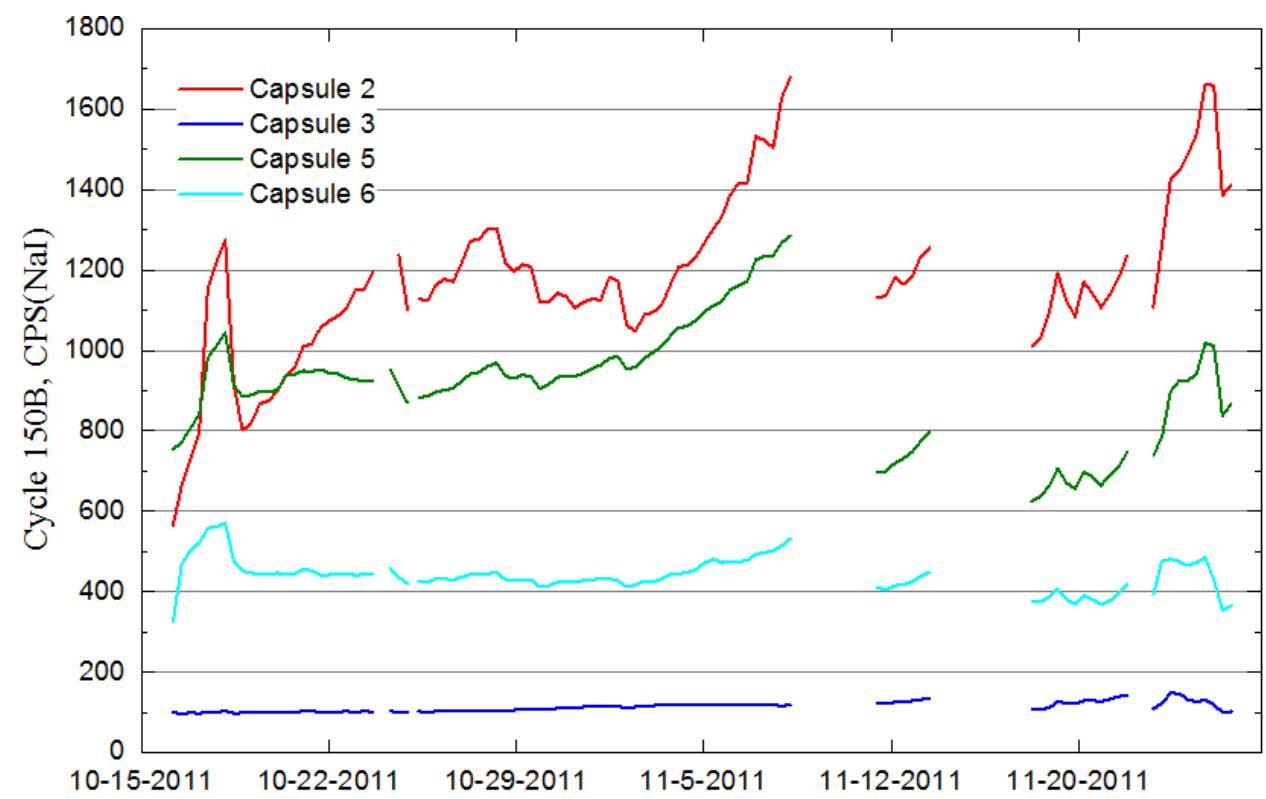

Figure 64. Gross gamma for Cycle 150B, total counts per second for Capsules 2, 3, 5, and 6. 
TEM-10200-1

$03 / 01 / 2012$

ENGINEERING CALCULATIONS AND ANALYSIS

Page 55 of 73

Rev. 06

Title:

Release-to-Birth Ratios for AGR-2 Operating Cycles 147A through 154B

ECAR No.: 2420

Rev. No.: 0

Project No.:

23843, 23841 Date: 03/04/2014

\section{Cycles 151A and 151B}

Nuclides of greatest interest from the R/B determinations for ATR Operating Cycle 151A and 151B are presented in Figures 65 through 68.

ATR reached full power for Cycle 151A on December 14, 2011, at 17:00 (Day 281.9) and continued until an unplanned outage on December 25, 2011, at 10:00 (Day 292.6). Cycle 151A resumed on December 28, 2011, (Day 292.6), reaching full power at 20:00. The reactor continued operation until February 11, 2012, at 11:00 (Day 337.6).

On December 22, 2011, it was discovered that effluent from Capsule 1 was escaping from FPM1 and accumulating in the $2 \mathrm{C}$ secondary cubicle. Therefor the effluent was routed instead to the spare FPM7. During the 151A outage, an effort had been made to flush cesium out of the FPM traps. This had required them to be disconnected from the effluent lines. When the traps were reconnected, the connections to FPM1 were not sufficiently tightened, resulting in the leak into the $2 \mathrm{C}$ secondary cubicle. Therefor AGR-2 was placed in standby mode with all inlet and isolation valves closed until the krypton and xenon could decay or disperse. By December 24, 2011, the connection to the FPM trap was tightened and flow was restored to all FPMs. It was recommended that flow rebalancing of the throttle values for AGR-2 be performed again and that a gas mix ratio of 20 neon and 10 helium be used.

On December 25, 2011, the reactor was scrammed due to loss of diesel; therefore, AGR-2 was brought down during the unplanned outage. The reactor was brought back to full power on December 28, 2011. Capsule 1 from AGR-1 was placed back into its normal configuration and Capsule 6 was sent to spare because FPM count rates dropped to zero and gave an indication of a high-voltage power failure. Upon investigation, the preamp cable connected to the detector preamplifier had become disconnected during the flow adjustments. By December 30, 2011, all FPM modules were functioning and Capsule 6 was placed back into its normal configuration. At 16:34 on the same day, LOC received a Capsule 6 inlet pressure high alarm and at $16: 50$ the $2 \mathrm{C}$ secondary continuous air monitor (CAM) alarmed. At 18:03, AGR-2 was isolated from the reactor. R/B data for the time period of December 30. 2011 through January 11, 2012 are not valid R/B measurements. The FPMS detectors were monitoring residual effluent and cubicle background during this time period. $\mathrm{R} / \mathrm{B}$ values were calculated because non-zero flow data from the NDMAS data base was provided for this time period. Nominal flow for the AGR-2 experiment is on the order of $30 \mathrm{sccm}$. Flow during the isolated experiment was recorded in the NDMAS system to be on the order of $0.05 \mathrm{sccm}$. On January 11, 2012, AGR-2 was returned to operating status, where it remained in operation until February 11, 2012, without any further problems. It became clear during Cycle 151A that the helium/neon gas mixture within the AGR-2 capsules was ambiguous because of the damage sustained to the experiment during movement of the experiment in Cycle 150A PALM. The program decided to set all of the capsules and leadout flow mixture ratios (i.e., neon fraction) to the same value on January 17, 2012 [14].

ATR reached full power for Cycle 151B on March 1, 2012, at 16:00 (Day 337.8) and shutdown on March 22, 2012, at 17:00 (Day 358.8). The reactor again reached full power on March 25, 2012, at 21:00 (Day 359.0); however, it was only at full power for a couple of days before it was brought down on March 27, 2012, at 15:00 (Day 360.8). On April 7, 2012, the reactor reached full power at 14:00 (Day 361.0) and continued until May 5, 2012 (Day 388.9). 
TEM-10200-1

$03 / 01 / 2012$

ENGINEERING CALCULATIONS AND ANALYSIS

Page 56 of 73

Rev. 06

Title: $\quad$ Release-to-Birth Ratios for AGR-2 Operating Cycles 147A through 154B

$\begin{array}{llll}\text { ECAR No.: } 2420 & \text { Rev. No.: } 0 & \text { Project No.: } & \text { 23843, } 23841 \text { Date: } 03 / 04 / 2014\end{array}$

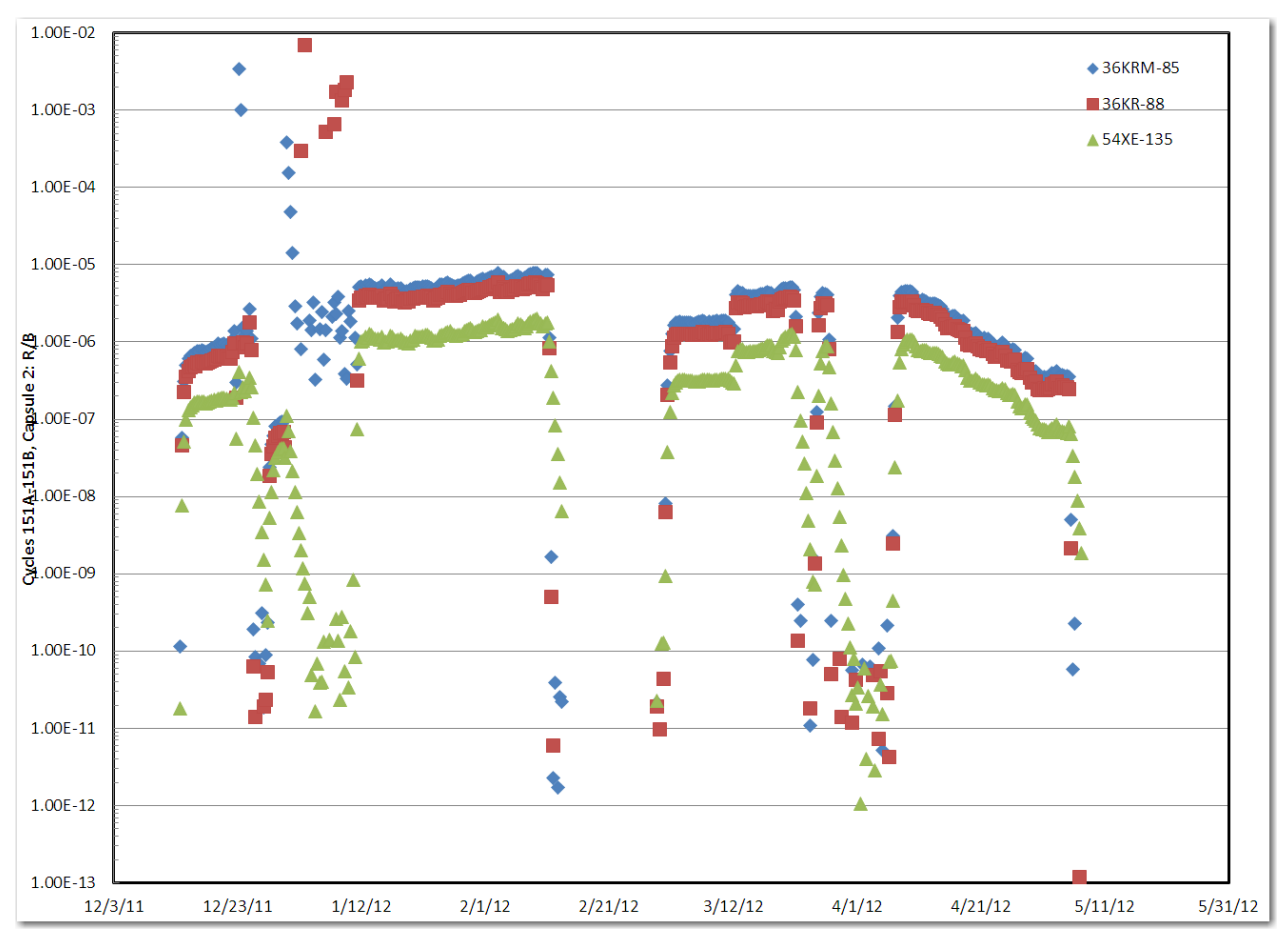

Figure 65. Cycle 151A and 151B, Capsule 2 R/B ratios Kr-85m, Kr-88, and Xe-135.

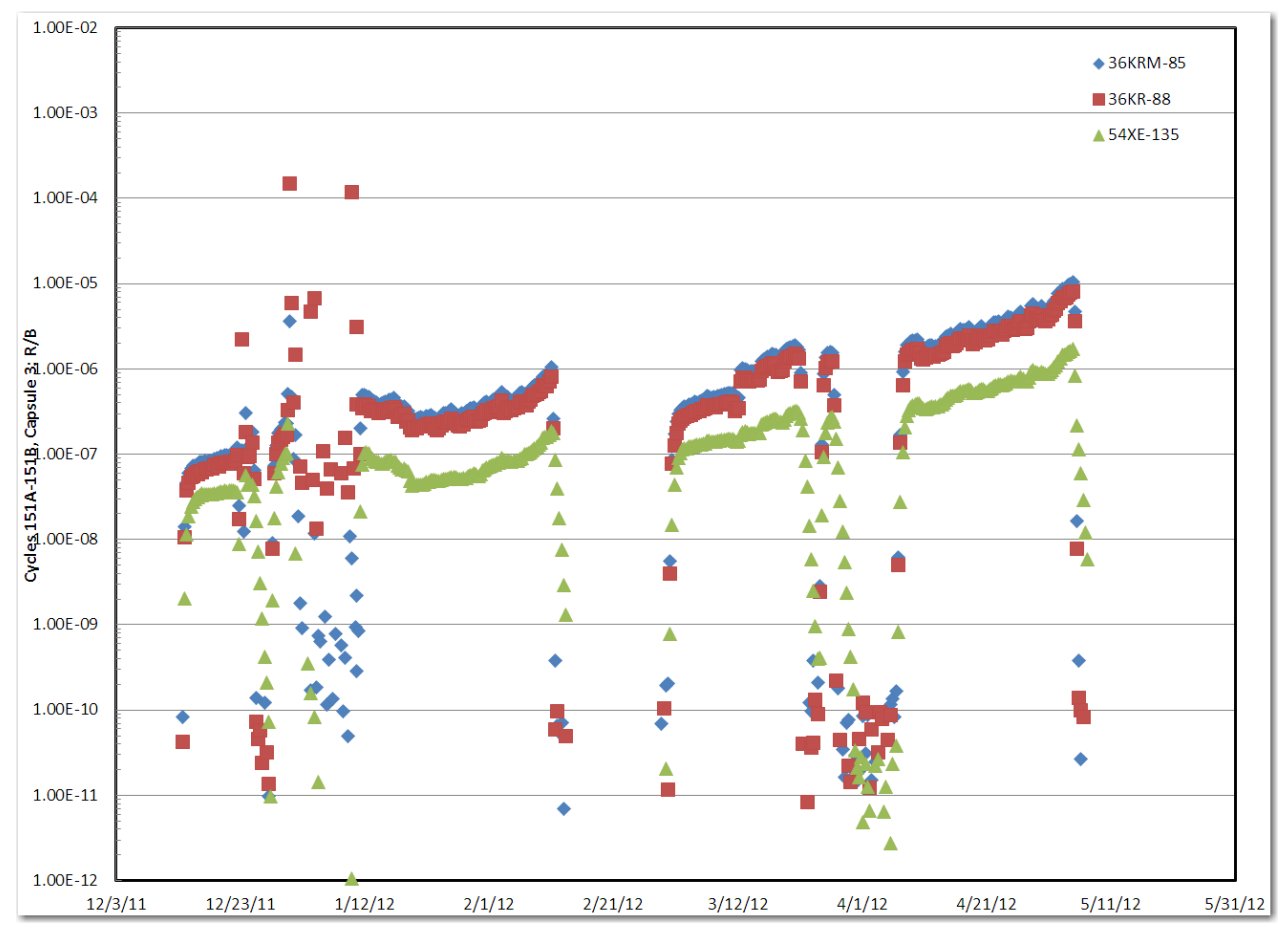

Figure 66. Cycle 151A and 151B, Capsule 3 R/B ratios Kr-85m, Kr-88, and Xe-135. 
TEM-10200-1

$03 / 01 / 2012$

ENGINEERING CALCULATIONS AND ANALYSIS

Page 57 of 73

Rev. 06

Title: $\quad$ Release-to-Birth Ratios for AGR-2 Operating Cycles 147A through 154B

ECAR No.: 2420

Rev. No.: 0

Project No.: $\quad 23843,23841$ Date: $03 / 04 / 2014$

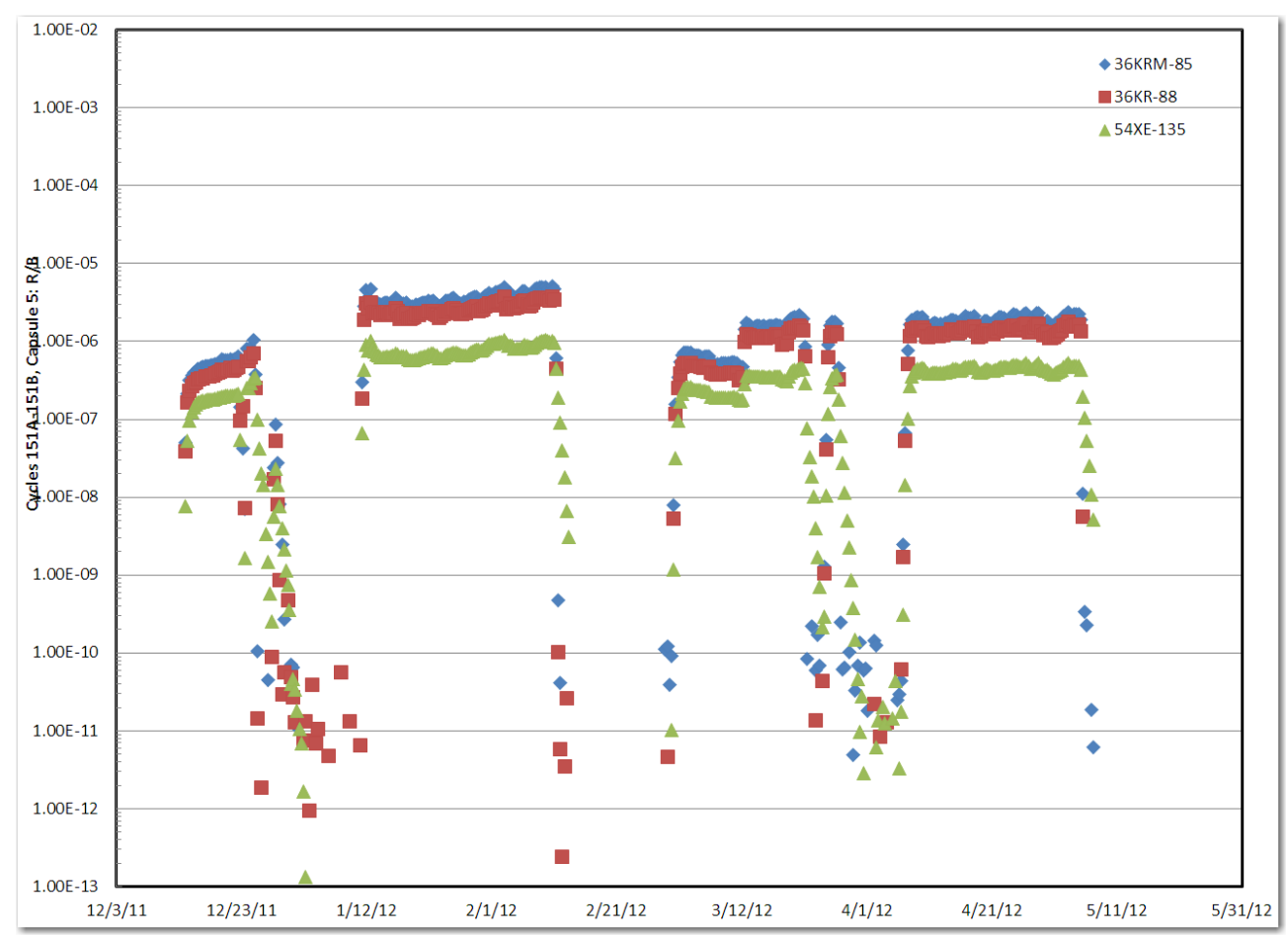

Figure 67. Cycle 151A and 151B, Capsule 5 R/B ratios Kr-85m, Kr-88, and Xe-135.

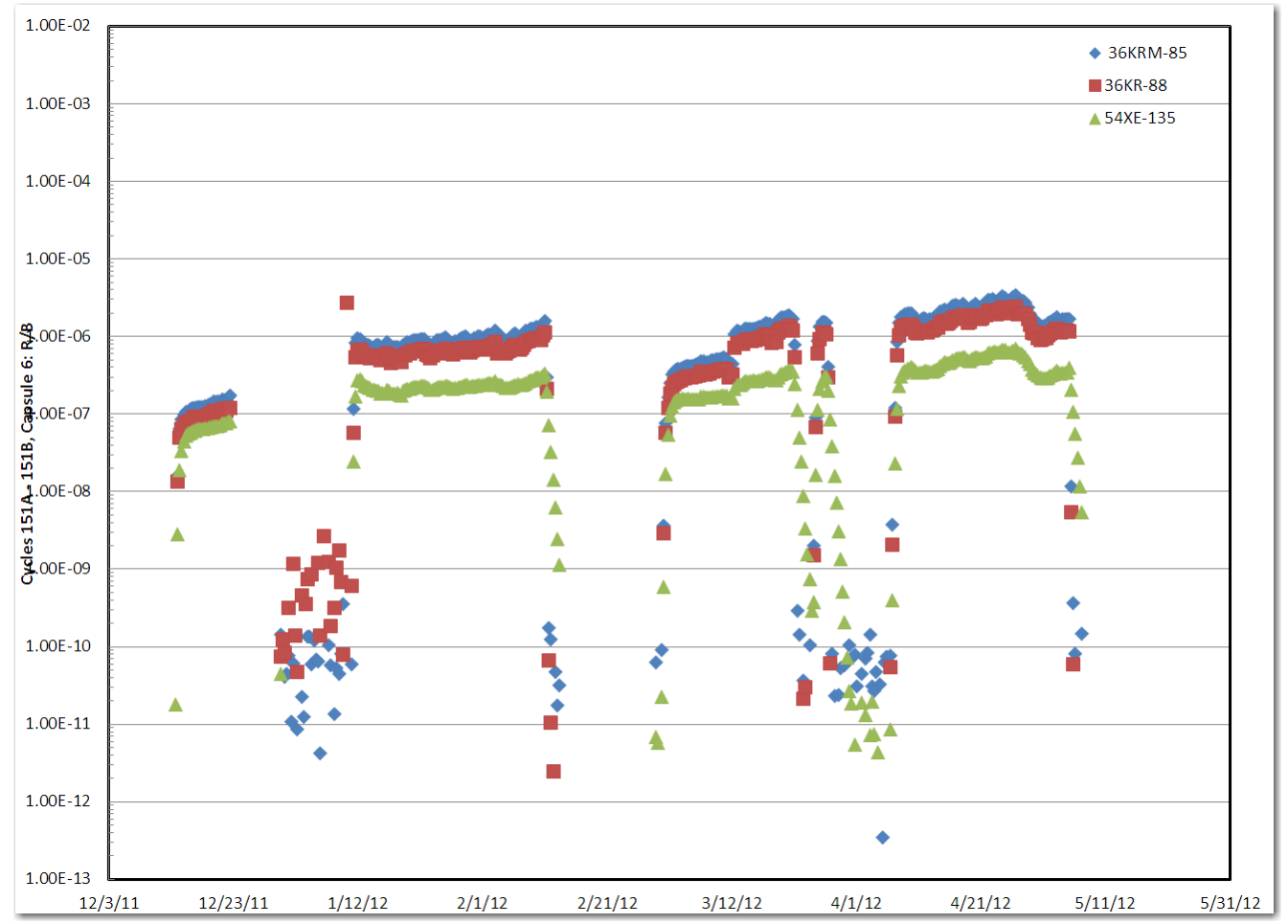

Figure 68. Cycle 151A and 151B, Capsule 6 R/B ratios Kr-85m, Kr-88, and Xe-135. 
TEM-10200-1

$03 / 01 / 2012$

ENGINEERING CALCULATIONS AND ANALYSIS

Page 58 of 73

Rev. 06

Title: $\quad$ Release-to-Birth Ratios for AGR-2 Operating Cycles 147A through 154B

$\begin{array}{lllll}\text { ECAR No.: } 2420 & \text { Rev. No.: } 0 & \text { Project No.: } & 23843,23841 \text { Date: } & 03 / 04 / 2014\end{array}$

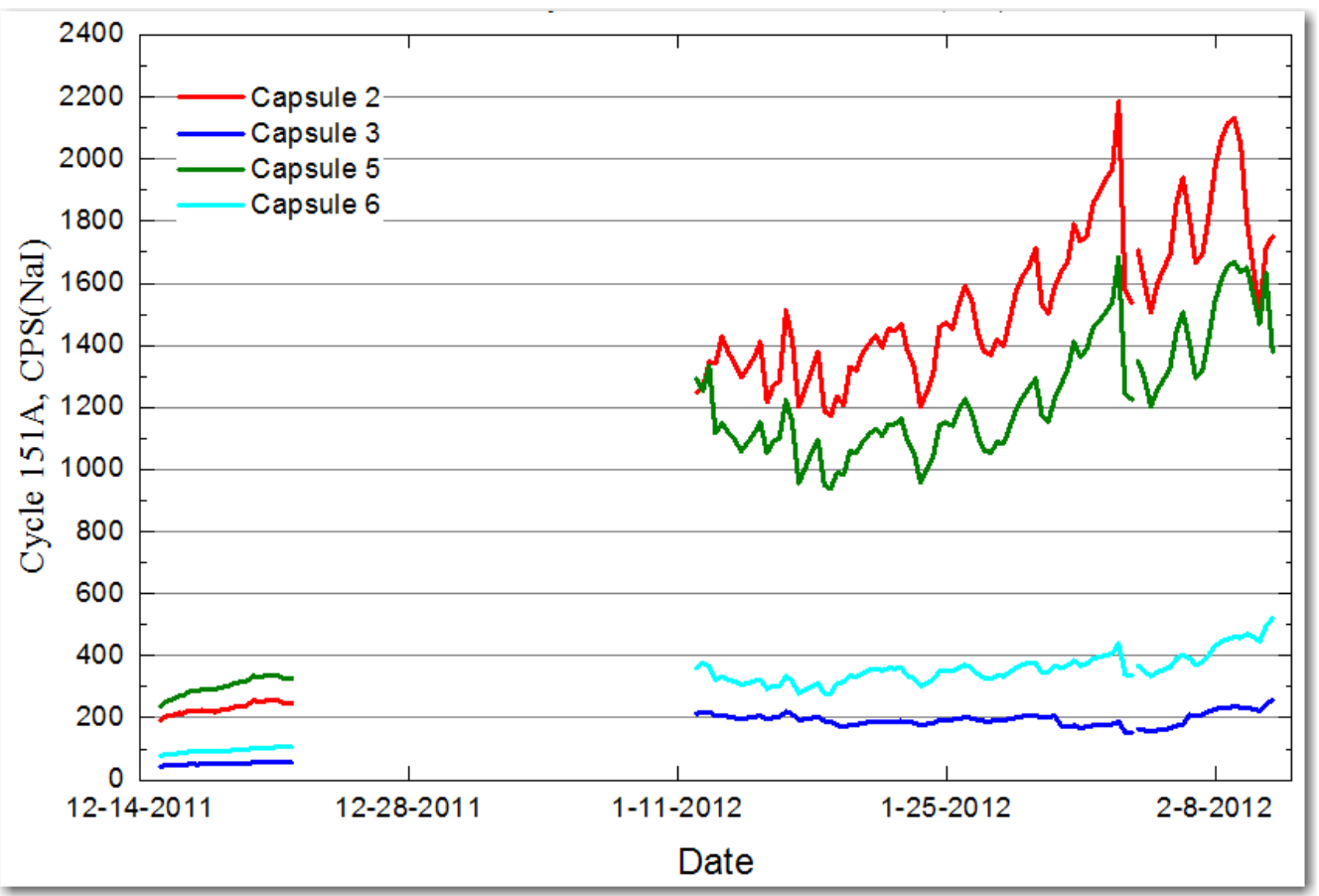

Figure 69. Gross gamma for Cycle 151A, total counts per second for Capsules 2, 3, 5, and 6.

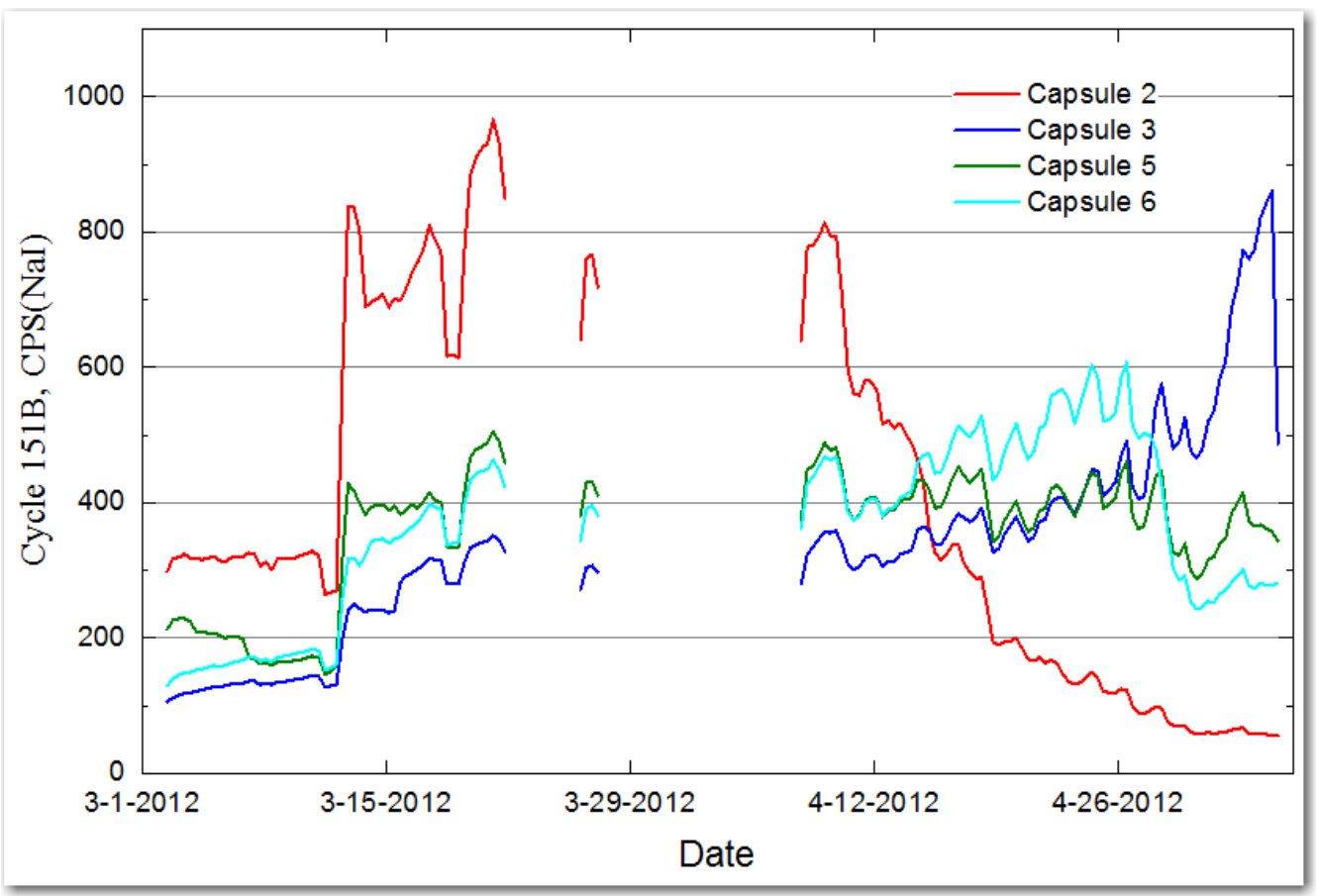

Figure 70. Gross gamma for Cycle 151B, total counts per second for Capsules 2, 3, 5, and 6. Capsule 2 decrease in believed to have been cause by a releasing relief valve. 
TEM-10200-1

$03 / 01 / 2012$

ENGINEERING CALCULATIONS AND ANALYSIS

Page 59 of 73

Rev. 06

Title: $\quad$ Release-to-Birth Ratios for AGR-2 Operating Cycles 147A through 154B

ECAR No.: 2420

Rev. No.: 0

Project No.:

23843, 23841 Date: 03/04/2014

\section{Cycles 152B and 153B}

Nuclides of greatest interest from the R/B determinations for ATR Operating Cycle 152B and 153B are presented in Figures 71 through 76.

ATR reached full power for Cycle 152B on November 28, 2012, at 21:00 (Day 389.3) and continued until January 18, 2013, at 11:00 (Day 439.9).

During the Cycle 153A outage, seven flow meters were installed on the outlet side the FPM warm traps. These meters were installed to help verify that the flow coming out of the AGR-2 capsules is the same flow that is leaving the FPM warm traps. If there were to be a difference in flow reading, it would indicate that something was amiss between the experiment and the warm traps, indicating a potential leak in the valves or tubing toward the FPMS. During installation of the flow meters, severe noise (on the order of hundreds of thousands of counts per second) was introduced into the FPMS via the sodium iodide detectors (gross gamma). The FPM team was able to work with plant operations to remove the noise that rendered the FPMS gross gamma detectors inoperable as far as measuring the count rate from the AGR-2 experiment. Because of time constraints, not all the plant noise was removed from the system and it would still show up periodically in the gross gamma spectra. The FPM team was able to work around the intermittent noise that was present in the spectra. The gaps present in Figures 76, 81, and 82 capture the gross gamma count rate for each respective cycle, with the noise aberrations removed.

During the Cycle 153B outage, AGR-2 was moved to position I-24 to avoid being overheated. ATR reached full power for Cycle 153B on March 30, 2013 at 23:00 (Day 440.5) and continued until April 12, 2013, at 19:00 (Day 453.4).

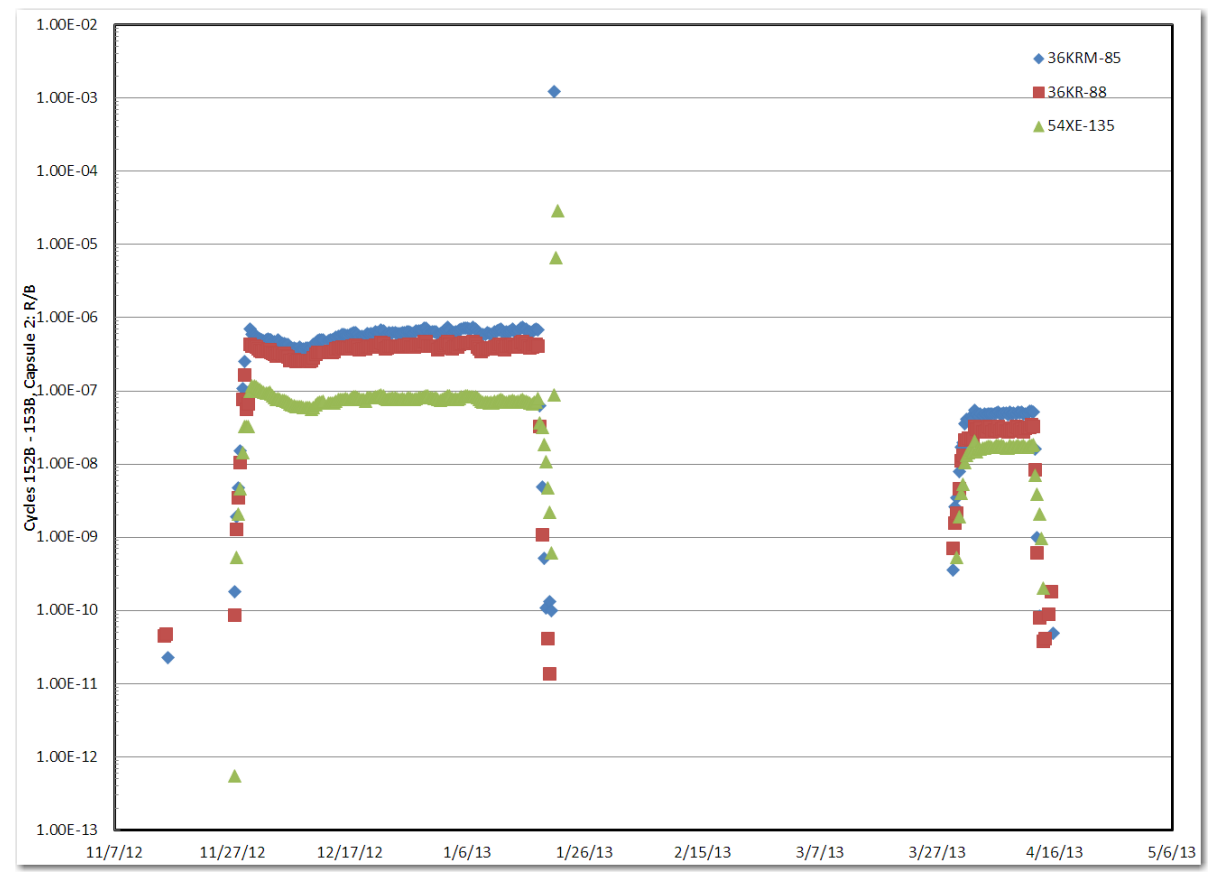

Figure 71. Cycle 152B and 153B, Capsule 2 R/B ratios Kr-85m, Kr-88, and Xe-135. 
TEM-10200-1

$03 / 01 / 2012$

ENGINEERING CALCULATIONS AND ANALYSIS

Page 60 of 73

Rev. 06

Title: $\quad$ Release-to-Birth Ratios for AGR-2 Operating Cycles 147A through 154B

ECAR No.: 2420

Rev. No.: 0

Project No.: $\quad 23843,23841$ Date: $03 / 04 / 2014$

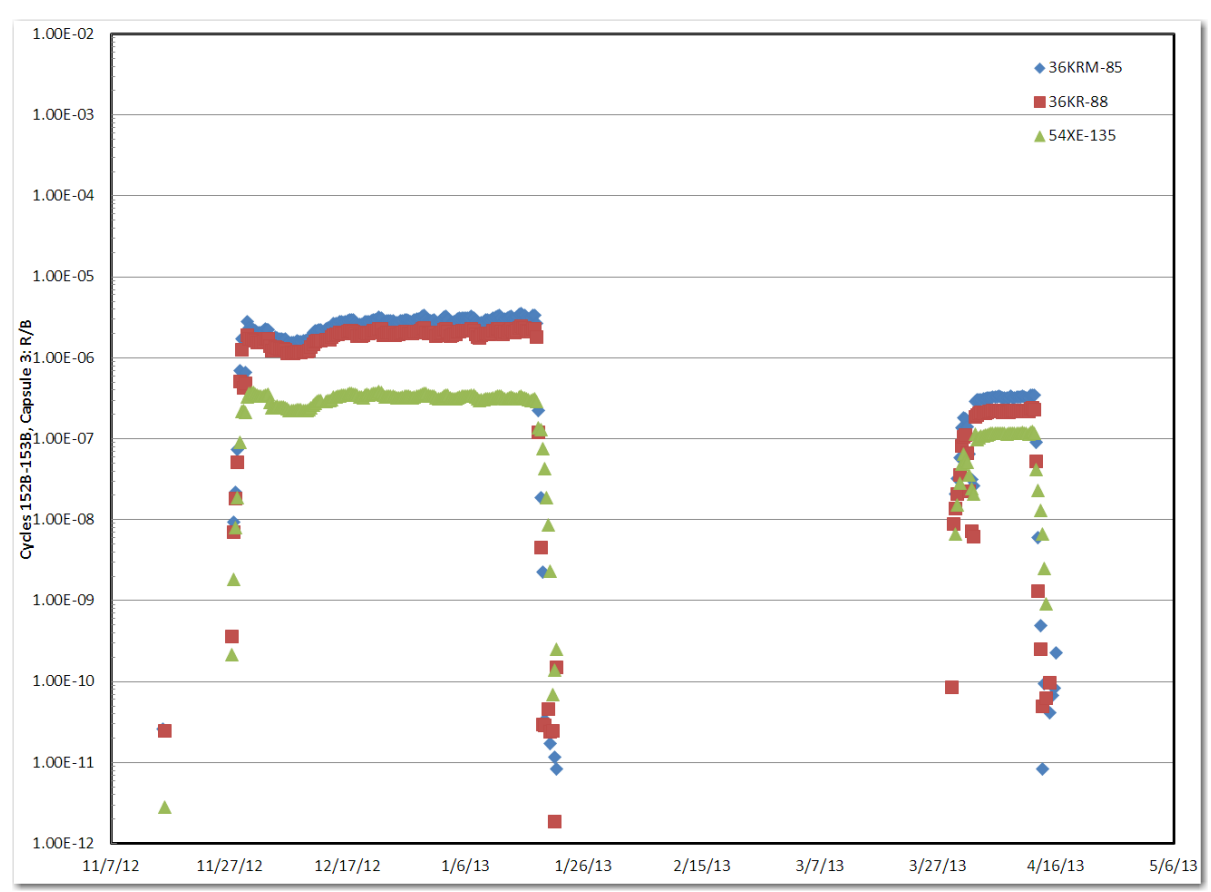

Figure 72. Cycle 152B and 153B, Capsule 3 R/B ratios Kr-85m, Kr-88, and Xe-135.

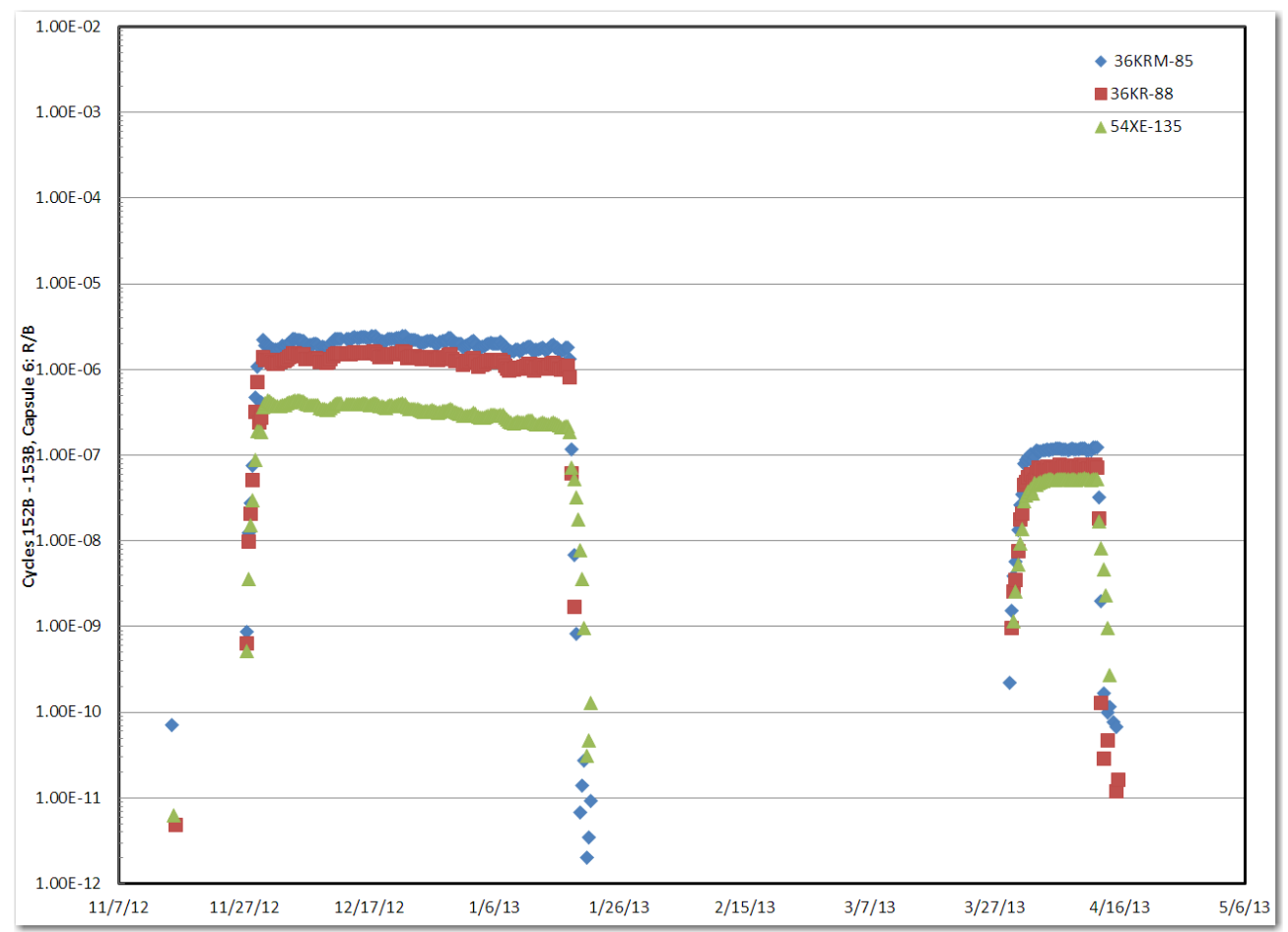

Figure 73. Cycle 152B and 153B, Capsule 6 R/B ratios Kr-85m, Kr-88, and Xe-135. 
TEM-10200-1

$03 / 01 / 2012$

Rev. 06

Title: $\quad$ Release-to-Birth Ratios for AGR-2 Operating Cycles 147A through 154B

ECAR No.: 2420

Rev. No.: 0

Project No::

23843, 23841 Date: 03/04/2014

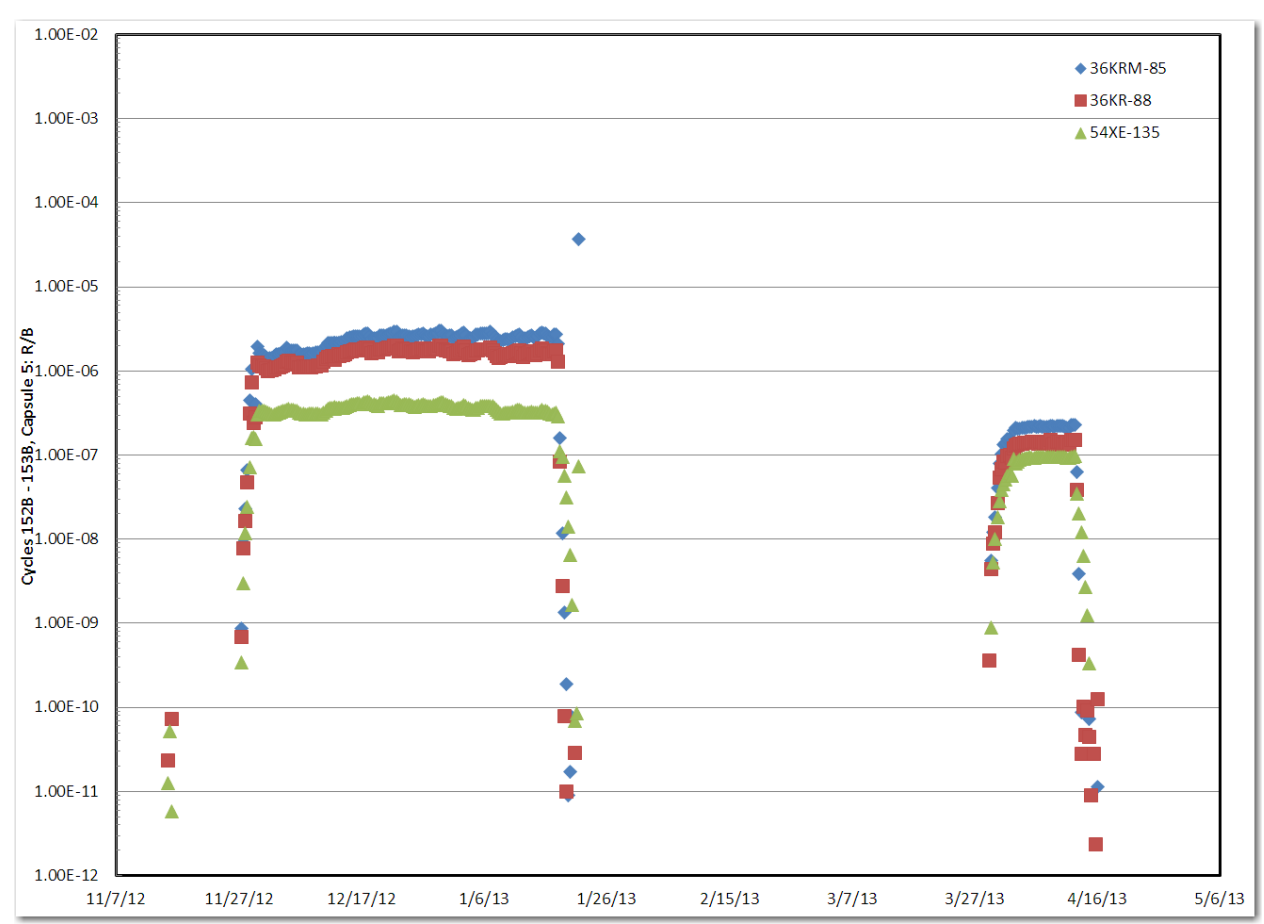

Figure 74. Cycle 152B and 153B, Capsule 5 R/B ratios Kr-85m, Kr-88, and Xe-135.

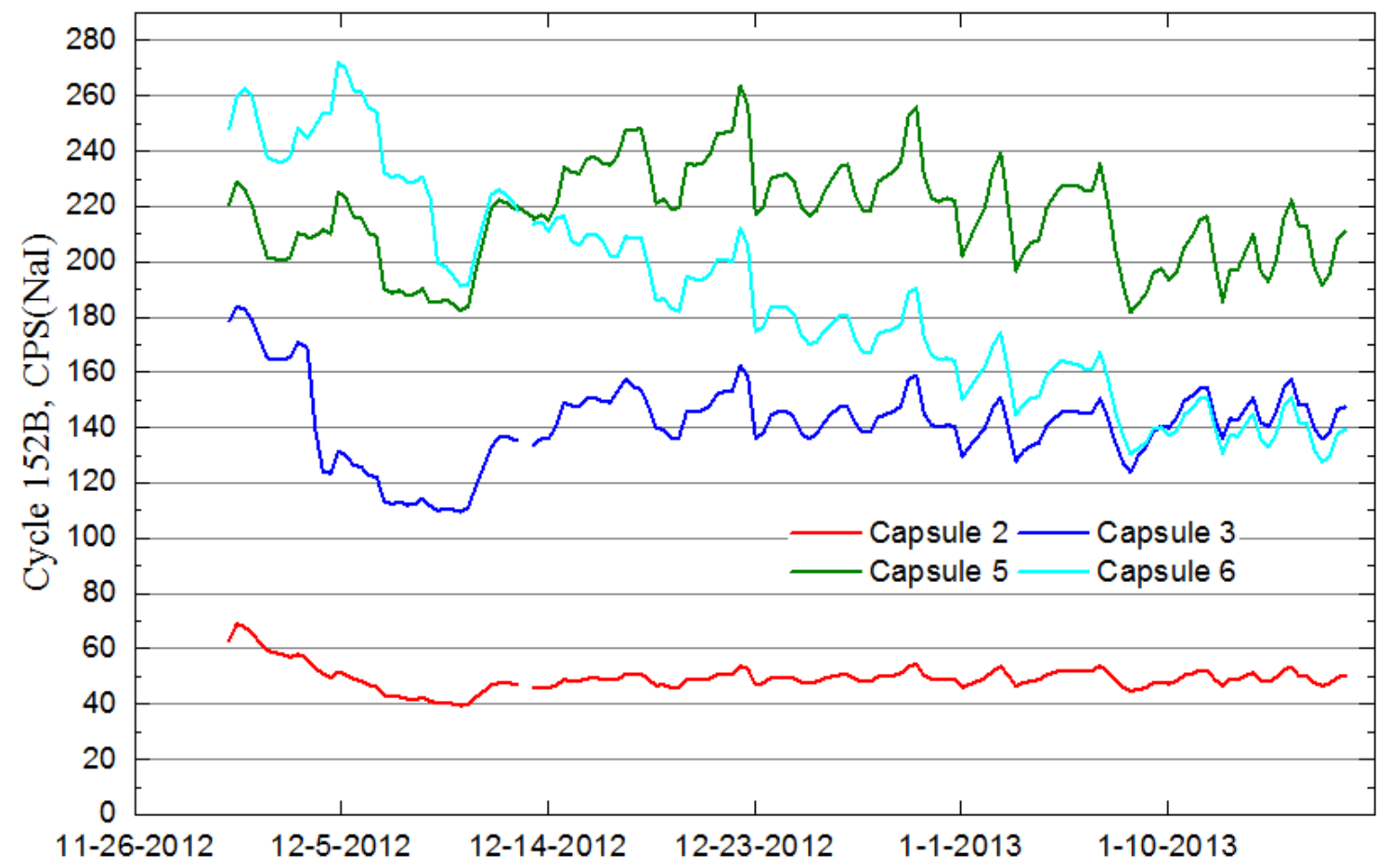

Figure 75. Gross gamma for Cycle 152B, total counts per second for Capsules 2, 3, 5, and 6. 
TEM-10200-1

$03 / 01 / 2012$

ENGINEERING CALCULATIONS AND ANALYSIS

Page 62 of 73

Rev. 06

Title: $\quad$ Release-to-Birth Ratios for AGR-2 Operating Cycles 147A through 154B

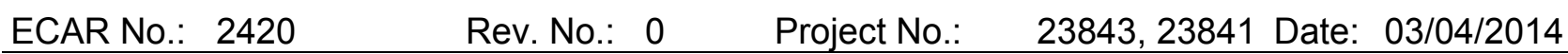

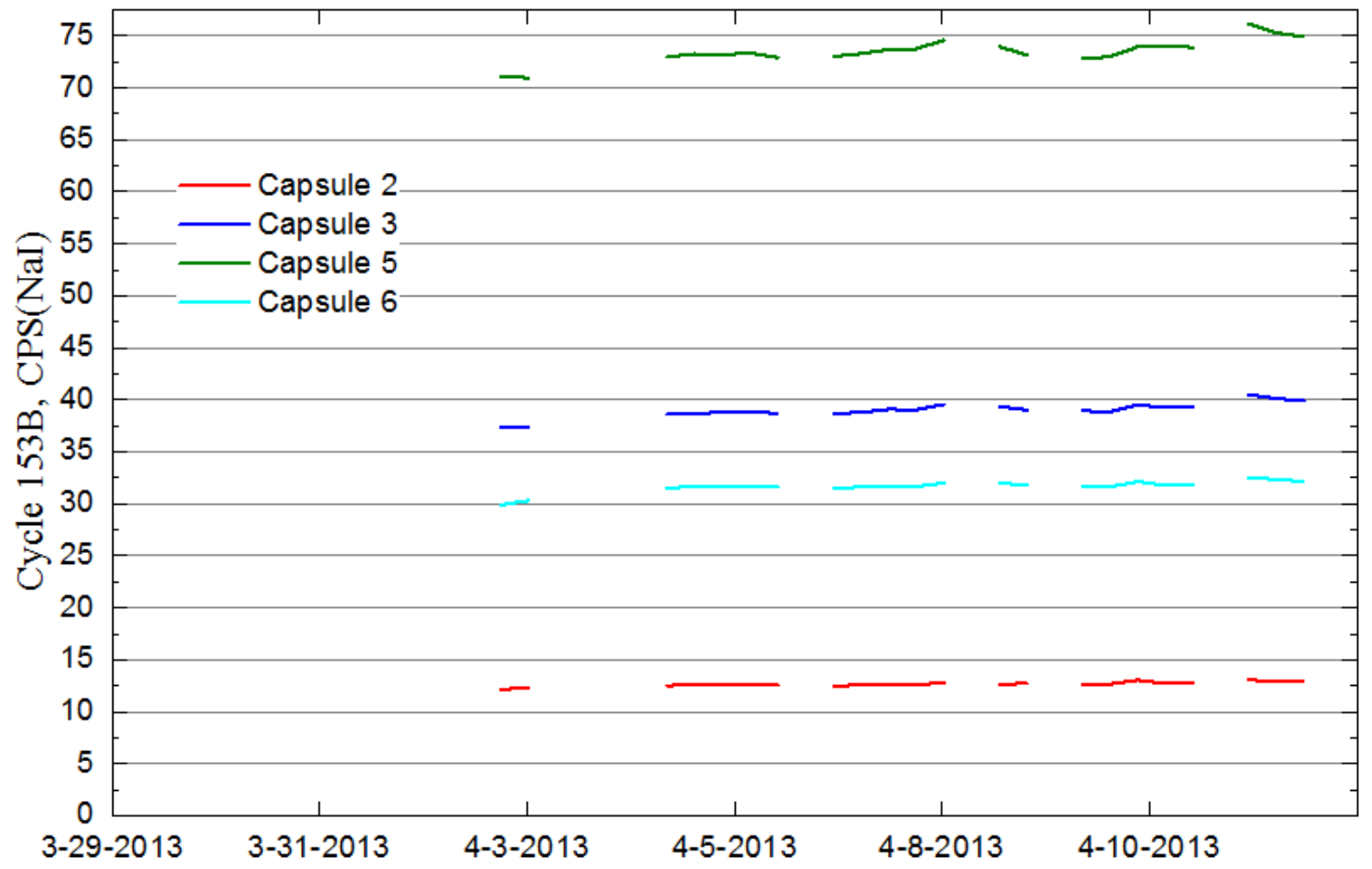

Figure 76. Gross gamma for Cycle 153B, total counts per second for Capsules 2, 3, 5, and 6.

\section{Cycles 154A and 154B}

Nuclides of greatest interest from the R/B determinations for ATR Operating Cycle 154A and 154B are presented in Figures 77 through 82.

ATR reached full power for Cycle 154A on May 19, 2013, at 15:00 (Day 453.6) and continued until May 21, 2013, at 06:00 (Day 455.2). The reactor reached full power again on May 24, 2013, at 03:00 (Day 455.3) and continued operation until the planned reactor shutdown on July 13, 2013, at 11:00 (Day 505.7).

ATR reached full power for Cycle 154B on August 24, 2013, at 06:00 (Day 506.0) and continued operation until the planned reactor shutdown on October 16, 2013, at 11:00 (Day 559.2).

The AGR-2 experiment completed irradiation on October 16, 2013. Figure 83 summarizes the R/B for $\mathrm{Kr}-85 \mathrm{~m}, \mathrm{Kr}-88$, and $\mathrm{Xe}-138$ for the entire duration of the experiment. The R/B values for this figure were computed using the four-point interpolation method.

Figure 84 summarizes the gross gamma total count rate for the entire AGR-2 experiment. The gross gamma data trended with the spectrometer data for the duration of the experiment. 
TEM-10200-1

$03 / 01 / 2012$

ENGINEERING CALCULATIONS AND ANALYSIS

Page 63 of 73

Rev. 06

Title: $\quad$ Release-to-Birth Ratios for AGR-2 Operating Cycles 147A through 154B

ECAR No.: 2420

Rev. No.: 0

Project No.: $\quad 23843,23841$ Date: $03 / 04 / 2014$

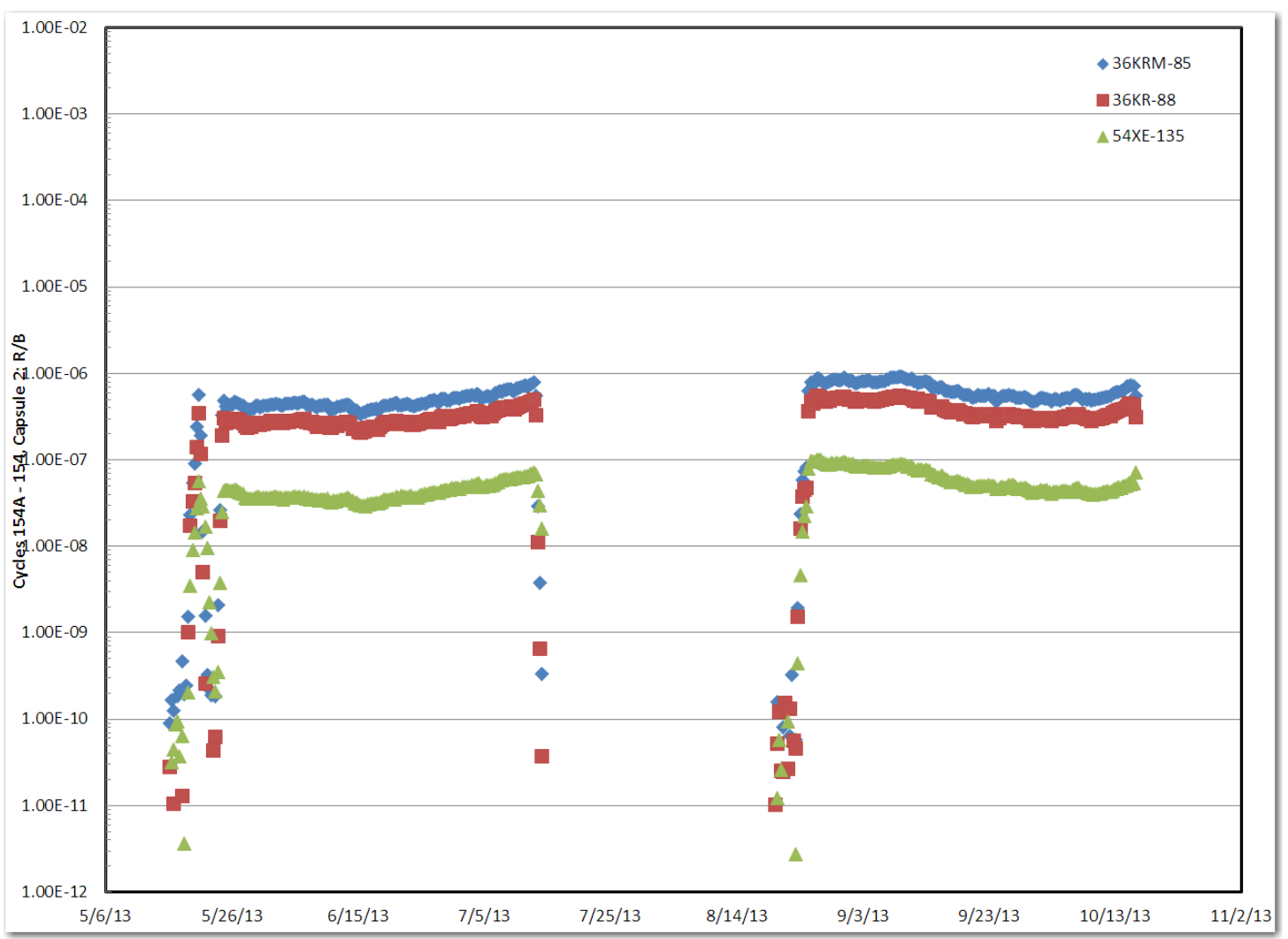

Figure 77. Cycle 154A and 154B, Capsule 2 R/B ratios Kr-85m, Kr-88, and Xe-135.

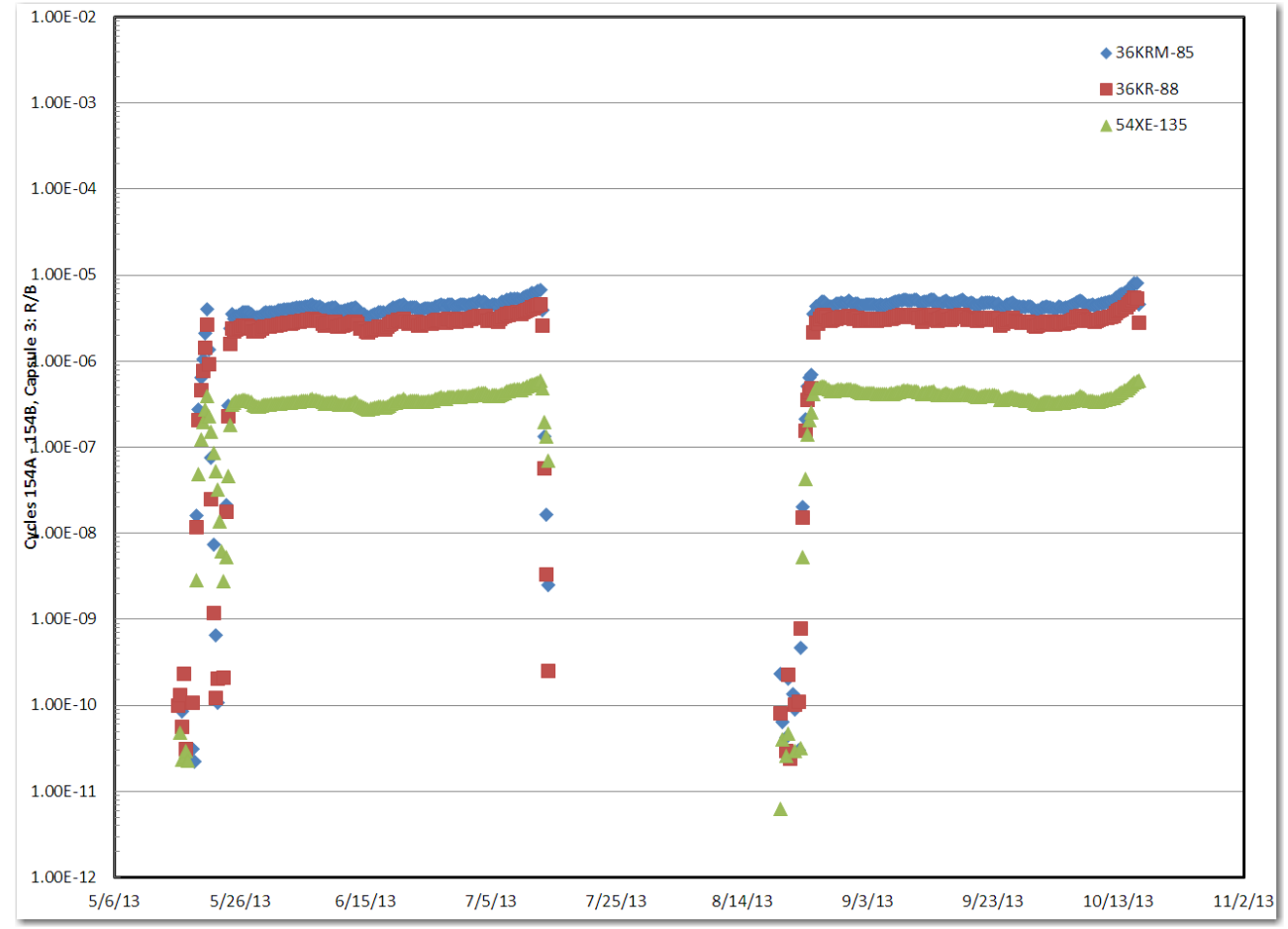

Figure 78. Cycle 154A and 154B, Capsule 3 R/B ratios Kr-85m, Kr-88, and Xe-135. 
TEM-10200-1

$03 / 01 / 2012$

ENGINEERING CALCULATIONS AND ANALYSIS

Page 64 of 73

Rev. 06

Title: $\quad$ Release-to-Birth Ratios for AGR-2 Operating Cycles 147A through 154B

ECAR No.: 2420

Rev. No.: 0

Project No.: $\quad 23843,23841$ Date: $03 / 04 / 2014$

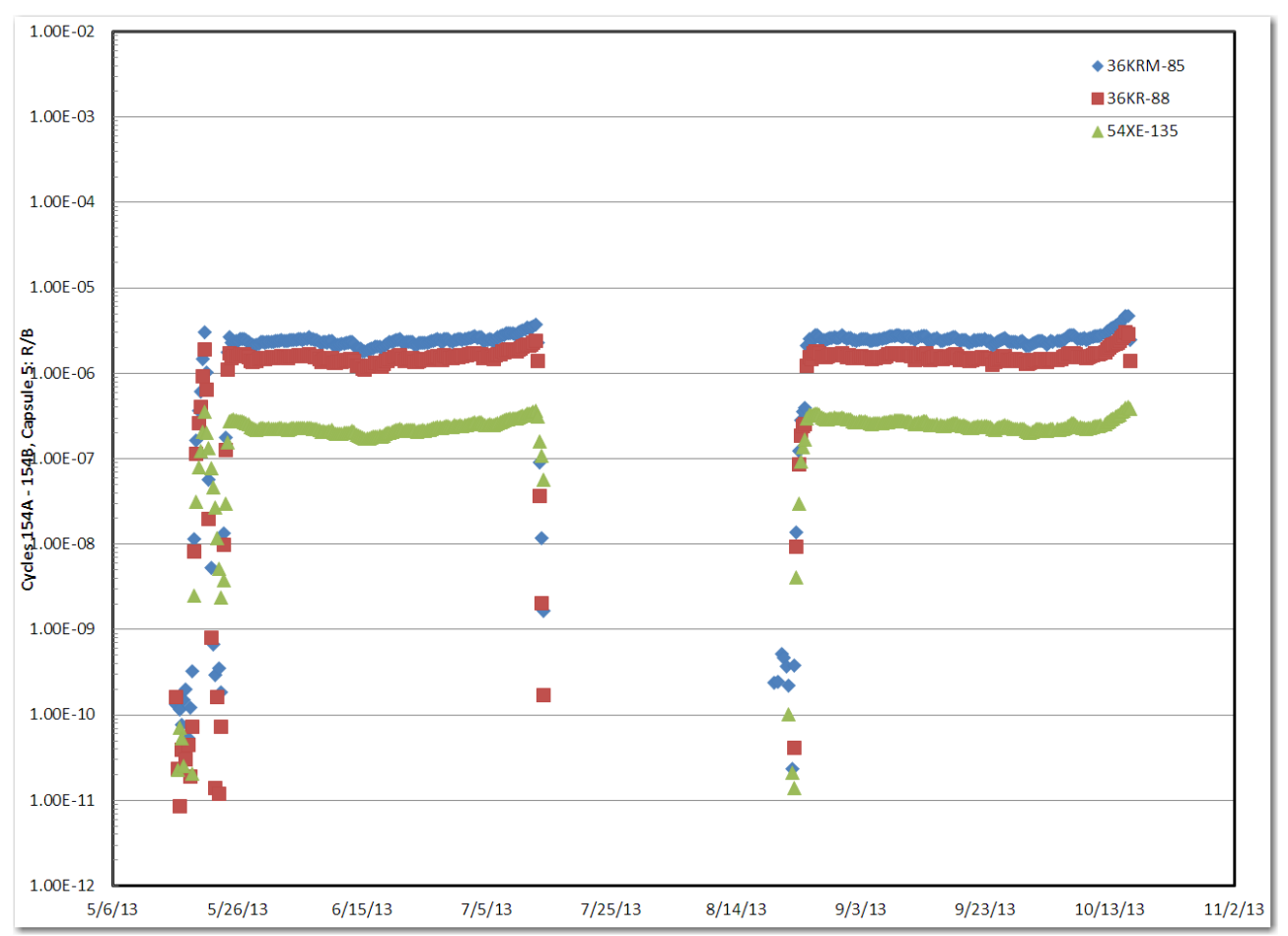

Figure 79. Cycle 154A and 154B, Capsule 5 R/B ratios Kr-85m, Kr-88, and Xe-135.

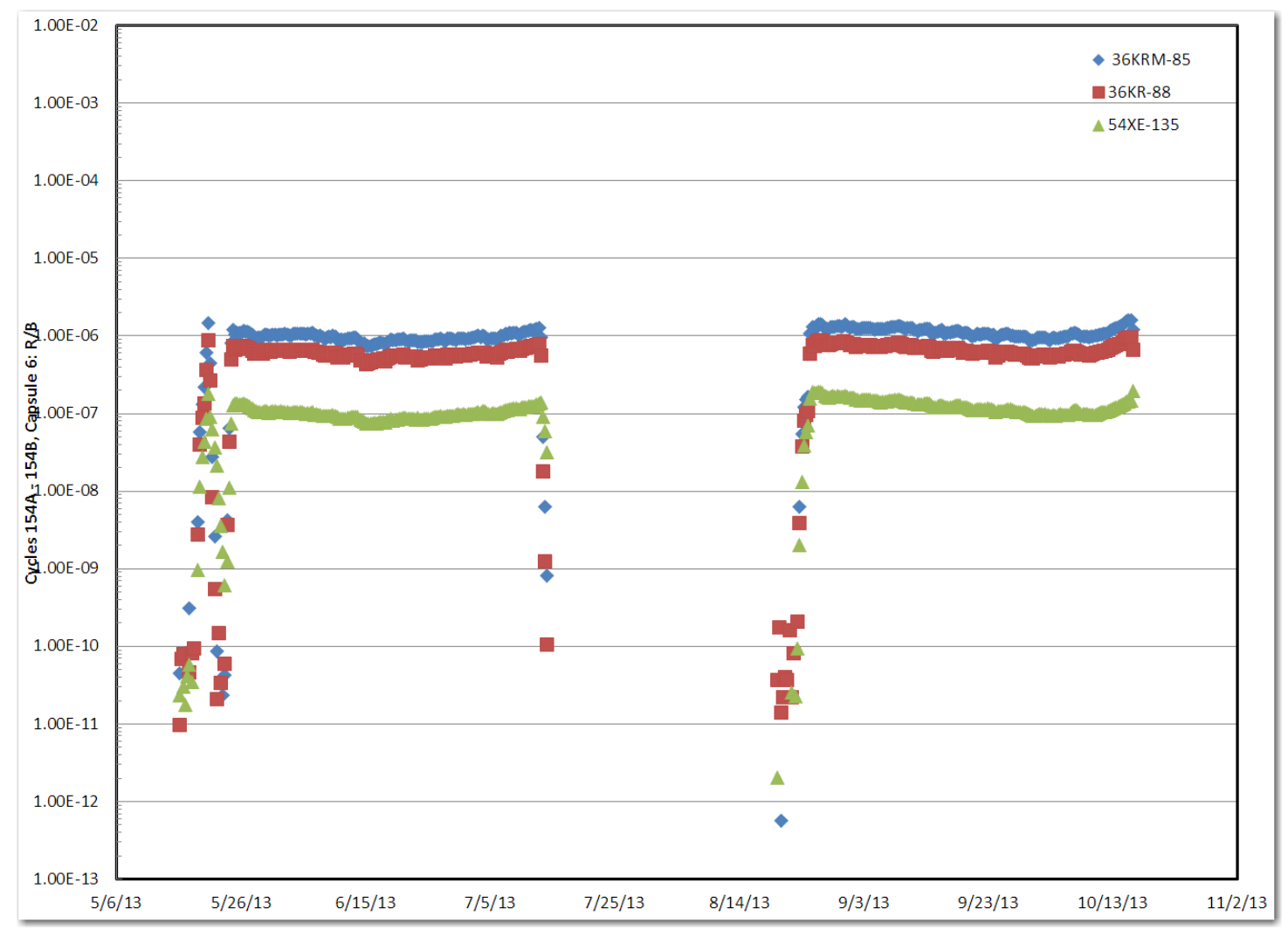

Figure 80. Cycle 154A and 154B, Capsule 6 R/B ratios Kr-85m, Kr-88, and Xe-135. 
TEM-10200-1

$03 / 01 / 2012$

ENGINEERING CALCULATIONS AND ANALYSIS

Page 65 of 73

Rev. 06

Title: $\quad$ Release-to-Birth Ratios for AGR-2 Operating Cycles 147A through 154B

ECAR No.: 2420

Rev. No.: $0 \quad$ Project No.: $\quad 23843,23841$ Date: $03 / 04 / 2014$

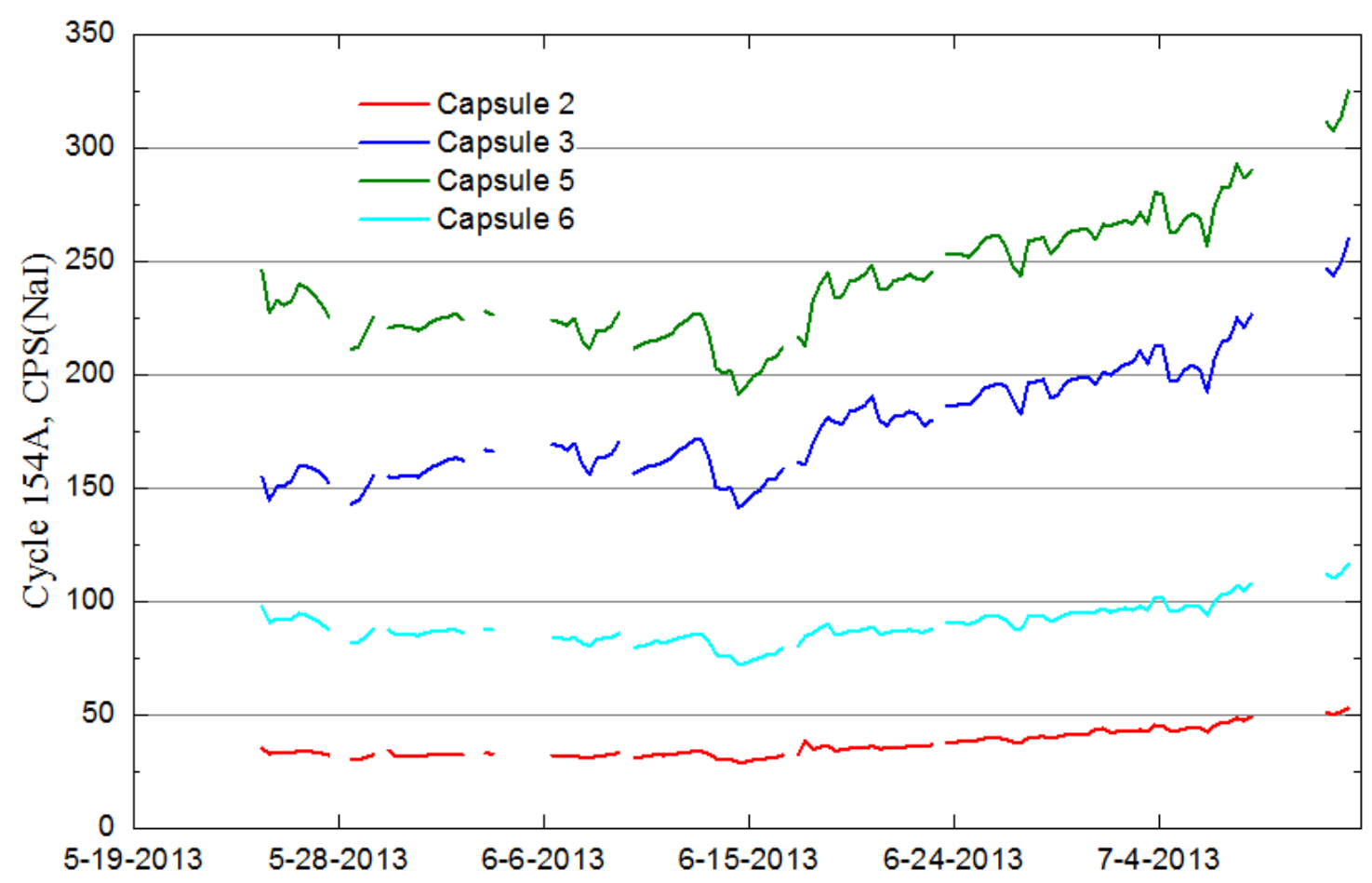

Figure 81. Gross gamma for Cycle 154A, total counts per second for Capsules 2, 3, 5, and 6.

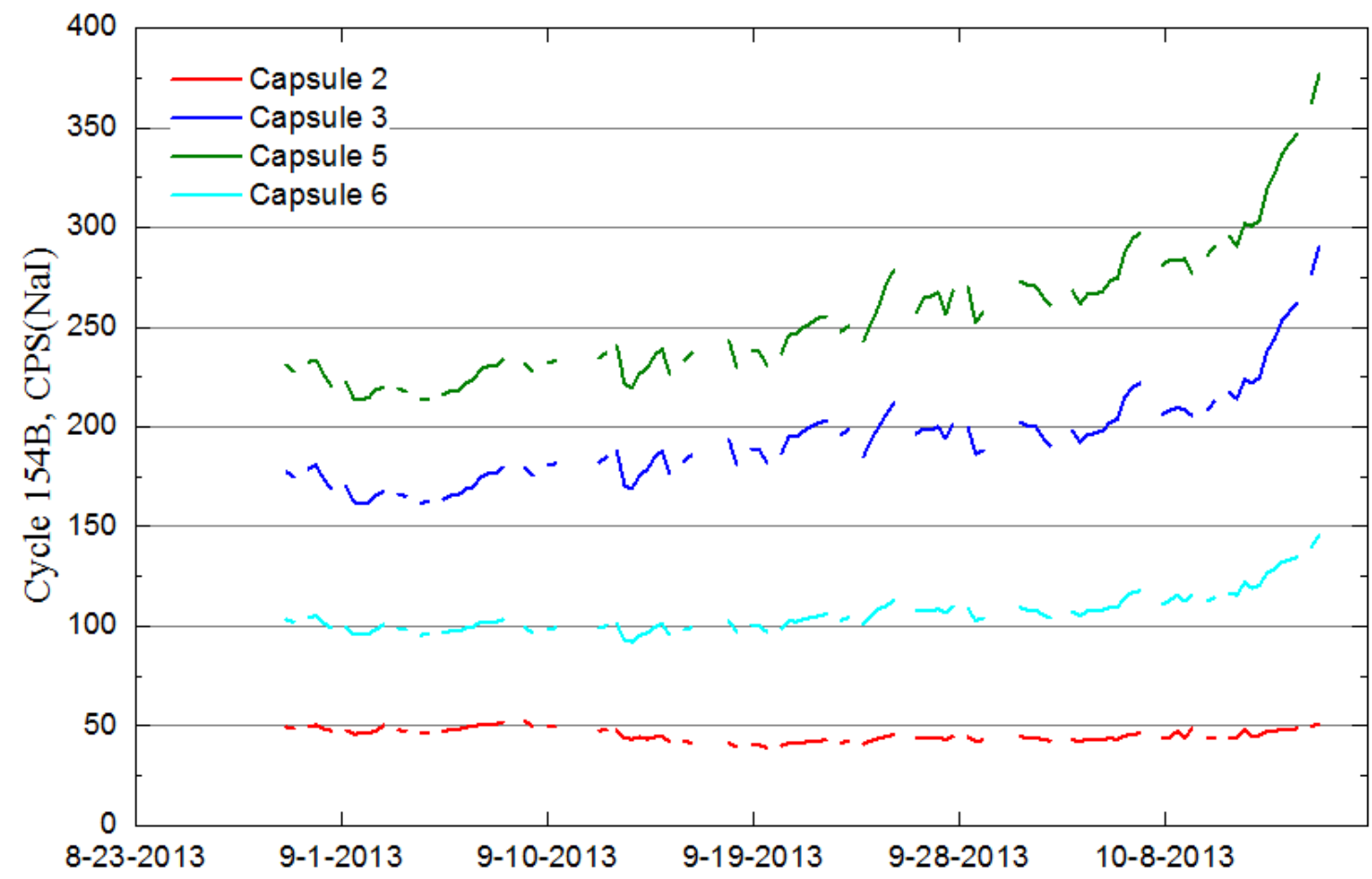

Figure 82. Gross gamma for Cycle 154B, total counts per second for Capsules 2, 3, 5, and 6. 
TEM-10200-1

$03 / 01 / 2012$

ENGINEERING CALCULATIONS AND ANALYSIS

Page 66 of 73

Rev. 06

Title:

Release-to-Birth Ratios for AGR-2 Operating Cycles 147A through 154B

ECAR No.: 2420

$\begin{array}{lll}\text { Rev. No.: } 0 & \text { Project No.: } \quad 23843,23841 \text { Date: } 03 / 04 / 2014\end{array}$

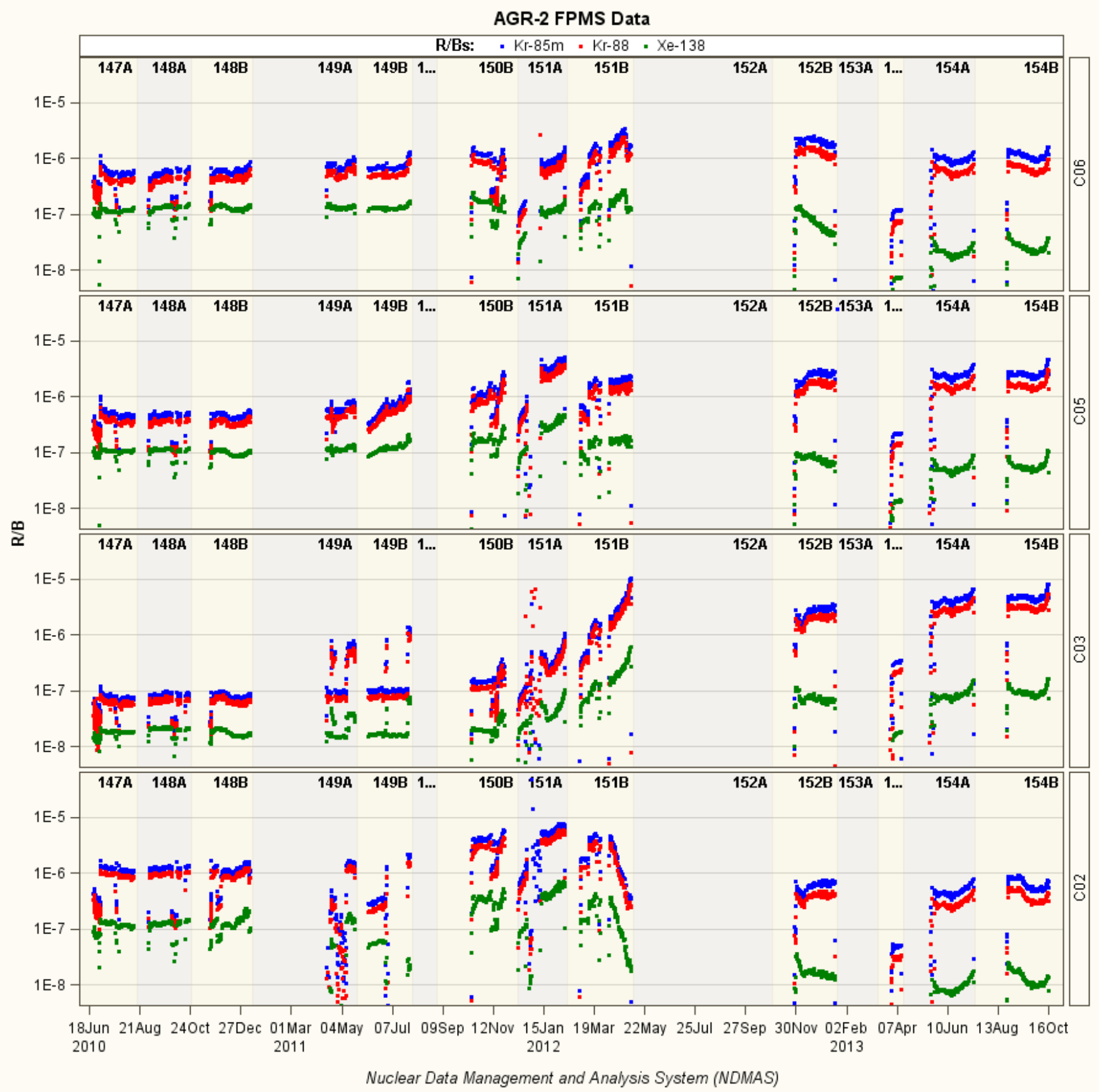

Figure 83. AGR-2 R/B from the four-point birthrates for Kr-85m, Kr-88, and Xe-138. 
TEM-10200-1

$03 / 01 / 2012$

ENGINEERING CALCULATIONS AND ANALYSIS

Page 67 of 73

Rev. 06

Title: $\quad$ Release-to-Birth Ratios for AGR-2 Operating Cycles 147A through 154B

$\begin{array}{llll}\text { ECAR No.: } 2420 & \text { Rev. No.: } 0 & \text { Project No.: } & \text { 23843, } 23841 \text { Date: } 03 / 04 / 2014\end{array}$

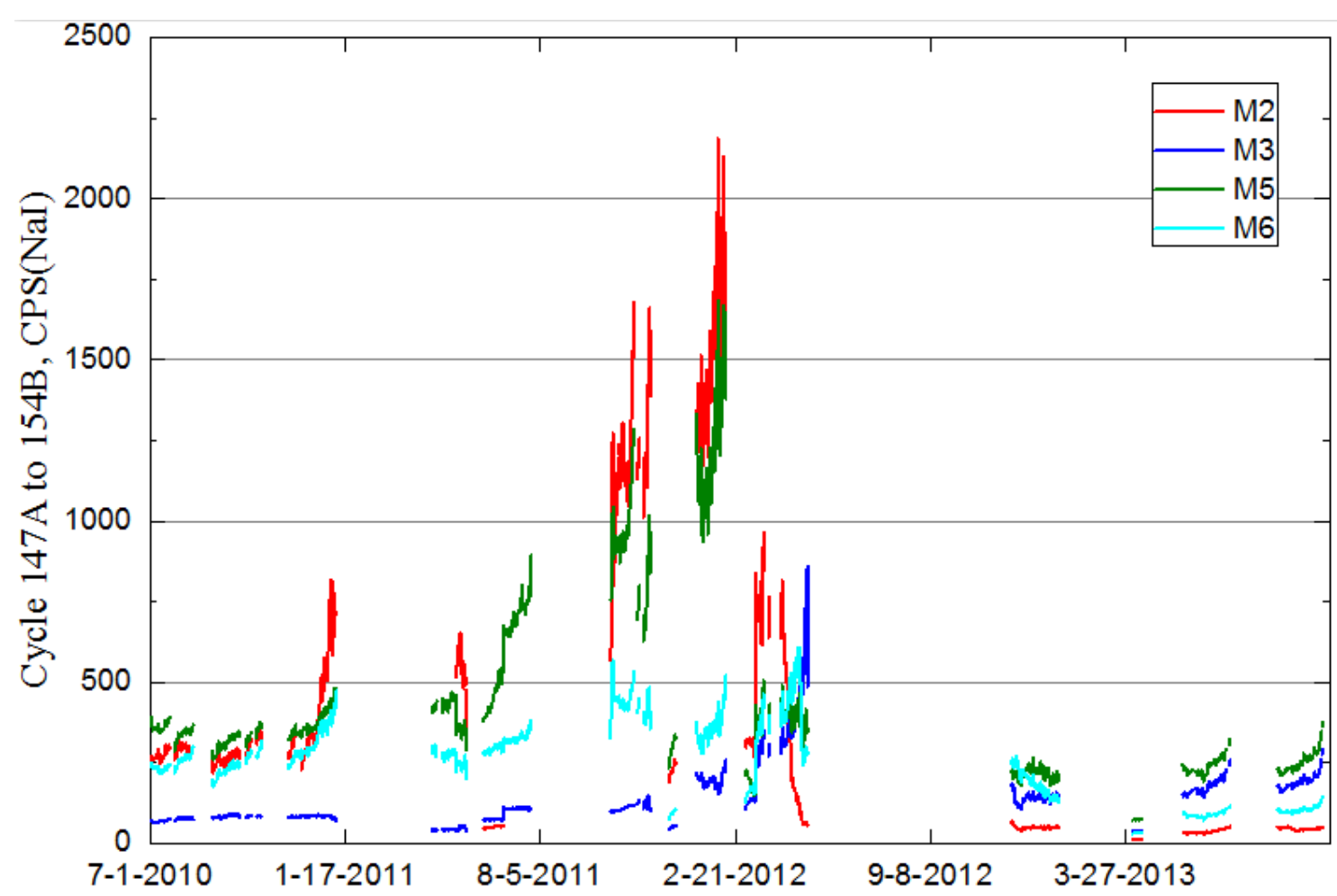

Figure 84. Gross gamma for Cycle 147A through 154B, total counts per second for Capsules 2, 3, 5, and 6.

\section{Differences in Birthrates}

Originally, birthrates for the AGR-2 experiment were computed at the end of each irradiation cycle. The provided birthrates for the beginning, two middle, and end of each cycle were interpolated by the FP_PostProc to obtain birthrates for each release activity and were used to compute the fractional release or R/B. These data supplied the experiment team with information pertaining to fuel integrity during the multiyear irradiation. At the conclusion of the AGR-2 experiment, high-resolution daily depletion calculations were performed to provide daily compact and component heat rates for highresolution thermal analyses. The daily physics analysis also increased the number of tracked fission product isotopes in the TRISO particle compacts in order to assist in post-irradiation examination measurements and to better characterize the irradiated compacts.

For the AGR-2 test, the depletion time step was changed from four time steps per interval (or 15 days per time step) to a 24-hour period (daily). Switching to a 24-hour time step enables the user to model daily changes or perturbations in core power and reactivity. The daily depletion method also generated daily reaction cross sections for the tracked actinides and fission products and compact fission powers. These values were then used to compute the birthrate of specific fission product isotopes (Table 2) for each day of irradiation. The daily depletion analysis used 590 time steps (as opposed to the four-point/interval analysis, which only used 48 steps for the entire 3-year irradiation period), thus resulting in 509,760 ORIGEN2 input files for daily birthrate computation instead of the original 82,944 ORIGEN input files [15]. 
TEM-10200-1

$03 / 01 / 2012$

ENGINEERING CALCULATIONS AND ANALYSIS

Page 68 of 73

Rev. 06

Title: $\quad$ Release-to-Birth Ratios for AGR-2 Operating Cycles 147A through 154B

ECAR No.: 2420

Rev. No.: 0

Project No:

23843, 23841 Date: 03/04/2014

Because AGR-2 was a multicapsule experiment, the percent differences between the four-point and daily birthrates are presented in Table 3, which shows the daily birthrates for the entire AGR-2 experiment, averaging $7 \%$ lower than the original four-point birthrates. Figures $85-88$ graphically illustrate the difference between the 4-point and the daily birth method for computed R/B values for $\mathrm{Kr}$ $85 \mathrm{~m}$.

Table 3. AGR-2 birthrate percent difference capturing the variation between the four-point and daily birthrate values.

\section{AGR-2}

Birthrate Percent Difference

\section{Capsule 1}

Capsule 2

Capsule 3

Capsule 4

Capsule 5

Capsule 6

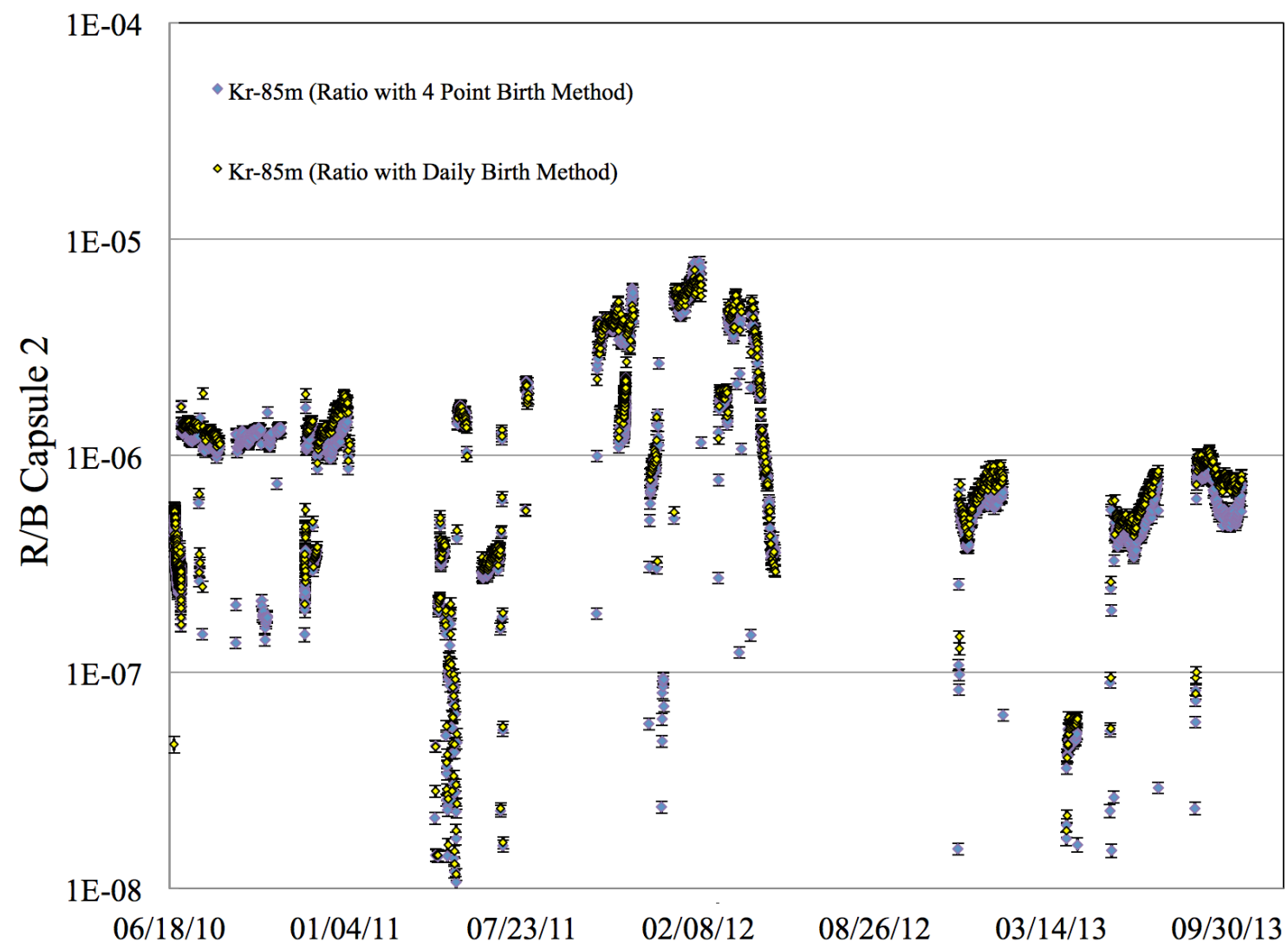

Figure 85. The R/B values for $\mathrm{Kr}-85 \mathrm{~m}$, showing the differences of the ratio using the four-point and daily depletion calculational birthrate method for Capsule 2. 
TEM-10200-1

$03 / 01 / 2012$

ENGINEERING CALCULATIONS AND ANALYSIS

Page 69 of 73

Rev. 06

Title: $\quad$ Release-to-Birth Ratios for AGR-2 Operating Cycles 147A through 154B

ECAR No.: 2420

Rev. No.: 0

Project No::

23843, 23841 Date: 03/04/2014

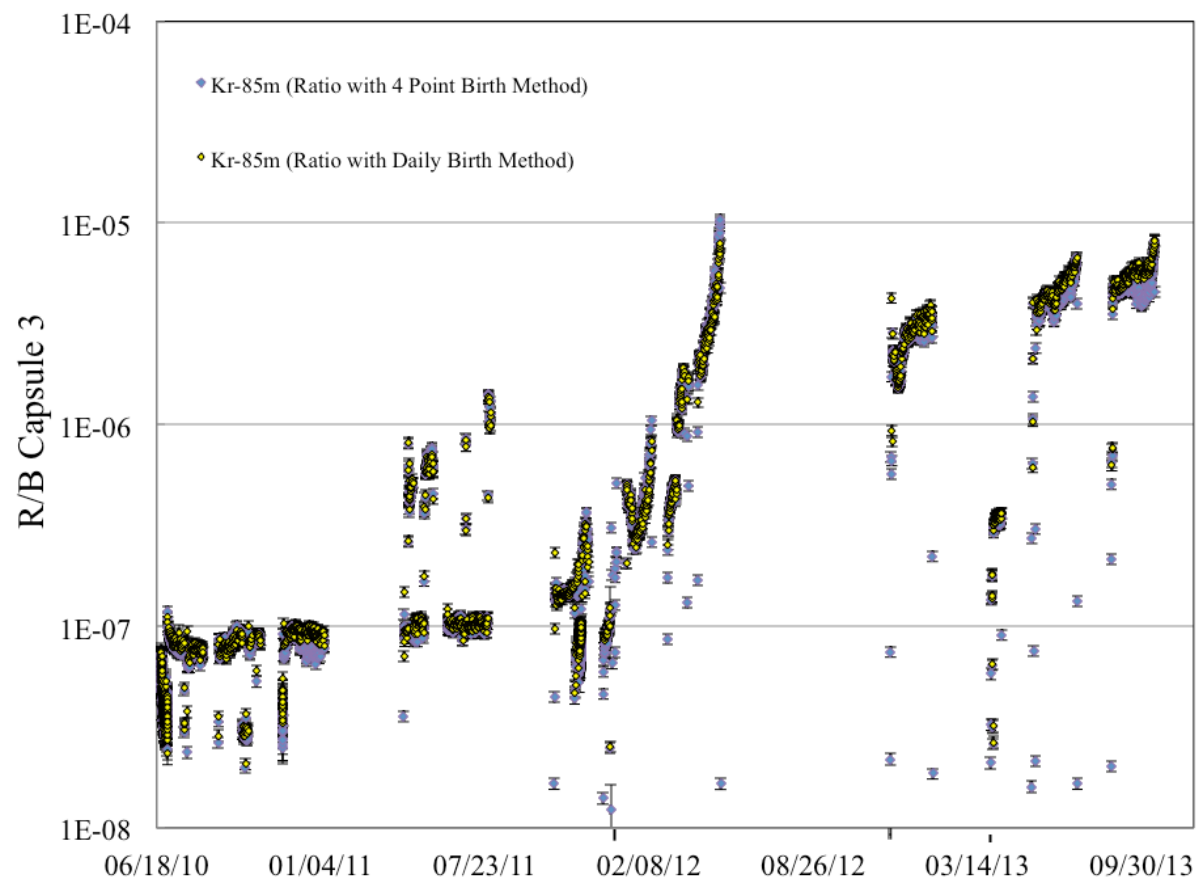

Figure 86. The R/B values for $\mathrm{Kr}-85 \mathrm{~m}$, showing the differences of the ratio using the four-point and the daily depletion calculational birthrate method for Capsule 3.

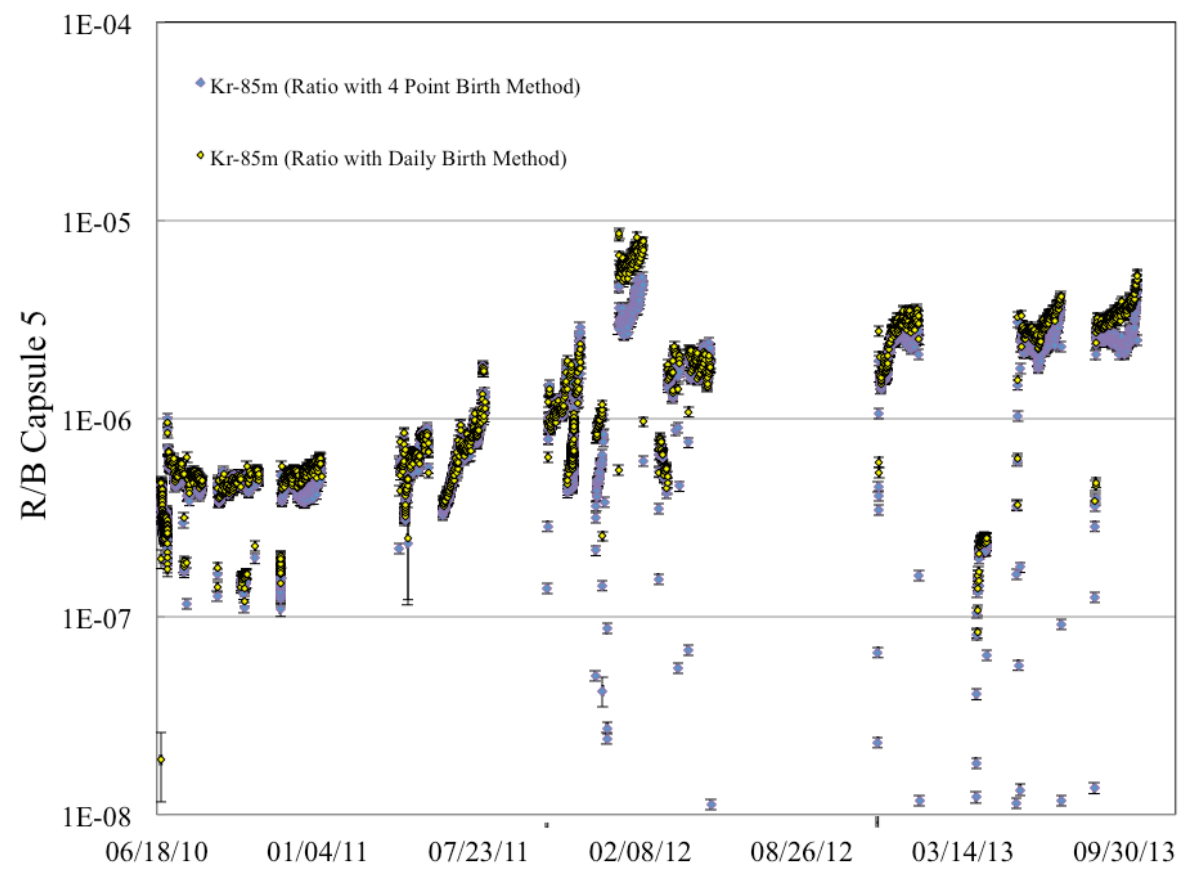

Figure 87. The R/B values for $\mathrm{Kr}-85 \mathrm{~m}$, showing the differences of the ratio using the four-point and the daily depletion calculational birthrate method for Capsule 5. 
TEM-10200-1

$03 / 01 / 2012$

ENGINEERING CALCULATIONS AND ANALYSIS

Page 70 of 73

Rev. 06

Title: $\quad$ Release-to-Birth Ratios for AGR-2 Operating Cycles 147A through 154B

$\begin{array}{lllll}\text { ECAR No.: } 2420 & \text { Rev. No.: } 0 & \text { Project No.: } & 23843,23841 \text { Date: } & 03 / 04 / 2014\end{array}$

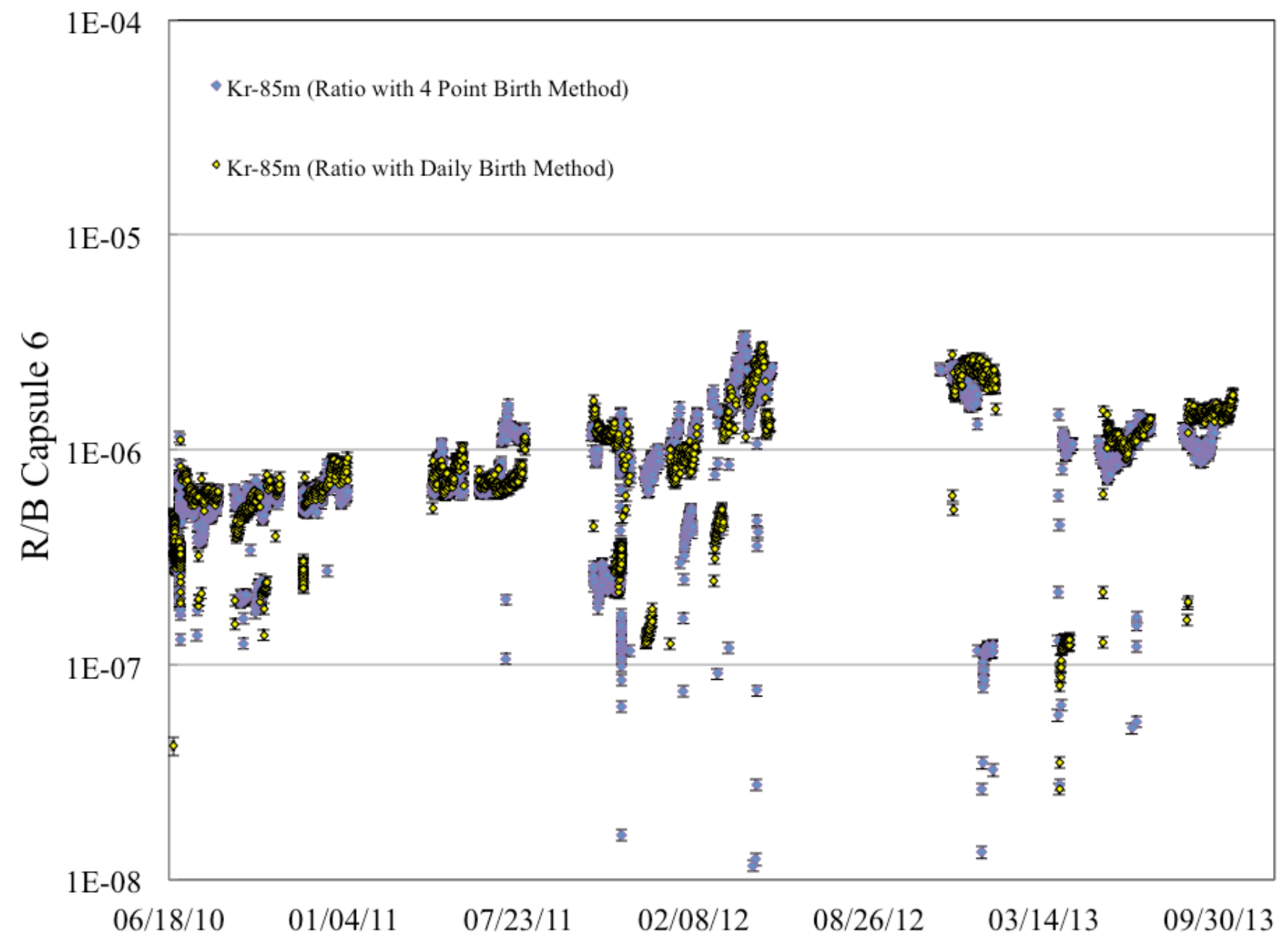

Figure 88. The R/B values for $\mathrm{Kr}-85 \mathrm{~m}$, showing the differences of the ratio using the four-point and the daily depletion calculational birthrate method for Capsule 6.

The raw data that were used to generate the R/B plots for this report are uploaded to the NDMAS database for qualified data usage. Once FPMS technical staff have reviewed the generated data, the NDMAS team pulls the data from the FSISC1 server location [IlisasapplNgnp_agr2_fpms IRB_Ratiosl]. A detailed description of the NDMAS capture process can be found in the following INL reports: $A G R-2$ Data Qualification Report for ATR Cycles 147A, 148A, 148B, and 149A (INL/EXT-11-22798), AGR-2 Data Qualification Report for ATR Cycles 149B, 150A, 150B, 151A, and 151B (INL/EXT-12-26184), AGR-2 Data Qualification Report for ATR Cycles 151B-2, 152A, 152B, 153A, 153B, and 154A (INL/EXT-13-29701), and AGR-2 Data Qualification Report for ATR Cycle 154B (INL/EXT-13-30750).

The $\mathrm{R} / \mathrm{B}$ ratios using the high-resolution daily depletion method will be the data that are used for information purposed within NDMAS and is captured in Figure 89. The four-point data will be stored within the NDMAS system and will be saved as historical information. 
TEM-10200-1

$03 / 01 / 2012$

ENGINEERING CALCULATIONS AND ANALYSIS

Page 71 of 73

Rev. 06

Title: $\quad$ Release-to-Birth Ratios for AGR-2 Operating Cycles 147A through 154B

ECAR No.: $2420 \quad$ Rev. No.: $0 \quad$ Project No.: 23843,23841 Date: $03 / 04 / 2014$

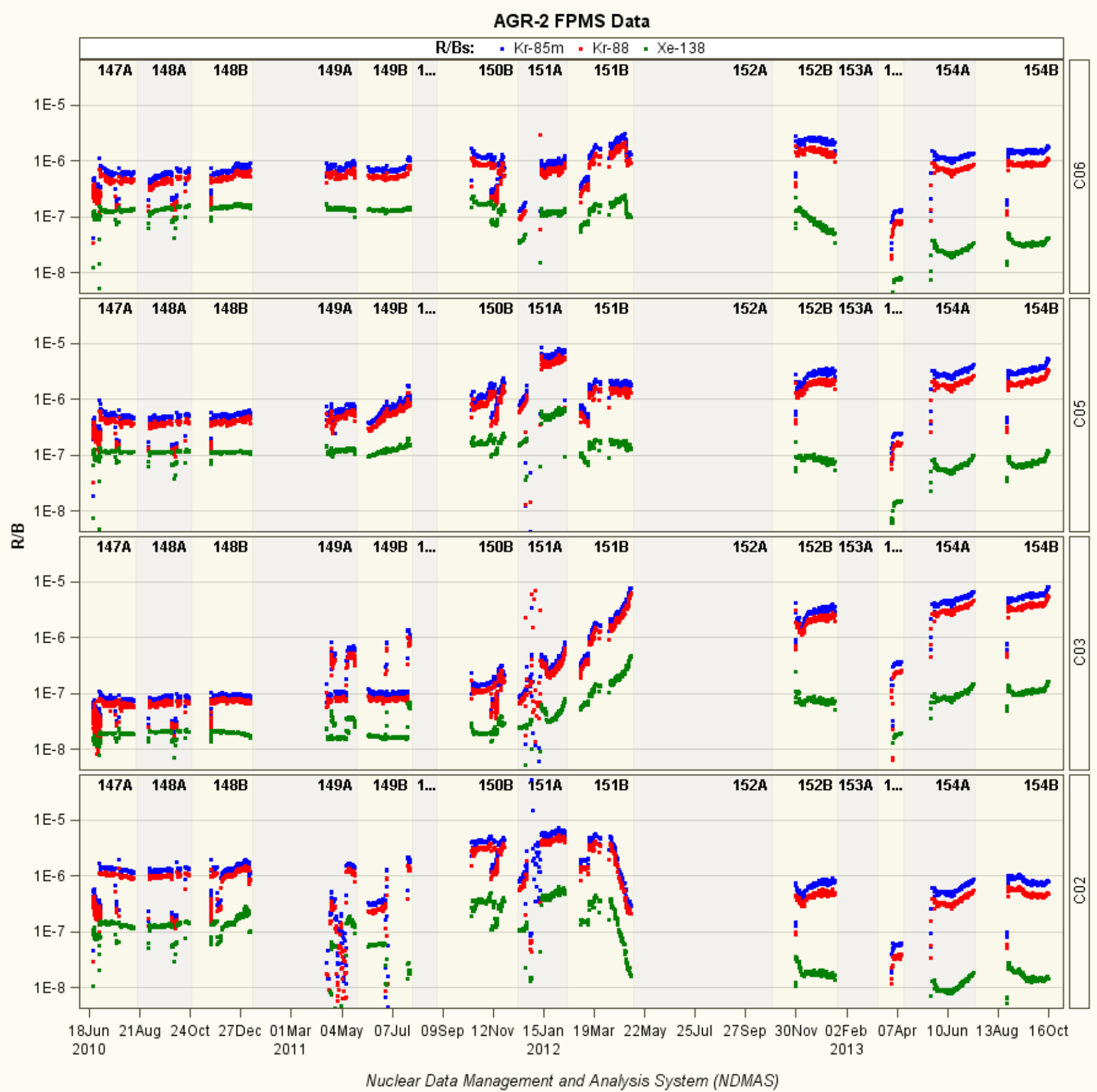

Figure 89. AGR-2 R/B from daily birthrates.

All AGR-2 cycle data from June 21, 2010, through October 17, 2013, have been reviewed for TRISO fuel failure indicators. Significant capsule gas line cross talk and leadout leakage problems started to occur early in Cycle 150B after the AGR-2 test was reinstalled back into the reactor following the 150A PALM cycle. These cross talk and leakage problems made it impossible to control the temperature in each capsule through independent gas mixture composition as designed. R/B's for cycle 151A for capsules 2 and 5 in figure 89 reflect the large amount of crosstalk and leakage problems. On January 17, 2012, (middle of Cycle 151A), AGR-2 operational staff implemented a procedure to set all capsules 
TEM-10200-1

$03 / 01 / 2012$

ENGINEERING CALCULATIONS AND ANALYSIS

Page 72 of 73

Rev. 06

Title:

Release-to-Birth Ratios for AGR-2 Operating Cycles 147A through 154B

ECAR No.: 2420

Rev. No.: 0

Project No.:

23843, 23841 Date: 03/04/2014

to the same helium/neon gas mixture ratio (neon fraction) for overall experiment temperature control [14].

For all cycles evaluated in this report, there are no indications that the FPMs failed to capture data reliably. At the end of each cycle, each FPM is put through an energy calibration test and all data were reliably verified per test plans mentioned earlier in this document. However, there is concern that the helium/neon gas flows recorded during Cycle 149A and forward may not adequately represent the gas flow mixture through their associated capsule due to relief valve failure, gas line cross talk, and capsule leakage (the data are correct but do not support application to the defined intended use); therefore, the reported values from the FPMs will serve as trending information and not as quantifiable capsule isotopic data.

\section{REFERENCES}

1. Sterbentz, J. W., "JMOCUP As-Run Daily Depletion Calculation for the AGR-1 Experiment in ATR B-10 Position,” ECAR-958,Rev 3. Idaho National Laboratory, September 3, 2013.

2. Scates, D. M., "The Effect of Birthrate Granularity on the Release- to-Birth Ratio for the Advanced Gas Reactor -1 In-Core Experiment," Nucl. Eng.Des., December 12, 2013.

3. Killian, E. W. and L. V. East, "PCGAP: Application to analyze gamma-ray pulse-height spectra on a personal computer under Window NT@," J. Radioanalytical Nucl. Chem., Vol. 233, No. 1-2, pp. 109-114, 1998.

4. Killian, E. W. and J. K. Hartwell, PCGAP: Users guide and algorithm description, INEEL/EXT-2000-00908, Idaho National Engineering and Environmental Laboratory, September 2000.

5. Hartwell, J. K. et al., Determination of the AGR-1 Capsule to FPMS Spectrometer Transport Volumes from Leadout Flow Test Data, INL/EXT-07-12494, Idaho National Laboratory, May 2007.

6. Scates, D. M., “User's Guide for the Fission Product Monitoring System," GDE-503, Idaho National Laboratory, April 16, 2009.

7. Scates, D. M., "Fission Product Monitoring System PCGAP Software Modification and Operability Test Plan," PLN-3392, Idaho National Laboratory, February 2, 2010.

8. Scates, D. M., "Fission Product Monitoring System Operability Test Plan for the AGR Experiment Series," Idaho National Laboratory, November 29, 2011.

9. Scates, D. M., "Preliminary Release-to-Birth Ratios for AGR-2 Operating Cycle 147A," ECAR-1348, Idaho National Laboratory, February 3, 2011.

10. Scates, D. M., "Preliminary Release-to-Birth Ratios for AGR-2 Operating Cycle 148A," ECAR-1355, Idaho National Laboratory, February 23, 2011.

11. Scates, D. M., "Preliminary Release-to-Birth Ratios for AGR-2 Operating Cycle 148B," ECAR-1412, Idaho National Laboratory, March 14, 2011. 
Rev. 06

Title: $\quad$ Release-to-Birth Ratios for AGR-2 Operating Cycles 147A through 154B

ECAR No.: $2420 \quad$ Rev. No.: $0 \quad$ Project No.: 23843,23841 Date: 03/04/2014

12. Scates, D. M., "Preliminary Release-to-Birth Ratios for AGR-2 Operating Cycle 149A," ECAR-1614, Idaho National Laboratory, September 8, 2011.

13. Scates, D. M., "Preliminary Release-to-Birth Ratios for AGR-2 Operating Cycle 149B", ECAR-1724, Idaho National Laboratory, March 14, 2011.

14. Abott, M. L., AGR-2 Data Qualification Report for ATR Cycles 149B, 150A, 150B, 151A and 151B, INL/EXT-12-26184, Idaho National Laboratory.

15. Parry, J. R., E-Mail - AGR-2 Daily Birth Rates, December 9, 2013. 
TEM-10200-1

$03 / 01 / 2012$

ENGINEERING CALCULATIONS AND ANALYSIS

Page $\mathrm{A} 1$ of $\mathrm{A} 2$

Rev. 06

Title: $\quad$ Release-to-Birth Ratios for AGR-2 Operating Cycles 147A-154B

ECAR No.: 2420

Rev. No.: 0

Project No:

23843; 23841 Date: 03/04/2014

\section{Appendix A}

\section{FP_PostProc Constants Text File}

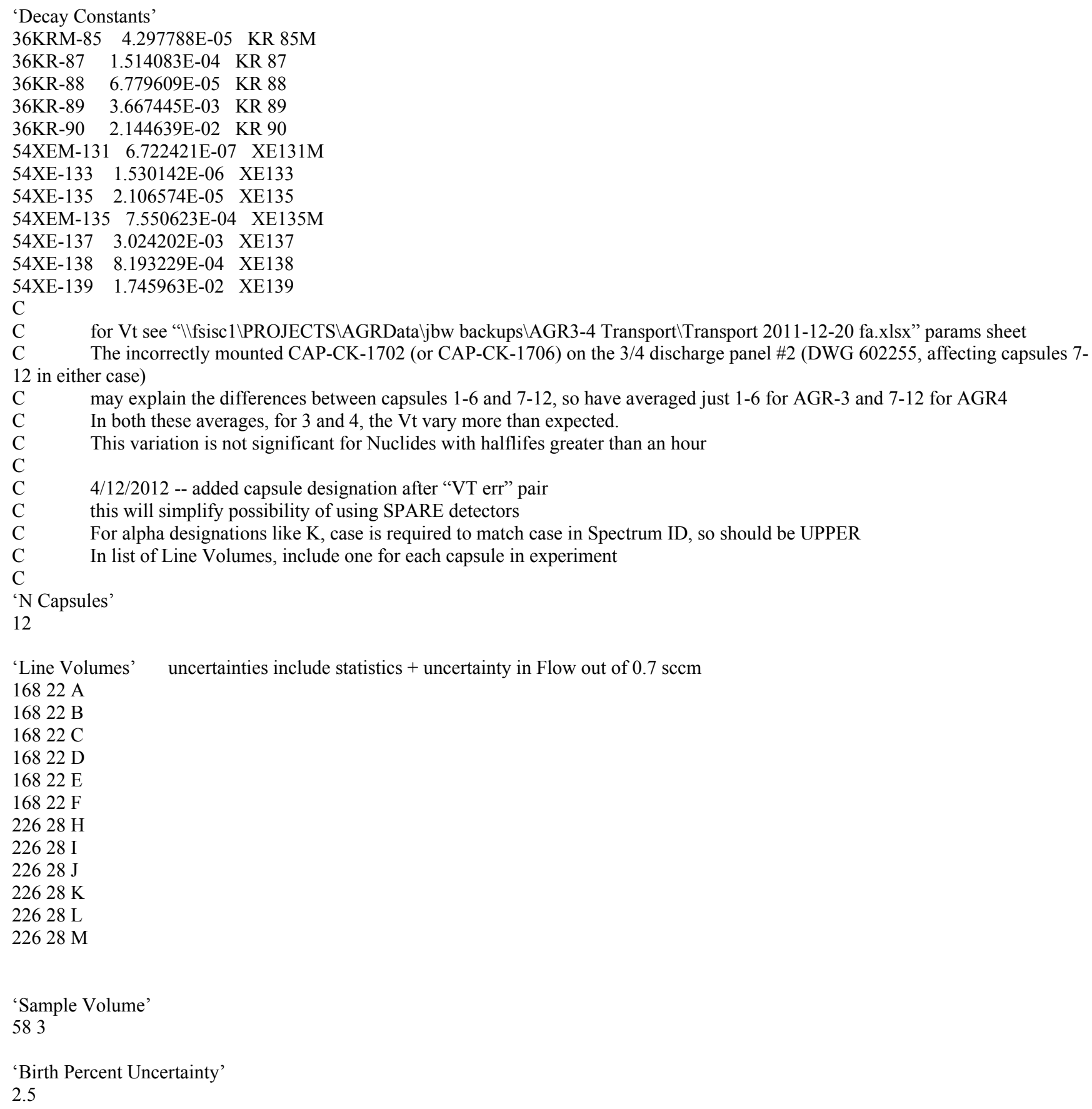


TEM-10200-1

$03 / 01 / 2012$

ENGINEERING CALCULATIONS AND ANALYSIS

Page $\mathrm{A} 2$ of $\mathrm{A} 2$

Rev. 06

Title: $\quad$ Release-to-Birth Ratios for AGR-2 Operating Cycles 147A-154B

ECAR No.: 2420

Rev. No.: 0

Project No.:

23843; 23841 Date: 03/04/2014

AGR-2 VT.TXT

$\mathrm{C}$

C 4/12/2012 -- Added 'Experiment' to get description, like 'AGR-1' for FP-PostProc

$\mathrm{C} \quad$ Also added ' $\mathrm{N}$ Capsules' to declare number of capsules in experiment

C adding capsule designation after "VT err" pair for each capsule

$\mathrm{C}$

C 4/13/2012 -- extracted transport volumes from constants.txt

$\mathrm{C}$ to be read from an experiment specific Transport Volume text file

$\mathrm{C}$

C this will simplify possibility of using SPARE detectors

C For alpha designations like K, case is required to match case in Spectrum ID, so should be UPPER

C In list of Line Volumes, include one for each capsule in experiment

$\mathrm{C}$

C for Vt see "AGR2-trans 2010-11-18.xlsx" params sheet

$\mathrm{C}$

'Experiment'

'AGR-2'

'N Capsules'

6

'Line Volumes' uncertainties include statistics + uncertainty in Flow out of $0.7 \mathrm{sccm}$

13691

12782

12683

13284

12965

13496 
TEM-10200-1

$03 / 01 / 2012$

ENGINEERING CALCULATIONS AND ANALYSIS

Page B1 of B1

Rev. 06

Title: $\quad$ Release-to-Birth Ratios for AGR-2 Operating Cycles 147A-154B

ECAR No.: 2420

Rev. No.: 0

Project No.:

23843; 23841 Date: 03/04/2014

\section{Appendix B}

\section{Sample Flow Data}

The FP_PostProc system uses AGR-2 cycle-dependent, five-minute outlet flow data. These data are transferred from the ATR DCS system to the NDMAS system. FPMS support staff queries the outlet flow data for a period of time and then exports the data set to a .csv file. This .csv file is then opened and a "count" column is added as shown below (column A and the source date and standard date/time are formatted as follows: ddMMMyyyy:hh:mm:ss).

\begin{tabular}{|c|c|c|c|c|c|c|c|c|c|}
\hline 4 & A & B & C & D & E & $\mathrm{F}$ & G & H & 1 \\
\hline 1 & & Source Date Time & Standard Date Time & Capsule 1 & Capsule 2 & Capsule 3 & Capsule 4 & Capsule 5 & Capsule 6 \\
\hline 2 & & 06Jun2011:09:05 & 06Jun2011:08:05 & 30.32639 & 30.79244 & 28.48739 & 28.73461 & 32.38785 & 28.92918 \\
\hline 3 & & 06Jun2011:09:10 & 06Jun2011:08:10 & 30.5202 & 30.81034 & 28.48739 & 28.73461 & 32.5789 & 28.92918 \\
\hline 4 & & 06Jun2011:09:15 & 06Jun2011:08:15 & 0.69552 & 30.81668 & 28.48739 & 28.73461 & 32.76799 & 28.92918 \\
\hline 5 & & 06Jun2011:09:20 & 06Jun2011:08:20 & 30.78942 & 30.82315 & 28.48739 & 28.73762 & 32.86717 & 28.94028 \\
\hline 6 & & 06Jun2011:09:25 & 06Jun2011:08:25 & 30.89933 & 30.84076 & 28.48739 & 28.83531 & 32.95744 & 28.96642 \\
\hline 7 & & 06Jun2011:09:30 & 06Jun2011:08:30 & 30.96645 & 30.82863 & 28.48739 & 28.83531 & 33.0495 & 29.00928 \\
\hline 8 & & 06Jun2011:09:35 & 06Jun2011:08:35 & 30.96645 & 30.83855 & 28.48739 & 28.83531 & 33.0495 & 29.00928 \\
\hline 9 & & 06Jun2011:09:40 & 06Jun2011:08:40 & 30.96645 & 30.83393 & 28.54635 & 28.83531 & 33.06537 & 28.99904 \\
\hline 10 & & 06Jun2011:09:45 & 06Jun2011:08:45 & 30.96645 & 30.84291 & 28.58809 & 28.83531 & 33.07242 & 29.00558 \\
\hline 11 & 10 & 06Jun2011:09:50 & 06Jun2011:08:50 & 30.96645 & 30.84959 & 28.58809 & 28.83531 & 33.07242 & 29.00681 \\
\hline 12 & 11 & 06Jun2011:09:55 & 06Jun2011:08:55 & 0.96645 & 30.85083 & 28.58809 & 28.83531 & 33.07242 & 29.007 \\
\hline 13 & 12 & 06Jun2011:10:00 & 06Jun2011:09:00 & 30.96645 & 30.84141 & 28.58809 & 28.83531 & 33.07242 & 29.007 \\
\hline 14 & 13 & 06Jun2011:10:05 & 06Jun2011:09:05 & 30.95271 & 30.85901 & 28.53317 & 28.79183 & 33.02146 & 29.00172 \\
\hline 15 & 14 & 06Jun2011:10:10 & 06Jun2011:09:10 & 95271 & 30.86625 & 28.53317 & 28.79183 & 33.12733 & 29.02131 \\
\hline 16 & 15 & 06Jun2011:10:15 & 06Jun2011:09:15 & 30.95271 & 30.87176 & 28.53317 & 28.79183 & 33.12733 & 28.99783 \\
\hline 17 & 16 & 06Jun2011:10:20 & 06Jun2011:09:20 & 30.95271 & 30.86196 & 28.53317 & 28.79183 & 33.12733 & 29.0101 \\
\hline 18 & 17 & 06Jun2011:10:25 & 06Jun2011:09:25 & 30.95271 & 30.86539 & 28.53317 & 28.79183 & 33.12733 & 29.0276 \\
\hline 19 & 18 & 06Jun2011:10:30 & 06Jun2011:09:30 & .95271 & 30.86423 & 28.53317 & 28.79183 & 33.12733 & 29.0276 \\
\hline 20 & 19 & 06Jun2011:10:35 & 06Jun2011:09:35 & 30.90728 & 30.85479 & 28.53317 & 28.79183 & 33.02422 & 29.0276 \\
\hline 21 & 20 & 06Jun2011:10:40 & 06Jun2011:09:40 & 30.65713 & 30.84032 & 28.53317 & 28.79183 & 32.74365 & 29.0276 \\
\hline 22 & 21 & 06Jun2011:10:4 & 06Junn2011:09:45 & 30.49034 & 30.83619 & 28.53317 & 28.79183 & 32.53872 & 9.0276 \\
\hline 23 & 22 & 06Jun2011:10:50 & 06Jun2011:09:50 & 49034 & 30.83665 & 28.53317 & 28.79 & 32.52974 & 29.0276 \\
\hline 24 & 23 & 06Jun2011:10:55 & 06Jun2011:09:55 & 30.61287 & 30.84423 & 28.53317 & 28.79183 & 32.69349 & 28.99242 \\
\hline 25 & 24 & 06Jun2011:11:00 & 06Jun2011:10:00 & 30.72248 & 30.84873 & 28.53317 & 28.79183 & 32.82247 & 29.04799 \\
\hline 26 & 25 & 06Jun2011:11:05 & 06Jun2011:10:05 & 30.8291 & 30.85505 & 28.57895 & 28.82388 & 32.90179 & 29.00014 \\
\hline 27 & 26 & 06Jun2011:11:10 & 06Jun2011:10:10 & .89738 & 30.87145 & 28.57895 & 28.82388 & 33.01056 & 28.99651 \\
\hline 28 & 27 & 06Jun2011:11:15 & 06Jun2011:10:15 & 93438 & 30.88559 & 28.57895 & 28.82388 & 33.05049 & 29.01807 \\
\hline 29 & 28 & 06Jun2011:11:20 & 06Jun2011:10:20 & 30.95824 & 31.00365 & 28.6797 & 28.90912 & 33.14249 & 29.1024 \\
\hline 30 & 29 & 06Jun2011:11:25 & 06Jun2011:10:25 & 31.06717 & 30.88191 & 28.61352 & 28.8262 & 33.2234 & 29.03453 \\
\hline 31 & 30 & 06Jun2011:11:30 & 06Jun2011:10:30 & 31.06717 & 30.87967 & 28.57211 & 28.8262 & 33.33335 & 29.03568 \\
\hline 32 & 31 & 06Jun2011:11:35 & 06Jun2011:10:35 & 31.06717 & 30.88356 & 28.57211 & 28.8262 & 33.33335 & 29.03908 \\
\hline 33 & 32 & 06Jun2011:11:40 & 06Jun2011:10:40 & 1.06717 & 30.87641 & 28.57211 & 28.8262 & 33.33335 & 29.03178 \\
\hline 34 & 33 & 06Jun2011:11:45 & 06Jun2011:10:45 & 31.06717 & 30.89087 & 28.57211 & 28.8262 & 33.32095 & 29.03556 \\
\hline 35 & 34 & 06Jun2011:11:50 & 06Jun2011:10:50 & 31.06717 & 30.88523 & 28.57211 & 28.8262 & 33.23264 & 29.03917 \\
\hline 36 & 35 & 06Jun2011:11:55 & 06Jun2011:10:55 & 0.9676 & 30.8869 & 28.57211 & 28.8262 & 33.14323 & 29.05281 \\
\hline 37 & 36 & 06Jun2011:12:00 & 06Jun2011:11:00 & .71761 & 30.86338 & 28.57211 & 28.8262 & 32.89545 & 29.06159 \\
\hline 38 & 37 & 06Jun2011:12:05 & 06Jun2011:11:05 & 30.53089 & 30.84564 & 28.54004 & 28.79183 & 32.67186 & 29.06423 \\
\hline 39 & 38 & 06Jun2011:12:10 & 06Jun2011:11:10 & 30.33731 & 30.84371 & 28.54004 & 28.79183 & 32.45321 & 29.06264 \\
\hline 40 & 39 & 06Jun2011:12:15 & 06Jun2011:11:15 & 30.26145 & 30.83186 & 28.54004 & 28.79183 & 32.33144 & 29.06652 \\
\hline 41 & 40 & 06Jun2011:12:20 & 06Jun2011:11:20 & 26145 & 30.83458 & 28.54004 & 28.79183 & 32.29182 & 29.06652 \\
\hline 42 & 41 & 06Jun2011:12:25 & 06Jun2011:11:25 & 30.26145 & 30.82484 & 28.54004 & 28.79183 & 32.29182 & 29.05966 \\
\hline 43 & 42 & 06Jun2011:12:30 & 06Jun2011:11:30 & 30.21684 & 30.83288 & 28.54004 & 28.79183 & 32.32087 & 29.06652 \\
\hline
\end{tabular}


TEM-10200-1

$03 / 01 / 2012$

ENGINEERING CALCULATIONS AND ANALYSIS

Page C1 of C2

Rev. 06

Title: $\quad$ Release-to-Birth Ratios for AGR-2 Operating Cycles 147A-154B

ECAR No.: 2420

Rev. No.: 0

Project No.:

23843; 23841 Date: 03/04/2014

\section{Appendix C}

\section{Sample Input Birthrate Files}

\section{Four-Point Birthrate Files}

In the following sample birthrate file, the reactor reached full power on May 19, 2013, at 14:24:00. Nf is when the reactor reaches full power and is the start date of the R/B calculations. The birthrates are calculated at four time periods (i.e., Day 0.0, Day 17.0, Day 34.0, and Day 52.3) and correlate the effective full power days to calendar days by using the reactor scram date input data at the top of this birthrate file. The FP_PostProc software interpolates the data between these times to generate data for every 8-hour data acquisition period. One birthrate file contains all isotopic information for all six capsules.

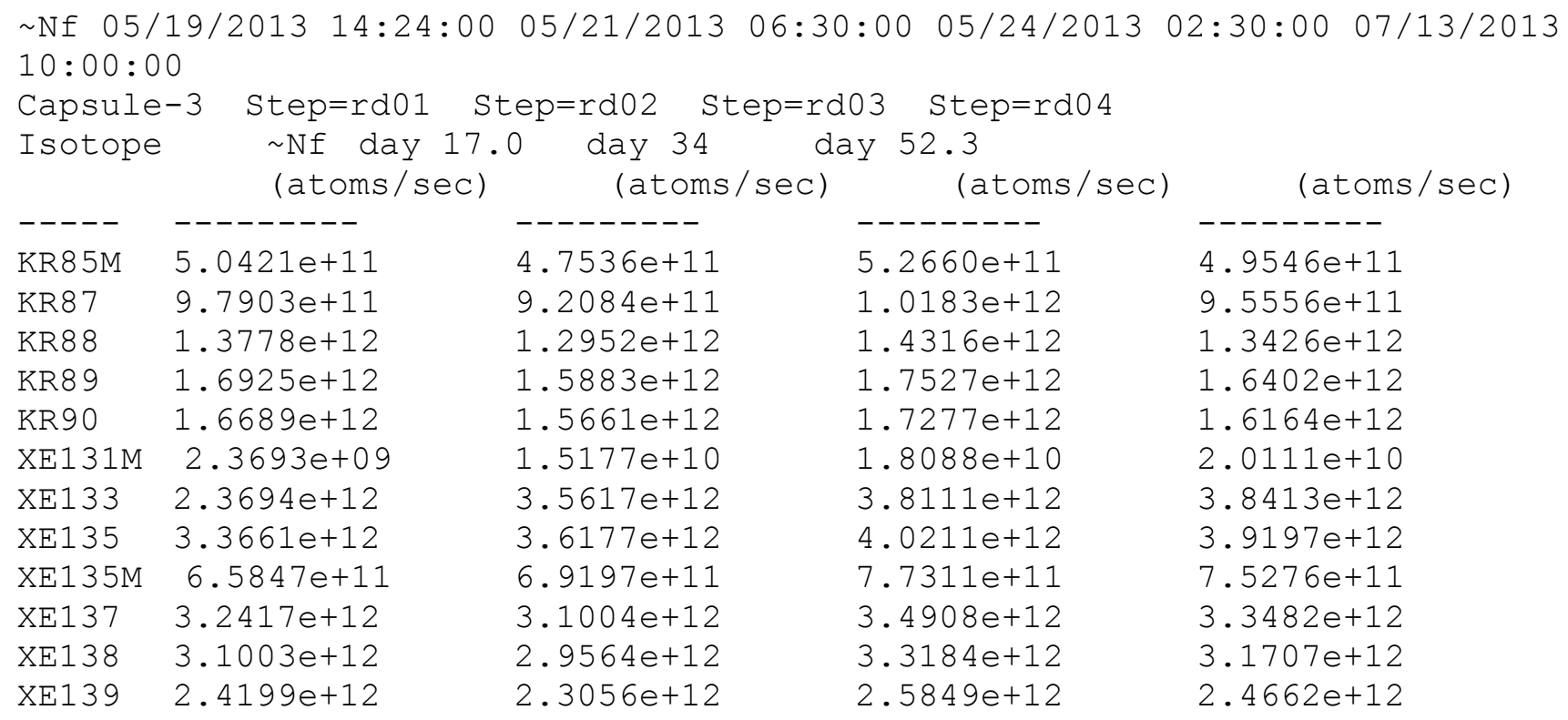


TEM-10200-1

$03 / 01 / 2012$

ENGINEERING CALCULATIONS AND ANALYSIS

Page $\mathrm{C} 2$ of $\mathrm{C} 2$

Rev. 06

Title: $\quad$ Release-to-Birth Ratios for AGR-2 Operating Cycles 147A-154B

ECAR No.: 2420

Rev. No.: 0

Project No.:

23843; 23841 Date: 03/04/2014

\section{Daily Depletion Birthrate File}

In the sample birthrate file below, $\sim \mathrm{Nf}$ is when the reactor reaches full power and is the start date of the $\mathrm{R} / \mathrm{B}$ calculations. The birthrates are calculated for each day the reactor is at full power and correlate the effective full power days to calendar days by using the reactor scram date input data at the top of this birthrate file. The FP_PostProc software interpolates the data between these times to generate data for every 8-hour data acquisition period. One birthrate file contains all isotopic information for all six capsules.

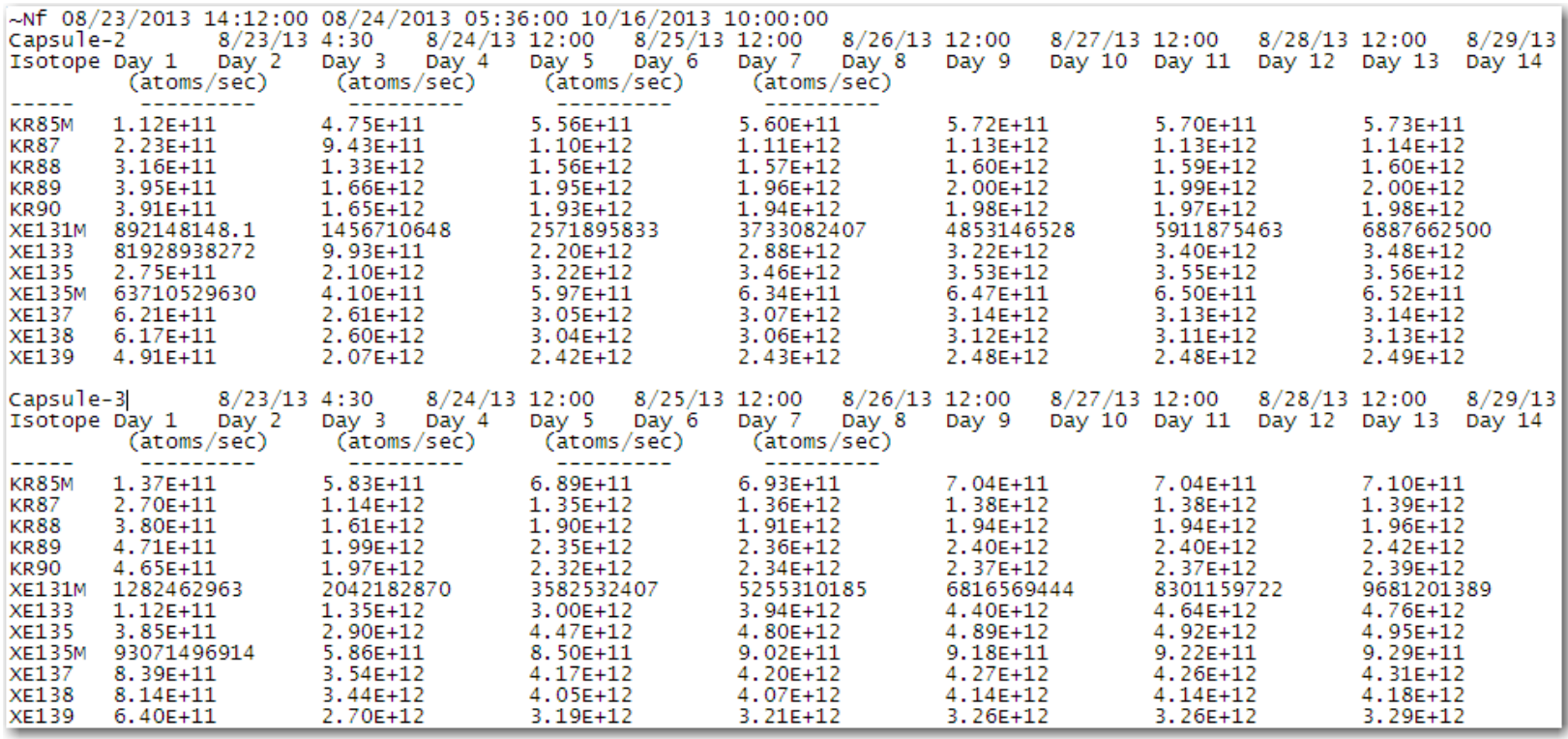


TEM-10200-1

$03 / 01 / 2012$

ENGINEERING CALCULATIONS AND ANALYSIS

Page D1 of D1

Rev. 06

Title: $\quad$ Release-to-Birth Ratios for AGR-2 Operating Cycles 147A-154B

ECAR No.: 2420

Rev. No.: 0

Project No::

23843; 23841 Date: 03/04/2014

\section{Appendix D}

\section{Sample FP_PostProc Output Files}

The FP_PostProc software takes the input files mentioned in Appendices $A$ through $C$ and calculates the following three output .csv files. Once these data are reviewed by the FPM team, the data are sent to the NDMAS server for processing.

Sample R/B Ratio Output File:

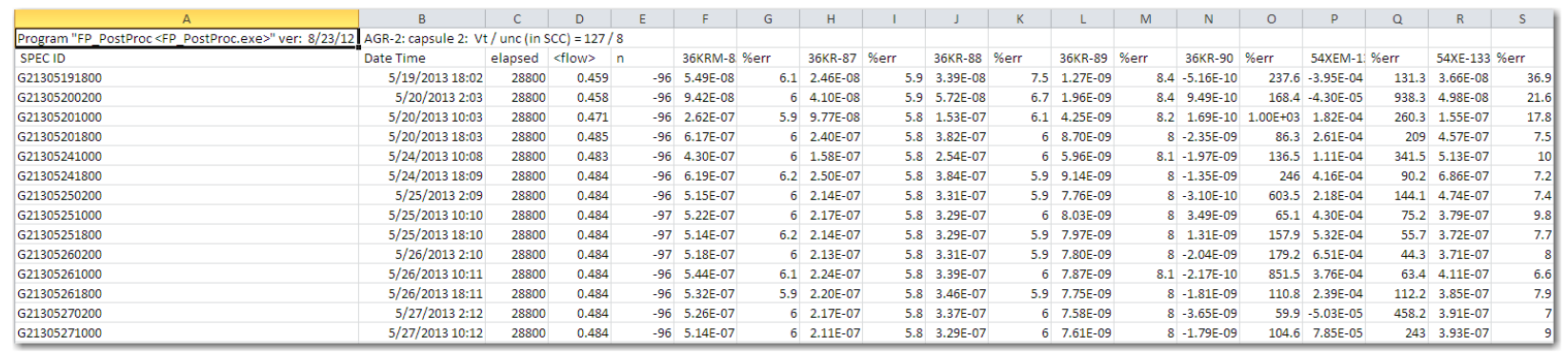

Sample Release Activity File Output File:

\begin{tabular}{|c|c|c|c|c|c|c|c|c|c|c|c|c|c|c|c|c|c|c|}
\hline A & B & c & D & E & $\mathrm{F}$ & G & H & 1 & $J$ & k & L & M & $\mathrm{N}$ & 0 & p & Q & R & $s$ \\
\hline stProc $<$ & R-2: capsule 2: & t/ unc li & in $\mathrm{SCC}$ = 12 & $17 / 8$ & & & & & & & & & & & & & & \\
\hline SPECID & Date Time & elapsed & $\langle$ flow $\rangle$ & $n$ & $36 \mathrm{KRM}-8$ & \%err & $36 \mathrm{KR}-87$ & \%err & $36 \mathrm{KR}-88$ & \%err & $36 \mathrm{KR}-89$ & \%err & $36 K R-90$ & \%err & 54XEM-1: & \%err & 54XE-133 & \%err \\
\hline G21305160100 & $5 / 16 / 20131: 58$ & 28800 & 0.259 & -15 & $8.28 E+01$ & 92.3 & $-3.24 E+01$ & 231.8 & $7.13 E+01$ & 290.4 & $1.48 E+01$ & 467.4 & $-7.55 E+04$ & 108.1 & $-1.58 E+05$ & 112.2 & $1.04 E+04$ & 57.1 \\
\hline G21305160900 & 5/16/20139:58 & 28800 & 0.257 & .79 & $1.52 E+02$ & 65.7 & $-3.48 E+01$ & 218.3 & $-1.18 E+02$ & 175.1 & $6.75 E+00$ & $1.00 E+03$ & $-8.97 E+04$ & 98.1 & $2.61 \mathrm{E}+05$ & 70.8 & $4.34 E+03$ & 133.7 \\
\hline G21305161700 & $5 / 16 / 201317: 58$ & 28800 & 0.255 & -96 & $1.14 E+02$ & 66.7 & $-8.32 E+00$ & 853.5 & $2.66 E+01$ & 767.4 & $-5.80 E+01$ & 124.5 & 9.52E+04 & 108.8 & $7.82 E+04$ & 247.4 & $1.16 E+04$ & \\
\hline G21305170100 & $5 / 17 / 20131: 59$ & 28800 & 0.461 & -96 & $-1.03 E+02$ & 123.4 & $1.62 E+02$ & 79.8 & $-3.74 E+01$ & 978.3 & $-4.67 E+01$ & 100.5 & 4. $97 E+02$ & 163.1 & 4.17E+05 & 79.3 & $1.61 E+04$ & 65.5 \\
\hline G21305170900 & 5/17/2013 9:59 & 28800 & 0.474 & -96 & $1.69 E+02$ & 81 & $-1.37 E+02$ & 106.5 & $-3.31 E+02$ & 113.5 & $5.05 E+01$ & 101.7 & $-4.20 E+02$ & 150.9 & $2.29 E+05$ & 150.1 & $6.13 E+03$ & 173 \\
\hline G21305171800 & $5 / 17 / 201318: 00$ & 28800 & 0.468 & -97 & $1.98 \mathrm{E}+02$ & 85.1 & $-1.70 E+02$ & 73.2 & $-1.54 E+02$ & 242.1 & $-7.88 E+01$ & 56.9 & $9.60 E+02$ & 90.6 & 1.12E+05 & 293 & $5.75 E+03$ & 207.1 \\
\hline G21305180200 & $5 / 18 / 20132: 00$ & 28800 & 0.461 & -97 & $4.34 E+02$ & 33.3 & $1.12 E+02$ & 112.4 & $3.30 E+01$ & $1.00 E+03$ & $-2.23 E+01$ & 222.1 & 8.48E+02 & 105.6 & $-4.08 E+04$ & 855.7 & $5.93 E+03$ & 186.8 \\
\hline G21305181000 & $5 / 18 / 201310: 00$ & 28800 & 0.461 & -97 & $1.78 E+02$ & 74.9 & $-1.92 E+02$ & 62.8 & $-6.63 E+01$ & 551.4 & $-9.57 E+00$ & 521.1 & $-3.50 E+02$ & 224.4 & $3.17 \varepsilon+05$ & 172 & $-1.46 E+04$ & 69 \\
\hline G21305181800 & $5 / 18 / 201318: 01$ & 28800 & 0.46 & .96 & $2.24 E+02$ & 60.4 & $-3.05 E+00$ & $5.00 E+03$ & $-3.70 E+02$ & 98 & $2.32 E+01$ & 204.3 & 3. $72 E+02$ & 197.4 & $9.89 E+04$ & 333.4 & $9.71 E+03$ & 108.1 \\
\hline G21305190200 & $5 / 19 / 20132: 01$ & 28800 & 0.461 & -96 & $1.40 E+03$ & 13.3 & $1.56 \mathrm{E}+03$ & 17.5 & $2.60 E+03$ & 14.4 & $2.38 E+02$ & 20.7 & $-6.44 E+02$ & 172.8 & $-2.92 E+05$ & 122.5 & $3.92 E+03$ & 294.6 \\
\hline G21305191000 & $5 / 19 / 2013$ 10:02 & 28800 & 0.46 & -96 & $2.09 E+04$ & 6.4 & $2.03 E+04$ & 5.6 & $4.47 E+04$ & 5.8 & $2.21 E+03$ & 8.3 & $-8.57 E+02$ & 313.4 & $6.39 E+04$ & 862.8 & $1.71 E+04$ & 102.3 \\
\hline G21305191800 & $5 / 19 / 201318: 02$ & 28800 & 0.459 & .96 & $4.89 E+04$ & 5.6 & $4.35 E+04$ & 5.4 & $8.44 E+04$ & 7.1 & $3.93 E+03$ & 8. & $-1.58 E+03$ & 237.6 & $-5.18 E+05$ & 131.3 & $6.05 E+04$ & 36.8 \\
\hline G21305200200 & $5 / 20 / 20132: 03$ & 28800 & 0.458 & -96 & $8.20 E+04$ & 5.5 & $7.06 E+04$ & 5.3 & $1.39 E+05$ & 6.2 & $5.92 E+03$ & 8.1 & $2.84 E+03$ & 168.4 & $-8.58 E+04$ & 938.3 & $1.13 E+05$ & 21.4 \\
\hline G21305201000 & $5 / 20 / 201310: 03$ & 28800 & 0.471 & -96 & $2.23 E+05$ & 5.4 & $1.64 E+05$ & 5.3 & $3.62 E+05$ & 5.5 & $1.25 E+04$ & 7.8 & 4.91E+02 & $1.00 E+03$ & 4.88E+05 & 260.3 & $4.48 E+05$ & 17.6 \\
\hline G21305201800 & $5 / 20 / 201318: 03$ & 28800 & 0.485 & -96 & $5.14 E+05$ & 5.5 & $3.91 E+05$ & 5.3 & $8.79 E+05$ & 5.4 & $2.49 E+04$ & 7.6 & $-6.66 E+03$ & 86.3 & $8.78 E+05$ & 209 & $1.60 E+06$ & 7.1 \\
\hline G21305210200 & $5 / 21 / 20132: 04$ & 28800 & 0.318 & -96 & $1.77 E+05$ & 5.4 & $1.23 E+05$ & 5.3 & $2.97 E+05$ & 5.7 & $1.05 E+04$ & 10.3 & $8.07 E+03$ & 975.4 & $1.73 E+06$ & 48.4 & $6.46 \mathrm{E}+05$ & 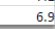 \\
\hline
\end{tabular}

Sample Birthrate Interpolation Output File:

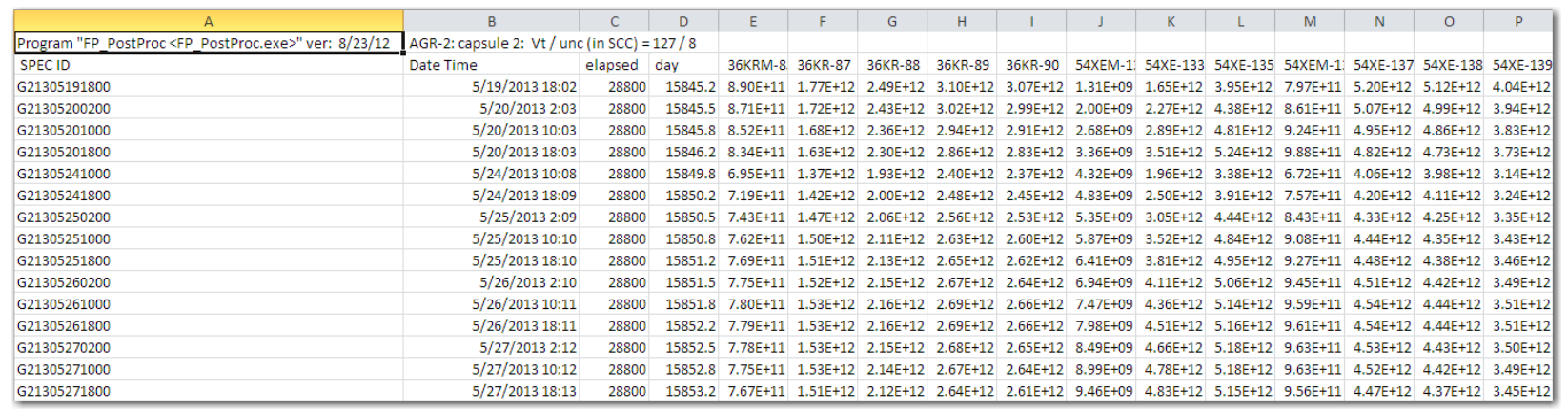


TEM-10200-1

$03 / 01 / 2012$

ENGINEERING CALCULATIONS AND ANALYSIS

Page E1 of E1

Rev. 06

Title: $\quad$ Release-to-Birth Ratios for AGR-2 Operating Cycles 147A-154B

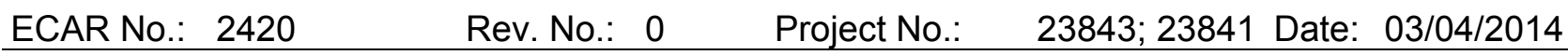

\section{Appendix E}

Supplemental Information to Support ECAR-2420;

AGR-2 Cycles 147A through 154B, Capsule 1 
TEM-10200-1

$03 / 01 / 2012$

ENGINEERING CALCULATIONS AND ANALYSIS

Page F1 of F1

Rev. 06

Title: $\quad$ Release-to-Birth Ratios for AGR-2 Operating Cycles 147A-154B

$\begin{array}{lllll}\text { ECAR No.: } 2420 & \text { Rev. No.: } 0 & \text { Project No.: } & 23843 ; 23841 \text { Date: } 03 / 04 / 2014\end{array}$

\section{Appendix F}

Supplemental Information to Support ECAR-2420;

AGR-2 Cycles 147A through 154B, Capsule 4 